\title{
Complement activation and apoptosis in renal ischemia-reperfusion injury : from basic insights to clinical applications
}

Citation for published version (APA):

de Vries, B. (2005). Complement activation and apoptosis in renal ischemia-reperfusion injury : from basic insights to clinical applications. [Doctoral Thesis, Maastricht University]. Universiteit Maastricht. https://doi.org/10.26481/dis.20050128bv

Document status and date:

Published: 01/01/2005

DOI:

10.26481/dis.20050128bv

Document Version:

Publisher's PDF, also known as Version of record

\section{Please check the document version of this publication:}

- A submitted manuscript is the version of the article upon submission and before peer-review. There can be important differences between the submitted version and the official published version of record. People interested in the research are advised to contact the author for the final version of the publication, or visit the DOI to the publisher's website.

- The final author version and the galley proof are versions of the publication after peer review.

- The final published version features the final layout of the paper including the volume, issue and page numbers.

Link to publication

\footnotetext{
General rights rights.

- You may freely distribute the URL identifying the publication in the public portal. please follow below link for the End User Agreement:

www.umlib.nl/taverne-license

Take down policy

If you believe that this document breaches copyright please contact us at:

repository@maastrichtuniversity.nl

providing details and we will investigate your claim.
}

Copyright and moral rights for the publications made accessible in the public portal are retained by the authors and/or other copyright owners and it is a condition of accessing publications that users recognise and abide by the legal requirements associated with these

- Users may download and print one copy of any publication from the public portal for the purpose of private study or research.

- You may not further distribute the material or use it for any profit-making activity or commercial gain

If the publication is distributed under the terms of Article $25 \mathrm{fa}$ of the Dutch Copyright Act, indicated by the "Taverne" license above, 
COMPLEMENT ACTIVATION AND APOPTOSIS

IN RENAL ISCHEMIA-REPERFUSION INJURY

From basic insights to clinical applications 



\section{COMPLEMENT ACTIVATION AND APOPTOSIS IN RENAL ISCHEMIA-REPERFUSION INJURY}

From basic insights to clinical applications

\section{PROEFSCHRIFT}

ter verkrijging van de graad van doctor aan de Universiteit Maastricht, op gezag van de Rector Magnificus,

Prof. mr. G.P.M.F. Mols

volgens het besluit van het College van Decanen, in het openbaar te verdedigen

op vrijdag 28 januari 2005 om 14.00 uur

door

Bart de Vries

Geboren te Geleen, 27 september 1975 
Prof.dr. W.A. Buurman

Copromotor

Dr. L.W.E. van Heurn

Beoordelingscommissie

Prof. dr. H. ten Cate (voorzitter)

Dr. M. Christiaans

Prof. dr. M. Daemen

Prof. dr. G. Kootstra

Prof. dr. J. Pirenne (Universiteit Leuven, Bellgië)

This thesis with pictures in color can be found on www.bartsthesis.nI

ISBN: $90-9018959-9$

NUGl: 743

Omslag illustratie: Henk van der Sluijs

Layout: B-Point, 's-Hertogenbosch

Druk: FEBOdruk, Enschede

Affirn the study presented in this thesis was performed at the Nutrition and iUti II Toxicology Research Institute Maastricht (NUTRIM)

The financial support for publication of this thesis and activities accessory to defending it from: Nierstichting Nederland, Nederlandse Transplantatie Vereniging, Fujisawa Holland BV (producent van Prograft ${ }^{\circledR}$ ), Roche BV, Wyeth Pharmaceuticals BV, Novartis Pharma BV, Radiometer Nederland BV (Horiba ABX), Genzyme Nederland BV and Greiner Bio-One B.V. (96-well plates, pipette tips, tubes) is gratefully acknowledged. 


\section{CONTENTS}

$\begin{array}{lll}\text { Chapter } 1 \quad \text { General introduction } & 7\end{array}$

Chapter 2 Apoptic cell death is initiated during normo-thermic ischemia in human kidneys

Chapter 3 Reduction of circulating redox-active iron by apotransferrin protects against renal ischemiareperfusion injury

Chapter 4 Redox-active iron released during cold machinepreservation predicts post-transplant organ function of ischemically injured kidneys

Chapter 5 Lysophosphatidic acid prevents renal ischemiareperfusion injury by inhibition of apoptosis and complement activation

Chapter 6 The mannose binding lectin pathway is involved in complement-activation in the course of renal ischemia-reperfusion injury

Chapter $7 \quad$ Inhibition of complement factor $\mathrm{C} 5$ protects against renal ischemia-reperfusion injury: inhibition of late apoptosis and inflammation

Chapter 8 Complement factor C5a mediates renal ischemiareperfusion injury independent from neutrophils

Chapter 9 Exogenous alpha-1-acid glycoprotein protects against renal ischemia-reperfusion injury by inhibition of inflammation and apoptosis

Chapter 10 General discussion 
Summary / Samenvatting

Dankwoord

Curriculum Vitae

Publications 


\section{CHAPTER}

\section{General Introduction}

Apoptosis and inflammatory responses in renal ischemia-reperfusion injury 
Renal transplantation is the best treatment for patients suffering end-stage renal disease. In comparison to dialysis, transplantation provides superior clinical outcome and far better quality of life for the patient with end-stage renal disease. Moreover, transplantation is the most cost-effective treatment strategy.

However, since the demand for transplantable kidneys is overwhelming the current availability of suitable donor kidneys, the list of patients awaiting renal transplantation is steadily increasing [1].

In order to reduce waiting-lists and to increase the number of available donor-organs, alternative sources of transplantable organs, next to the use of living organ donors and brain-death organ donors, have regained interest in the past decade $[2,3]$. In particular the Non-Heart-Beating (NHB) organ donor has become an important additional source of transplantable donor organs [4-8]. However, a major problem using NHB donor-organs is the relative high rates of post-transplant organ failure due to the inevitable ischemic injury which is suffered before and during organ procurement and the subsequent ischemia-reperfusion (I/R) injury [4-8]. The devastating effects of I/R injury still limit the general acceptance and broad implementation of NHB donation. The fact that little is known about the early events, which initiate $1 / R$ injury is a major problem. In general, cell-death induced by ischemia is believed to play an important role in the induction of an inflammatory response which is held responsible for the organ injury and organ dysfunction observed after $I / R$ [9-15].

Insight in the early processes induced by ischemia would have important clinical implications. First, reliable diagnostic methods, assessing ischemic damage in donor kidneys exposed to ischemia of uncertain time (as in NHB organ donation), are of crucial importance [16-18]. Methods that can accurately establish whether ischemically damaged donor organs are still suitable for transplantation (viability testing) will minimize complications from the use of NHB grafts. Viability tests that estimate the extent of ischemic damage and predict post-transplant function would thereby justify wider implementation of this donor pool . Second, insight in the early processes of ischemic injury would be of great importance in the development of effective therapeutic interventions to treat $1 / R$ injury. However, how early cell-death ultimately induces post-ischemic organ failure is largely unknown. And although inflammation is believed to play a crucial role in renal I/R injury, in which way celldeath and inflammation interact remains to be estimated.

Thus, insight in the processes regulating cell-death and inflammation will have enormous value in the development of new strategies to diagnose and treat $I / R$ injury such as seen after NHB kidney transplantation. 


\section{THE PATHOPHYSIOLOCY OF ISCHEMIA-REPERFUSION INJURY}

Ischemia followed by reperfusion is known to induce cell-death, which can be both necrotic and apoptotic $[19,20]$. Cell-death is crucially involved in the induction of an inflammatory response which is believed to be largely responsible for the tissue injury and organ dysfunction observed after I/R. Necrotic, apoptotic but also sublethally injured cells are reported to initiate inflammatory cascades [21-23]. This inflammatory response induced by $/ / R$ is characterized by, among others, the induction and release of cytokines (TNF- $\alpha, I L-1)$ and chemokines (KC, MIP-2), the activation of the complement system, and the infiltration of inflammatory cells, mainly polymorphonuclear neutrophilic cells, into the post-ischemic tissue.

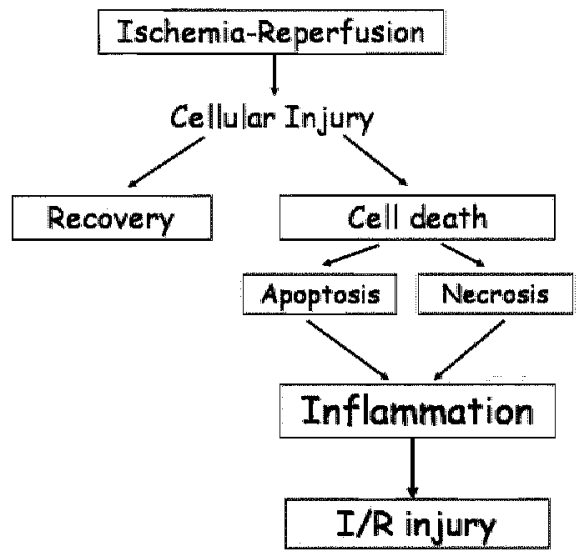

Figure 1: Overview I/R injury. Ischemia followed by reperfusion induces injury at the cellular level. If injury is severe enough cells will die in an apoptotic or necrotic fashion. Both have been impliw cated in the initiation of an inflammatory respons which is believed to crucially mediate the develle opment of the $1 / R$ syndrame.

THE ROLE OF APOPTOTIC CELL-DEATH IN ISCHEMIA-REPERFUSION INJURY

Ischemia and apoptotic cell-death

Until recently, necrosis was believed to be the major form of cell dleath involved in ischemic acute renal failure (ARF). This assumption has given birth to the misleading synonym of ARF: acute tubular necrosis. However, also apoptosis has been implicated in the pathophysiology of renal I/R injury recent years. 
In experimentall studies, apoptotic cell-death has been observed in the course of renal I/R injury [20]. In a human study Burns et al. showed that significantly more apoptosis occurred in post-reperfusion compared with prereperfusion biopsy specimens from cadaveric donor transplants [24]. Recently, Oberbauer et al. postulated that the number of apoptotic tubular epithelial cells in donor biopsies predicts early graft function [25]. These data would suggest that apoptotic cell-death observed in the course of renall $I / R$ injury is initiated during ischemia. The amount of apoptotic cells has been correlated with the degree of $1 / R$ injury, implicating that the early molecular events during (warm or cold) ischemia may be employed as a diagnostic tool to predict the amount of apoptosis, inflammation and organ function following transplantation of an ischemically damaged organ $[25,26]$. Moreover, the inhibition of apoptotic cell-death could potentially prevent I/R-induced inflammation and organ failure [9].

\section{Induction of apoptosis after renal $\mathbb{R} / \mathrm{R}$}

Apoptosis, or programmed cell death, is a highly conserved biological process. At the intra-cellular level apoptosis is characterised by activation of caspases, the intracellular execution enzymes of apoptotic cell-death [27, 28]. Activated caspases cleave a wide range of intracellular substrates, ultimately leading to formation of apoptotic bodies which can be ingested by neighbouring cells or macrophages.

Two major signalling pathways in the induction of apoptosis have been identified so far: an extrinsic or death-receptor mediated pathway, and an intrinsic pathway (also called the mitochondrial or death-receptor independent pathway) $[28,29]$. Both have been implicated in I/R-induced apoptosis.

Extrinsic pathway. The extrinsic pathway of apoptosis is triggered by the binding of TNF- $\alpha$, TRAIL (TNF- $\alpha$-Related Apoptosis Inducing Ligland), or Fasligand (CD95L) to their so called death- receptors, respectively TNF-Receptor 1 (CD120a), TRAIL-Receptor $\|$ to 4 , and Fas. Ligand-receptor binding induces clustering of the intracellular receptor-coupled death-domains. These recruit adapter proteins TRADD (TNF-receptor associated death domain) or FADD (Fas-associated death domain), both containing a death effector domain (DED), forming a death inducing signalling complex (DISC). In the DISC multiple procaspase- 8 molecules are recruited from the cytoplasm resulting in activation of caspase- 8 . Activated caspase- 8 initiates the cleavage cascade of downstream caspases, such as caspase-3, which leads to the execution of apoptotic cell-death [28,29). Caspase activation has to be closely regulated and therefore apoptotic processes are tightly controlled at multiple levels. 
Within the extrinsic pathway, the cytoplasmatic protein CFLIP (cellular FLICE inhibitory protein) is a competitive inhibitor of caspase -8 , regulating activation of this initiator caspase and thereby preventing uncontrolled cell-death. In vivo, the extrinsic pathway has been shown to be involved in renal $U / R$ injury. Of the TNF-receptor family, TNF-R [30, 31] as well as Fas [32] are activated in the course of renal $1 / R$.

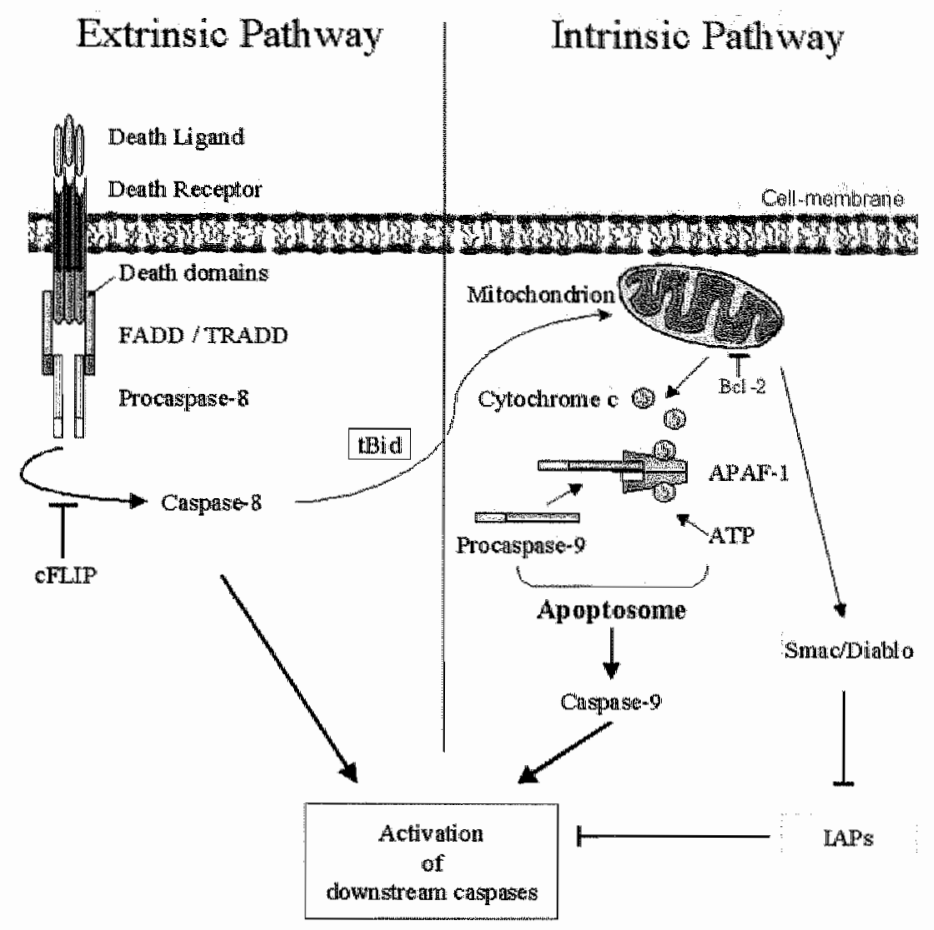

Figure 2: Apoptosis pathways. Schematic representation of extrinsic and intrinsic pathway of apoptosis. The extrinsic pathway is triggered by binding of a death ligand to their death-receptors, leading to clustering of the intracellular receptor-coupled death-domains. These receptorcoupled death domains recruit adaptor proteins TRADD or FADD, containing a death effector domain (DED), forming a death inducing signalling complex (DISC). In the DISC multiple procaspase -8 molecules are recruited and activated. The intracellular protein cFLIP inhibits caspase -8 activation. The intrinsic pathway is localised to the mitochondrion. Cytochrome- $C$ is released from the mitochondrion, a process regulated by the $B C l-2$ family. Cytochrome- $C$ released from the mitochondrion associates with APAF- 1 in the presence of ATP. Procaspase-9 is reciruited, forming the apoptosome complex, consequently leading to activation of procaspase-9. IAPS (inhibitors of apoptosis proteins) and Smac/DIABLO (IAP-inhibitor) are involved in the regulation of apoptosis. Bid, a pro-apoptotic BCl-2 family member, provides a linkage between the extrinsic and intrinsic pathway. Bid is cleaved by caspase -8 (tBid), greatly increasing its pro-apoptotic capacity via the intrinsic pathway. 
Intrinsic pathway. The intrinsic pathway is defined as not receptor-mediated and is mainly localized to the mitochondria. A characteristic of this pathway is the increased mitochondrial permeability and release of cytochrome-C from the mitochondrion, which can be initiated by, among others, hypoxia, ATP-depletion, and radiation [33, 34]. Oxygen free radicals, which are known to play a role in I/R injury, are important initiators of the intrinsic pathway of apoptosis [35, 36]. In particular redox-active iron, catalyzing the formation of oxygen free radicals, has been implicated in the induction of apoptotic cell-death $[37,38]$. The release of cytochrome-C is closely regulated by proand anti-apoptotic proteins from the $\mathrm{BCl}-2$ family [39]. Bid, a pro-apoptotic $\mathrm{BCl}-2$ family member; provides a linkage between the intrinsic and the extrinsic pathway $[40,41]$. In the presence of ATP, cytochrome-C released from the mitochondrion associates with the extramitochondrial protein Apoptosis Protease Activating Factor-1 (APAF-1). Conformational changes lead to exposure of a caspase recruitment domain (CARD) which recruits procaspase-9, forming the apoptosome complex, consequently leading to activation of procaspase-9. Activated caspase-9 further activates downstream caspases like caspase-3, resulting in progression to the execution phase of apoptosis [29].

The intrinsic pathway is involved in hypoxia-reoxygenation injury in vitro, among others in cultured kidney cells $[42,43]$. Little is known about the functional role of the intrinsic pathway in vivo. Changes in distribution and expression of the different $\mathrm{BCl}-2$ family members have been reported upon reperfusion after renal ischemia. Recent work indicates that renal $I / R$ also leads to the activation of Bid providing evidence that also in vivo the extrinsic and intrinsic pathway are closely linked [44]. However, whether the intrinsic pathway plays a functional role in renal $I / R$ injury still has to be established $[45,46]$.

\section{Regulation of apoptosis}

The apoptotic process, deciding on cell-death and cell-survival, has to be closely regulated, and several regulating factors, extra- as well as intracellular, have been described. The intracellular protein cFLIP and the $\mathrm{BCl}-2$ family as regulators of the extrinsic and the intrinsic pathway have already been mentioned. Other intracellular proteins involved in the regulation of apoptotic cell-death are the IAPs (inhibitors of apoptosis proteins) [47]. Among others the $X$-linked inhibitor of apoptosis protein (XIAP), cellular inhibitor of apoptosis protein-1 and -2 (CIAP-1 and -2 ) have been implicated as important endogenous inhibitors of apoptotic cell-death. The inhibitory activity of the IAPs is counter-balanced by Omi/Htr2 and Smac/DIABLO, two IAP-inhibitors [48-50]. Thus, at the cellular level apoptosis is tightly regulated 
in order to prevent unwanted, spontaneous apoptosis but to be able to induce rapid apoptosis once cell-death has become inevitable.

Also the extracellular environment is of crucial importance for cellular function and survival. For instance cell-cell and cell-matrix interactions are essentiall in cell survival and loss of these interactions results in apoptosis in various cell types [51].

In vitro work has shown that growth factors, such as Insulin-like Growth Factor (IGF-1), Epidermal Growth Factor (EGF), Hepatocyte Growth Factor (HGF) and Lysophosphatidic acid (LPA) are also involved in the regulation of apoptosis [52, 53]. Recently, also in vivo studies have demonstrated that survival factors regulate $1 / \mathrm{R}$-induced apoptosis and inflammation in experimental ARF [9].

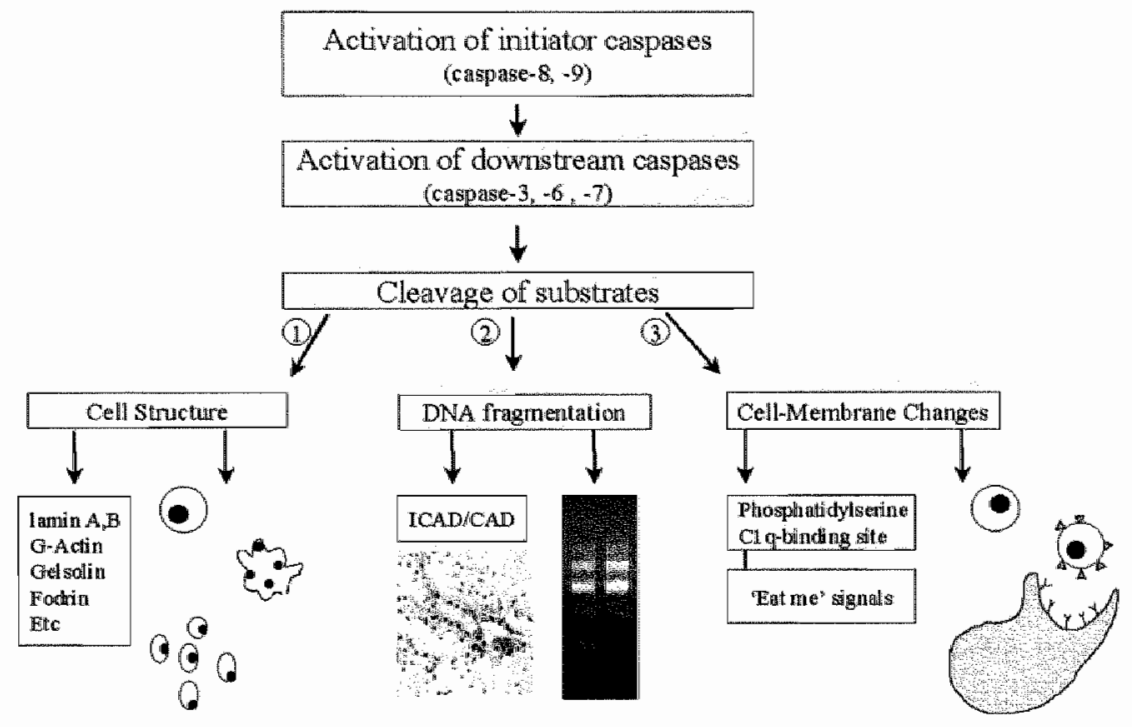

Figure 3: Execution of apoptosis. Simplified schematic view of execution phase of apoptosis. Activation of initiator caspases leads to activation of downstream caspases. Activated caspases cleave various substrates leading to the apoptotic phenotype: (1) Changes in cell structure, cleavage of proteins involved in maintenance of cell-structure results in so-called "membrane blebbing" and the formation of "apoptotic bodies". (2) Fragumentation of DNA activation of CAD (Caspase-activated DNase) leads to internucleasomal DNA fragmentation, often used to detect apoptosis as shown in this figure by TUNEL-staining and ligase-mediated polymerase chain reaction (LM-PCR). (3) Changes of the cell-membrane: among others exposure of phosphatidylserine (PS) detectable by Annexin $V$ labeling. Cell-membrane changes lead to recognition of apoptotic cells by macrophages or neighboring cells "facilitating efficient clearance of apoptotic cells. 
After induction, the execution of apoptosis is performed by caspases, a group of intracellular cysteine proteases, which cleave their substrates behind specific aspartic acid residues. Caspases are constitutively present as inactive pro-enzymes. After induction of apoptosis, initiator caspases (caspase -8 and caspase-9) are activated, which in turn leads to activation of socalled effector caspases (caspase-3, -6 , and -7) [29]. These caspases cleave specific substrates, leading to their activation or inactivation. At this moment, hundreds of different caspase substrates have been described [54]. Activation of these caspase-substrates can be employed as a diagnostic tool for detecting apoptotic cell-death: most importantly, the cleavage of actin (fractin), cytokeratin 18, lamin B and PARP. Substrate cleavage leads to dismantling of the apoptotic cell, degradation of DNA, and expression of phagocyte recognition molecules, processes which can be used for apoptosis detection by among others TUNEL-staining. DNA-laddering assay, Annexin- $V$ staining. Ultimately the apoptotic process results in phagocytosis of apoptotic cell fragments by neighbouring cells or macrophages [29].

Activation of caspases in experimental renal $I / R$ injury has been documented [9, 19]. The inhibition of caspase-activation has been shown protective against I/R injury [9]. Whether caspases are activated in clinical ischemic injury is largely unknown, although the apoptotic degradation of DNA has been reported in renal transplantation [24-26].

\section{THE ROLE OF INFLAMMATION IN ISCHEMIA-REPERFUSION INJURY}

Inflammation is regarded to be a crucial event in the development of tissue injury and organ dysfunction induced by $1 / R$. Renal $I / R$ injury is characterised by the massive influx of neutrophils, which are believed to play an important role in the pathophysiology of post-ischemic renal failure [55]. Recent work indicates that also other inflammatory cells, such as macrophages, T- and Bcells might be involved in the pathophysiology of renal $I / R$ injury [56-58].

The infiltration of neutrophils into tissue sites of inflammation is regulated by CXC chemokines such as $I L-8$, Gro- $\alpha$, of which cytokine induced neutrophil chemoattractant (KC) is the murine homologue, and macrophage inflammatory protein-2 (MIP-2). In experimental renal I/R it has been shown that the inhibition of $\mathrm{CXC}$ chemokines reduces the post-ischemic infiltration of neutrophils and via this mechanism abrogates I/R injury [59]. 
The complement system is an important part of the innate immune system. Activation of the complement system, as a part of the inflammatory response upon renal $I / R$, was already reported in 1985 by Stein et al. showing complement-deposition in a rat model for renal $I / R$ injury [60]. Only recently, an active role for the complement-system in the pathophysiology of $I / R$ injury was demonstrated by Zhou and colleagues, showing that complement-deficient mice are protected against I/R injury [61].

\section{Activation of the complement system}

The complement system can be activated via three pathways which converge at the level of the complement factor $\mathrm{C3}$.

The classical pathway is activated by antigen-antibody interaction, leading to activation of complement factor $\mathrm{C} 1 \mathrm{q}$, followed by the formation of the classical $\mathrm{C} 3$-convertase $(\mathrm{C} 4 \mathrm{~b} 2 \mathrm{a})$ which subsequently cleaves $\mathrm{C} 3$. Finally the $\mathrm{C} 5$-convertase $\mathrm{C} 4 \mathrm{~b} 2 \mathrm{a} 3 \mathrm{~b}$ is formed which cleaves $\mathrm{C5}$ into its active fragments.

The lectin pathway is activated by mannose present on microbial surfaces recognized by mannose binding lectin (MBL), which is homologous to $\mathrm{Clq}$. This triggers the activation of MBL-associated proteases (MASPs), which gives rise to the formation of the $\mathrm{C} 3-$ and $\mathrm{C} 5$-convertase as described above.

The alternative pathway is activated by microbial products and to a certain extend by spontaneously generated $\mathrm{C} 3 \mathrm{~b}$. Upon activation, $\mathrm{C} 3$ binds to factor $B$, forming a complex which is cleaved by factor $D$ to form the alternative C3convertase $(\mathrm{C} 3 \mathrm{Bb})$. Subsequently $\mathrm{C} 3 \mathrm{~b}$ binds to this complex, forming the alternative $\mathrm{C} 5$-convertase $\mathrm{C} 3 \mathrm{BbC} 3 \mathrm{~b}$ which is capable to activate $\mathrm{C} 5$.

\section{Effects of complement-activation}

All three pathways converge at the levels of $C 3$ activation, forming a $C 5$-convertase, which activates $C 5$. Activation of $C 5$ results in the formation of $\mathrm{C} 5 \mathrm{a}$ and $C 5 b$, the latter one being the first step in the formation of the membrane attack complex (MAC). Both the formation of membrane attack complex (MAC) as well as the generation of the anaphylatoxin $\mathrm{C5a}$ can potentially mediate I/R injury. The MAC has been reported to mediate neutrophil influx, synthesis of pro-inflammatory cytokines and may cause direct cell injury, apoptosis and necrosis [62-68]. Responses to $C 5$ a are mediated by the $C 5 a$ receptor (C5aR), a member of the rhodopsin family of seven transmembranespanning G-protein-linked receptors [69]. Activation of C5aR induces recruitment of neutrophils and macrophages, and activates these and other cells to produce cytokines, chemokines and adhesion molecules [70, 71]. 


\section{Activation pathways}

C3 convertase

CS convertase

Terminal Pathway

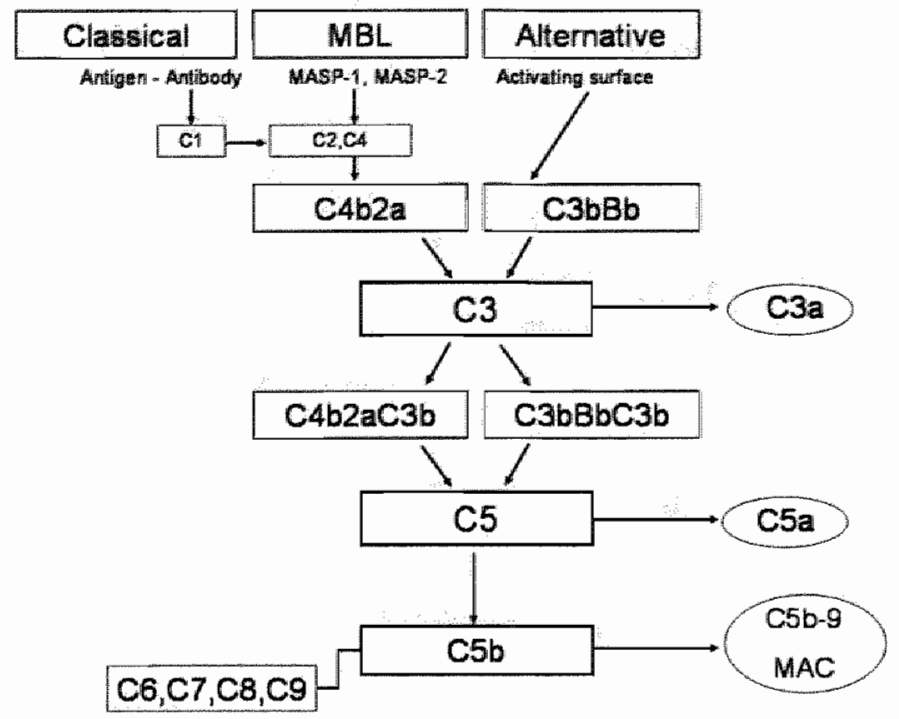

Figure 4: Activation of the complement system. The complement system can be activated via the classical, mannose binding lectin (MBL), or alternative pathway. Activation of the system results in the formation of a $\mathrm{C} 3$ convertase and subsequently a $\mathrm{C5}$-convertase. The $\mathrm{C5}$-convertase activates $C 5$ into its active fragments: $C 5 a$ and $C 5 b$. The generation of $C 5 b$ is the first step in the formation of the membrane attack complex (MAC).

Complement-activation after ischemia-reperfusion injury

Activation of the complement-system is observed after ischemic injury in several organ systems $[60,72,73]$. Moreover, complement-inhibition has been proven to protect against $I / R$ injury in numerous models [74-77]. However, via which pathway(s) complement-activation is initiated in the course of $I / R$ injury is still unclear.

In cardiac I/R injury complement-activation has been attributed mainly to the classical pathway of complement-activation and in particular CRP is regarded as an important initiator of myocardial complement-mediated injury [78-80]. Lately, new insight has been provided by the group of Stahl showing that also the MBL-pathway is involved in cardiac $I / R$ injury $[81,82]$. Complement-activation upon intestinal and skeletal $I / R$ has traditionally been regarded as completely dependent on the classical pathway $[83,84]$. Interestingly, the alternative pathway has been implicated in intestinal $I / R$ injury recently as well [85].

In contrast to other organ-systems post-ischemic complement-activation in the kidney is mainly attributed to the alternative pathway. Park et al. demonstrated that renal I/R does not induce IgG or IgM deposition [86]. Moreover, $\mathrm{RAG}-1 \%$ mice subjected to $\| / \mathrm{R}$ still showed renal complement 
deposition, indicating that renal $I / R$ is not mediated via the classical pathway [86]. Indeed, in contrast to C3-deficient mice, C4-deficient mice are not protected against renal I/R injury [6 1]. In line, Thurman et al. showed recently that mice lacking a functional alternative complement pathway (factor B mice) are protected against renal ischemic injury [87]. Whether the MBLpathway is activated and whether the alternative pathway is the initiating or an enhancing pathway of complement-activation observed after renal $1 / R$ remains to be established. In particular since it has been suggested that the activation pathways of the complement-system may not be as independent as originally proposed and that cross-talk and interplay exist [88]. In general, the mechanism by which ischemia induces complement-activation, via either route remains unclear.

As pointed out above, ischemia-induced complement-activation, independent from its activation route, will result in the production of $C 5 \mathrm{a}$ and the MAC which are believed to be important in the pathophysiology of (renal) I/R injury. Therefore, complement-inhibition at the level where the different routes of complement-activation have merged would be the most potent strategy to inhibit complement-induced I/R injury.

\section{INTERPLAY BETWEEN APOPTOSIS AND INFLAMMATION IN THE COURSE OF I/R}

An important unresolved question is whether and how apoptotic cell-death and inflammation interact in the course of I/R injury. In vitro, apoptotic cells activate the complement system and also after hypoxia-reoxygenation cells which become apoptotic specifically deposit complement-factor C3 [89-91]. On the other hand activation of the complement-system has been reported to induce necrotic as well as apoptotic cell-death [62-67, 92].

Thus, apoptosis in renal $I / R$, may be functionally involved in the development of the inflammatory response. In line, we previously showed that inhibition of caspase activation with a specific inhibitor in a murine model of renal $I / R$ not only prevents initial apoptosis, but also diminishes the subsequent inflammatory reaction [9].

\section{THIS THESIS}

As described above the pathophysiology of renal I/R is complex and many questions remain unanswered. Apoptotic cell-death, complement-activation and neutrophil-influx are three important features of renal $I / R$ injury. How ischemia induces (apoptotic) cell-death, and subsequently induces inflammation characterised by complement-activation and neutrophil-influx, ultimately giving rise to the organ-injury observed after an ischemic insult is largely 
unknown. Therefore the main goals of the present thesis were to get insight in:

- The initiation of apoptotic cell-death induced by ischemia

- The role of redox-active iron and oxidative stress in ischemia-induced apoptotic cell-death and inflammation

- The role of apoptotic cell-death in ischemia-induced inflammation and post-ischemic organ failure

- The role of the complement-activation in ischemia-induced apoptosis, inflammation and renal failure

In the first chapter (Chapter 2) we study the initiation of apoptotic celldeath in a human model for warm ischemic injury. In this human model, kidneys explanted because of a small renal cell carcinoma were kept ischemic for various periods, in order to study apoptotic changes in the ischemic human kidney.

Since, oxidative stress is believed to initiate apoptotic cell-death and inflammatory processes in the context of $\| / R$ injury we studied the role of redox-active iron in the induction of apoptosis and inflammation in the course of renall I/R injury (Chapter 3 ). This study indicates that redox-active iron plays an important role in experimental I/R injury. Therefore, we subsequently studied the role of redox-active iron in clinical transplantation (Chapter 4).

In order to get more insight in the role of apoptotic cell-death in postischemic inflammation, we inhibited apoptotic cell-death during experimental I/R injury, using the growth factor LPA, and studied the effects of apoptosis inhibition on complement-activation and neutrophil-influx (Chapter 5). These studies indicated that in our experimental model for $I / R$ injury complement-activation is an evident feature. Therefore we investigated the ischemia-induced activation of the complement-system: showing that in particular the MBL-pathway is activated in the course of renal I/R (Chapter 6). in subsequent studies the functional role of the complement-system was studied: the complement-system was inhibited, using an antibody preventing $\mathrm{C} 5$ activation and a peptide inhibiting $\mathrm{C5a}-\mathrm{C} 5 \mathrm{aR}$ interaction (Chapter 7 and 8 respectively).

Finally, we used alpha-1 acid glycoprotein (AGP), an acute phase protein, as an intervention in order to prevent $1 / R$ injury, in particular since AGP has been described to inhibit apoptosis as well as inflammation and thus interferes with multiple pathways involved in renal I/R injury (Chapter 9). 


\section{REFERENCES}

1. Persijn GG, De Meester JM: Demand, supply and allocation in Eurotransplant. Amn Transplant $1997 ; 2: 26-33$.

2. Kootstra G, Kievit $\rfloor_{1}$ Nederstigt A: Organ donors: heartbeating and non-heartbeating. World ال Surg 2002; $26: 181-4$.

3. Lopez-Navidad A, Caballero F: Extended criteria for organ acceptance. Strategies for acheving organ safety and for increasing organ pool. Clin Transplant 2003; 17:308-24.

4. Nicholson ML, Metcalfe MS, White SA, Waller JR, Doughman TM, Horsburgh T, Feehally J, Cair S), Veitch PS: A comparison of the results of renal transplantation from non-heart-beating. conventional cadaveric, and living donors. Kidney Int 2000: $58: 2585-91$.

5. Koffman $G$, Gambara $G$ : Remal transplantation from non-heart-beating donors: a revlew of the European experience. J Nephrol 2003; 16:334-41.

6. Rudich SM, Kaplan B, Magee JC, Arenas, JD, Punch JD, Kayler LK, Merion RM, Meler-Kriesche HU: Renal transplantations performed using non-heart-beating organ donors: going back to the future? Transplantation 2002: 74:1715-20.

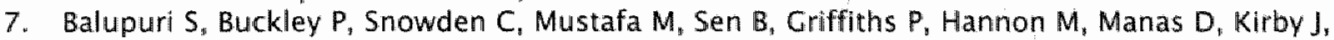
Talbot $D$ : The trouble with kidneys derived from the non heart-beating donor: a single center 10-year experience. Transplantation 2000; 69:842-6.

8. Wijnen RM, Booster MH, Stubenitsky BM, de Boer J, Heineman E, Kootstra G: Outcome of transplantation of non-heart-beating donor lkidneys. Lancet 1995; 345:1067-70.

9. Daemen MA, van "t Veer $C$, Denecker $G$, Heemskerk VH, Wolfs TG, Clauss $M$, Vandenabeele $P$, Buurman WA: Inhibition of apoptosis induced by ischemia-reperfusion prevents inflammation. I Clin Invest 1999; 104:541-9.

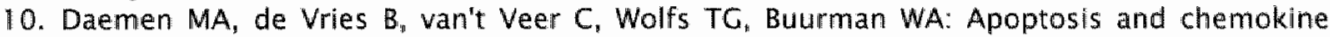
induction after renal ischemia-reperfusion. Transplantation 2001; 71:1007-11.

11. Daemen MA, de Vries B, Buurman WA: Apoptosis and inflammation in renal reperfusion injury. Transplantation 2002; 73:1693-1700.

12. Endres $H$, Namura $S$, SkimizuSasamata $M$, Waeber $C$, Zhang $L$, Gomezlsla $T$, Hyman BT, Moskowitz MA: Attenuation of dellayed neuronal death after mild focal ischemia in mice by inhibition of the caspase family. Journal of Cerebral Blood Flow And Metabolism 1998; $18: 238-47$.

13. Yaoita $H$, Ogawa $K$, Maehara $K$, Maruyama $Y$ : Attenuation of ischemia/reperfusion injury in rats by a caspase inhibitor. Circulation 1998; 97:276-81.

14. Farber $A_{4}$ Connors JP, Friedlander RM, Wagner RJ, Powell RJ, Cronenwett JL: A specific inhibitor of apoptosis decreases tissue injury after intestinal ischemia-reperfusion in mice. J Vasc Surg $1999 ; 30: 752-60$.

15. Cursio $R$, Gugenheim J, Ricci JE, Crenesse $D$, Rostagno $P$, Maulon $L$, Saint $P M$, Ferrua $B$, Auberger AP: A caspase inhibitor fully protects rats against lethal normothernic liver ischemia by inhibition of liwer apoptosis. FASEB J 1999: 13:253-61.

16. Brook NR, Waller JR, Nicholson ML: Nonheart-beating kidney donation: current practice and future developments. Kidney Int 2003; 63:1516-29.

17. Daemen JW, Oomen AP, Janssen MA, van de Schoot $L$, van Kreel BK, Heineman E, Kootstra $G$ : Glutathione S-transferase as predictor of functional outcome in transplantation of machinepreserved non-heart-beating donor kidneys. Transplantation 1997;63:89-93.

18. Cok MA, Pelsers M, Glatz JF, Bhatti AA, Shenton BK, Peaston R, Cornell C, Mantle D, Talbot D: Comparison of perfusate activities of glutathione S-transferase, alanine aminopeptidase and fatty acid binding protein in the assessment of non-heart-beating donor kidneys. Ann Clin Biochem 2003: 40:252-8.

19. Padanilam BJ: Cell death induced by acute renal injury: a perspective on the contributions of apoptosis and necrosis. Am J Physiol Renal Physiol 2003:284:F608-27.

20. Schumer $M_{1}$ Colombel MC, Sawczuk IS, Gobe G, Connor J, O'Toole KM, Olsson CA, Wise GJ, Buttyan R: Morphologic, biochemical, and molecular evidence of apoptosis during the reperfusion phase after brief periods of renal ischemia. Am J Pathol 1992; 140:831-8. 
21. Scaffidi P, Misteli T, Bianchi ME: Release of chromatin protein HMCB1 by necrotic cells triggers inflammation. Nature 418:191-195, 2002

22. Kriles UE, Behrensdorf HA, Mitchell CA, Deutsch U, Risau W, Drexler HC, Clauss M: Regulation of endothelial monocyte-activating polypeptide II release by apoptosis. Proc Natl Acad Sci U S A 95:12322-12327, 1998

23. Yan SF, Fujita T, Lu J, Okada K, Shan Zou Y, Mackman N, Pinsky DJ, Stern DM: Egr-1, a master switch coordinating upregulation of divergent gene families underlying ischemic stress. Nat Med 6:1355-1361,2000

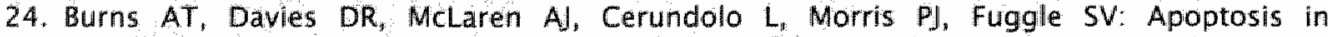
ischemia/reperfusion injury of human renal allografts. Transplantation $66: 872-876,1998$

25. Oberbauer R, Rohimoser $M$, Regele $H$, Muhlbacher $F$, Mayer $G$ : Apoptosis of tubular epithelial cells in donor kidney biopsies predicts early renal allograft function. J Am Soc Nephrol $10.2006-2013,1999$

26. Castaneda MP, swiatecka-Urban A, Mitsnefes MM, Feuerstein D, Kaskel FJ, Tellis V, Devarajan P: Activation of mitochondrial apoptotic pathways in human renal allografts after ischemiareperfusion injury. Transplantation 76:50-54, 2003

27. Cohen CM: Caspases: the executioners of apoptosis. Biochem $\| 326(\mathrm{Pt} \mathrm{1}): 1-16,1997$

28. Reed JC: Mechanisms of apoptosis. Am J Pathol 157:1 415-1 430, 2000

29. Hengartner $\mathrm{MO}$ : The biochemistry of apoptosis. Nature 407:770-776,2000

30. Donnahoo KK, Shames BD, Harken $\mathrm{AH}$, Meldrum DR: Review article: the role of tumor necrosis factor in renal ischemia-reperfusion injury. IUrol 162:196-203, 1999

31. Daemen MA, van de Ven MW, Heineman $E$, Buurman WA: Involvement of endogenous interleukin-10 and tumor necrosis factor-alpha in renal ischemia-reperfusion injury. Transplantation 67:792-800, 1999

32. Nogae $S$, Miyazaki M, Kobayashi N, Saito T, Abe K, Saito H, Nakane PK, Nakanishi Y, Koji T: Induction of apoptosis in ischemia-reperfusion model of mouse kidney: possible involvement of Fas. J Am Soc Nephrol 9:620-631, 1998

33. Zamzami $N$, Kroemer $G$ : The mitochondrion in apoptosis: how Pandora's box opens. Nat Rev Mol Cell Biol 2:67-7 2001

34. Green DR, Reed JC: Mitochondria and apoptosis. Science 281:11309-1312, 1998

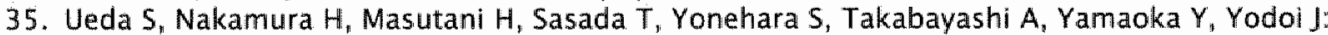
Redox Regulation of Caspase-3(-like) Protease Activity: Regulatory Roles of Thioredoxin and Cytochrome C. J Immunol 161:6689-6695, 1998

36. Hampton MB, Fadeel B, Orrenius 5: Redox Regullation of the Caspases during Apoptosis. Ann NY Acad Sci $854: 328-335,1998$

37. Kotamraju S, Chitambar CR, Kalivendi SV ${ }_{n}$ Joseph J, Kalyanaraman B: Transferrin Receptordependent Iron Uptake Is Responsible for Doxorubicin-mediated Apoptosis in Endothelial Cells. Role of oxidant-induced trom signaling in apoptosis. J. Biol. Chem. 277:17179-17187, 2002

38. Yu Z, Persson $\mathrm{HL}_{\mathrm{L}}$, Eaton JW, Brunk UT: Intralysosomal iron: a major determinant of oxidantinduced cell death. Free Radical Biology and Medicine 34:1243-1252, 2003

39. Vander Heiden $M G_{1}$, Thompson $\mathrm{CB}$ : $\mathrm{BCl}-2$ proteins: regulators of apoptosis or mitochondriat homeostasis? Nat Cell Biol 1:E209-216, 1999

40. Li H, Zhu H, Xu CJ, Yuan J: Cleavage of BID by caspase 8 mediates the mitochondrial damage in the Fas pathway of apoptosis. Cell $94: 491-501,1998$

41. Luo $X$, Budihardjo I, Zow $H$, Slaughter $C$, Wang $X$ : Bid, a Bcl2 interacting protein, mediates cytochrome $c$ release from mitochondria in response to activation of cell surface death receptors. Cell $94: 481-490,1998$

42. Cuttle $L$, Zhang $X J$, Endre $Z H$, Winterford $C$, Gobe $G C$. BCl-X(L) translocation in renal tubular epithellal cells in witro protects distal cells from oxidative stress. Kidney Int 59:1779-1788, 2001

43. Salkumar $P$, Dong $Z$, Patel $Y$, Hall $K$, Hopfer $U$, Weinberg JM, Venkatachalam MA: Role of hypoxia induced Bax translocation and cytochrome $c$ release in reoxygenation injury. Oncogene 17:3401-3415,1998

44. Wei $Q$, Alam MMM, Wang $M-H_{4}$ Yu F, Dong $Z$ : Bid Activation in Kidney Cells Following ATP Depletion in vitro and Ischemia in vivo. Am J Physiol Renal Physiol:00093.02003, 2003 


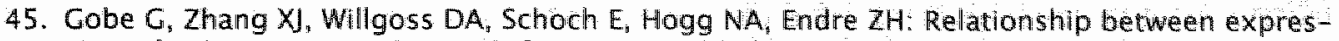
sion of $\mathrm{BCl}-2$ genes and growth factors in isichemic acute renal failure in the rat. J Am soc Nephrol 2000; $11: 454-67$.

46. Benitez-Bribiesca L, Gomez-Camarillo $M$, Castellanos-Juarez E, Mravko E, Sanchez-Suarez P: Morphologic, Biochemical and Molecular Mitochondrial Changes during Reperfusion Phase following Brief Renal Ischemia. Ann NY Acad Sci 2000; 926:165-79.

47. Salvesen GS, Duckett CS: IAP proteins: blocking the road to death"s door. Nat Rev Mol Cell Biol $2002 ; 3: 401-10$.

48. Du C, Fang $M_{3}$ Li Y, Li L, Wang X: Smac, a mitochondrial protein that promotes cytochrome $C$ dependent caspase activation by eliminating IAP inhibition. Cell 2000; 102:33-42.

49. Verhagen AM, Ekert PG, Pakusch M, silke J Connolly LM, Reid GE, Moritz RL, simpson RJ, Vaux DL: Identification of DIABLO a mammalian protein that promotes apoptosis by binding to and antagonizing IAP proteins. Cell 2000; 102:43-53.

50. Suzuki $Y$, Imai $Y$, Nakayama $H_{*}$ Takahashi $K$, Takio $K$, Takahashi $R: A$ serine protease, HtrA2, is released from the mitochondria and interacts with XIAP, inducing cell death. Mol Cell 2001 ; $8: 613-27$.

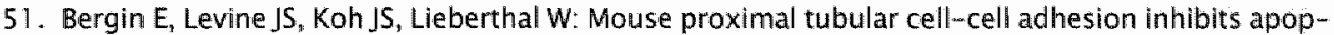
tosis by a cadherin-dependent mechanism. Am J Physiol Renal Physioll 2000; 278.F758-68.

52. Hammerman MR: Growth factors and apoptosis in acute renal injury. Curr Opin Nephrol Hypertens 1998; 7:419-24.

53. Levine JS, Koh IS, Triaca V, Lieberthal W: Lysophosphatidic acid: a novel growth and survival factor foir renal proximal tubular cells. Am J Physiol 1997; 273:F575-85.

54. Fischer $U$, Janicke RU, Schulze-Osthoff $K$ : Many cuts to ruin: a comprehensive update of caspase substrates. Cell Death Differ 2003; 10:76-100.

55. Heinzellmann $M$, Mercer-Jones MA, Passmore JC: Neutrophils and renal failure. Am J Kidney Dis 1999; 34:384-99.

56. Takada $M$, Chandraker A, Nadeau KC, Sayegh $M H_{3}$, Tilney NL: The role of the $B 7$ costimulatory pathway in experimental cold ischemia/reperfusion injury. J Clin Invest 1997; 100:1199-1203.

57. Rabb H, Daniels F, O'Donnell M, Haq M, Saba SR, Keane W, Tang WW: Pathophysiological role of $\mathrm{T}$ lymphocytes in remal ischemia-reperfusion injury in mice. Am J Physiol Renal Physiol 2000; $279: F 525-31$.

58. Burne-Taney MJ, Ascon DB, Danlels $F$, Racusen L, Baldwin W, Rabb $\mathrm{H}$ : B cell deficiency confers protection from renal ischemia reperfusion injury. I Immunal 2003; 171:3210-15.

59. Miura $M$, Fu $X$, Zhang $Q W$, Remick DG, Fairchild RL: Neutralization of Gro alpha and macrophage inflammatory protein-2 attenuates renal ischemia/reperfusion injury. Am J Pathol 2001; 159:2137-45.

60. Stein JH, Osgood RW, Barnes JL, Reineck HJ, Pinckard RN, McManus LM: The role of comple-ment in the pathogenesis of postischemic acute renal failure. Miner Electrolyte Metab 1985; $11: 256-61$.

61. Zhou W, Farrar CA, Abe K, Pratt JR, Marsh JE, Wang $Y$, Stahll GL, Sacks SH: Predominant role for $C 5 b-9$ in renal ischemia/reperfusion injury. J Clin Invest 2000; 105:1363-71.

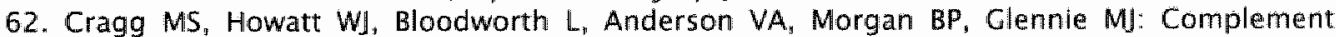
mediated cell death is associated with DNA fragmentation. Cell Death Differ 2000; 7:48-58.

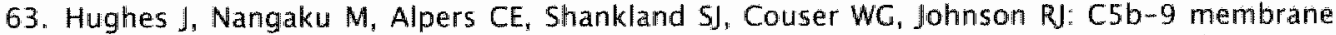
attack complex mediates endothelial cell apoptosis in experimental glomerulonephritis. Am J Physiol Renal Physiol 2000; 278:F747-57.

64. Kilgore KS, Flory CM, Miller BF, Evans VM, Warren JS: The membrane attack complex of complement induces interleukin-8 and monocyte chemoattractant protein-1 secretion from human umbilical vein endotheliat cells. Am I Pathol 1996: 149:953-61.

65. Sato T, Van Dixhoorn MG, Prins FA, Mooney A, Verhagen $N$, Muizert $Y$, Savill J, Van Es LA, Daha MR: The terminal sequence of complement plays an essential role in antibody-mediated renal cell apoptosis. I Am Soc Nephrol 1999; 110:1242-52. 
66. Nauta A), Daha MR, Tijsma $O$, van de Water $B_{i}$ Tedesco $F_{\text {, Roos }}$ : The membrane attack complex of complemerit induces caspase activation and apoptosis. Eur J Immunol 2002; $32: 783-92$.

67. Shimizu A, Masuda $Y$, Kitamura $H$, Ishizaki $M$, Ohashi $R$, Sugisaki $Y$, Yamanaka $N$ : Complement-mediated killing of mesangial cells in experimental glomerulonephritis: cell death by a combination of apoptosis and necrosis. Nephron 2000; 86:152-60.

68. David S, Biancone ${ }_{2}$, Caserta C, Bussolat B, Cambi V, Camussi C: Alternative pathway complement activation induces proinflammatory activity in human proximal tubular epithelial cells. Nephrol Dial Transplant 1997; 12:51-6.

69. Gerard C, Cerard NP: CSA Anaphylatoxin and Its Seven Transmembrane-Segment Receptor. Annual Review of Immunology 1994; 12:775-808.

70. Czermak B.j, Sarma V, Blless NM, Schmal H, FriedI HP, Ward PA: In vitro and in vivo dependenCy of chemokine generation on C5a and TNF-alpha. I Immunol 1999; 162:2321-25.

71. Schieferdecker $H L$, Schlaf $C$, Jungermann $K$, Gotze $O$ : Functions of anaphylatoxin $C 5 a$ in rat liver: direct and indirect actions on nonparenchymal and parenchymal cells. International Immunopharmacology $2001 ; 1: 469-81$.

72. Hill $\mathrm{IH}$, Ward PA: The phlogistic role of $\mathrm{C} 3$ leukotactic fragments in myocardial infarcts of rats. J Exp Med 1971; 133:885-900.

73. Austen WC, Ji . Kobzik $L$, Carroll MC, Hechitman HB, Moore FD, لIr.: The role of complement and natural antibody in intestinal ischemia-reperfusion injury. Int J Immunopathol Pharmacol $2003 ; 16: 1-8$.

74. Weisman HF, Bartow T, Leppo MK, Marsh HC, Jr., Carson GR, Concino MF, Boyle MP, Roux KH, Weisfeldt ML, Fearon DT: Soluble human complement receptor type 1 : in vivo inhibitor of complement suppressing post-ischemic myocardial inflammation and necrosis. Science 1990; 249:1 46- 51 .

75. Hill J, Lindsay TF, Ortiz F, Yeh CG, Hechtman HB, Moore FD, لr.: Soluble complement receptor type 1 ameliorates the local and remote organ injury after intestinal ischemia-reperfusion in the rat. J Immunol 1992; 149:1723-8.

76. Huang J, Kim LJ, Mealey R, Marsh HC, Jr., Zhang $Y$, Tenner AJ, Connolly ES, Jr., Pinsky DJ: Neuronal protection in stroke by an sLex-glycosylated complement inhibitory protein. Sclence I1999; 285:595-9.

77. Kyriakides C, Wang $Y$, Austen WG, Jr., Favulzza J, Kobzik L, Moore FD, Jr. Hechtman HB: Moderation of skeletal muscle reperfusion injury by a sLe( $x)$-glycosylated complement inhibitory protein. Am J Physiol Cell Physiol 2001; $281:$ C224-30.

78. Buerke M, Schwertz H, Seitz W, Meyer $\rfloor$, Darius H: Novel small molecule inhibitor of $\mathrm{Cl}$ s exerts cardioprotective effects in ischemia-reperfusion injury in rabbits. J Immunol 2001; 167:5375-80.

79. Griselli M, Herbert $\rrbracket$, Hutchinson WL, Taylor KM, Sohail M, Krausz $\pi$, Pepys MB: C-reactive protein and complement are important mediators of tissue damage in acute myocardial infarction. J Exp Med 1999; 190:1733-40.

80. Nijmeijer R, Lagrand WK, Lubbers YT, Visser CA, Meijer CJ, Niessen HW, Hack CE: C-reaCtive protein activates complement in infarcted human myocardium. Am J Pathol 2003; $163: 269-75$.

81. Collard CD, Vakeva A, Morrissey MA, Agah A, Rollins SA, Reenstra WR, Buras JA, Meri S, Stahl GL.: Complement activation after oxidative stress: role of the lectin complement pathway. Am J Pathol 2000; 156:1549-56.

82. Jordan JE, Montalto MC, Stahl GL: Inhibition of mannose-binding lectin reduces postischemic myocardial reperfusion injury. Circulation 2001: 104:1413-8.

83. Welser MR, Williams JP, Moore FD, Jr., Kobzik L, Ma M, Hechtman HB, Carroll MC: Reperfusion injury of ischemic skeletal muscle is mediated by naturall antibody and complement. $J$ Exp Med 1996; 83:2343-8.

84. Williams JP, Pechet $T$, Weiser MR, Reid R, Kobzik L, Moore FD, Jr., Carroll MC, Hechtman HB: Intestinal reperfusion injury is mediated by $\mathrm{IgM}$ and complement. $\rfloor$ Appl Physiol 1999; 86:938-42.

85. Stahl GL, Xu Y, Hao L, Miller M, Buras JA, Fung M, Zhao $H$ : Role for the alternative complement pathway in ischemia/reperfusion injury. Am J Pathol 2003; 162:449-55. 
86. Park $P$, Haas $M$, Cunningham $P N, B a O L$, Alexander $J$, Quigg $R J$ : Injury in renal ischemia-reperfusion is independent from immunoglobulins and T lymphocytes. Am I Physiol Renal Physiol $2002 ; 282: F 352-7$.

87. Thurman JM, Ljubanovic D, Edelstein $\mathrm{CL}_{t}$ Gilkeson GS, Holers VM: Lack of a functional alternative complement pathway ameliorates ischemic acute renal failure in mice. $J$ inmunol $2003 ; 170: 1517-23$.

88. Riedemann $\mathrm{NC}_{n}$ Ward PA: Complement in ischemia reperfusion injury. Am J Pathol 2003; 162:363-7.

89. Nauta AJ, Raaschou-Jensen N, Roos A, Daha MR, Madsen HO, Borrias-Essers MC, Ryder LP, Koch $C$, Garred $\mathbf{P}$. Mannose-binding lectin engagement with late apoptotic and necrotic cells.. Eur J IImmunol 2003; 33:2853-63.

90. Nauta AJ, Trouw LA, Daha MR, Tijsma $O$, Nieuwland $R_{t}$ Schwaeble WJ, Gingras AR, Mantovani A, Hack EC, Roos A: Direct binding of Clq to apoptotic cells and cell blebs induces complement activation. Eur $\$ Immunol 2002; 32:1726-36.

91. Mold C, Morris CA: Complement activation by apoptotic endothelial cells following hypoxia/reoxygenation. Immunology 2001 : 102:359-64.

92. Cole DS, Morgan BP: Beyond lysis: how complement influences cell fate. Clin Sci (Lond) 2003; 104:455-66. 



\section{CHAPTER 2}

\section{Apoptotic cell-death is initiated during normothermic ischemia in human kidneys}

Tim G.A.M. Wolfs, Bart de Vries, Sarah J. Walter, Carine J. Peutz-Kootstra, L.W. Ernest van Heurn, Gosse O. N. Oosterhof and Wim A. Buurman 
Ischemic damage plays an important role in post-transplant organ failure. Activation of the apoptotic cascade is crucially involved in post-ischemic inflammation resulting in tissue damage and organ dysfunction. Here we investigate the initiation of the apoptotic cascade during ischemia in human kidneys using a model for normothermic ischemia with kidneys nephrectomized because of renal cell carcinoma.

Ex vivo, kidneys were stored at $37^{\circ} \mathrm{C}$ and consecutive biopsies were taken from disease free tissue. Pro- and anti-apoptotic proteins were assessed by western blotting and immunofluorescence.

During normothermic ischemia the pro-apoptotic proteins Bax and activated caspase -9 increased with ischemia time, whereas caspase -8 was not activated. The anti-apoptotic proteins $\mathrm{BCl}-2$ and cFLIP decreased in time. Data on $\mathrm{BCl}-2$ and $\mathrm{Bax}$ were supported by immunofluorescence for $\mathrm{BCl}-2$ and activated Bax. However, activation of the centrall effector caspase-3, essential for execution of the apoptotic process, was not detected.

In conclusion, during normothermic ischemia the apoptotic cascade in the human kidney is initiated, but not fulfilled. Our data show that the duration of ischemia significantly correlates with activation of the apoptotic cascade. These findings provide insight in the initiation of apoptotic cell-death during warm ischemia and may be useful in the assessment of ischemic injury.

\section{INTRODUCTION}

Post-transplant acute renal failure (ARF) is an important determinant of renal transplant survival. The occurrence of ARF is substantial in organs derived from cadaveric donors and in particular non-heart beating (NHB) category 2 donors [1], as compared to living donors [2]. The inevitable ischemia of such NHB donor kidneys explains these differences in graft failure to a large extent [2]. Understanding the mechanisms of injury initiated by ischemiareperfusion ( $(/ R)$ is therefore of critical importance for defining strategies to improve post-transplant organ function.

In different experimental models it has been established that renal ischemia followed by reperfusion leads to apoptotic cell death $[3,4]$. Moreover, activation of the apoptotic cascade is crucially involved in the induction of post-ischemic inflammation and subsequent organ failure [3]. In line, enhanced apoptotic cell death established by tunel-staining, was detected in post-transplant biopsies from cadaveric allografts as compared to transplants derived from living donors, indicating that ischemic injury induces apoptosis in clinical transplantation [5]. 
Apoptosis is executed by a family of cysteine proteases, called caspases [6]. Two major pathways of caspase activation have been described; i.e. the extrinsic and intrinsic pathway [7]. Activation of the extrinsic pathway, triggered by binding of extracellular ligands to cell surface death receptors, results in recruitment of the adlaptor molecule and Fas-associated death domain (FADD) and activation of caspase-8 upon recruitment to the deathinducing signalling complex (DISC). The latter are controlled by CFLIP, an intracellular protein that inhibits death receptor signaling by regulating both recruitment and processing of pro-caspase-8 within the DISC [8].

The intrinsic pathway is activated by various intracellular stimuli, such as anoxia, growth factor deprivation and DNA damage, all affecting the mitochondria, where they promote mitochondrial membrane permeabilization and the release of caspase activating factors, among others cytochrome c, into the cytosol $[9,10]$. Cytosolic cytochrome c interacts with apaf-1, leading to its oligomerization and the recruitment of pro-caspase-9, which autoactivates within the so called apoptosome [11]. Members of the Bcl-2 family, among others pro-apoptotic Bax and anti-apoptotic BCl-2, control activation of the intrinsic pathway. For any given apoptotic stimulus, the balance between death and survival seems to be determined by the ratio of the apoptosis-stimulating and -suppressing BCl-2 family members $[12,13]$. The activation of either extrinsic or intrinsic pathway participates in a cascade that culminates in the activation of effector caspases. Activation of primarily effector caspases $-3,-6$, and -7 , results in cleavage of a wide range of substrates leading to chromosomal DNA fragmentation and cellular morphologic changes characteristic of apoptosis [6].

Although it appears that apoptotic cell death plays a role in the induction of organ damage due to renal $I / \mathbb{R}$ in humans $[5,14]$, it is currently unknown whether the apoptotic cascade is already initiated during ischemia or becomes initiated upon reperfusion. In this context, we developed a human model for renal normothermic ischemia. This model was used to study proteins involved in the initiation of the apoptotic cascade during normothermic ischemia. In particular, we investigated the consumption of endogenous caspase inhibitors as well as the activation of initiator and effector caspases. Our data indicate that during normothermic ischemia the apoptotic cascade is initiated in the human kidney. These data implicate that during normothermic ischemia, the circumstances are created that facilitate execution of apoptosis upon reperfusion.

Therefore our data may be useful in the development of methods to assess ischemic injury. Moreover, renewed insight in early ischemic changes provides important opportunities to prevent clinical manifestations of reperfusion injury in the kidney, and potentially in other organs. 


\section{Antibodies}

The following antibodies (ab) were used: anti-murine Bax ab P19 from Santa Cruz Biotechnology (Santa Cruz, CA); anti-BCl-2, anti-human caspase-9 and anti-human caspase-3 from Stressgen (Victoria, Canada); monoclonal murine anti-caspase- 8 was kindly provided by Dr. Klaus Schulze-Osthoff (Institute of Molecular Medicine, University of Duesseldorf, Germany); anti human CFLIP (Biocarta; San Diego, CA); Goat anti rabbit Texas Red and peroxidase conjugated goat anti-rabbit IgG from Jackson Immuno-Research Laboratories (West Grove, PA) and peroxidase conjugated goat anti-mouse IgC from Caltag (Burlingame, CA). Anti-Bcl-2 and anti-Bax from Upstate biotechnology (Lake Placid, NY) and Lotus Tetragonolobus Lectin from Vector (Burlingame, CA) were used for immunohistochemistry.

Human model for renal normothermic ischemia

In the present study, kidneys used were nephrectomized because of a renal cell carcinoma. Normothermic ischemia started at ligation of the renal artery about 5 min before nephrectomy. Thereafter, kidneys $(n=5$ per group) were immediately stored at $37^{\circ} \mathrm{C}$ and rapidly inspected by the responsible pathologist. Full-thickness biopsies were taken from non-diseased tissue. Subsequently, normothermic renal ischemia was prolonged up to $85 \mathrm{~min}$. Renal temperature was measured during storage and remained between 36 and $37.5^{\circ} \mathrm{C}$. Approximately every 15 min full-thickness biopsies were taken. Control kidneys $(n=4)$ were cooled at $0^{\circ} \mathrm{C}$ immediately upon nephrectomy. Biopsies from these control kidneys were taken within 10 min after nephrectomy. All biopsies were divided in several parts and either immediately stored in liquid nitrogen for western blotting, or embedded in Tissue Tek (EMS; Washington, PA) and snap-frozen in isopentane at $-80^{\circ} \mathrm{C}$ for immunohistochemistry. All biopsies were stored at $-80^{\circ} \mathrm{C}$ until further processing.

\section{Western blotting}

Renal tissue samples were homogenized in lysis buffer $(200 \mathrm{mM} \mathrm{NaCl}, 10$ $\mathrm{mM}$ Tris base, $5 \mathrm{mM}$ EDTA, $10 \%$ Glycerin, $1 \mathrm{mM}$ PMSF, $0.1 \mathrm{U} / \mathrm{ml}$ Aprotinin and $1 \mu \mathrm{g} / \mathrm{ml}$ Leupeptin). Homogenates were centrifuged at $300 \mathrm{rpm}$ for $10 \mathrm{~min}$, supernatants were collected and centrifuged again at $10.000 \mathrm{rpm}$ for $3 \mathrm{~min}$. Final supernatants were harvested and total protein concentrations were determined using the Bradford method. To confirm equal protein loading immunoblotting was performed with an anti-actin antibody (Sigma, Chicago, IL). Aliquots with equal amounts of protein were heated at $100^{\circ} \mathrm{C}$ for 5 min in SDS sample buffer, separated on $15 \%$ SDS-polyacrylamide gels and transferred to polyvinylidene fluoride membranes (Immo- 
bilon P; Millipore, Bedford, MA). After transfer of proteins, blocking, ab incubation steps and washing of the membrane were performed in Phosphate buffered saline (PBS) supplemented with $3 \%$ nonfat dry milk and $0.05 \%$ Tween. Except for incubations with ab to cFLIP, which were blocked in $50 \mathrm{mM}$ Tris, $150 \mathrm{mM} \mathrm{NaCl}, 0.1 \%$ Tween 20 (TBST) supplemented with $5 \%$ milk and washed in TBST with $0.5 \%$ milk.

After the incubation with the primary ab and washing, membranes were incubated with the appropriate horseradish peroxidase-conjugated secondary $a b$ to rabbit or mouse IgG. Positive bands were visualized using chemiluminescence (Supersignal; Pierce, Rockford, IL).

Immunoreactive bands for all proteins were evaluated densitometrically using a computer-controlled display camera (Imagemaster; Pharmacia, Piscataway, NJ) and image analysis Sigma Gel software (SPSS). For each protein, the optical density of each ischemic sample was compared with the average value of the four control samples.

\section{Immunohistochemistry}

Cryostat sections $(5 \mu \mathrm{m})$ of frozen tissue were cut and stained for $\mathrm{Bcl}-2$ or active Bax. Briefly, slides were dried, fixed in acetone for $10 \mathrm{~min}$, and airdried. Slides were rehydrated in PBS for $5 \mathrm{~min}$ and subsequently incubated in 10\% normal goat serum in PBS to block aspecific ab binding. Slides were stained for 2 hours at RT with either anti-BCl-2 or anti-Bax primary ab in PBS with 1\% bovine serum albumin. After three washes in PBS for 5 min each, slides were incubated for 30 min with the Texas Red labeled secondary ab dilluted in the same buffer with the addition of FITC-labeled Lotus Lectin for identification of proximal tubular epithelium [15]. After three washes in PBS, the slides were mounted using glycerol-PBS with 1,4-diazabicyclo $(2,2,2)$ octane and 4,6-diamidino(2)phenylindole (DAPI) and viewed with an immunofluorescence microscope. No significant staining was detected in slides incubated with control ab instead of the primary ab indicating the absence of significant background staining.

\section{Statistical analysis}

We used the Mann-Whitney $U$ test to compare Bax protein expression between the control and the "early" ischemia group. The Spearman analysis was used to determine correlation between the duration of normothermic ischemia and initiation of apoptosis. A P value of less than 0.05 was considered significant. 
Initiation of the intrinsic pathway during normothermic renal ischemia

To determine whether apoptogenic processes are initiated during ischemia, we evaluated the effect of normothermic ischemia on proteins involved in activation of both the intrinsic and extrinsic pathway. Since activation of the intrinsic pathway is regulated by members of the $\mathrm{BCl}-2$ protein family, we first determined the pro-apoptotic Bax protein content during ischemia by western blotting. As described by others, we observed that monomeric Bax (21 kDa) is constitutively expressed in human renal tissue [16] (Figure 1). A short period of renal ischemia (15 until $35 \mathrm{~min}$ ) led to a significant increase of Bax protein (P 0.02, Mann-Whitney U test) (Figure 1).

$21 \mathrm{kDa}$

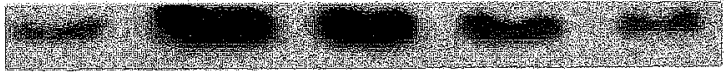

A

control $\quad 35 \mathrm{~min} \quad 50 \mathrm{~min} \quad 65 \mathrm{~min} \quad 80 \mathrm{~min}$

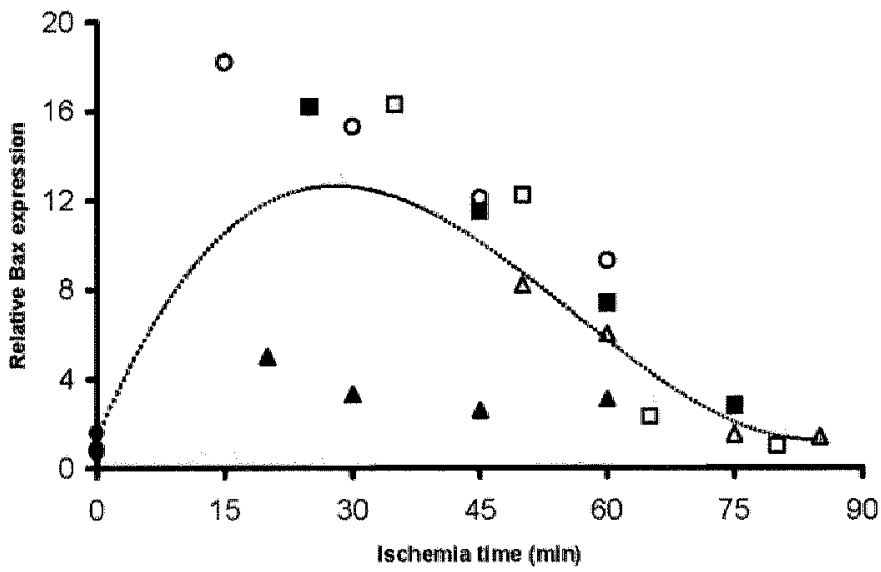

B

Figure 1. Bax protein shows a rapid increase followed by decrease during normothermic ischemia. A) Representative immunoblot analysis of Bax. B) Densitometric analysis of Bax immunololotting of ischemic $(n=5)$ and control kidneys $(n=4)$. Data of ischemic kidneys are expressed as the fraction of mean of controll data. Individual ischemic kidneys are displayed by different symbols $(\square, \Delta, 0, \square, \Delta)$ and control kidneys by a filled circle. Constitutive Bax expression (21 kDa) was detected in control tissue. After a short period of ischemia remal Bax expression levels were significantly increased ( $\mathrm{P} 0.02$, Mann-Whitney U test). Bax protein levels remained ele vated up to 60 min. Dotted line represents trendline of all data. 
Bax levels remained clearly ellevated up to 60 min. Further prolongation of ischemia reduced Bax expression back to basal levels. Next the localisation of active Bax was studied using immunohistochemistry. For this purpose, an ab directed to the $\mathrm{N}$-terminal region of active $\mathrm{Bax}$ that is inaccessible in the inactive conformation was applied. The data show that active Bax protein is nearly absent in control tissue (Figure 2). In concordance with the enhanced Bax protein content, as detected by western blotting, cytoplasmic active Bax staining increased in the early ischemic phase. After 30 min of ischemia, activated Bax was predominantly localised in distal tubular epithelial cells. At this timepoint, also some focal staining was observed in proximal tubules. Proximal tubules were identified using Lotus Lectin staining. Similarly, after 80 min of ischemia, the majority of active Bax was detected in distal tubules (Figure 2).
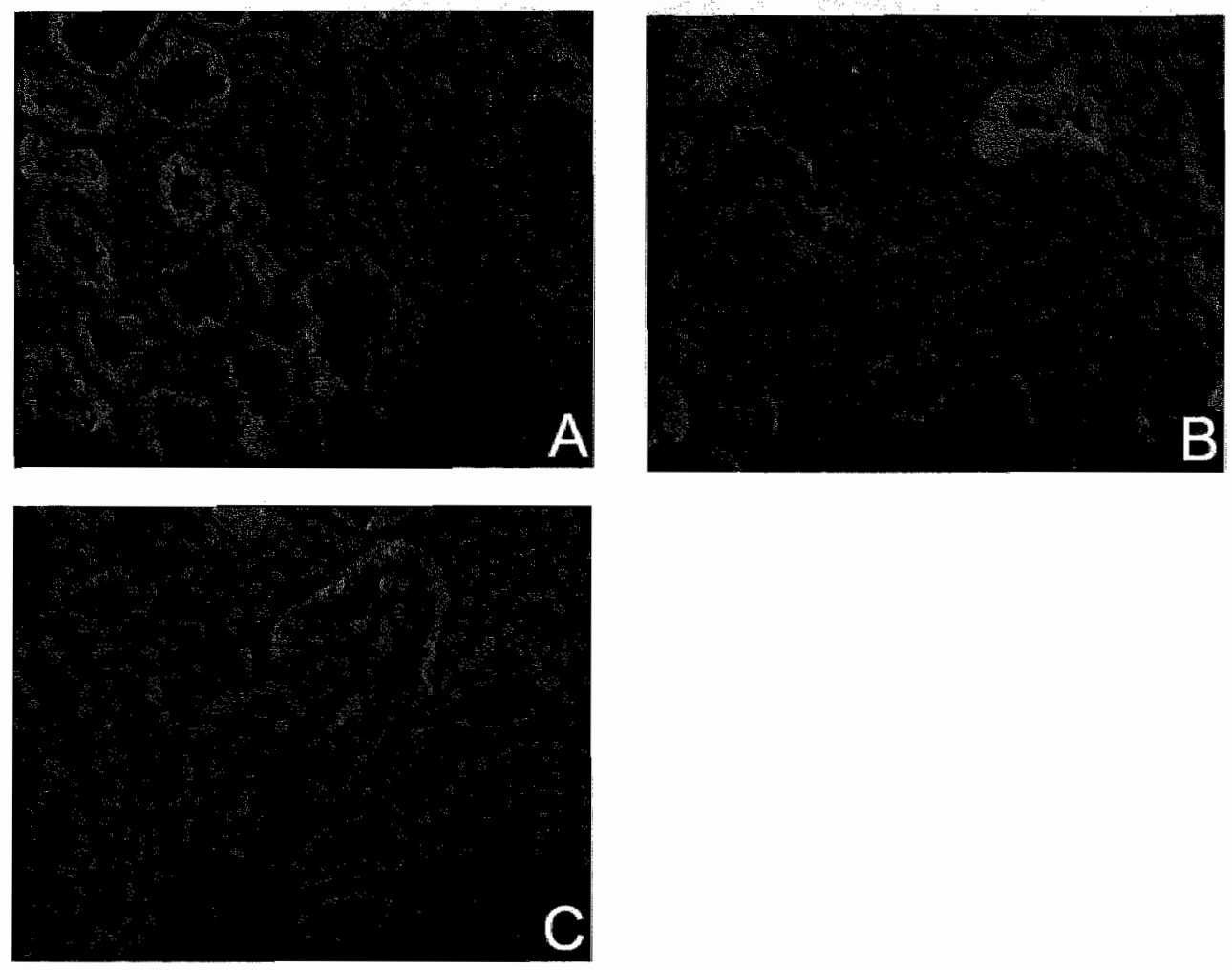

Figure 2. Activated Bax protein is predominantly expressed by distal tubular epithelial cells. While hardly detectable in control kidneys (A), Bax protein was increasingly expressed (red) in distal tubules in kidneys exposed to $30 \mathrm{~min}$ (B) or $80 \mathrm{~min}$ (C) of ischemia. In the ischemic sections also some focal staining of proximal tubules was observed $(B, C)$. Proximal tubules were identified by FITC Lotus Lectin staining (green). Red staining, active Bax protein (Texas Red): blue staining, nuclei (4,6-diamidino(2)phenylindole). Magnification: $\times 200$. 
Subsequently, we investigated the effect of ischemia on the regulation of the anti-apoptotic protein $\mathrm{BCl}-2$. Abundant monomeric $\mathrm{BCl}-2$ expression (26 $\mathrm{kDa}$ ) was observed in control tissue (Figure 3 ). Bcl-2 western blot analysis revealed that during ischemia $\mathrm{BCl}-2$ levels were reduced. Moreover, this reduction of $\mathrm{BCl}-2$ significantly correlated with the duration of the ischemic insult ( $r=0.86, P 0.001$, Spearman correlation analysis) (Figure 3 ). Immunohistology for $\mathrm{BCl}-2$ resulted in similar data; a decrease of $\mathrm{BCl}-2$ with time. $\mathrm{BCl}-2$ was primarily detected at the basolateral side of tubular epithelial cells. The expression was predominantly observed in proximal tubules while a lower expression was detected in distal tubules (Figure 4).

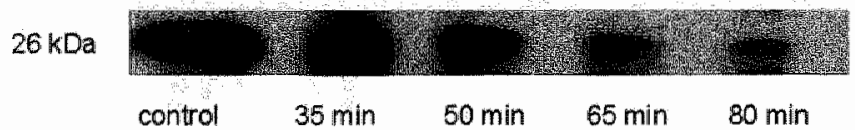

A

control $\quad 35 \mathrm{~min} \quad 50 \mathrm{~min} \quad 65 \mathrm{~min} \quad 80 \mathrm{~min}$

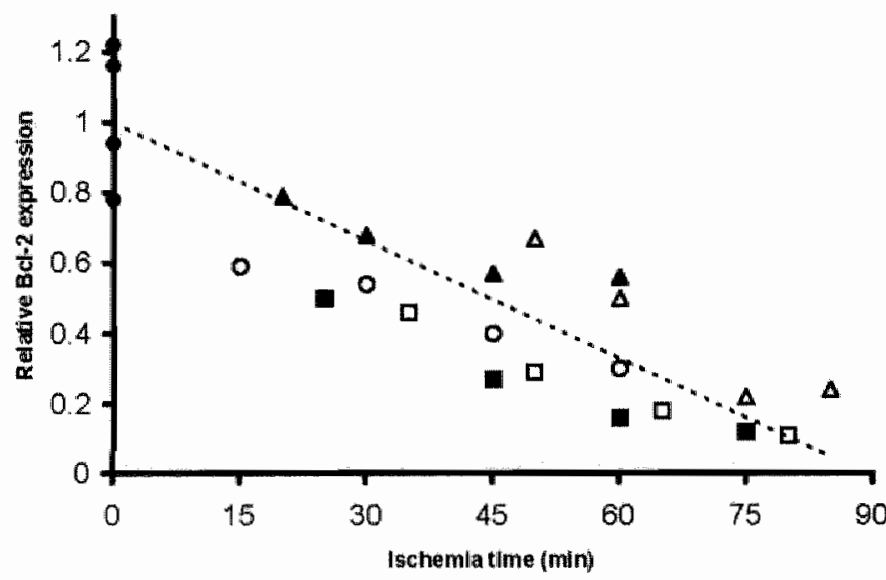

B

Figure 3. Depletion of renal BCl-2 during normothermic ischemia. A) Representative immunoblot analysis of $\mathrm{BCl}-2$. B) Densitometric analysis of $\mathrm{BCl}-2$ immunoblotting with ischemic $(n=5)$ and control kidneys $(n=4)$. Data of ischemic kidneys are expressed as fraction of the mean of control data. Individual ischemic kidneys are displayed by different symbols $(\mathbb{m}, \Delta, 0, \square, \Delta)$ and control kidneys by a filled circle. A significant correlation was detected between renal 26 $\mathrm{kDa} B \mathrm{Cl}-2$ levels and the length of normothermic ischemia $(r=0.86, \mathrm{P} 0.001$, Spearman correlation analysis). Dotted line gives trendline of all data. 


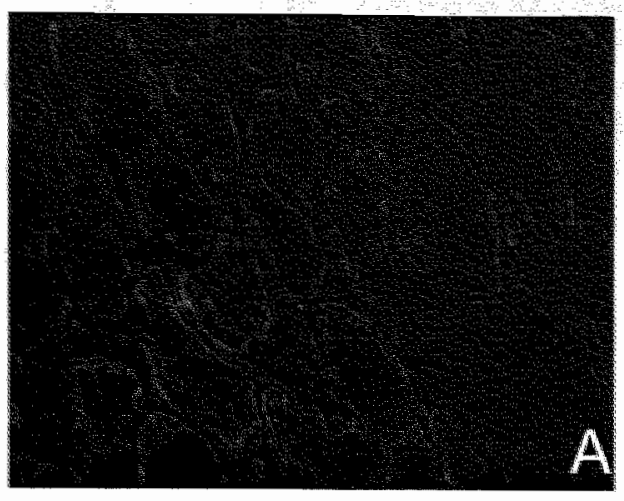

Figure 4. Immunafluorescence staining of $\mathrm{BCl}-2$ during renal normothermic ischemia. Renal $\mathrm{BCl}-$ 2 staining was most abundant (red) in proximal tubules of control tissue (A) and in kidneys tendered ischemic for $35 \mathrm{~min}$ (B) and 80 min respectively (C). Less staining was detected in distal tubules in both control and ischemic tissue. Proximal tubules were identified by FiTC Lotus Lectin staining (green). Red staining, Bcl-2 protein (Texas Red); green staiming, Lotus Lectin (fluorescein isothiocyanate); blue staining, nuclei (4,6-diamidino(2)phenylindole). Magnification: $\times 200$ 
Collectively, enhanced Bax protein levels combined with decreased $\mathrm{Bcl}-2$ levels suggests that normothermic ischemia enhances susceptibility for the activation of the intrinsic pathway. In this context we determined the activation of initiator caspase- 9 . We observed a significant correlation between activation of caspase-9 $(34 / 37 \mathrm{kDa})$ and the normothermic ischemia time $(r=0.79, P 0.001$, Spearman correllation analysis) (Figure 5$)$. Taken together, these data show that already during normothermic ischemia, activation of the intrinsic pathway of the apoptotic cascade occurs.

$34 / 37 \mathrm{kDa}$

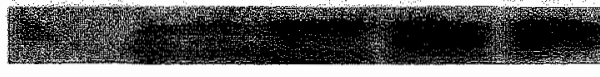

control $\quad 35 \mathrm{~min} \quad 50 \mathrm{~min} \quad 65 \mathrm{~min} \quad 80 \mathrm{~min}$

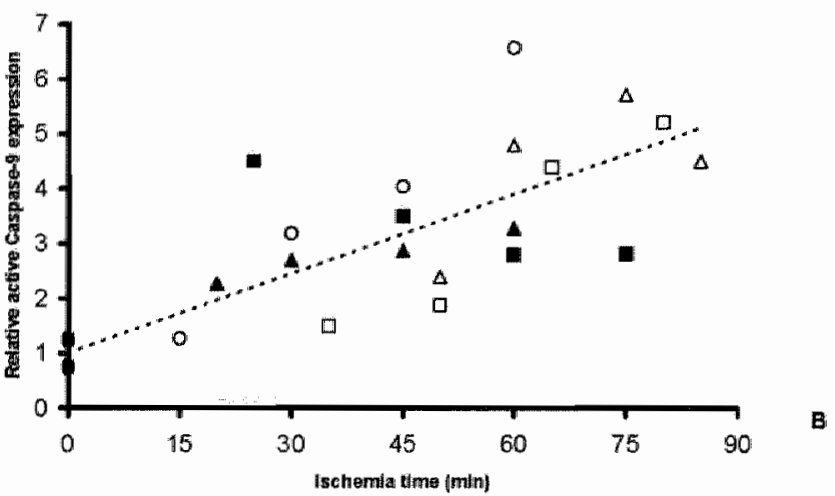

Figure 5. Ischemia induces intrarenal caspase-9 activation. A) Representative immunoblot analysis of actiwated caspase-9. B) Densitometric analysis of caspase-9 immunoblotting with ischemic $(n=5)$ and control kidneys $(n=4)$. Data of ischemic kidneys are expressed as fraction of the mean of control data. Individual ischemic kidneys are displayed by different symbols $(\mathbf{C}, \triangle, \square, \triangle)$ and control kidneys by a filled circle. Activation of caspase-9 (34/3.7 kDa) is significantly correlated with the ischemia time $(r=0.79, P \quad 0.001$, Spearman correlation analysis). Dotted line gives trendine of all data.

Initiation of the extrinsic pathway during normothermic renal ischernia

Next, we examined whether, besides initiation of the intrinsic pathway, also the extrinsic pathway was activated during ischemia. Activation of this route is regulated by the cytoplasmic protein CFLIP, a competitive inhibitor of caspase-8 [17]. We therefore measured CFLIP levels during ischemia. Here we show that CFLIP ( $55 \mathrm{kDa}$ ) was normally expressed in the human kidney and got depleted during normothermic ischemia (Figure 6). Interestingly, the reduction of cFLIP levels significantly correlated with the duration of ischemia ( $r=0.78, P 0.001$, Spearman correlation analysis). 
Subsequently, we determined whether CFLIP depletion results in activation of caspase-8, the initiator caspase of the intrinsic pathway. Similar levels of the pro-form of caspase-8 $(43 / 44 \mathrm{kDa})$ were found in control and ischemic tissue (Figure 7A). In line, activated caspase- 8 fragments were not detectable during normothermic ischemia (data not shown). Thus, although cFLIP was depleted during ischemia, no active caspase-8 was detected.

\section{Activation of effector caspases during normothermic renal ischemia}

To evaluate whether the observed activated intrinsic pathway leads to execution of the apoptotic process, processing of the central effector caspase, caspase -3 was determined. The caspase- 3 proform $(34 \mathrm{kDa})$ was detected in control tissue. The basal expression levels did not change during ischemia (Figure 7B). In line, fragments representing active caspase- 3 were not observed. Taken together, our data implicate that during ischemia the circumstances are created for activation of the apoptotic cascade upon reperfusion.

$55 \mathrm{kDa}$

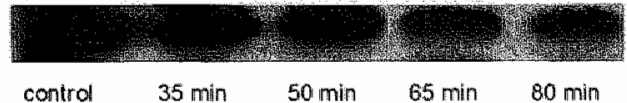

A

contral $\quad 35 \mathrm{~min} \quad 50$ min $\quad 65 \mathrm{~min} \quad 80 \mathrm{~min}$

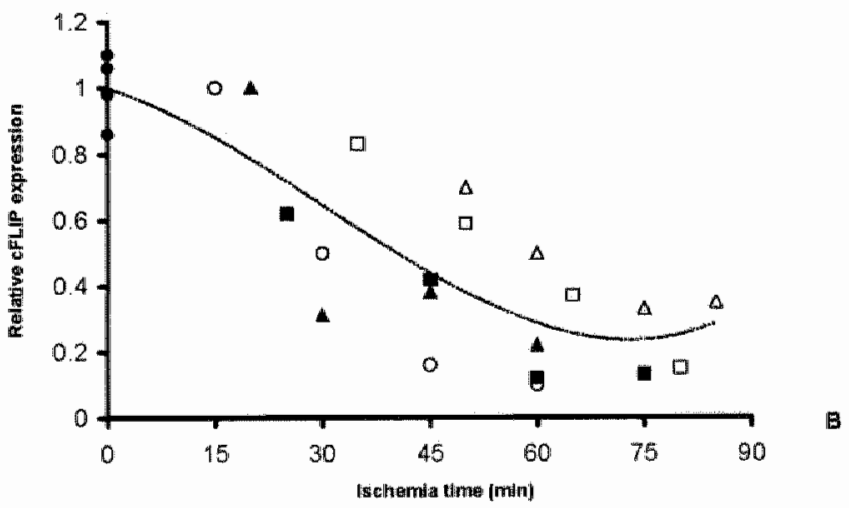

Figure 6. Depletion of cFLIP during normothermic renal ischemia. A) Representative immunoblot analysis of intrarenal CFLIP. B) Densitometric analysis of CFLIP immunoblotting with ischemic $(n=5)$ and control kidneys $(n=4)$. Data of ischemic kidneys are expressed as fraction of the mean of control data. Individual ischemic kidneys are displayed by different symbols $(\mathbf{C}, \Delta, 0, \square, \Delta)$ and control kidneys by a filled circle. CFLIP ( $55 \mathrm{kDa}$ ) expression levels reduces in time with induction of the length of ischemia and this correlation is statistically significant $(r=0.78, P 0.001$, Spearman correlation analysis). Dotted line gives trendline of all data. 
$55 \mathrm{kOa}$

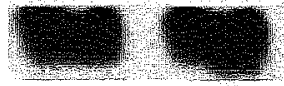

$34 \mathrm{kDa}$

(ris
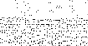

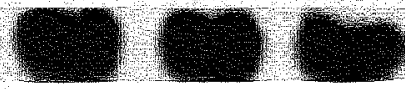

政

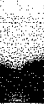

Conthol

G5) min

$50 \mathrm{~min}$

65 的期

$80 \mathrm{~min}$
A

B

Figure 7. Processing of caspase- 8 and caspase-3 during renal ischemia. A) The $54 / 55 \mathrm{kDa}$ inactive isoforms of caspase- 8 are detected in ischemic and control tissue. The $43 / 44 \mathrm{kDa}$ fragment compromising the intermediate caspase- 8 cleavage fragments are not detected (data not shown). A representative blot is shown. B) $34 \mathrm{kDa}$ pro-form caspase-3 was present in healthy and ischemic tissue. Activation of caspase-3 could not be detected in any samples (data not shown). A representative blot is shown.

\section{DISCUSSION}

In the current study, we investigated the initiation of apoptotic cell-death during normothermic renal ischemia. In renal transplantation, normothermic warm ischemia occurs in NHB donation, especially in category 2 donors. This warm ischemia is considered to be the major cause of delayed graft function and primary non-function. Also cold ischemia as occurs during preservation of donor organs can lead to organ damage. In cadaveric donors, cold ischemia time was associated with the numbers of apoptotic cells, present 1 hour after onset of reperfusion/transplantation $[5,14]$. In vitro experiments showed that cold storage of proximal tubular cells for $48 \mathrm{~h}$ resulted in activation of apoptosis, only after rewarming. The apoptotic process was not activated during cold storage [18].

Here we investigate initiation of the apoptotic process during normothermic ischemia in an ex vivo model. Initiation of the apoptotic cascade occurs either via activation of the extrinsic or the intrinsic pathway. Because regulation of the intrinsic pathway is accomplished in part through the stoichiometric balance of pro-apoptotic and anti-apoptotic $\mathrm{BCl}-2$ proteins [12, 19], we studied alterations in levels of anti-apoptotic ( $\mathrm{BCl}-2)$ and pro-apoptotic (Bax) members of this protein family. Using a human model for renal normothermic ischemia we demonstrated that depletion of monomeric $\mathrm{BCl}-2$, that is able to prevent dimerization of the pro-apoptotic Bax, significantly correlated with the extent of ischemia. Our findings further extend recent data from Schwarz et al. [20]. They showed that low mRNA levels for $\mathrm{BCl}-2$ in proximal tubular epithelial cells in pre-transplant cadaveric donor kidney biopsies are associated with apoptosis and subsequent ARF and delayed allograft function [20]. These data support our findings that epithelial cells of the proximal tubules are the predominant site of renal $\mathrm{BCl}-2$ protein 
Next, we showed that protein levels of monomeric Bax are strongly enhanced by normothermic ischemia, predominantly in the early ischemic phase. These data are supported by findings from the group of Hébert, who showed in an experimental rat model elevation of renal Bax protein expression, $10 \mathrm{~min}$ after the induction of cardiac arrest [21]. Moreover, our western blotting data are completed by immunohistochemistry experiments with an ab that detects active Bax. Immunohistochemistry data revealed that renal ischemia also resulted in activated Bax protein expression. Activated Bax was primarily detected in distal tubules. This increased distal active Bax expression and the decreased proximal $\mathrm{BCl}-2$ expression suggests a pro-apoptotic state in both distal and proximal tubular epithelium. At this stage there is no explanation for the observed expression pattern of apoptotic proteins. Many mechanisms could be responsible such as differences in "stress" in the different parts of the tubule during ischemia. It is generally said that the proximal part is more sensitive to ischemia and reperfusion with more necrotic cell-death while the distal tubules suffer more from apoptotic cell-death [9]. However, it is not completely ellucidated as yet which part of the nephron suffers the most severe after an ischemic insult $[22,23]$.

Next, for the first time we showed that a significant correlation exists between activation of caspase- 9 and the duration of normothermic renal ischemia. The observed activation of caspase- 9 in the present study did however not result in activation of the downstream caspase-3 during normothermic ischemia. Activation of this central effector caspase- 3 is essential for cleavage of different substrates resulting in execution of the apoptotic process. Previous published findings in experimental models have been contradictory as to whether caspase- 3 is induced during ischemia or rather during reperfusion [24-27]. We do not have an explanation for the observed data that activated caspase- 9 fails to activate caspase -3 at this stage. However, it is known that next to caspases, also XIAP, an inhibitor of caspase-3, is recruited to the apoptosome [28]. How the inhibitory effect of XIAP is overcome and how cellular caspase- 3 activation and cell death can take place is, at this stage, unknown. Possibly, reperfusion is necessary to overcome the protective effect of XIAP, resulting in cell death.

Besides activation of the intrinsic pathway, we also demonstrated that the extrinsic pathway is already initiated during ischemia. In particular, we show that depletion of the competitive caspase- 8 inhibitor, CFLIP, significantly correlated with the length of normothermic renal ischemia. These findings further extend data from Rasper et al. who showed significant CFLIP depletion after ischemia in the reperfused heart [17]. Since CFLIP prevents death-receptor mediated apoptosis by precluding recruitment of caspase- 8 to the DISC $[17,29]$, reductions of the CFLIP content facilitate caspase- 8 activation. However, in our model cFLIP depletion was not accompanied by caspase- 8 activation during ischemia, indicating that low CFLIP levels alone are insufficient to activate the intrinsic pathway. Presumably, activation of 
the extrinsic pathway needs conditions that are only met during reperfusion. Indeed, in a rat cardiac $1 / R$ model it has been demonstrated that caspase- 8 activation occurs in the reperfusion phase, but not by ischemia alone [30].

Taken together, we show in a human model for renal normothermic ischemia that the intrinsic as well as the extrinsic pathway of apoptosis are initiated during ischemia. These data indicate that during ischemia the circumstances are created that facilitate execution of apoptosis upon reperfusion. This hypothesis is supported by data obtained in our murine model of renal I/R. In this modell, we confirmed the observation that initiation of the apoptotic process emerges during ischemia. Furthermore, the length of the ischemic period corresponds with the extent of apoptosis and the concomitant organ function during reperfusion (unpublished findings). Potentially, assessment of proteins involved in the early apoptotic process in pre-transplant kidney biopsies might be helpful to estimate ischemic damage and predict concomitant graft function. Evidence that apoptosis is crucially involved in clinical transplantation has been provided by different groups, showing that apoptotic cell death is enhanced in post-reperfusion biopsies from cadaveric allografts compared with living related renal transplants $[5,14]$. However, these studies report apoptotic cell death in brain death donors. In these donors, besides ischemia, other factors such as periods of diminished organ perfusion, hemodynamic instability and activation of the immune-system affect post-transplant organ function [31]. In contrast, our model is restricted to the effect of ischemia itself, thereby reflecting the situation in NHB organ donation, in which warm ischemia forms the major determinant of graft outcome. Therefore, our novel finding that ischemia alone, already initiates the apoptotic process, might explain the increased risk for NHB graft dysfunction.

In conclusion, in a human model for renal normothermic ischemia we demonstrate that the apoptotic cascade is initiated during ischemia. For the first time, the time dependent regulation of proteins responsible for the onset of the apoptotic cascade in the course of normothermic ischemia is shown. Determination of these processes might be beneficial in assessing the degree of ischemic injury in NHB donor kidneys and other organs. Furthermore, these new insights can be explored for the development of specific anti-apoptotic treatment to prevent organ damage upon transplantation due to ischemic injury. 
1. Kootstra $G_{\text {, Daemen }} \mathrm{H}_{\mathrm{H}}$ Oomen AP. Categories of non-heart-beating donors. Transplant Proc $1995 ; 27(5): 2893-4$.

2. Nicholson ML, Metcalfe MS, White $S A$, Waller $J R_{1}$ Doughman TM, Horsburgh $T$, et al. A comparison of the results of renal transplantation from non-heart-beating, conventional cadaveric, and living donors. Kidney Int 2000;58(6):25:5-91.

3. Daemen MA, van 't Veer $C_{n}$ Denecker $G$, Heemskerk $V H$, Wolfs $T G_{\text {, }}$ Clauss $M$, et al. Inhibition of apoptosis induced by ischemia-reperfusion prevents inflammation. J Clin Invest 1999; 104(5):541-9.

4. Nagae S, Miyazaki M, Kobayashi N, Saito T, Abe K, Saito H, et al. Induction of apoptosis in ischemia-reperfusion model of mouse kidney: possible involvement of Fas. ل Am Soc Nephrol $1998 ; 9(4): 620-31$.

5. Burns AT, Davies DR, McLaren AJ, Cerundolo $L_{1}$ Morris PJ, Fuggle SV. Apoptosis in ischemia/reperfusion injury of human renal allografts. Transplantation 1998;66(7):872-6.

6. Thormberry NA, Lazebnik $Y$. Caspases: enemies within. Science 1998;281(5381):1312-6.

7. Budihardjo I, Oliver $H$, Lutter M, Luo X, Wang X. Biochemical pathways of caspase activation during apoptosis. Annu Rev Cell Dev Biol 1999;15:269-90.

8. Krueger A, Baumann S, Krammer PH, Kirchhoff 5. FLICE-inhibitory proteins: regulators of death receptor-mediated apoptosis. Mol Cell Biol 2001;21(24):8247-54.

9. Saikumar P, Venkatachalam MA. Role of apoptosis in hypoxic/ischemic damage in the kidney. Semin Nephrol 2003;23(6):511-21.

10. Kroemer G, Reed JC. Mitochondrial control of cell death. Nat Med 2000;6(5):513-9.

11. Adrain $C$, Martin Sl. The mitochondrial apoptosome: a killer unleashed by the cytochrome seas. Trends Biochem Scil 2001;26(6):390-7.

12. Saikumar P, Dong Z, Mikhaillov V, Denton M, Weinberg JM, Venkatachalam MA. Apoptosis: definition, mechanisms, and relevance to disease. Am J Med 1999;107(5):489-506.

13. Antonsson B. Bax and other pro-apoptotic Bcl-2 family "killer-proteins" and their victim the mitochondrion. Cell Tissue Res 2001;306(3):347-61.

14. Castaneda MP, Swiatecka-Urban $A_{1}$, Mitsnefes MM, Feuerstein D, Kaskel Fl, Tellis V, et al. Activation of mitochondrial apoptotic pathways in human renal allografts after ischemia reperfusion injury. Transpllantation $2003 ; 76(1): 50-4$.

15. Markowitz GS, Radhakrishnam J, Kambham $N_{*}$ Valeri AM, Hines WH, D'Agat VD. Lithium nephrotoxicity: a progressive combined glomerular and tubulointerstitial nephropathy. $\rfloor$ Am Soc Nephrol 2000;11(8):1439-48.

16. Wever PC, Aten J, Rentenaar RJ, Hack CE, Koopman G, Weening Il, et al. Apoptotic tubular cell death during acute renal allograft rejection. Clin Nephrol 1998;49(1):28-34.

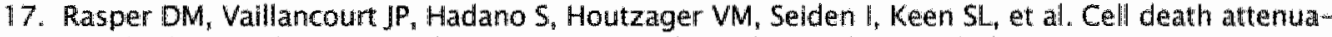
tion by 'Usurpin', a mammalian DED-caspase homologue that precludes caspase- 8 recruitment and activation by the CD-95 (Fas, APO-1) receptor complex. Cell Death Differ 1998;5(4);271-88.

18. Salahudeen AK, Huang $H_{1}$ Joshil M, Moore NA, Jenkins JK. Involvement of the mitochondrial pathway in cold storage and rewarming-associated apoptosis of human renal proximal tubular cells. Am I Transplant 2003"3(3):273-80.

19. Adams $\mathrm{IM}_{\mathrm{t}}$ Cory $\mathrm{S}$. The BCl-2 protein family: arbiters of cell survival. Science 1998; $281(5381): 1322-6$.

20. Schwarz $C_{n}$ Hauser $P$, Steininger $R$, Regele $H_{0}$ Heinze $G$, Mayer $G$, et al. Failure of $B C L-2$ upregulation in proximal tubular epithelfal cells of donor kidney biopsy specimens is associated with apoptosis and delayed graft function. Lab Invest $2002 ; 82(7): 941,-8$.

21. Bellemare S, Vigneault N, Madore F, Raymond MA, Callhier JF, Hebert MJ. Enhanced development of caspase-independent cortical cell death during cold storage in kidneys of nonheart-beating donors. Transplantation 2002;73(1)1:1742-51.

22. Lieberthal $W_{1}$ Nigam $S K$. Acute renal failure. I. Relative importance of proximal vs. distal tubular injury. Am J Physiol 1998;275(5 Pt 2):F623-31. 
23. Padanilam B]. Cell death induced by acute renal injury: a perspective on the contributions of apoptosis and necrosis. Am d Physiol Renal Physiol 2003;284(4):F608-27.

24. Borutaite $V$, Jekabsone A, Morkuniene R, Brown CC. Inhibition of mitochondrial permeabillity transition prevents mitochondrial dysfunction, cytochrome $c$ release and apoptosis induced by heart ischemia. J Mol Cell Cardiol 2003;35(4):357-66.

25. Soeda J, Miyagawa $S$, Sano K, Masumoto J, Taniguchi $S$, Kawasaki $S$. Cytochrome c release into cytosol with subsequent caspase activation during warm ischemia in rat liver. Am J Physiol Gastrointest Liver Physiol 2001:281(4):C1115-23.

26. Benchoua $A$, Cuegan $C$, Courlaud $C$, Hosseini $H$, Sampaio $N$, Morin $D$, et al. Specific caspase pathways are activated in the two stages of cerebral infarction. J Neurosci $2001 ; 21(18): 7127-$ 34.

27. Zhao 20 , Nakamura $M$, Wang NP, Wilcox JN, Shearer $S_{\text {, Ronson }} R S_{\text {, }}$ et al. Reperfusion induces myocardial apoptotic cell death. Cardiovasc Res 2000;45(3):651-60.

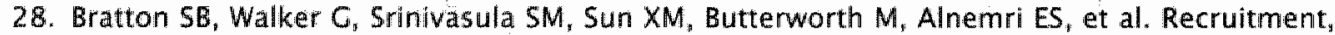
activation and retention of caspases -9 and -3 by Apaf-I apoptosome and associated XIAP complexes. Emibo J $2001 ; 20(5): 998-1009$.

29. Tschopp J, Irmler $M$. Thome $M$. Inhibition of fas death signals by FLIPs. Curr Opin Immunol $1998 ; 10(5): 552-8$.

30. Scarabelli TM, Stephanou A, Pasini E, Comini L, Raddino R, Knight RA, et al. Different signaling pathways induce apoptosis in endothelial cells and cardiac myocytes during ischemia/reperfusion injury. Circ Res 2002;90(6):745-8.

31. van der Hoeven $\rrbracket A$, Molema G, Ter Horst GJ, Freund RL, Wiersema J, van Schilfgaarde R, et al. Relationship between duration of brain death and hemodymamic (in)stability on progressive dysfunction and increased immunologic activation of donor kidneys. Kidney Int $2003 ; 64(5): 1874-82$. 


\section{CHAPTER}

\section{Reduction of circulating redox-active iron by apotransferrin protects against renal ischemia-reperfusion injury}

Bart de Vries, Sarah J. Walter, Leni von Bonsdorff, Tim G.A.M. Wolfs L.W. Ernest van Heurn, Jaakko Parkkinen, Wim A. Buurman

Transplantation: $2004 ; 77(5): 669-675$ 
Warm ischemia-reperfusion (I/R) injury plays an important role in posttransplant organ failure. In particular organs from marginal donors suffer $1 / R$ injury. Although iron has been implicated in the pathophysiology of renal $I / R$ injury, the mechanism of iron-mediated injury remains to be established. We therefore investigated the role of circulating redox-active iron in an experimental model for renal I/R injury.

Male Swiss mice were subjected to unilateral renal ischemia for 45 minutes, followed by contralateral nephrectomy and reperfusion. To investigate the role of circulating iron, mice were treated with apotransferrin, an endogenous ironbinding protein, or iron-saturated apotransferrin (holotransferrin).

Renal ischemia induced a significant increase in circulating redox-active iron levels during reperfusion. Apotransferrin, in contrast to holotransferrin, reduced the amount of circulating redox-active iron and abrogated renal superoxide formation. Apotransferrin treatment did not affect I/R-induced renal apoptosis, whereas holotransferrin aggravated apoptotic cell-death. Apotransferrin, in contrast to holotransferrin, inhibited the influx of neutrophils. Both apo- and holotransferrin reduced I/R-induced complementdeposition, indicating that the effects of transferrin are differentially mediated by its iron and protein moiety. Finally, apotransferrin, in contrast to holotransferrin, dose-dependently inhibited the loss of renal function induced by ischemia.

In conclusion, redox-active iron is released into the circulation in the course of renal I/R. Reducing the amount of circulating redox-active iron by treatment with apotransferrin protects against renal $1 / R$ injury, inhibiting oxidative stress, inflammation and function-loss. Apotransferrin could be used in the treatment of acute renal failure, as seen after transplantation of ischemically damaged organs.

\section{INTRODUCTION}

Renal ischemia-reperfusion ( $/ / R)$ injury plays a crucial role in post-transplant organ failure, in particular in the setting of Non-Heart-Beating organ donation [1]. Moreover, renal ischemia plays an evident pathophysiological role in the development of acute renal failure in hypovolemic and septic shock, and after major (cardiovascular) surgery. Although the molecular mechanisms underlying renal $I / R$ injury are only partially understood, oxidative stress and the formation of oxygen free radicals are considered to be essentially involved in the pathophysiology of I/R injury [2]. Oxygen free radicals have been reported to crucially mediate the induction of apoptotic as well as necrotic cell-death and subsequent inflammatory responses in the course of $1 / R$ injury $[2,3]$. 
The specific role of redox-active iron in the pathophysiology of renal $I / R$ injury is less understood. In vitro, redox-active iron catalyses the formation of tissue damaging oxygen free radicals such as the superoxide anion and the hydroxyl radical by catalysing the Haber-Weiss reaction [4]. Experimental work indicates that redox-active iron is increased in postischemic renal tissue [5]. Iron-scavenging with deferoxamine is protective against $I / R$ mediated tissue injury and organ failure in experimental models [5-7]. However, deferoxamine is not applicable for the treatment of clinical $1 / R$ injury due to its toxicity $[8,9]$. Thus, although redox-active iron plays a crucial role in the pathophysiology of $I / R$ injury, effective clinical treatment using iron-scavengers in ischemic syndromes is not available.

Endogenous mechanisms that regulate iron-availability are based on iron-binding proteins, among others ferritin and hemosiderin for intracellular iron-storage and transferrin for extracellular iron-binding and transport. Transferrin is an endogenous iron-binding glycoprotein of approximately $80 \mathrm{kDa}$ that circulates in concentrations of 2-5 grams per litre. In physiological situations all of the nonheme iron in the circulation is bound to transferrin, occupying approximately $30 \%$ of the transferrin iron-binding sites. Apotransferrin has been shown to significantly reduce circulating redox-active iron in patients undergoing bone marrow transplantation, without any adverse effects [8].

Whether iron is released into the circulation during renal $I / R$ injury and whether circulating redox-active iron plays a pathophysiological role in $I / R$ injury is unknown. This tempted us to determine whether redox-active iron is released into the circulation in an experimental model of renal I/ $R$ injury. Subsequently, we tested whether specific improvement of endogenous ironbinding capacity, by apotransferrin administration, could reduce circulating levels of redox-active iron. Finally, we questioned whether apotransferrin treatment could prevent the development of $I / R$ injury. Therefore we determined the effects of apotransferrin treatment on renal oxygen free radical formation, apoptotic cell-death, inflammation, in particular, complementactivation and neutrophil-influx, and renall function loss.

\section{MATERIALS AND METHODS}

\section{Reagents and antibodies}

Human apotransferrin (iron-free transferrin) was purified as described elsewhere [10]. Human holotransferrin (iron-saturated transferrin) was purified with a similar method with an additional iron-saturation step, after which free iron was removed with excessive diafiltration. The iron saturation was $0.4 \%$ and $90 \%$ for the apo- and holotransferrin, respectively. Dihydroethidium (DHE) was purchased from Molecular Probes (Eugene, OR). 
Goat anti-mouse C3 polyclonal antibody was purchased from Cappel (ICN Biomedicals, Aurora, OH). NIMP-R14 (rat anti-mouse neutrophil monoclonal antibody) was kindly provided by Dr. M. Strath (National Institute for Medical Research, London, UK). Secondary antibodies, peroxidase conjugated rabbit anti-goat and goat anti-rat IgG were purchased from Jackson (West Grove, PA). All other reagents were purchased from Sigma (St. Louis, MO).

\section{Experimental Protocol}

Male Swiss mice weighing 25-30 g were obtained from Charles River Breeding Laboratories (Heidelberg, Germany). Animals were housed individually in standard laboratory cages and were allowed free access to food and water. The studies were carried out under a protocol approved by the Institutional Animal Care Committee of the University of Maastricht. At the start of the experiments, mice were anaesthetised with sodium pentobarbital $\left(100 \mathrm{mg} / \mathrm{kg}\right.$ i.p.). Body temperature was maintained at $38^{\circ} \mathrm{C}$ by a heating pad until animals recovered from anaesthesia. Under aseptic conditions a $1.0 \mathrm{~cm}$ long midline abdominal incision was made and ischemia was induced by applying a non-traumatic vascular clamp to the left renal pedicle for 45 minutes. After removal of the clamp the contralateral kidney was removed and the wound was closed in two layers. The animals were sacrificed 1, 2, or 24 hours after reperfusion. At the time of sacrifice, blood was collected and the left kidney was harvested for analysis.

Interventions were performed during ischemia, just before removal of the clamps, to be effective at the time of reperfusion. Mice were administered $0.1,0.25,0.5$, or $5 \mathrm{mg}$ of apotransferrin i.p. dissolved in $0.5 \mathrm{ml}$ PBS $(n=6$ per group). The control group was treated with holotransferrin at the same dosages ( $n=4$ per group) or with vehicle consisting of $0.5 \mathrm{ml}$ PBS i.p. $(n=6$ per group). Transferrin is rapidly absorbed into the circulation after i.p. administration [11]. The protein is not changed, and holotransferrin retains its iron during passage into the circulation [11].

\section{Renal Histology}

For immunohistological staining-procedures cryostat sections $(5 \mu \mathrm{m})$ of complete renal cross sections were used. For detection of superoxide formation dihydroethidium (DHE) was used as described by others with minor modifications [12]. Briefly, freshly cut, non-fixed sections were incubated with DHE (1 $\mu \mathrm{mol} / /$ in PBS) for 30 minutes, coverslipped and immediately viewed with a fluorescence microscope. Sections were semiquantitatively graded ( 3 sections per kidney, 4-6 kidneys per group) on a scale from 0 to 4 , in which 0 denotes no fluorescence, and $1,2,3,4$ indicate mild, moderate, strong, and fulminant fluorescence. Staining for complement factor $\mathrm{C} 3$ and neutrophils was performed as described previously [13]. Briefly, acetone fixed slides were immersed in $0.3 \% \mathrm{H}_{2} \mathrm{O}_{2}$ in Tris buffered saline (TBS) to eliminate endogenous peroxidase activity, and in 5\% normal rabbit serum in TBS to block aspecific 
antibody binding. Subsequently, slides were incubated for 1 hour with the primary antibody, goat anti-mouse $C 3$ polyclonal antibody or rat antimouse neutrophil monoclonal antibody, in TBS with $0.1 \%$ bovine serum albumin. After washing, slides were incubated for 30 minutes with the appropriate peroxidase labelled secondary antibody diluted in the same buffer. After washing staining was visualised by 3-amino-9-ethylcarbazole (AEC) followed by hematoxylin counterstain. Finally, the slides were coverslipped, and viewed with a light microscope. C3-staining was quantified using a computerized morphometry system (Quantimet 570; Leica, Cambridge, UK). To obtain representative, data 4 sections of 4 kidneys per group were included. Per section, 30 fields of vision (10 cortical, 10 corticomedullary, and 10 medullary fields) at $\times 200$ magnification were measured. Data are expressed as percentages of positive stained tissue of the total tissue measured. Neutrophils were counted by examining 10 fields of vision per kidney section (3-4 sections per kidney, 4 kidneys per group) at $\times 200$ magnification in a blinded fashion.

\section{Redox-active iron assay}

The bleomycin assay for detecting redox-active iron in mouse serum was carried out according to the method described by Evans and Halliwell, adopted for small sample volumes as described earlier [14]. The assay had a detection limit of $0.1 \mu \mathrm{M}$ for serum.

\section{Apoptosis assay}

Presence of internucleosomal DNA cleavage in kidneys was investigated with a commercial ligase mediated (LM)-PCR assay kit (Apoalert, Clontech, Palo Alto, CA) enabling semiquantitative measurement of the extent of apoptosis. In brief, DNA was isolated from renal tissue employing a commercially available DNA purification kit (Promega, Madison, WI). DNA purity and concentration were determined by electrophoresis through a $0.8 \%$ agarose gel containing ethidium bromide, followed by visualisation under ultraviolet illumination, as well as by measuring absorbance at $260 / 280 \mathrm{~nm}$. Dephosphorylated adaptors were ligated to 5 "-phosphorylated blunt ends with T4 DNA ligase (during $16 \mathrm{~h}$ at $16 \mathrm{C}$ ) and served as template for primers in a LM-PCR. Amplified DNA was subjected to gel electrophoresis on a $1.2 \%$ agarose gel containing ethidium bromide.

\section{Renal function}

Blood urea nitrogen (BUN) was measured in serum obtained at the time of sacrifice using a Urea 25 Kit (ABX Diagnostics, Eindhoven, Holland) in a Cobas Fara autoanalyzer (Roche, Basle, Switzerland). 
Data are expressed as the mean \pm SEM, except for data obtained from C3-quantification of renal histology, which are expressed as the median with interquartile ranges. Statistical significance was evaluated by one-way ANOVA with Bonferroni's post-hoc test. $P<0.05$ was taken to denote statisticall significance.

\section{RESULTS}

Redox-active iron is released after renal ischemia-reperfusion First, we determined whether renal ischemia leads to the release of redoxactive iron into the circulation during reperfusion. The data show that renal ischemia followed by reperfusion induced a significant release of redox-active iron into the circulation (Fig. 1). In control mice circulating redox-active iron levels were bellow detection limit. After 45 minutes of renal ischemia followed by 1 hour reperfusion no redox-active iron could be measured, however after 2 hours reperfusion a significant amount of circulating redox-active iron was detectable. Also at 24 hours reperfusion, when inflammation and organ injury are maximal, a significant amount of circulating redox-active iron was present. These data show that renal ischemia induces a sustained presence of redox-active iron in the circulation upon reperfusion. Moreover, the data indicate that endogenous iron-binding capacity, which in physiological situations prevents the availability of redox-active iron in the circulation, is overwhelmed in the course of renal $I / R$ injury.

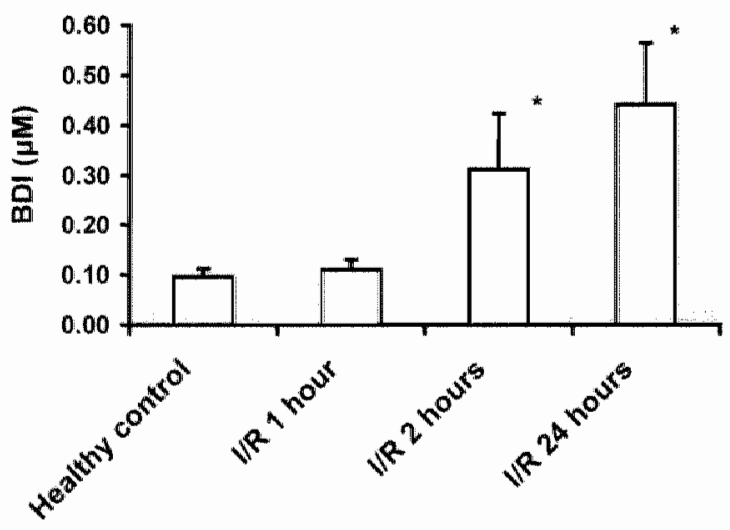

Figure 1: Renal ischemia-reperfusion (I/R) causes an increase of redox-active iron in the circulation. Redox-active iron was measured in mouse sera using the bleomycin detectable iron (BDI) assay ( $n=5-6$ per group). Compared to healthy controll mice, 45 minutes ischemia folllowed by 1 hour reperfusion did not induce a rise in BDI. However after 2 hours reperfusion redox-active iron levels increased significantly. Also at a later phase (after 24 hours reperfusion) BDI was significantly elevated. Statistical significance as compared to healthy control mice was denoted at $P<0.05$ ". The data shown are means $\pm S E M$. 
Circulating redox-active iron is reduced by exogenous apotransferrin

To test our hypothesis that during the course of renal $1 / R$ the endogenous iron-binding capacity is overwhelmed, mice were treated with exogenous apotransferrin $(0.5 \mathrm{mg})$ to enhance endogenous iron binding capacity: Ironsaturated transferrin, holotransferrin $(0.5 \mathrm{mg})$, was used as a control intervention. The data show that whereas treatment with apotransferrin tended to reduce the amount of free circulating redox-active iron after 2 hours reperfusion, at 24 hours apotransferrin treatment resulted in a significant decrease of circulating redox-active iron (Fig. 2). As expected, holotransferrin treatment did not reduce circulating redox-active iron as compared to PBS treated animals. These data indicate that indeed endogenous iron binding capacity is overwhelmed in the course of renal $/ / R$. Moreover, treatment with exogenous apotransferrin significantly reduces serum levels of redoxactive iron.

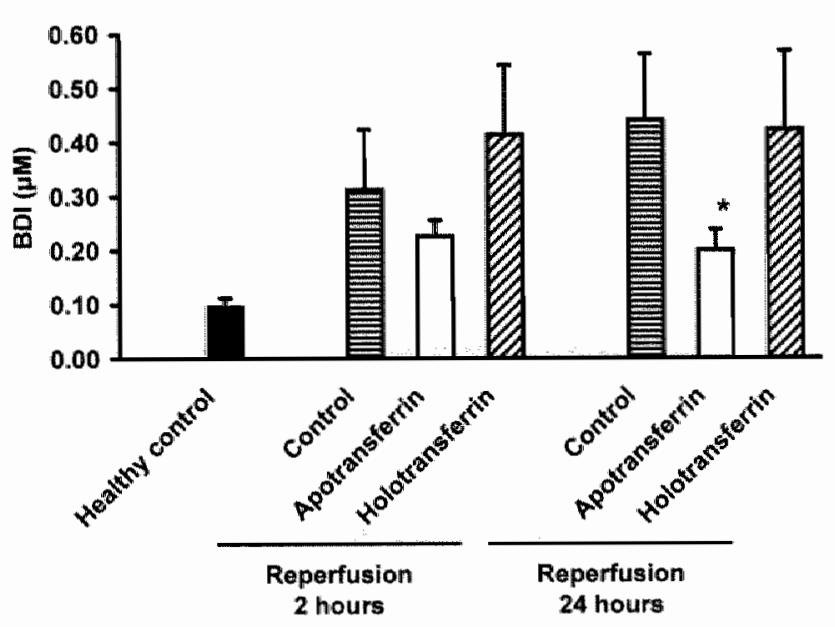

Figure 2: Apotransferrin treatment reduces the amount of circulating redox-active iron after renal ischemia-reperfusion ( $/ / R)$. Redox-active iron was measured in mouse sera using the bleomycin detectable iron (BDI) assay ( $n=5-6$ per group). Compared to control treated mice, apotransferrin treatment during renal ischemia significantly reduced the amount of circulating redox-active iron (BDI) after 24 hours reperfusion induced by renal $\| / R$. Statisticall significance as compared to control treated mice was denoted at $\mathrm{P}<0.05^{*}$. The data shown are means \pm SEM. 
Apotransferrin reduces oxygen free radical formation in the course of renal ischemia-reperfusion injury

Since, iron has been implicated in the formation of oxygen free radicals, we determined whether the reduction of circulating redox-active iron by apotransferrin treatment could reduce superoxide formation induced by renal I/R. Here we show that renal ischemia followed by 2 hours reperfusion induced the formation of the superoxide anion (Fig. 3A and B). Apotransferrin treatment $(0.5 \mathrm{mg})$ evidently reduced superoxide formation as compared to PBS and holotransferrin treatment (Fig. 3C compared to B and D). The formation of superoxide was semiquantitatively graded as described in Materials and Methods. The data show that apotransferrin treatment significantly reduced ischemia-induced superoxide generation, as compared to holotransferrin treatment, at 2 as well as 24 hours reperfusion (Fig. 3E). Taken together, apotransferrin treatment significantly reduces oxygen free radical formation induced by renal I/R by improvement of the iron-binding capacity.

Apotransferrin does not affect ischemia-reperfusion induced renal apoptosis whereas holotransferrin aggravates apoptotic cell-death

Previously, we showed that apoptosis is crucially involved in the pathophysiology of renal I/R injury [15]. Since recent work indicates that redox-active iron induces apoptotic cell-death in vitro [16], the influence of the reduction of circulating redox-active iron, by apotransferrin treatment, on renal $I / R$ induced apoptosis was assessed using a semiquantitative DNA-laddering assay. Apotransferrin treatment did neither reduce renal cell apoptosis compared to PBS treated mice at 2 hours (data not shown) nor at 24 hours reperfusion (Figure 4). These data appear to be in contrast to the opinion that redoxactive iron is essentially involved in the induction of apoptosis after renal $I / R$ injury. Interestingly however, holotransferrin treatment strongly enhanced apoptotic cell-death at 24 hours reperfusion (Figure 4). In sham-operated animals apo- nor holotransferrin induced apoptosis indicating that transferrin treatment itself does not affect renal apoptosis (data not shown). Taking into account that circulating redox-active iron in holotransferrin treated animals is not elevated compared to control treated animals (Figure 2), this suggests that transferrin, if saturated with iron (holotransferrin), directly enhances renal apoptosis in the course of renal I/R.

Apotransferrin inhibits complement-activation independent from its iron binding properties

Complement-activation plays a crucial role in the pathophysiology of renal I/R injury [13]. In vitro, iron is believed to play a role in the activation of the complement system after hypoxia [17]. We therefore hypothesised that apotransferrin, compared to holotransferrin, treatment would reduce $I / R$ induced activation of the complement-system. In line with our earlier data, renal I/R induced intense depositions of complement factor C3 which were 
most prominent in the cortico-medullary region (Fig, 5). Apotransferrin treatment significantly reduced $C 3$ deposition after renal I/R. Unexpectedly however, holotransferrin treatment reduced the deposition of complement factor C3 as effectively as apotransferrin. These data indicate that the complement-inhibitory effect of transferrin in the course of renal $I / R$ is not mediated by its iron binding capacity but rather by its protein molety.
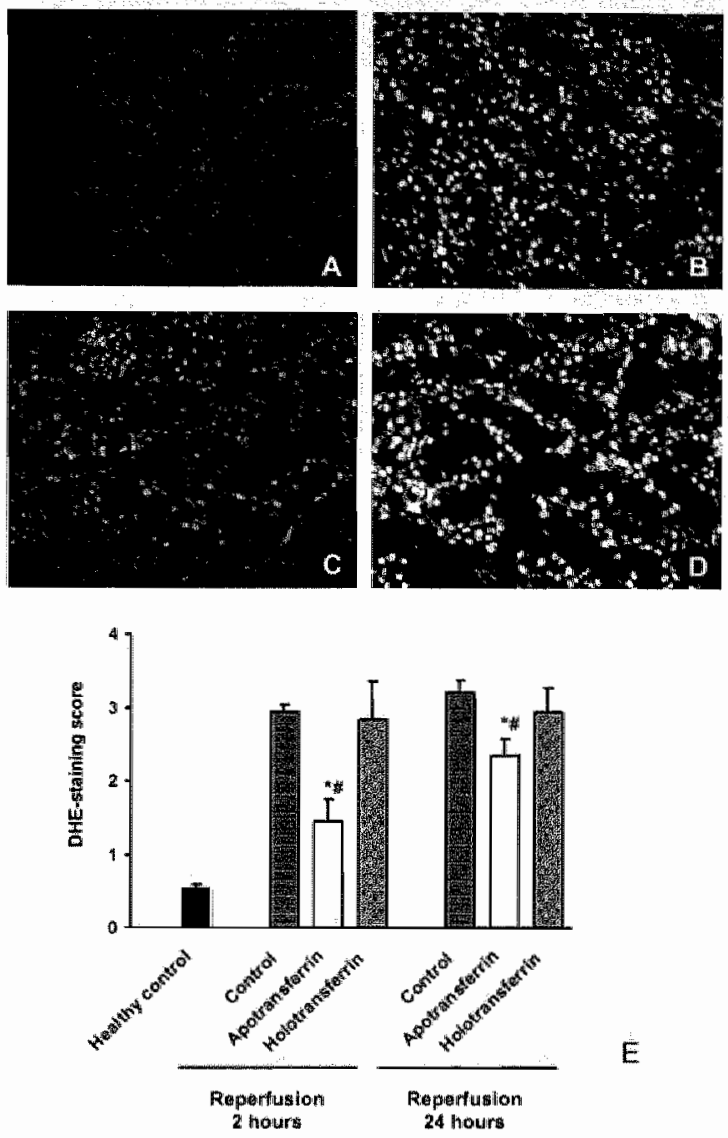

Figure 3: Treatment with apotransferrin abrogates ischemia-reperfusion ( $1 / R)$ induced oxygen free radical formation. Renal sections were stained for superoxide anion formatlon (DHE staining). Evident renal superoxide formation is induced by ischemia followed by 2 hours reperfusion (B) as compared to kidneys from healthy mice (A). Apotransferrin treatment reduced superoxide formation (C), as compared to PBS (B) and holotransferrin treatment (D). Positive superoxide staining was quantified in 3-4 kidneys per group (5 sections per kidney) showing that apotransferrin treatment significantly reduced ischemia-induced superoxide formation at 2 as well as 24 hours reperfusion (E). Statistical significance as compared to PBS treatment (") or holotransferrin treatment (\#) was denoted at $\mathrm{P}<0,05$. 


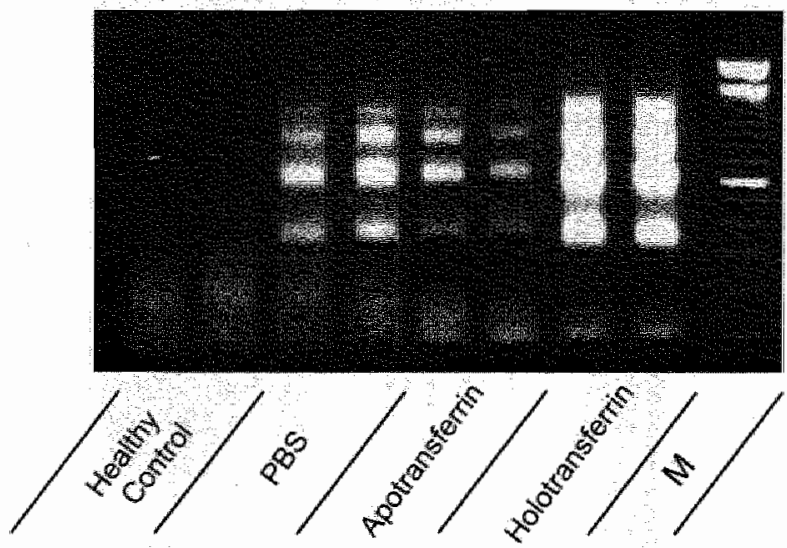

Figure 4: Apotransferrin treatment does not influence ischemia-reperfusion (I/R) induced renal apoptosis, whereas holotransferrin strongly enhances apoptotic cell-death. The extent of renal apoptosis was reflected by fragmented DNA amplified by LM-PCR and visualised on ethidiumbromide stained gel. Compared to healthy control mice renal ischemia followed by 24 hours reperfusion induced internucleosomal DNA-cleavage which was not essentially affected by apotransferrin treatment. However, holotransfermin treatment evidently aggravated $/ / R$ induced apoptotic cell-death. Data shown are representative for 3 independent assays on different renall samples ( $n=4$ per group). $M, 100$ base pairs molecular weight marker.

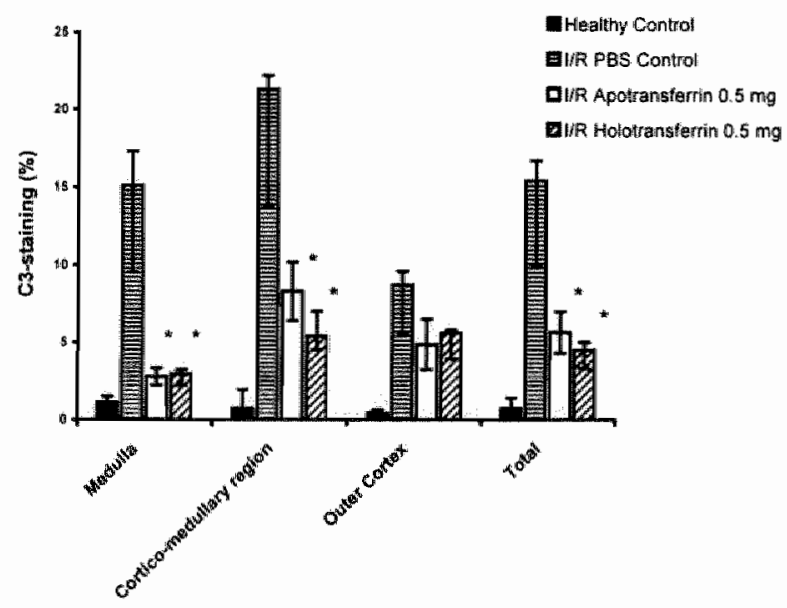

Figure 5: Apotransferrin reduces ischemia-reperfusion (I/R) mediated complement-deposition independent from its iron binding properties. Renal C3-deposition was assessed by immunohistochemistry and quantified using the Leica Quantimet 570 system ( $3-4$ kidneys per group, 30 fields of vision per kidney). Renal ischemia followed by 24 hours of reperfusion induced a C3 deposition which was most prominent in the cortico-medullary region. Apotransferrin as well as holotransferrin significantly reduced renal complement-deposition, most pronounced in the medullar and cortico-medullary region. Data are expressed as median percentages of positive stained tissue with interquartile ranges. Statistical significance as compared to control treated mice was denoted at $P<0.05 *$. 
Apotransferrin reduces $I / R$ induced neutrophil-influx dependent on its iron binding capacity

One of the hallmarks of the inflammatory response after renal I/R injury is the massive influx of neutrophils, which is, among others, mediated by activation of the complement system [13]. Therefore, we measured renal infiltration of neutrophils 24 hours after renal I/R injury. Apotransferrin significantly reduced the influx of neutrophils in a dose-dependent manner, whereas holotransferrin had no evident effect on neutrophil infiltration (Fig. 6). These data indicate that the reduction of circulating free iron by administration of apotransferrin reduces post-ischemic inflammation, characterised by neutrophilinfilltration.

Transferrin protects against $1 / R$ induced renal function loss depending on its iron binding capacity

Finally, we determined renal function, 24 hours after renal $1 / R$, in mice treated with apotransferrin, holotransferrin as well as PBS. Administration of apotransferrin dose-dependently reduced renal function loss induced by $1 / R$ injury (Fig. 7). This is in contrast to holotransferrin treatment, which did not affect renal function as compared to PBS treatment. These data are the first to show that enhancement of iron-binding capacity with the endogenous protein apotransferrin may be an effective therapeutic strategy in improving renal function in the course of I/R injury.

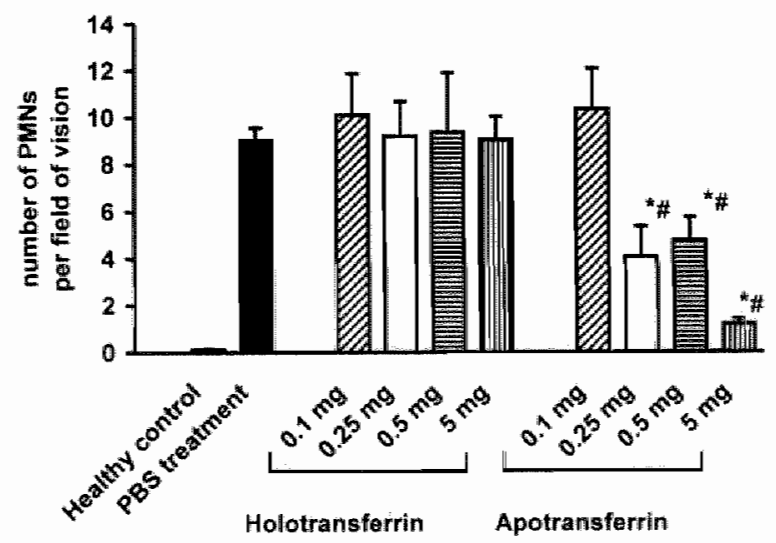

Figure 6: Apotransferrin inhibits the post-ischemic renal infiltration of neutrophils. Neutrophils were counted in 3-4 sections per kidney, 4 kidneys per group after immunohistochemical staining. Apotransferrin as compared to holotransferrin treatment dose-dependently inhibited the influx of neutrophils. Data are expressed as mean number of neutrophills per field of vision \# SEM. Statistical significance as compared to PBS treatment (") or holotransferrin treatment (然) was denoted at $P<0.05$. 


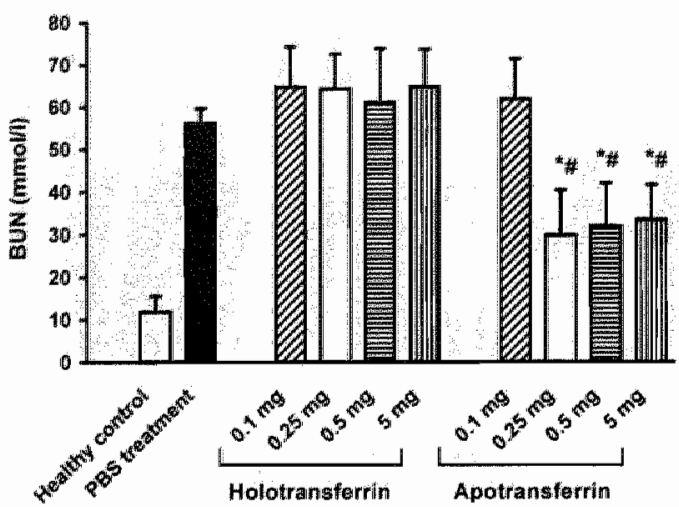

Figure 7 : Apotransferrin treatment inhibits renal function loss after renal ischemia reperfusion (I/R). Renal function was measured by BUN 24 hours after $1 / R(n=6$ per group). Renal $/ / R$ induced loss of renal function was significantly reduced by apotransferrin treatment, whereas holotransferrin treatment did not affect BUN levels. BUN values are expressed as mean \pm SEM. Statistical significance as compared to PBS treatment ( $\left({ }^{(}\right)$or holotransferrin treatment (\#) was denoted at $\mathrm{P}<0.05$.

\section{DISCUSSION}

Redox-active iron has been implicated in the pathophysiology of $I / R$ injury in several organ systems $[6,7]$. In the setting of $1 / R$ injury redox-active iron is believed to catalyse the formation of oxygen free radicals, which are known to induce apoptotic and necrotic cell-death and subsequent inflammatory responses $[2,3]$. Indeed, redox-active iron is released during $I / R$ injury in several organ systems [5,7]. Applying a rat model for warm renal $I / R$ injury, Baliga et al. showed that levels of redox-active iron in renal tissue are increased during reperfusion [5]. Also cold ischemia has been indicated to induce tissue accumulation of redox-active iron, which is considered a critical step in cold-storage induced injury $[18,19]$. It is hypothesised that ischemia, either warm or cold, induces the release of iron from its normal intracellular storage sites. Recent work indicates that extracellular iron is taken up in post-ischemic liver tissue, thus providing a source of intracellular redox-active iron (20). This elegant study provides evidence that besides intracellular, also extracellular iron might play an important role in the pathophysiology of I/R injury. Indeed, systemic hypoxia has been shown to increase the amount of free iron in the circulation [21]. In the present study we show for the first time that a local ischemic insult gives rise to the presence of redox-active iron in the circulation during reperfusion. 
Iron-chelators, such as deferoxamine, have been shown to have beneficial effects in reducing $I / R$ injury in experimental models $[6,7]$. A major problem regarding the use of iron-chelators such as deferoxamine is their toxicity when given in high dosages, as needed in acute syndromes such as I/R injury. Thus, although redox-active iron plays a crucial role in the pathophysiology of $1 / R$ injury, effective clinical treatment using iron-scavengers in ischemic syndromes is as yet not available [9]. Here we show that improvement of the iron-binding capacity by apotransferrin, an endogenous iron-binding protein, significantly reduced the amount of circulating redox-active iron after $I / R$. Moreover, the administration of apotransferrin reduced oxygen free radical formation and was protective against acute renal failure. These data are supported by others showing that apotransferrin protects against ischemiainduced increased vascular permeability [22, 23]. A major advantage regarding the use of apotransferrin as a clinical treatment of acute renal failure, compared to other iron-chelators, is that apotransferrin has already been used safely in clinical studies without drug-related adverse effects [8]. Apotransferrin treatment was shown to bind circulating redox-active iron very efficiently after myeloablation in haematological stem cell transplant patients [8]. Taken together, apotransferrin may be a potential safe ironscavenger in the treatment of disease states mediated by $I / R$ injury.

Recent in vitro studies indicate that transferrin has also toxic effects and induces the production of complement-factor $\mathrm{C} 3$ in tubular epithelial cells $[24,25]$. In contrast, we show here that apotransferrin treatment has potent anti-inflammatory effects in vivo. Apotransferrin significantly inhibited the influx of neutrophils in the course of renal $/ / R$. Surprisingly, both apo- and holotransferrin inhibited renal $\mathrm{C} 3$-deposition. We recently provided evidence that activation of the complement system plays a crucial role in renal $\mathrm{I} / \mathrm{R}$ injury by showing that complement-inhibition is strongly protective against ischemic injury $[13,26]$. For the present study, one could speculate that the potential protective complement-inhibitory effects of holotransferrin are nullified by the toxic, pro-apoptotic effects of iron-saturated transferrin. Indeed next to activation of the complement-system also apoptosis has been implicated to play a role in renal $I / R$ injury [15]. In this context it is important to take into consideration that renal $I / R$ injury is mediated by several interacting mechanisms, effective treatment of this complex type of injury should therefore be focussed on combination therapy.

Another interesting hypothesis is that transferrin has other effects besides its iron-binding properties. Both transferrin-receptor-1 (TfR-1) and-receptor2 (TfR-2) are expressed in the kidney [27]. Next to cellular iron-uptake, these transferrin receptors have been suggested to have other functions, which might also play a role in the protective effects of apotransferrin against $I / R$ injury [28]. For instance, apoptosis induced by oxygen free radicals seems to be dependent on cellular iron-uptake mediated by transferrin receptors [29]. 
This iron-dependent apoptosis may account for the pro-apoptotic effects of holotransferrin as observed in the present study. Whether and to what extent the iron-binding properties and the two transferrin receptors are involved in the protective effects of apotransferrin observed in the present study still needs to be elucidated.

The induction of heme oxygenase- $1(\mathrm{HO}-1)$, an enzyme degrading heme proteins into bilirubin, carbon monoxide and free iron, is regarded as a cytoprotective mechanism during cellular stress and $I / R$ injury [30]. However, protective effects of $\mathrm{HO}-1$ induction are critically counteracted by the toxic effects of increased iron levels [31]. Thus, another potential protective effect of apotransferrin treatment could be the enhancement of $\mathrm{HO}$ 1 mediated protective effects by preventing iron toxicity. Further research is needed to see whether protective effects of iron-scavenging are related to the heme oxygenase system.

In conclusion, the present study shows for the first time that renal I/R leads to enhanced circulating levels of redox-active iron. Apotransferrin treatment significantly reduces the amount of circulating redox-active iron after $I / R$ and protects against $I / R$ induced inflammation and orglan failure. These data indicate that during renal $I / R$ endogenous iron-binding capacity is overwhelmed leading to free circulating redox-active iron which is crucially involved in the development of organ failure. Enhancement of endogenous iron-binding capacity by administration of apotransferrin might therefore be a potential therapeutic strategy in the treatment of clinical acute renal failure as seen after transplantation of ischemically damaged organs.

\section{ACKNOWLEDGEMENT}

The authors acknowledge Dr. J. Cleutjens (Department of Pathology, Cardiovascular Research Institute Maastricht, Maastricht University) for technical assistance.

\section{REFERENCES}

1. Weber $M$, Dindo D, Demartines $N$, Ambuhl PM, Clavien PA. Kidney transplantation from donors without a heartbeat. $N$ Engl \# Med 2002; 347 (4): 248.

2. Lloberas $N$, Torras J, Herrero-Fresneda I, et al. Postischemic renal oxidative stress induces inflammatory response through PAF and oxidized phospholipids. Prevention by amtioxidant treatment. Faseb $\rfloor 2002 ; 16(8): 908$.

3. Chien CT, Lee PH, Chen CF, Ma MC, Lai MK, Hsu SM. De novo demonstration and co-localw ization of free-radical production and apoptosis formation in rat kidney subjected to ischemia/reperfusion. J Am Soc Nephrol 2001; 12 (5): 973.

4. Pletrangelo A. Physiology of Iron transport and the hemochromatosis gene. Am I Physiol Gastrointest Liver Physiol 2002; 282 (3): G403. 
5. Baliga $R$, Ueda $N$, Shah SV. Increase in bleomycin-wetectable iron in ischaemia/reperfusion injury to rat kidneys. Biochem」1993;291 (Pt 3): 901.

6. Green CJ, Gower JD, Healing G, Cotterill LA, Fuller BJ, Simpkin S. The importance of Iron, calcium and free radicals in reperfusion injury: an overview of studies in ischaemic rabbit kidneys. Free Radic Res Commun $1989 ; 7(3-6): 255$.

7. Kirschner RE, Fantini GA. Role of iron and oxygen-derived free radicals in ischemia-reperfusion injury. J Am Coll Surg 1994; 179 (1): 103.

8. Sahlstedt $\mathbb{L}$, von Bonsdorff $L$, Ebeling $F$, Rututu $T$, Parkkinen $\mathbb{J}$. Effective binding of free iron by a single intravenous dose of human apotransferrin in haematological stem cell transplant patients. Br J Haematol 2002; 119 (2): 547.

9. Dragsten $\mathbb{P R}$, Hallaway $P E$, Hanson $G$, Berger $A E$, Bernard $B$, Hedlund BE. First human studies with a high-molecular-weight iron chelator. J Lab Clin Med 2000; 135 (1): 57.

10. von Bonsdorff L, Tolo H, Lindeberg $E$, Nyman T, Harju A, Parkkinen J. Development of a pharmaceutical apotransferrin product for iron binding therapy. Biologicals $2001 ; 29$ (1):27.

11. Regoeczi $\mathbb{E}$, Zaimi $O_{n}$ Chindemi PA, Charlwood PA. Absorption of plasma proteins from peritoneal cavity of normal rats. Am J Physiol 1989; 256 (4 Pt 1): E447.

12. Miller FJ, Jr., Gutterman DD, Rios CD. Heistad DD, Davidson BL. Superoxide production in vascular smooth muscle contributes to oxidative stress and impaired relaxation in atherosclerosis. Circ Res $1998 ; 82$ (12)): 1298.

13. Vries de $B$, Matthijsen RA, Wolfs TG, Van Bijnen $A_{A}$, Heeringa $P$, Buurman WA. Inhibition of complement factor C5 protects against renal ischemia-reperfusion injury: inhibition of late apoptosis and inflammation. Transplantation 2003; 75 (3): 375.

14. von Bonsdorff L, Lindeberg E, Sahlstedt $L$, Lehto J, Parkkinen J. Bleomycin-detectable iron assay for non-transferrin-bound iron in hematologic malignancies. Clin Chem 2002; 48 (2): 307 .

15. Daemen MA, van 't Veer $C$, Denecker $G$, et al. Inhibition of apoptosis induced by ischemiareperfusion prevents inflammation. J Clin Invest 1999; 104 (5): 541.

16. Dobsak P, Siegelova J, Wolf JE, et al. Prevention of apoptosis by deferoxamine during 4 hours of cold cardioplegia and reperfusion: in vitro study of isolated working rat heart model. Pathophysiology 2002; 9 (1): 27.

17. Collard $\mathrm{CD}$, Agah A, Stahl GL. Complement activation following reoxygenation of hypoxic human endothelial cells: role of intracellular reactive oxygen species, NF-kappaB and mew protein synthesis. Immunopharmacology $1998 ; 39(1): 39$.

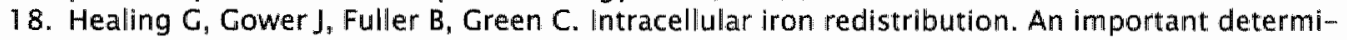
nant of reperfusion damage to rabbit kidneys. Biochem Pharmacol 1990; 39 (7): 1239.

19. Huang $H$, Salahudeen AK. Cold induces catalytic iron release of cytochrome P-450 origin: a critical step in cold storage-induced renal injury. Am J Transplant 2002;2 (7):631.

20. Tacchini $L$, Fusar Poli D, Bernelli-Zazzera A, Cairo $G$. Transferrin receptor gene expression and transferrin-bound iron uptake are increased during postischemic rat liver reperfusion. Hepatology $2002 ; 36$ (1): 103 .

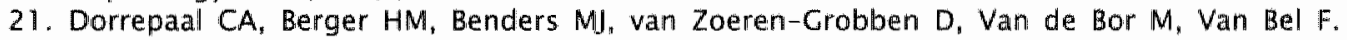
Nonprotein-bound iron in postasphyxial reperfusion injury of the newborn. Pediatrics 1996; $98(5): 883$.

22. Smith JK, Carden DL, Grisham MB, Granger DN, Korthuis RJ. Role of iron in postischemic microvascular injury. Am J Physiol 1989; 256 (5 Pt 2): HI 472.

23. Hernandez $L A$, Grisham $M B$, Granger DN. A role for iron in oxidant-mediated ischemic injury to intestinal microvasculature. Am J Physiol 1987; 253 (1 Pt 1): G49.

24. Chen $L_{n}$ Boadle RA, Harris DC. Toxicity of holotransferrin but not allbumin in proximal tubule cells in primary culture. I Am Soc Nephrol 1998; 9 (1): 77.

25. Tang S, Lai KN, Chan TM, Lan HY, Ho SK, Sacks SH. Transferrin but not albumin mediates stimulation of complement $\mathrm{C} 3$ biosyrthesis in human proximal tubular epithelial cells. Am J Kidney Dis 2001; 37 (1): 94.

26. Vries de $B, K$ Khl J, Leclercq WK, et al. Complement factor C5a mediates renal ischemia-reperfusion injury independent from neutrophils. J Immunol 2003: 170 (7): 3883. 
27. Kawabata $H$, Cermain $R S_{\text {, lkezoe }} T$, et al. Regulation of expression of murine transferrin receptor 2. Blood 2001; $98(6): 1949$.

28. Kawabata H, Germain $\mathrm{RS}$, Vuong PT, Nakamaki T, Said JW, Koeffler HP. Transferrin receptor 2-alpha supports cell growth both in iron-chelated cultured cells and in wivo. J Biol Chem 2000; $275(22): 16618$.

29. Kallivendi $S V$, Kotamraju $S$, Cunningham $S$, Shang $T$, Hillard $C$, Kalyanaraman $B$. 1-Methyl-4phenylpyridinium (MPP + ) - induced apoptosis and mitochondrial oxidant generation: Role of transferrin receptor dependent iron and hydrogen peroxide. Biochem $\| 2003$; Pt.

30. Katori $M$, Busuttill RW, Kuplec-Weglinski JW. Heme oxygenase-1 system in organ transplantation. Transplantation 2002; 74 (7): 905.

31. Suttner DM, Dennery PA. Reversal of HO-1 related cytoprotection with increased expression is due to reactive iron. Faseb J 1999; 13 (13): 1800. 


\title{
CHAPTER 4
}

\begin{abstract}
Redox-active iron released during cold machinepreservation predicts post-transplant organ function of ischemically injured kidneys
\end{abstract}

Bart de Vries, Sylvia Schaefer, Leni von Bonsdorff, L.W. Ernest van Heurn, Jaakko Parkkinen, and Wim A. Buurman

submitted for publication 
Renal warm ischemia and subsequent graft failure limit the use of ischemically injured non-heart-beating (NHB) donor kidneys for transplantation. Although redox-active iron has been implicated in experimental ischemiareperfusion injury, it is not known whether redox-active iron is involved in clinical transplantation. We therefore measured redox-active iron levels in preservation fluid during machine-preservation of 218 NHB kidneys which were machine preserved at our institution between Jully 1998 and January 2003 and transplanted within the Eurotransplant region. During machine preservation of $\mathrm{NHB}$ donor kidneys, in contrast to heart-beating donor kidneys, redox-active iron was released into the preservation fluid in substantial amounts. Redox-active iron levels correlated well with donor characteristics, such as warm ischemic injury. Moreover, redox-active iron levels during machine preservation adequately predicted post-transplant organ failure, of in particular NHB category 2 donor kidneys which most evidently suffer from warm ischemia.

The present data show that redox-active iron is released in clinical transplantation of ischemically injured organs. Redox-active iron levels correlate well with post-transplant organ function and therefore pre-transplant assessment of redox-active iron levels could potentially be used for viabilitytesting of ischemically injured organs. Moreover, the addition of iron-scavengers to preservation fluid could possibly improve functional outcome of machine-preserved ischemically injured grafts.

\section{INTRODUCTION}

An increasing shortage of donor organs for transplantation has led to the use of marginal donors as a source of transplantable kidneys [1,2]. In particular the use of non-heart-beating (NHB) donors has regained wide interest $[3,4]$. However, a major problem using NHB donor-organs are the relative high rates of post-transplant organ failure due to the inevitable ischemic injury which is suffered before and during organ procurement [2-5].

Pre-transplant viability assessment is of crucial importance in the selection of suitable NHB donor kidneys for transplantation [6-9]. The measurement of biochemical markers, such as lactate dehydrogenase (LDH), glutathione S-transferase (CST) and fatty acid binding proteins (H-FABP), reflecting tissue injury in the kidney perfusate during machine preservation is the most commonly used method to assess organ viability $[7,10,11]$. These assays are based on the release of cytoplasmic contents of damaged cells into the interstitial and intravascular space due to ischemic injury. 
However, there is still no reliable biochemical marker available which differentiates between viable and non-viable kidneys.

We recently showed that during experimental renal ischemia-reperfusion $(\mathrm{I} / \mathrm{R})$ injury redox-active iron is released into the circulation [12]. Moreover, reducing the amount of circulating redox-active iron, by apotransferrin administration, abrogated the development of post-ischemic organ injury and renal failure. This indicates that circulating redox-active iron plays a deleterious role in the pathophysiology of renal I/R injury [12]. These insights tempted us to investigate first whether redox-active iron is released into the preservation fluid during machine preservation of ischemically damaged, NHB-donor kidneys. Next we questioned whether the release of redox-active iron reflects warm ischemic injury and could thereby predict post-transplant organ failure.

\section{MATERIALS AND METHODS}

\section{Donor kidneys}

All kidneys obtained from NHB donors or from heart-beating (HB) donors that were preserved by machine preservation at our institution between July 1998 and January 2003 and transplanted within the Eurotransplant region were included in the present study. A total number of $218 \mathrm{NHB}$ donor kidneys were procured after declaration of cardiac death. Final cardiac arrest occurred either after unsuccessful cardiopulmonary resuscitation (Maastricht NHB donor category 2: 52 kidneys) or in the intensive care unit after ventilator switch-off (NHB donor category 3: 156 kidneys) or in braindeath donors (NHB donor category 4: 10 kidneys) [13]. In the same period also $23 \mathrm{HB}$ donor kidneys were preserved by machine preservation and included as control kidneys in the present study.

\section{Organ procurement and preservation}

In-situ preservation using a double-balloon-triple lumen femoral cooling catheter was performed as described in detail previously [14]. After donor nephrectomy the kidneys were prepared for machine preservation on the back table and placed in specially designed organ chambers fitting into Gambro PF-3B perfusion machines (Gambro, Lund, Sweden). Kidneys were machine perfused with $500 \mathrm{ml}$ of Belzer University of Wisconsin (UW) solution, a UW preservation fluid developed for machine preservation (MP-UW) [15]. After the kidney was connected to the perfusion system, perfusion flow was set to a systolic pressure of $60 \mathrm{mmHg}$. The perfusion flow was kept constant but the pressure was allowed to vary. Samples for redox-active iron analysis were taken from the perfusate at time points $0,1,2$, and 4 hours of preservation and immediately stored at $-70^{\circ} \mathrm{C}$ until used. 


\section{Donor and recipient data}

Donor data of all machine preserved kidneys are routinely recorded at our institution. Recipient data, were collected by questionnaires send to the transplant centres. Posttransplant function was classified as: immediate function (IF), i.e. immediate life-sustaining renal function without posttransplant dialysis; delayed function (DF), i.e. renall function that ultimately was life-sustaining but required one or more dialysis sessions; primary non-function (PNF), i.e. persistent renal failure, patient was never without dialysis.

\section{Redox-active iron assay}

The bleomycin assay for detecting redox-active iron in perfusate fluid was carried out according to the method described by Evans and Halliwell, adopted for small sample volumes as described earlier $[12,16]$. All results were corrected for kidney weight.

\section{Statistical analysis}

All data are expressed as median with interquartile ranges, and highest and lowest values. For statistical analysis one-way ANOVA with Bonferroni's post-hoc test for multiple comparison correction was used. Statistical significance was denoted at $\left.\mathrm{p}<0.001{ }^{* *}\right)$ and $\left.\mathrm{p}<0.05{ }^{*}\right)$.

\section{RESULTS}

\section{UW contains substantial amounts of redox-active iron}

Commercial UW (Viaspan) has been reported to contain substantial amounts of redox-active iron [17]. At our institution Belzer UW, adapted for machine preservation (MP-UW), is used [15]. We therefore first measured the redoxactive iron content of commercial UW as well as MP-LW obtained immediately after bag opening ( $n=6$ per group). Both commercial UW and MP-UW contained substantial amounts of redox-active iron. For commercial UW the mean redox-active iron content was $1.85 \mu \mathrm{mol} / \mathrm{l}$ (range $1.57-2.37$ ) which was comparable to Belzer UW containing $1.92 \mu \mathrm{mol} / /$ redox-active iron (range $1.40-2.62$ ).

Redox-active iron is released during the early phase of machine preservation

After experimental renal $I / R$ injury redox-active iron is released in substantial amounts into the circulation [12]. Also during experimental cold organ preservation redox-active iron is released into perfusion fluid $[17,18]$. We 
therefore first examined whether and when redox-active iron is released into the perfusion fluid during machine preservation of ischemically injured human kidneys $(n=15)$. In line with experimental data, our clinical data show for the first time that redox-active iron is released in considerable amounts during machine-preservation of ischemically injured NHB-kidneys (Figure 1).

Just before start of machine preservation $(t=0)$ redox-active iron levels in the perfusate are comparable to control commercial UW or MP-UW. Within the first hour after start of machine reperfusion the perfusate levels of redoxactive iron increased evidently $(\mathrm{t}=1)$, whereas prolonged machine preservation for 2 or 4 hours did not further enhance elevated iron levels $(t=2$ and $t=4)$ (Figure 1).

Even extended cold machine preservation up to 72 hours; of kidneys which were not accepted for transplantation, did not result in further increase of redox-active iron levels (data not shown). Taken together, these data show that redox-active iron is released into perfusion fluid during the early phase of machine preservation of ischemically injured kidneys.

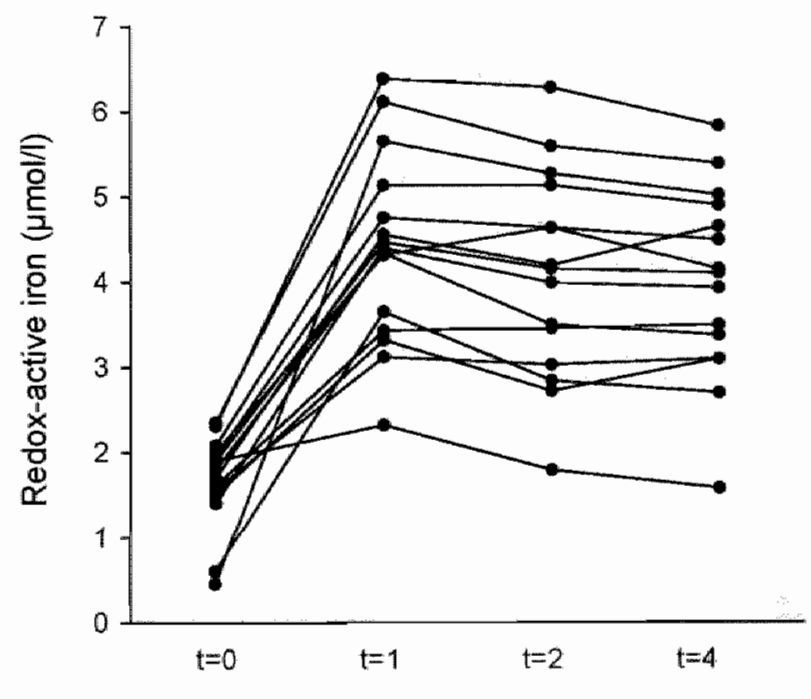

Duration of machine preservation (in hours)

Figure 1. Redox-active iron is released in preservation fluid during the early phase of machinepreservation. Redox-active iron was measured using the bleomycin detectable iron (BDI) assay. $A$ time series of 15 different NHB donor kidneys was analyzed. Of each kidney samples were taken at different time points before $(t=0)$ and after start of machine preservation $(t=1,2$ and 4 hours). Redox-active iron mainly increased in the initial phase of machine perfusion of machine preserved NHB donor kidneys. 
Next we investigated whether the release of redox-active iron during cold machine preservation is related to warm ischemic injury which per definition occurs in NHB-donors. Therefore we determined the release of redox-active iron in different categories of organ-donors (HB, NHB-2, NHB-3, NHB-4) [13].

The data show that perfusates from kidneys which did not suffer evident warm ischemia e.g. heart-beating ( $\mathrm{HB}$ ) donor kidneys contained slightly increased amounts of redox-active iron measured 4 hours after start of machine preservation as compared to base-line MP-UW values (Figure 2).

The release of redox-active iron was significantly increased in the group of NHB donor kidneys, which per definition suffer warm ischemia, as compared to HB donors (NHB vs. HB $\mathrm{p}<0.01$ ). In NHB category 2 donor kidneys, organs that are most evidently subjected to warm ischemia (sudden cardiac arrest, resuscitation, 10 minutes no-touch, in situ preservation procedure), the release of redox-active iron was most pronounced (NHB-2 vs. HB $\mathrm{p}<0.001$ ) (Figure 2). In NHB category 3 donor kidneys (ventilator switch-off), donors are subjected to shorter periods of absolute warm ischemia (10 minutes no-touch, in situ preservation procedure), though systemic events prior to cardiac death, e.g. hypotensive episodes, hypovolemia, cerebral injury, might also have contributed to organ injury.

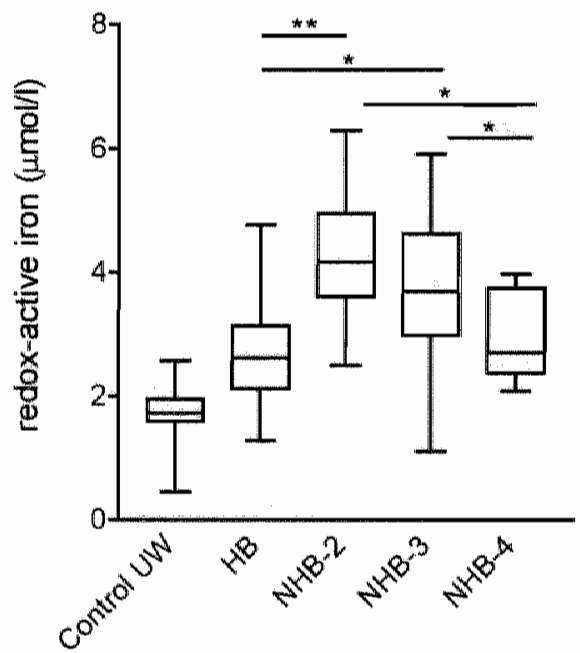

Figure 2. The release of redox-active iron during machine-preservation depends on donor warm ischemic injury. Redox-active iron was measured in perfusates of $218 \mathrm{NHB}$ and $23 \mathrm{HB}$ kidneys sampled 4 hours after start of machine preservation. HB and NHB category 4 , which suffer limited warm ischemia, displayed slightly increased redox-active iron levells as compared to control UW. NHB category 2 and 3 kidneys, which suffer eviclent warm ischemia, demonstrated significantly increased redox-active iron levels as compared to control UW as well as HB and NHB category 4 kidneys. Data shown are medians with interquartille ranges (0th, 25th, 75 th and 1100 th percentile). Statistical significance was denoted at $p<0.001\left(^{* *}\right)$ and $p<0.05\left(^{*}\right)$. 
In line, NHB category 3 kidneys displayed high but variable levels of redoxactive iron which reached statistical significance as compared to $\mathrm{HB}$ donor kidneys (NHB-3 vs. HB p <0.05) (Figure 2). NHB category 4 kidneys are procured from brain-death donors and thus subjected to limited warm ischemia (no 10 minutes no-touch, thus only during in-situ preservation procedure) and this is reflected in redox-active iron levels which are not statistically different from HB kidneys (Figure 2).

These data implicate that the release of redox-active iron during cold machine preservation to a substantial extent depends on warm ischemic injury, and potentially to other donor related factors, rather than on cold ischemia.

The release of redox-active iron has predictive value in post-transplant organ function

Redox-active iron has been shown to be essentially involved in the development of organ failure after warm ischemic injury $[12,18,19]$. Since the release of redox-active iron during organ preservation appears to correlate with warm

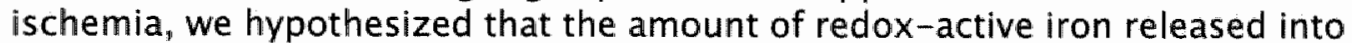
the perfusate during machine-preservation correlates with post-transplant function.

To test this hypothesis we first analysed perfusate redox-active iron levels of all transplanted NHB kidneys and correlated these with graft outcome. Immediate functioning (IF $n=42$ ), delayed functioning (DF $n=136$ ) as well as primary non-functioning ( $P N F n=40$ ) kidneys displayed significantly higher redox-active iron levels after 4 hours of machine perfusion as compared to control MP-UW. Interestingly, IF kidneys had significant lower redox-active iron values during machine-preservation than transplanted kidneys with DF $(p<0.01)$ and PNF $(p<0.001)$ (Figure 3$)$. Although grafts with PNF tended to have higher redox-active iron levels than DF graft the difference did not reach statistical significance.

In particular NHB category 2 kidneys suffer from acute warm ischemic injury whereas category 3 kidneys, next to warm ischemia, suffer from more complex injury prior to cardiac death (hemodynamic instability, systemic inflammation, cerebral injury) which is known to affect graft outcome as well $[20,21]$. We therefore questioned whether the correlation between the release of redox-active iron and post-transplant organ function is more pronounced in NHB category 2 kidneys as compared to category 3 kidneys. In line with our hypothesis, NHB category 2 kidneys displayed an evident correlation between redox-active iron levels and post-transplant graft function: there were highlly significant differences in redox-active iron levels between IF, DF and PNF kidneys $(p<0.01)$ (Figure 4). In contrast, for NHB category 3 kidneys their was no significant correlation between redoxactive iron levels and post-transplant organ function. 


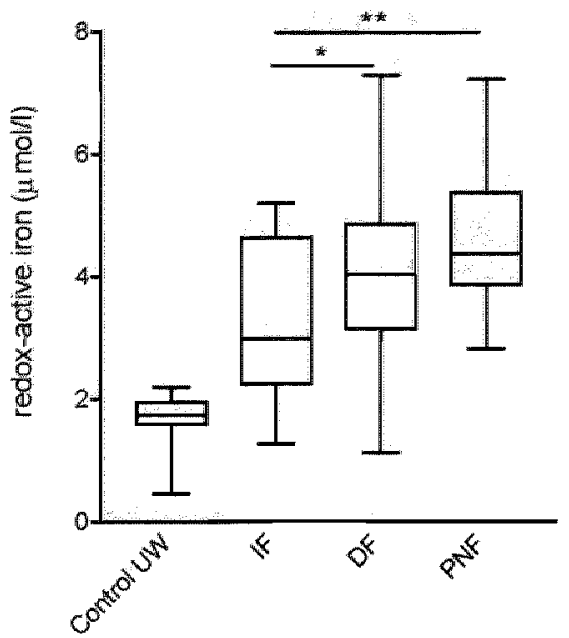

Figure 3. The release of redox-active iron during machine-preservation correlates with posttransplant organ function. Redox-active iron was measured using BDI-assay in perfusates of 218 NHB sampled after 4 hours of machine preservation. Kidneys which functioned immediately after transplantation (IF) had significant lower redox-acitve iron levels during machine preservation as compared to kidneys which displayed delayed function (DF) or primary inon-function (PNF). Data shown are medians with interquartile ranges (0th, 25th, 75 th and 100 th percentile). Statistical significance was denoted at $p<0.001$ (*t) and $p<0.05\left({ }^{*}\right)$.

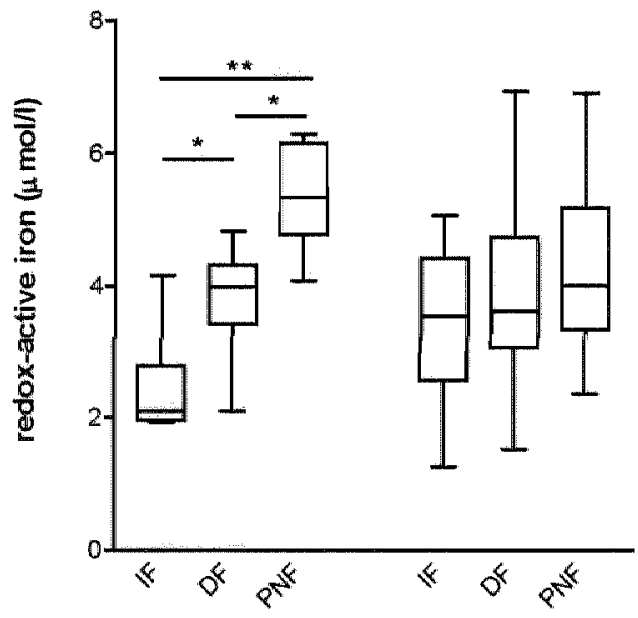

Figure 4. The correlation of redox-active tron with posttransplant organ function depends on donor characteristics. Redox-active iron was measured using BDI-assay in perfusates of all NHB category 2 and 3 kidneys sampled after 4 hours of machine preservation. In contrast to NHB category 3 kidneys, in NHB category 2 kidneys redox-active iron levels were significantly different between immediately functioning (IF), delayed function (DF) and primary non-function (PNF) kidneys. Data shown are medians with interquartile ranges (0th, 25th, 75 th and 100 th percentile). Statistical significance was denoted at $p<0.001$ (*) and $p<0.05(\%)$. 
These data strongly suggest that warm ischemia plays an important role in the release of redox-active iron during machine perfusion of NHB donor kidneys. Moreover, the redox-active iron levels have predictive value in the estimation of post-transplant organ function and could therefore potentially be used as a viability-marker of in particular NHB donor category 2 kidneys.

\section{DISCUSSION}

In the present study for the first time the release of redox-active iron during machine preservation of NHB donor kidneys is demonstrated. First of all we confirmed that UW solution, which is widely used for cold organ preservation, either by cold storage or machine preservation, contains substantial amounts of redox-active iron [17]. In both commercial UW (Viaspan) and MP-UW redox-active iron was present in concentrations of approximately $1.90 \mu \mathrm{mol} / \mathrm{l}$ (ranging form $1.40-2.62$ ) which is comparable to previously reported data [17]. The presence of these considerable amounts of redox-active iron in fresh UW, capable of catalyzing free radical reactions, is likely to have a negative influence on cold organ preservation. Especially since organ preservation induces additional redox-active iron release there is a good rationale for the addition of iron chelators to UW used for cold organ preservation.

In the kidney, warm ischemia has been reported to increase intra-renal redox-active iron levels in experimental warm $1 / R$ injury [22]. Also cold storage, without prior warm ischemia, led to increased intra-renal redoxactive iron levels in experimental models [23]. Recently, we reported that, renal warm I/R induces the release of redox-active iron into the circulation [12]. The group of Salahudeen reported the release of redox-active iron from proximal tubular epithelial cells during cold storage in vitro [18]. Moreover, perfusion fluid (UW) obtained after 48 hours cold storage of rat kidneys contained substantial amounts of redox-active iron [18]. These data indicate that in experimental models ischemia either warm or cold induces the extracellular liberation of redox-active iron. In line, in the present study we show for the first time that, in clinical transplantation, warm ischemia followed by cold machine preservation induces the release of redox-active iron in considerable amounts into the preservation fluid. It is of interest to note that redox-active iron was mainly released in the early phase of machine preservation, which suggests that cold induced injury during machine preservation (up to 72 hours) is not the main cause of the release of redox-active iron.

Since we recently showed that renal warm ischemia induces the release of redox-active iron in an experimental model for renal $1 / R$ injury [12], we hypothesized that donor characteristics, among others warm ischemia, play a role in the release of redox-active iron during machine preservation. 
Indeed donor-category appeared an important determinant of iron release. Kidneys which did not suffer evident warm ischemia (HB donor kidneys) showed only limited increased redox-active iron levels in their perfusates during machine-preservation. Also NHB category 4 donor kidneys, which suffer limited ischemia, displayed only slightly elevated redox-active iron levels in their perfusates. In contrast, NHB category 2 donors, characterised by cardiac arrest and unsuccessful resuscitation, are subjected to acute and severe warm ischemic injury during the periods of cardiac arrest, resuscitation, 10 minutes of no-touch and in situ preservation. In line with our hypothesis, category 2 donor kidneys displayed evident and highly significant increases in the amounts of circulating redox-active iron during machine preservation as compared to HB donor kidneys. NHB category 3 donors are patients on the intensive care unit where cardiac arrest is waited for after treatment is withheld. In this group of donors, although absolute warm ischemia might be limited, the time till cardiac arrest is variable and the absence of supportive treatment makes organ injury multifactorial and unpredictable. Systemic hypoperfusion (hypotensive episodes, hypovolemia), systemic inflammatory responses (trauma, cerebral injury, multi-organ failure) in addition to substantial renal warm ischemia $(10$ minutes no-touch and during in situ preservation) might explain the wide variation of redox-active iron values in category 3 donors.

Since redox-active iron has been shown to be essentially involved in warm ischemic injury and post-ischemic organ failure [12, 19], we hypothesized that the release of redox-active iron during machine preservation would correlate with graft outcome after transplantation. Our data show that indeed redox-active iron levels are indicative for post-transplant organ function. In particular in kidneys subjected to evident warm ischemia (NHB category 2 donor kidneys) redox-active iron levels are predictive for graft outcome. These data implicate that the measurement of redox-active iron could be used as a new marker in pre-transplant viability-testing [24]. Pretransplant viability assessment is of crucial importance in the selection of suitable NHB donor kidneys for transplantation $[6-9,24]$. Next to donor characteristics, macroscopic appearance of the graft, and machine preservation characteristics (pressure, flow, vascular resistance), the measurement of biochemical markers, such as lactate dehydrogenase (LDH), glutathione S-transferase (GST) and fatty acid binding proteins (H-FABP), reflecting tissue injury in the kidney perfusate during machine preservation are commonly used method to assess organ viability $[7,10,11,24]$.

Nevertheless, adequate viability tests, discriminating between viable and non-viable kidneys are still not available. In the present study, non-viable kidneys (PNF) displayed significant higher redox-active iron levels as compared to viable kidneys; for NHB category 2 kidneys, levels of more than $5 \mu \mathrm{mol} / \mathrm{l}$ were associated with poor graft function and had a positive predictive value 
for PNF of $100 \%$, a negative predictive value of $88 \%$, a sensitivity of $64 \%$, and a specificity of $100 \%$. In contrast, for NHB category 3 kidneys the predictive value of redox-active iron is limited. This implies that there are relevant differences in organ injury resulting in graft failure between NHB category 2 and 3 donors. Whereas redox-active iron levels reflect acute warm ischemia in category 2 donors, organ injury in category 3 donors is not related to iron levels. One could speculate that in category 3 donors periods of ischemia and reperfusion often already occur before cardiac arrest, resulting aggravated injury but allso in protective adaptive responses, such as the induction of heme oxygenase- $1[25,26]$. This could lead to redox-active iron levels during machine preservation that do not correlate with the actual graft function after transplantation. Therefore also more attention should be paid to the pathophysiological differences between NHB donor categories in the development of viability-tests.

Next to diagnostic importance in the assessment of graft-viability the presence of redox-active iron in perfusion fluid during machine preservation is likely to have pathophysiological relevance. In experimental models redoxactive iron, catalysing the generation of oxygen free radicals, plays an important role in both warm and cold renal $I / R$ injury $[12,18,19,27]$. In these transplantation models for warm and/or cold ischemic injury the administration of iron chelators such as deferoxamine and apotransferrin inhibited oxygen free radical generation and provided protection against organ failure. In clinical kidney transplantation the formation of oxygen free radicals during machine preservation has been reported prognostic for delayed graft function [28]. In concordance with our data this would implicate that the release of redox-active iron and subsequent oxygen free radical formation during warm and/or cold ischemic injury are essentially involved in post-transplant organ failure. In line, a recent clinical randomised trial indicates that the addition of among others anti-oxidants to Belzer UW for machine preservation of HB donor kidneys improves early graft function after transplantation [29]. These clinical studies, in combination with data obtained from experimental studies, would suggest the addition of iron-scavengers during machine preservation, and possibly recipient treatrnent after transplantation, could improve functional outcome of transplanted ischemically injured organs.

In an experimental model for renal I/R injury we showed that the reduction of circulating redox-active iron levels by apotransferrin administration significantly reduces renal oxidative stress and protects against the development of acute renal failure [12]. In clinical studies, apotransferrin treatment has been shown to bind circulating redox-active iron very efficiently without drug-related adverse effects $[30,31]$. Preliminary data indicate that the addition of apotransferrin to UW, in vitro as well as during clinical machine preservation, is highly effective in scavenging redox-active iron. 
The addition of iron-scavengers to UW has been shown beneficial in an experimental NHB renal transplantation model [19]. Thus apotransferrin added to $\mathrm{UW}$ during machine preservation could potentially ameliorate ischemic injury and thereby improve functional outcome in the setting of clinical NHB kidney transplantation. Also recipients of ischemically injured kidneys might benefit from apotransferrin treatment. Though, additional experimental and clinical studies should further unravel the effects of apotransferrin on warm and cold ischemic injury and graft outcome.

Taken together, in the present study we demonstrate for the first time that redox-active iron is released during machine preservation of NHB kidneys. The release of redox-active iron during machine preservation correlates with warm ischemic injury suffered prior to organ donation. Moreover, the amount of redox-active iron released is predictive for posttransplant organ function and could therefore potentially be used in the pretransplant viability testing of ischemically injured organs.

\section{REFERENCES}

1. Wijmen RM, Booster MH, Stubenitsky BM, de Boer J, Heineman E, Kootstra G. Outcome of transplantation of non-heart-beating donor kidneys . Lancet 1995;345(8957):1067-70.

2. Mizutani $K_{.}$Omo $Y$, Kinukawa $T$, Hattori $R$, Nishyama $N$, Kamihila $O$, et al. Use of marginal organs from non-heart-beating cadaveric kidney donors. Transplantation $2001: 72(8): 1376-80$.

3. Weber $M$, Dindo $D$, Demartines $N$, Ambuhl PM, Clavien PA. Kidney transplantation from donors without a heartbeat. N Engl J Med 2002;347(4):248-55.

5. Nicholson ML, Metcalfe MS, White SA, Waller JR, Doughman TM, Horsburgh $T$, et al. A comparison of the results of renal tiransplantation from non-heart-beating, conventional cadaweric and living domors. Kidney $\| n t 2000 ; 58(6): 2585-91$.

6. Daemen $\mathbf{J H}$, Heineman $\mathrm{E}$, Kootstra $\mathrm{G}$. Viability assessment of non-heart-beating donor kidneys during machine preservation. Transplant Proc 1995:27(5):2906-7; discussion 2907-8.

7. Daemen JW, Oomen AP, Janssen MA, van de Schoot $L$, van Kreel BK, Heineman $E$, et al. Clutathione 5-transferase as predictor of functional outcome in transplantation of machinepreserved mor wheart beating donor kidneys. Transplantation 1997;63(1):89-93.

8. Balupuri 5, Buckley P, Mohamed M, Cornell C, Mantle D, Krby J, et al. Assessiment of nonheart-beating donor (NHBD) kidneys for viability on machine perfusion. Clin Chem Lab Med $2000 ; 38(1 \|): 1103-6$.

9. St Peter SD, Imber CJ, Friend PJ. Liver and kidney preservation by perfusion. Lancet $2002: 359(9306): 604-13$

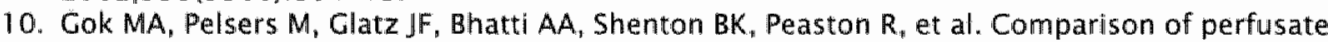
activities of glutathione S-transferase, alanine aminopeptidase and fatty acid binding protein in the assessment of mon-heart-beating donor kidneys. Ann Clin Biochem 2003;40(Pt 3) $252 \sim 8$

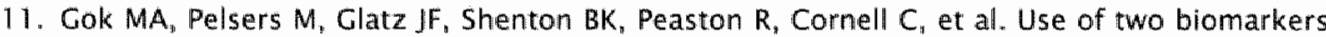
of renal ischemia to assess machine-perfused nom-heart-beating donor kidneys. Clin Chem $2003 ; 49(1) \div 1172-5$

12. de Wries B, Walter 5 , won Bonsdorff $L$, Wolfs TG, van Heurn LW, Parkkinen J, et al. Reduction of circulating redox-active iron by apotransferrin protects against renal ischemia-reperfusion injury. Transplantation 2004:77(5):669-75. 
13. Kootstra $\mathrm{G}_{1}$, Daemen $\mathrm{JH}_{4}$ Oomen AP. Categories of non-heart-beating donors. Transplant Proc $1995 ; 27(5): 2893-4$.

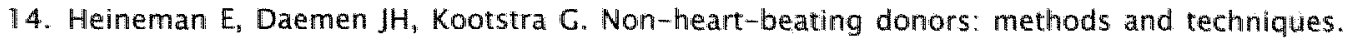
Transplant Proc 1995:27(5):2895-6; discussion 2896-7.

15. Hoffmann RM, Stratta RJ, D'Alessandro AM, Sollinger HW, Kalayoglu M, Pirsch JD, et al. Combined cold storage-perfusion preservation with a new synthetic perfusate. Transpllantation 1989;47(1):32-7.

16. von Bonsdorff $\mathbb{L}_{\text {n }}$ Lindeberg $\mathbb{E}_{n}$ Sahlstedt $L$, Lehto J, Parkikinen J. Bleomycin-detectable iron assay for non-transferrin-bound irom in hematologic malignancies. Clin Chem $2002 ; 48(2): 307-14$.

17. Evans PJ. Tredger $\mathbb{J} M$, Dunne $\mathbb{I} B$, Halliwell $B$. Catalytic metal ions and the loss of reduced glutathione from Uniwersity of Wisconsin preservation solution. Transplantation $1996 ; 62(8): 1046-9$.

18. Huang $H$, Salahudeen AK. Cold induces catalytic iron release of cytochrome P-450 origin: a critical step in cold storage-induced renal injury. Am \& Transplant 2002;2(7):631-9.

19. Baron P, Gomez-Marin O, Casas $C$, Heil J, Will $N$, Condie $R$, et al. Renal preservation after warm ischemia using oxygen free radical scavengers to prevent reperfusion injury. I Surg Res 7) $991 ; 51(1): 60-5$.

20. van der Hoeven JA, Molema G, Ter Horst GJ, Freund RL, Wiersema J, van Schilfgaarde R, et al. Relationship between duration of brain death and hemodynamic (n)stability on progressive dysfunction and increased immunologic activation of donor kidneys. Kidney Int 2003; 64:(5): $1874-82$.

21. Pratschke J, Wilhelm MJ, Kusaka M, Basker M, Cooper DK, Hancock WW, et al. Brain death and its influence on donor organ quality and outcome after transplantation. Transplantation 1999;67(3):343-8.

22. Balliga $R$, Ueda $N$, Shah SV. Increase in bleomycin-detectable iron in ischaemia/reperfusiom injury to rat kidneys. Biochem J 1993;291 (Pt 3):901-5.

23. Healing $G$, Gower $J$, Fuller $B$, Green $C$. Intracellular iron redistribution. An important determinant of reperfusion damage to rabbit kidneys. Biochem Pharmacol 1990;39(7):1239-45.

24. Brook NR, Waller JR, Nicholson ML. Nonheart-beating kidney donation: Current practice and future developments. Kidney Int 2003;63(4):1 516-29.

25. Baan $C$, Peeters $A$, Lemos $F$, Uitterlinden $A$, Doxiadis $I$, Claas $F$, et al. Fundamental Role for $\mathrm{HO}-1$ in the Self-Protection of Renal Allografts. Am J Transplant 2004;4(5):81 1-8.

26. Wagner M, Cadetg P, Ruf R, Mazzucchelli L, Ferrari P, Redaelli CA. Heme oxygenase-1 attenuates ischemia/reperfusion-induced apoptosis and improves survival in rat renal allografts.. Kidney Int 2003;63(4):1564-73.

27. Defraigne JO, Pincemail J, Detry O, Franssen C, Meurisse M, Limet R. Preservation of cortical microcirculation after kidney ischemia-reperfusion: value of am iron chellator. Ann Vasc 5urg $1994: 8(5): 457-67$

28. Kosieradzki M, Kuczynska J, Piwowarska J, Wegrowicz-Rebandell, Kwiatkowski A, Lisik W, et al. Prognostic significance of free radicals: mediated injury occurring in the kidney donor. Transplantation 2003:75(8):1221-7.

29. Guarrera JV, Polyak M, Arrington BO, Kapur S, Stubenbord WT, Kinkhabwala M. Pulsatile Machine Perfusion with Vasosol Solution Improves Early Graft Function after Cadaveric Renal Transplantation. Transplantation 2004:77(8):1264-1268.

30. Fellman V, von Bonsdorff $L$, Parkkinem J. Exogenous apotransferrin and exchange transfusions in hereditary iron overload disease. Pediatrics 2000;105(2):398-401.

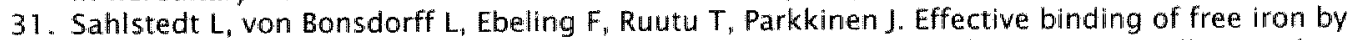
a single intravenous dose of human apotransferrin in haematological stem celll transplant patients. Br J Haematol 2002;119(2):547-53. 


\section{CHAPTER}

\section{Lysophosphatidic acid prevents renal ischemia- reperfusion injury by inhibition of apoptosis and complement activation}

Bart de Vries, Robert A. Matthijsen, Annemarie A. J. H. M. van Bijnen, Tim G. A. M. Wolfs, and Wim A. Buurman

American Journal of Pathology: 2003; 163(1): 47-56 


\section{ABSTRACT}

Renal ischemia-reperfusion (I/R) injury is an important cause of acute renal failure as observed after renal transplantation, major surgery, trauma and septic as well as haemorrhagic shock. We previously showed that the inhibition of apoptosis is protective against renal $/ / R$ injury, indicating that apoptotic cell-death is an important feature of I/R injury. Lysophosphatidic acid (LPA) is an endogenous phospholipid growth factor with anti-apoptotic properties. This tempted us to investigate the effects of exogenous LPA in a murine model of renal I/R injury. LPA administered at time of reperfusion dose-dependently inhibited renal apoptosis as evaluated by the presence of internucleosomal DNA-cleavage. I/R-induced renal apoptosis was only present in tubular epithelial cells with evident disruption of brush-border as assessed by immunohistochemistry for active caspase- 7 and filamentous actin respectively. LPA treatment specifically prevented tubular epithelial cell apoptosis but also reduced the $1 / R$-induced loss of brush-border integrity. Besides, LPA showed strong anti-inflammatory effects, inhibiting the renal expression of TNF- $\alpha$ and abrogating the influx of neutrophils. Next, LPA dose-dependently inhibited activation of the complement-system. Moreover, treatment with LPA abrogated the loss of renal function in the course of renal $I / R$.

This study is the first to show that administration of the phospholipid LPA prevents I/R injury, abrogating apoptosis and inflammation. Moreover, exogenous LPA is capable to prevent organ failure due to an ischemic insult and thus may provide new means to treat clinical conditions associated with $I / R$ injury, in the kidney and potentially also in other organs.

\section{INTRODUCTION}

Postischemic organ failure of organs such as the heart, brain and kidneys represents a major problem in clinical medicine. Acute renal failure due to ischemia-reperfusion (I/R) injury is observed after transplantation and as a major complication in cardiac and vascular surgery, septic as well as hypovolemic shock, and trauma [1].

Ischemia directly induces cellular injury, which is aggravated by reperfusion [2]. In the setting of $I / R$ injury cellular damage will, if severe enough, lead to cell-death which may be apoptotic as well as necrotic [3]. Both apoptosis and necrosis have been implicated in the induction of inflammation in the course of $1 / R_{\text {, }}$ an important cause of tissue injury induced by renal I/R [4]. This inflammatory response is characterised by activation of the complement system, induction of cytokines and chemokines, and subsequent influx of neutrophils $[2,4]$. 


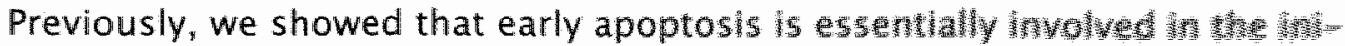
tiation of this inflammatory reaction and moreover that whbtuon sof apop-

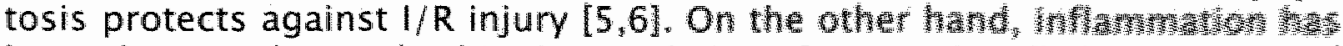

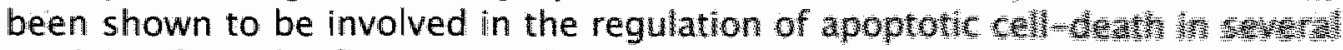
models of renal inflammation [7-11].

Growth and survival factors, such as IGF-1, FCF, HCF hate been shows to prevent apoptosis, inflammation and protect agains rend $[5,12]$. Lysophosphatidic acid (LPA) is a member of the phospholyto growth factor family, having pleiotropic effects such as enhancement of cell surwwats and cell proliferation. LPA is normally present in serum, binding whth this affinity to albumin, in concentrations ranging between $5-201 \mathrm{M} / \mathrm{T}$. signals via the $G$-protein coupled receptors LPA1, LPA2 and LPA3 I

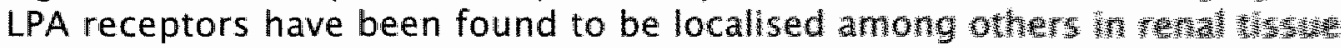
$[14,15]$. In vitro, LPA has been shown to function as a growth and surwwit factor for renal proximal tubular cells, inhibiting apoptosis movese by growth factor deprivation [16].

The aim of this study was to characterise the in vivo effects of waysem nous LPA in a renal I/R model, with special emphasis on the imfuence of 17 . on $\mathrm{I} / \mathrm{R}$-induced apoptosis. Furthermore, we aimed to study the effects of LPA on the inflammatory response in the course of renal $/ / R_{*}$ in particular the activation of the complement system, the induction of chenchins:s cytokines and the influx of neutrophils.

\section{MATERIALS AND METHODS}

\section{Antibodies and reagents}

Lysophosphatidic acid (1-Oleoyl-2-Hydroxy-sn-Glycero-3-Phosphate was purchased from Avanti Polar Lipids (Alabaster, AL), polyclonal rabbit anti-active caspase- 7 antibody from Biovision (Mountain View, CA) and Texas-red-Phalloidin from Molecular Probes (Eugene, OR). Rabbit antimouse C6 was kindly provided by Dr. N.R. Cooper (Scripps Research Institute, La Jolla, CA), rabbit anti-rat C9 was a kind gift from Dr. B.P. Morgan (University of Wales College of Medicine, Cardiff, UK) and goat anti-mouse C3 was purchased from Cappel (ICN Bilomedicals, Aurora, OH). NIMP-R 14 (rat anti-mouse neutrophil mAb) was kindly provided by Dr. M. Strath (National Institute for Medical Research, London, UK). Secondary antibodies, peroxidase conjugated rabbit anti-goat, goat anti-rabbit and goat anti-rat IgC as well as FITC-labelled goat anti-rabbit IgG were purchased from Jackson (West Grove, PA). All other reagents were purchased from Sigma (St. Louis, MO). 
Experimental Protocol

Male Swiss mice weighing 25-30g were obtained from Charles River Breeding Laboratories (Heidelberg, Germany). Animals were housed individually in standard laboratory cages and were allowed free access to food and water. The studies were carried out under a protocol approved by the Institutional Animal Care Committee of the University of Maastricht. At the start of the experiments, mice were anaesthetised with sodium pentobarbital $(100$ $\mathrm{mg} / \mathrm{kg}$ i.p.). Body temperature was maintained at $38^{\circ} \mathrm{C}$ by a heating pad until animals recovered from anaesthesia. Under aseptic conditions a $1.0 \mathrm{~cm}$ long midline abdominal incision was made and ischemia was induced by applying a non-traumatic vascular clamp to the left renal pedicle for 45 minutes. After removal of the clamp the contralateral kidney was removed and the wound was closed in two layers. The animals were sacrificed 24 hours after reperfusion. At the time of sacrifice, blood was collected and the left kidney was harvested for analysis.

During ischemia, just before reperfusion, mice were administered 0.01 , $0.1,1$ or $2 \mathrm{mg}$ of LPA i.p. dissolved in $1.0 \mathrm{ml}$ PBS $(n=6$ per group). The control group was treated with vehicle consisting of $1.0 \mathrm{ml}$ PBS i.p. $(n=6)$.

\section{Renal Histology}

Cryostat sections $(5 \mu \mathrm{m})$ of frozen tissue were cut and double-stained for active caspase- 7 and filamentous actin ( $\mathrm{F}$-actin). Briefly, slides were dried, fixed in acetone for 10 minutes and air-dried. Slides were immersed in Phosphate-buffered saline (PBS) for 5 minutes and subsequently in $5 \%$ normal goat serum in PBS to block aspecific antibody binding. Slides were stained for 1 hour at room temperature with the anti-active caspase -7 primary antibody in PBS with $0.1 \%$ bovine serum albumin. After three washes in PBS with $0.1 \%$ tween for 5 minutes each, slides were incubated for 30 minutes with the FITC-labelled secondary antibody diluted in the same buffer with the addition of Texas red-phalloidin which specifically binds to F-actin. After three washes in PBS-tween, the slides were mounted using glycerolPBS with 1,4-diazabicyclo(2,2,2)octane (DABCO) and 4,6-diamidino(2)phenylindole (DAPI), and viewed with an immunofluorescence microscope. No significant staining was detected in slides incubated with control serum instead of the primary antibody indicating the absence of significant background staining. The number of caspase -7 positive tubules was quantified by counting 20 fields of vision per kidney section ( 3 sections per kidney, 4 kidneys per group) at $\times 200$ magnification in a blinded fashion.

Cryostat sections $(5 \mu \mathrm{m})$ of frozen tissue were stained for complement factors C3, C6 and C9. Briefly, slides were dried, fixed in acetone. Slides were immersed in Tris-buffered saline (TBS) for 5 minutes, in $0.03 \% \mathrm{H}_{2} \mathrm{O}_{2}$ in TBS for 30 minutes at room temperature to eliminate endogenous peroxidase activity, and in 5\% normal goat or rabbit serum (depending on the antibodies 
used) in TBS to block aspecific antibody binding. Subsequently, slides were stained for 1 hour at room temperature with primary antibodies in TBS with $0.1 \%$ bovine serum albumin. After three washes in TBS with $0.1 \%$ tween (TTBS) for 5 minutes each, slides were incubated for 30 minutes with appropriate peroxidlase labelled secondary antibodies diluted in the same buffer. After three washes in TTBS staining was visualised by 3-amino-9-ethylcarbazole (AEC) followed by haematoxylin counterstain. Finally, the slides were coverslipped, and viewed with a light microscope. No significant staining was detected in slides incubated with control sera instead of the primary antibody indicating the absence of significant background staining.

Staining for neutrophils was performed with MAb NIMP-R 14 as described above. Neutrophils were counted by examining 10 fields of vision per kidney section (3-4 sections per kidney, 4 kidneys per group) at $\times 200$ magnification in a blinded fashion.

\section{Apoptosis assay}

Presence of internucleosomal DNA cleavage in kidneys was investigated with a commercial ligase mediated (LM)-PCR assay kit (Apoalert, Clontech, Palo Alto, CA) enabling semiquantitative measurement of the extent of apoptosis. In brief, DNA was isolated from tissue samples employing a commercially available DNA purification kit (Promega, Madison, WI). DNA purity and concentration were determined by electrophoresis through a $0.8 \%$ agarose gel containing ethidium bromide followed by visualisation under ultraviolet illumination as well as by measuring absorbance at $260 / 280 \mathrm{~nm}$.

Dephosphorylated adaptors were ligated to $5^{\prime}$-phosphorylated blunt ends with T4 DNA ligase (during $16 \mathrm{~h}$ at $16^{\circ} \mathrm{C}$ ) and served as primers in a LM-PCR. Amplified DNA was subjected to gel electrophoresis on a $1.2 \%$ agarose gel containing ethidium bromide.

Measurement of Renal KC, MIP-2 and TNF- $\alpha$ MRNA Levels by Reverse Transcriptase-PCR

For RT-PCR total RNA was extracted from kidneys using the SV Total RNA isolation system (Promega) and treated with RQ1 RNase-Free DNase (Promega). Total RNA was reverse transcribed using oligo (dT) primer and Moloney murine leukemia virus reverse transcriptase (Life Technologies, Paisley, UK).

For semiquantitative PCR analysis CDNA samples were standardised based on the content of $B$-actin cDNA as housekeeping gene. $B$-actin cDNA was evaluated by performance of a B-actin PCR on multiple dilutions of each cDNA sample. The amount of amplified product was estimated by densitometry of ethidiumbromide stained $1.2 \%$ agarose gels using a CCD camera and Imagemaster VDS software (Pharmacia, Uppsala, Sweden). To determine renal KC and MIP-2 MRNA expression, PCR reactions with specific primers 
were performed using appropriate dilutions of the CDNA. Primers used for B-actin, KC and MIP-2 PCR have been described in detail previously [6].

Real-time quantitative RT-PCR for TNF- $\alpha$ was performed on a Taqman AB 7700 Sequence Detection System (Applied Biosystems, Foster City, CA). $B$-actin was used as reference gene. The following oligonucleotide primers and probes were used: B-actin: 5'-GAC AGG ATG CAG AAG GAG ATT ACT G$3^{\prime}$ (sense) and 5'-CCA CCG ATC CAC ACA GAG TAC TT-3' (antisense) both at a concentration of $300 \mathrm{nM}$, and internal fluorescence-labelled probe (JOE) $5^{\prime}$-ATC AAC ATC ATT GCT CCT CCT GAC CGC-3' at a concentration of 200 nM. TNF- $\alpha$ : $5^{\prime}$-CAT CTT CTC AAA ATT CGA GTG ACA A-3" (sense) and $5^{\prime}-$ TGG GAG TAG ACA ACG TAC AAC CC-3' (antisense) both at a concentration of $200 \mathrm{nM}$, and internal fluorescence-labelled probe (FAM) $5^{\prime}$-CAC GTC GTA GCA AAC CAC CAA GTG GA-3' at a concentration of $100 \mathrm{nM}$. All primers and probes were obtained from Applied Biosystems.

\section{Renal function}

Blood urea nitrogen (BUN) was measured in serum obtained at the time of sacrifice using a Urea $25 \mathrm{Kit}$ ( $A B X$ Diagnostics, Eindhoven, Holland) in a Cobas Fara autoanalyzer (Roche, Basle, Switzerland).

Statistical analysis

Data are expressed as the mean \pm SEM, and statistical analysis was performed by Mann-Whitney $U$ test. $P<0.05$ was taken to denote statistical significance.

\section{RESULTS}

\section{LPA protects against renal dysfunction after renal I/R}

Renal I/R injury is characterised by loss of renal function. Renal function loss was measured by serum blood urea nitrogen (BUN). Mice treated with LPA showed a dose-dependent reduction in BUN values compared to control treated animals. A dose of $0.01 \mathrm{mg}$ of LPA already significantly reduced BUN levels $(25.86 \mathrm{mmol} / \mathrm{l}$ for LPA $0.01 \mathrm{mg}$ vs. $43.27 \mathrm{mmol} / /$ for control PBS treatment, $p<0.05$ ), whereas higher doses of LPA dose-dependently protected against renal function loss $(15.69 \mathrm{mmol} / \mathrm{I}$ for LPA $0.1 \mathrm{mg}$ and 10.38 $\mathrm{mmol} / /$ for LPA $1 \mathrm{mg}, \mathrm{p}<0.01)$. Higher doses of LPA $(2 \mathrm{mg})$ had no additional protective effects, thus at $1 \mathrm{mg}$ of LPA a plateau was reached regarding prevention of I/R induced renal function loss (Figure 1). These data show that LPA is strongly protective against renal failure in the course of renal I/R injury. 


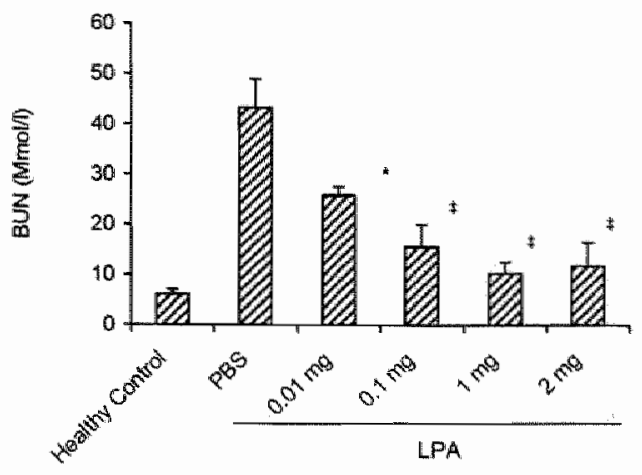

Figure 1. LPA dose-dependently reduces loss of renal function after renal ischemia-reperfusion (I/R). Compared to control treated animals LPA significantly reduced Blood Urea Nitrogen (BUN) values as measured 24 hours after renal I/R. Statistical significance as compared to control treated animals was denoted at $p<0.05 *$ or $p<0.01 \neq$. The data shown are means \pm SEM.

\section{LPA prevents I/R induced apoptosis in the course of renal I/R}

In vitro, LPA is known to have anti-apoptotic properties. This tempted us to study the effects of LPA in vivo on I/R induced apoptosis, especially since apoptotic cell-death has been shown to play a major role in renal $1 / R$ injury. Here, we show that LPA is capable to inhibit apoptosis in vivo (Figure 2 ).

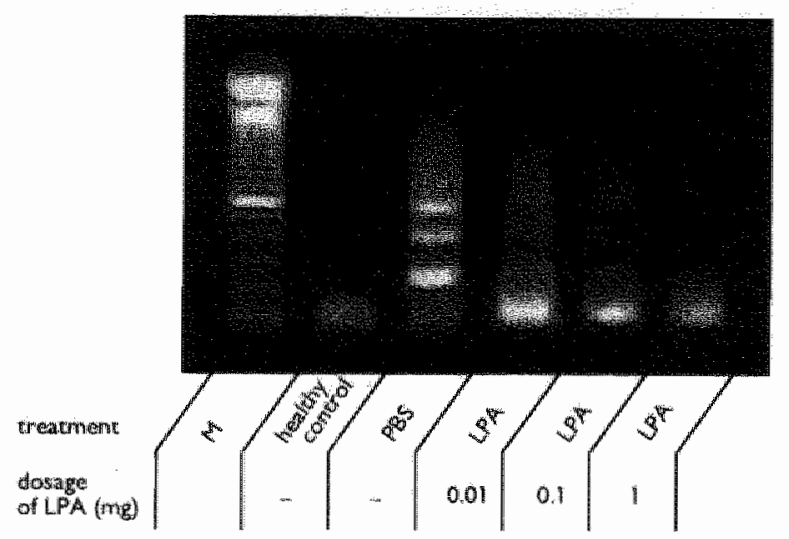

Figure 2. LPA treatment prevents ischemia-reperfusion induced apoptosis. The extent of renal apoptosis was reflected by fragmented DNA amplified by LM-PCR and visuallsed on ethidiumbromide-stained gel. In PBS treated animals internucleosomal DNA cleawage was evident. $\angle P A$ dose-dependently reduced renal apoptosis. Data shown are representative for 3 independent assays on different renal samples $(n=3$ per group). $M, 100$ base pairs molecular weight marker. 

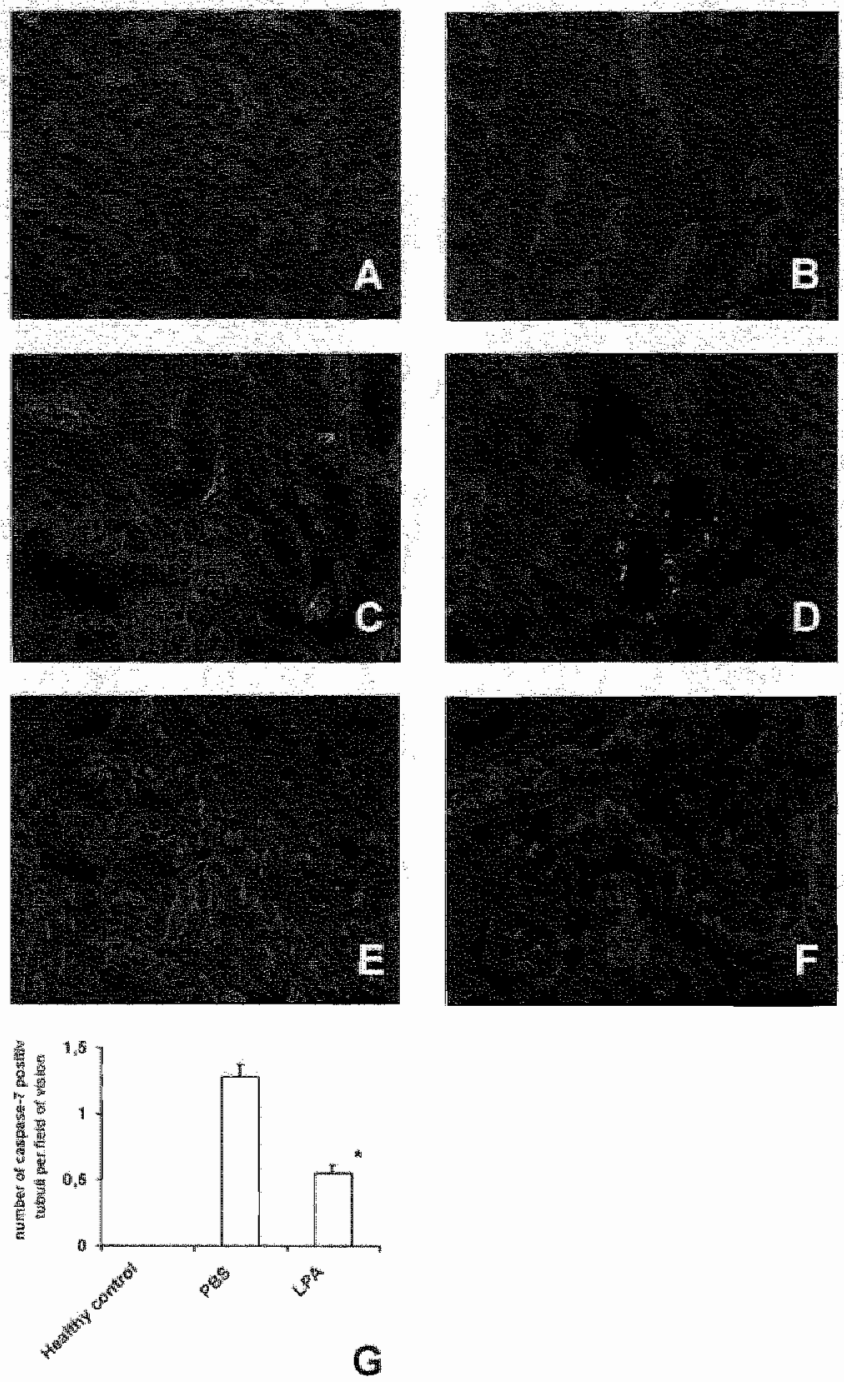

Figure 3. LPA significantly reduces ischemia-reperfusion (I/R) induced caspase 7 activation and brusth-border disruption. Kidneys of healthy animals (A and B) showed no activation of caspase7 (in green) and intact brush mborders as determined by filamentous actin staining (in red). Renal I/R (C and D) induced caspase-7 activation localised to tubular epithelial cells. Caspase-7 activation was only present in tubular cells which lost brush-border integrity ( $C$ and D). LPA treatment $(1 \mathrm{mg})$ evidently reduced the $/ / R$-induced activation of caspase -7 which is accompanied with the preservation of brush-border integrity ( $E$ an $F$ ). To quantify caspase-7 activity positive tubules were counted after immunohistochemical staining ( 3 sections per kidney, 4 kidneys per group). These data $(G)$ are expressed as the mean of number of positive tubules per field of vision $\$$ SEM. Statistical significance as compared to PBS treated animals was denoted at $p<0.05$ th.

Red staining: filamentous actin (Texas-red), green staining: active caspase-7 (FITC), blue staining: nuclel (DAPI). (Magnification 400x for $\mathrm{A}, \mathrm{C}$ and $\mathrm{E}$ and $600 \times$ for $\mathrm{B}, \mathrm{D}$ and $\mathrm{F}$.). 
Compared to control treated animals, kidneys of animals treated with LPA, showed a dose-dependent reduction in internucleosomal DNA cleavage, a specific hallmark of apoptosis. To determine the apoptotic cell type in the course of renal $1 / R$ we used immunofluorescence staining for active caspase-7. Here we show that in control kidneys no activation of caspase-7 isdetectable (Figure $3 \mathrm{~A}$ and B). Ischemia followed by reperfusion, however, induced a significant activation of caspase -7 which localised specifically to tubular epithelial cells (Figure 3C and D). Interestingly, apoptotic cells often co-localised within one tubule (Figure $3 C$ and D).

An important hallmark of cellular injury in the course of renal $I / R$ injury is the disruption of brush-border [17]. We therefore stained renal tissue for filamentous actin (F-actin), which is normally present in the brush-border of tubular epithelial cells but is broken down during renal $1 / R$ injury under influence of actin depolymerising factor (ADF) [ 8]. Indeed, in normal kidney sections F-actin is abundantly expressed in the brush-border of tubular epithelial cells (Figure $3 A$ and B). Renal $I / R$ induced a significant disruption of the brush-border visible as the disappearance of tubular F-actin staining (Figure $3 C$ and D). Moreover, the data show that the activation of caspase-7 is present in tubular cells which also showed a severe disruption of brushborder (Figure $3 C$ and D).

In animals treated with LPA ( $1 \mathrm{mg}) 1 / \mathrm{R}$ induced caspase- 7 activation is significantly reduced as shown in figure $3 G$. This reduction of tubular apoptosis by LPA is accompanied by a reduced loss of brush-border integrity (Figure $3 E$ and $F$ ).

\section{LPA prevents inflammation in the course of renal $/ / R$}

A prominent feature of $1 / R$ induced inflammation is the influx of neutrophils. Previously, we showed that the inhibition of apoptosis by caspase-inhibition or growth factor administration prevents massive neutrophil-infiltration [5]. In order to estimate the effects of LPA on inflammation we measured the influx of neutrophils by immunohistochemistry. To quantify the neutrophilinfilltration NIMP-R14 positive cells were counted in tissue sections of kidneys in control and experimental groups at 24 hours of reperfusion. The data show that LPA treatment significantly reduced neutrophil-influx in a dosedependent manner at 24 hours of reperfusion (Figure 4). Next, we investigated whether LPA reduces the induction of pro-inflammatory chemokines and cytokines involved in recruitment of inflammatory cells. We determined renal mRNA levels of TNF- $\alpha$ as well as the mouse CXC-chemokines KC and MIP-2. Here, we show that the induction of TNF- $\alpha$ is strongly inhibited after LPA treatment (1 $\mathrm{mg}$ LPA) (Figure 5A). Interestingly, the I/R induced up-regulation of the chemokines KC and MIP-2 was unaffected by LPA (Figure 5B). 


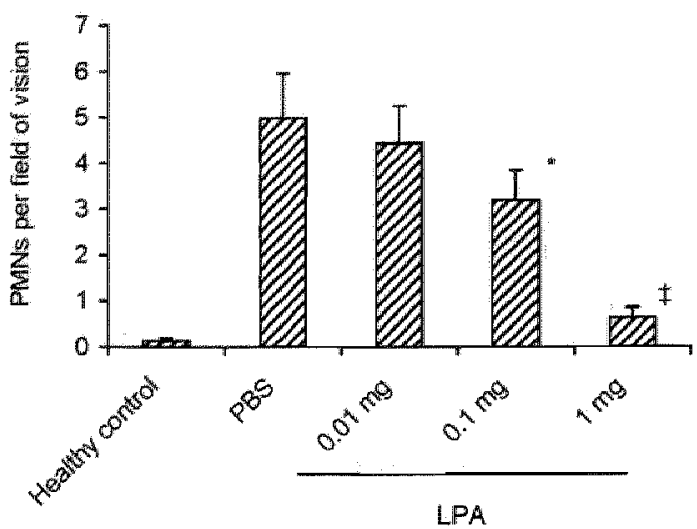

Figure 4. LPA significantly reduces ischemia-reperfusion induced neutrophil-influx. Neutrophils were counted after immunohistochemical staining (3-4 sections per kidnev, 4 kidineys per group). Neutrophils were scarcely present in kidneys obtained from healthy mice, whereas ischemia followed by 24 hours of reperfusion led to a strong influx of neutrophils. Treatment with LPA dose-dependently reduced the influx of neutrophils at 24 hours of reperfusion. Data are expressed as the mean of number of neutrophils per field of vision $\pm S E M$. Statistical sigmificance as compared to PBS treated animals was denoted at $p<0.05$ * and $\mathrm{p}<0.01 \neq$.

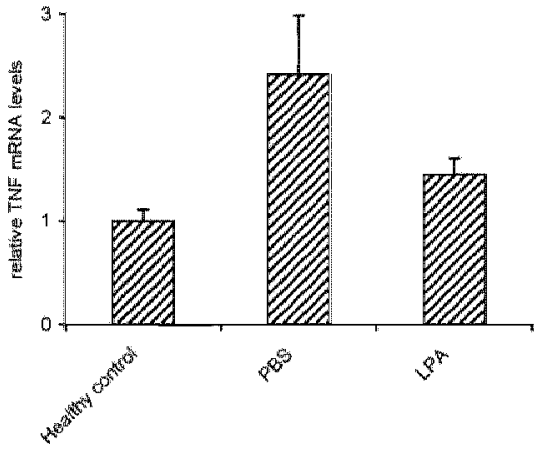

A
KC

MIP-2

$\beta$-actin

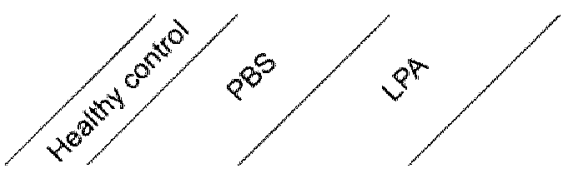

B

Figure 5. LPA treatment inhibits ischemia-reperfusion (I/R) induced upregulation of TNF $\alpha$ whereas KC. MIP-2 mRNA levels are unaffected. Renall $I / R$ induced a significant upregulation of TNF- $\alpha$, as well as KC and MIP-2 at 24 hours ( $A$ and $B$ respectively). Treatment with LPA (1 mg) strongly inhibited expression of TINF- $\alpha$ at 24 hours reperfusion (A). The induction of KC and MIP-2 was not effected by LPA treatment (B). Shown are representative samples ( $n=4$ per group) calibrated against equal amounts of $\mathbb{B}$-actin mRNA. 
The data show that LPA significantly inhibits apoptosis as well as inflammation in the course of renal I/R injury. An important system that regulates inflammatory responses as well as apoptosis upon renal $I / R$ injury is the complement system [7]. To investigate the effects of LPA on the activation of the complement system we stained renal tissue for early as well as late complement deposition. Here, we show that LPA strongly reduces C3-deposition. Compared to healthy animals, in control-treated animals renal $I / R$ induces severe depositions of $\mathrm{C} 3$ (Figure $6 \mathrm{~A}$ and $\mathrm{B}$ ). LPA dose-dependently inhibits $\mathrm{C} 3$ deposition as shown for animals treated with 0.1 and $1 \mathrm{mg}$ of LPA (Figure 6C and $D$ respectively).
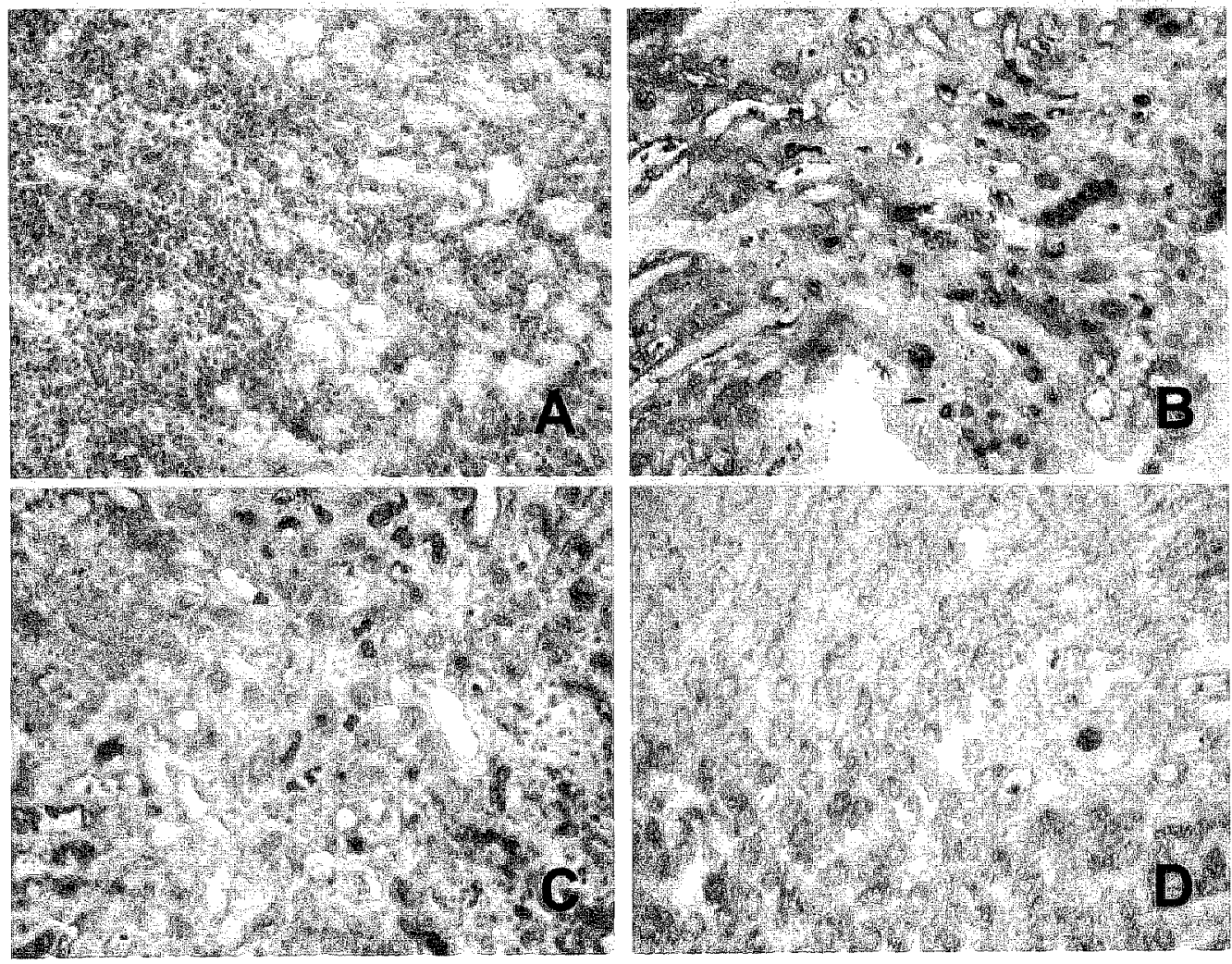

Figure 6. Treatment with LPA strongly reduces $C 3$ deposition induced by renal ischemia reperfusion $(1 / R)$. Healthy animals (A) showed no staining for $C 3$, whereas $\| / R$ induced an intense staining for $C 3$ localised to injured tubular epithelium and tubular debris as shown at 24 hours reperfusion (B). LPA treatment dose-dependently reduced the $1 / R$ induced deposition of $C 3(C, 0.1 \mathrm{mg}$ and $D, 1 \mathrm{mg}$ ). (Magnification 200x.) 
Moreover, LPA dose-dependently reduces $1 / R$-induced membrane attack complex (MAC) formation. Whereas the deposition of complement-factor $C 6$ (indicating MAC formation) is induced by renal I/R (Figure 7A and B), administration of LPA clearly prevented $C 6$ depositions at dosages of $0.1 \mathrm{mg}$ (Figure 7C) and $1 \mathrm{mg}$ (Figure 7D) of LPA. Staining for C9, also indicative for MAC formation, showed a similar inhibition of $I / R$ induced MAC deposition by LPA treatment (data not shown).

In conclusion, this study provides evidence that the administration of LPA dose-dependently abrogates renal failure upon I/R by inhibition of apoptosis and inflammation.
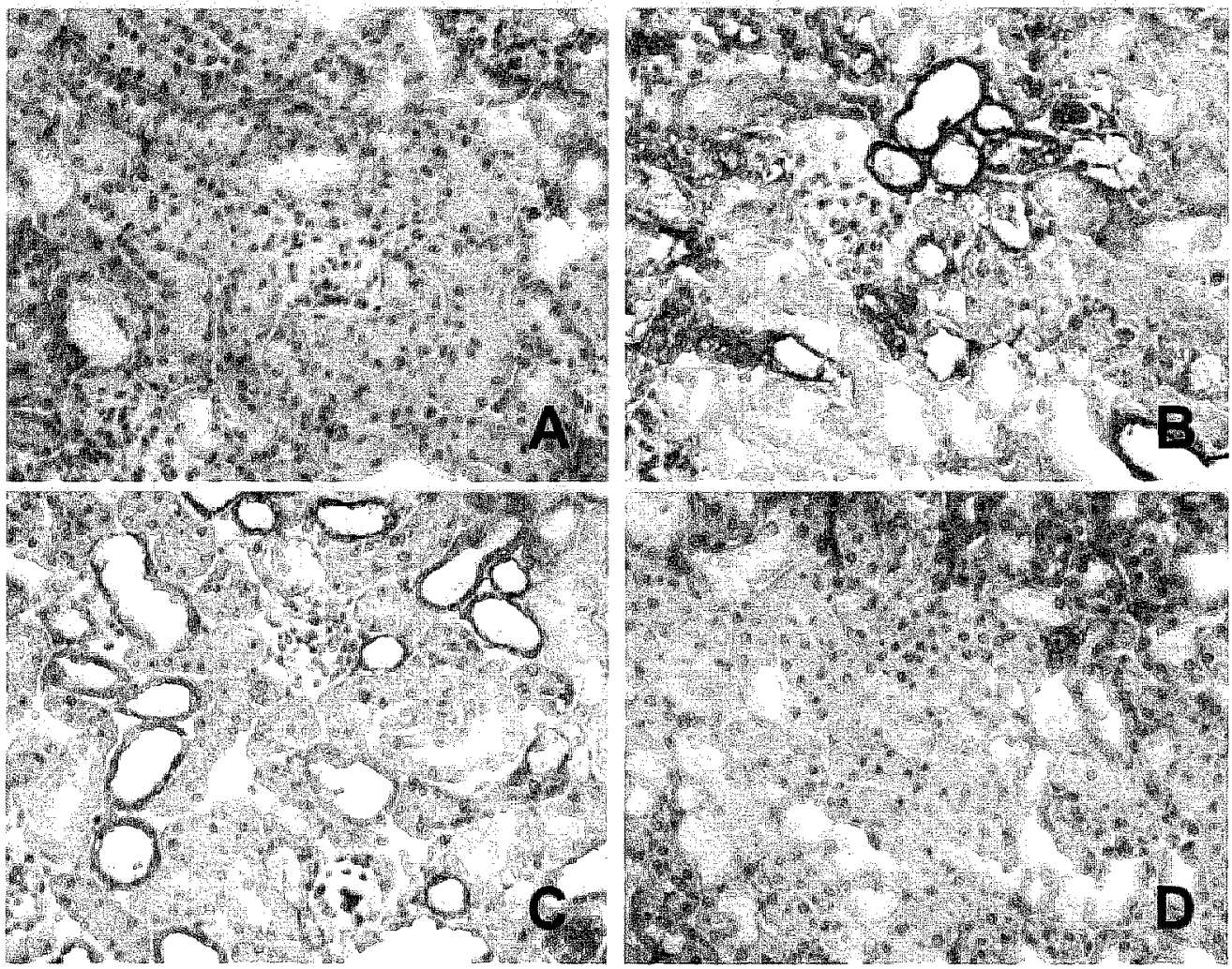

Figure 7. Ischemia followed by reperfusion leads to strong intrarenal deposition af $C 6$, which is totally abrogated by LPA treatment. Healthy animals showed a faint linear staining for $C 6$ at the basal aspect of tubular epithelium (A). $I / R$ induced intense additional staining of $C 6$ which was localised to damaged tubular epithelium (B). LPA treatment totally prevented $I / R$ induced deposi-tion of $C 6$ as shown at 24 hours of reperfusion in a dose-dependent manner $(C, 0.1 \mathrm{mg}$ and $D$, $1 \mathrm{mg}$ ). (Magnification $400 \mathrm{x}$.) 
LPA is a naturally circulating phospholipid with numerous biological actions. LPA signals via three different $G$ protein-coupled receptors, until recently called Edg-2, Edg-4 and Edg-7, however recently nomenclature changed to LPA1, LPA2 and LPA3 respectively [14,19]. All three LPA receptors have been localised in murine renal tissue $[14,15]$. Also in human kidney LPA receptors are present, although human and murine tissues have a different expression pattern of the LPA receptors [14]. The present study is based on reported in vitro properties of LPA: enhancement of cell survival and cell proliferation. and in particular its function as a growth and survival factor for renal proximal tubular cells [16]. This study is the first to show that LPA functions as a renal survival factor in vivo, abrogating ischemia-induced apoptosis, and moreover that LPA prevents function loss in the course of renal I/R injury. Earlier we showed that survival factors such as IGF-1 prevent apoptosis in vivo in the course of renal I/R injury [5]. These data suggest that administration of LPA could have beneficial effects in vivo in diseases that are mediated by apoptosis such as I/R injury. Besides the potent growth factor and antiapoptotic properties of LPA in vitro, this compound has been reported to have vaso-active effects in vivo $[20,21]$. Interestingly, in rodents LPA appears to have vasoconstrictive effects "whereas in rabbits and cats LPA has vasodilatory properties $[20,21]$. The extent to which the vaso-active properties in vivo add to the growth-factor and anti-apoptotic properties of LPA needs still to be elucidated.

In vitro, LPA also stimulates cytoskeletal activation and remodelling [22]. This cytoskeletal activation appears also to be of importance in ischemic injury, since disruption of the actin cytoskeleton has been implicated in the pathophysiology of renal I/R injury $[17,18,23]$. Indeed, this study shows that F-actin, which is a major constituent of the epithelial brush-border, is disrupted in the course of renal I/R injury. LPA treatment evidently prevents this disruption of brush-border. In vitro studies have shown a clear relationship between caspase-activation and changes in cell-structure [24-26]. Here, we show for the first time that caspase-activation induced by renal I/R is localised to tubular epithelial cells. Moreover, this study shows that caspase -7 activation is only present in tubular epithelial cells which have lost their brush-border. Whether the protective effects of LPA in this study are primarily mediated by protection of cellular integrity or by direct inhibition of apoptosis remains to be established.

In vitro studies have shown pro-inflammatory functions of LPA, mainly mediated by the activation of NF-KB. $[27-30]$. The activation of NF-KB and the subsequent induction of pro-inflammatory genes could potentially deteriorate $I / R$ injury by enhancing the $/ / R$-induced, tissue damaging, inflammatory response $[31,32]$. Thus, besides potential protective effects, LPA could also 
aggravate renal $1 / R$ injury. These in vitro data on LPA tempted us to study the role of LPA in $\| / R$-induced inflammation in vivo. The present study demonstrates that LPA treatment has strong anti-inflammatory effects. We previously showed, that the inthibition of apoptosis prevents the induction of chemokines and subsequently the influx of neutrophils after renal $I / R[5,6]$.

Our present data demonstrate that LPA prevents the induction of TNF- $\alpha$ and subsequent neutrophil-influx. Interestingly, LPA did not affect the induction of chemokines, indicating that the abrogation of neutrophil-influx by LPA is primary mediated by a reduction of both TNF- $\alpha$ production and complement-activation. The observation that LPA does not inhibit the induction of chemokines is in contrast to the effects of apoptosis inhibition by the caspase-inhibitor ZVAD-fmk on chemokine-induction in the course of renal I/R injury [6]. This induction of chemokines during ischemia has been attributed to hypoxia and to the activation of caspase- 7 that can lead to the generation and release of the mature chemoattractant endothelial monocyte-activating polypeptide (EMAP-II) $[5,6,33,34]$.

Recent work indicates that activation of the complement system plays an important role in $I / R$ injury in the kidney as well as in other organs [35-41]. We recently reported that inhibition of complement-activation protects against renal $1 / R$ injury by inhibition of chemokine-induction, neutrophilinflux as well as the inhibition of apoptosis [7]. The present study is the first to show that LPA abrogates the renal deposition of early as well as late complement-factors. LPA dose-dependently reduced the deposition of $C 3, C 6$ as well as C9 the latter two indicating formation of the MAC. The MAC has been implicated in renal $1 / R$ injury, by inducing pro-inflammatory cytokines, chemokines, promoting neutrophil-influx, and moreover the induction of apoptotic as well as necrotic cell-death $[35,36,42,43]$.

Recently, we showed that also C5a plays a major role in I/R injury of the kidney (submitted). Inhibition of C5a activity, using a C5a receptor (C5aR) antagonist, significantly reduced the renal induction of chemokines and the influx of neutrophils. Moreover, C5a / C5aR interaction was shown to be largely responsible for renal function loss after I/R. Also cardiac and intestinal $/ / R$ injury are mediated by activation of the complement-system and in particular by generation of C5a [37-41]. The reduced deposition of $C 3$ and MAC after LPA administration indicates that $C 5$ activation is also prevented, and thus that $C 5$ a mediated phenomena are inhibited by LPA. The mechanism that underlies the reduced complement-activation in LPA treated animals is as yet obscure. The activation of complement upon ischemic injury has been attributed to mannose-binding lectin, to the classical pathway for the heart and also to the alternative pathway for the kidney $[35,44,45]$. 
LPA may inhibit complement-activation directly by inhibition of apoptosis since hypoxia following reoxygenation has been shown to induce complement-activation by apoptotic cells in vitro [46]. Necrotic cells are also recognised as an important inducer of complement-activation. The LPA mediated inhibition of apoptosis might also prevent secondary necrosis, that occurs when apoptotic cells are not timely phagocytosed, which could also attribute to the abrogation of complement-activation $[47,48]$.

Taken together, this study shows that LPA dose-dependently inhibits inflammation by abrogation of complement-activation, cytokine-induction and neutrophil-infiltration in the course of renal $1 / R$. The exact mechanism of this anti-inflammatory capacity of LPA in vivo needs further investigation. The aim of the present study was to characterise the in vivo effects of exogenous LPA in an experimental model for renal I/R injury. Local application of LPA has been shown to have beneficial effects on intestinal and cutaneous wound healing in rat models $[49,50]$. Recently, also oral administration of LPA has been shown to have protective effects against radiation-induced apoptos is of intestinal epithelial cells in mice [51]. These studies demonstrate the therapeutic potential of the naturally circulating phospholipid growth factor LPA in a wide variety of diseases in which apoptotic cell-death as well as overwhelming inflammatory reactions play a pathophysiological role. Further in vivo studies are needed to delineate the LPA receptors responsible for the protective effects of LPA. Specific receptor agonists could be advantageous by having specific beneficial effects while abrogating potential side-effects of LPA [52].

In summary, this study is the first to show the protective effects of exogenous LPA against renal I/R injury. LPA abrogates renal apoptosis, TNF- $\alpha$ production, complement-activation and neutrophil-influx. Moreover, exogenous LPA is capable to prevent organ failure due to I/R and thus may provide new means to treat clinical conditions mediated by $I / R$ injury.

\section{REFERENCES}

1. Thadhani R, Pascual M, Bonventre JV: Acute renal failure. N Engl \Med 1996, 334:1448-1460

2. Daemen MA, de Vries $B$, Buurman WA: Apoptosis and inflammation in renal reperfusion injury. Transplantation 2002, 73:1693-1700.

3. Jassem $W$, Fuggle $S V$, Rela $M$, Koo $D D_{1}$. Heaton ND: The role of mitochondria in ischemia/reperfusion injury. Transplantation 2002, 73:493-9.

4. Heinzelmann $M_{n}$ Mercer JM, Passmore JC: Neutrophils and renal failure. Am J Kidney Dis 1999 , $34: 384-99$.

5. Daemen MA, van 't Veer $C$, Denecker $C$, Heemskerk VH, Wolfs TG, Clauss $M$, Vandenabeele $P$, Butrman WA: Inhibition of apoptosis induced by ischemia-reperfusion prevents inflammation. J Clin Invest 1999, 104:541-9.

6. Daemen MA, de Vries B, van't Veer C, Wolfs TG, Buturman WA: Apoptosis and chemokine induction after renal ischemia-reperfusion. Transplantation 2007, 71:1007-11. 
7. De Vifes $B$, Matthisen RA, Wolfs TG, Van Bunen AA, Heeringa $P$, Buurman W: Inhibition of complement factor $C 5$ protects against renal ischemia-reperfusion injury: inhibition of late apoptosis and inflammation. Transplantation 2003, in press.

8. Daemen $M A_{3}$, van de Ven $M W_{\text {, Heineman }} E_{\text {; }}$ Buturman WA: Involvement of endogenous interleukin-10 and tumor necrosis factor-alpha in renal ischemia-reperfusion injury. Transplantation 1999,67:792-800.

9. Shimizu $A$, Masuda $Y$, Kitamura $H$, Ishizaki $M$, Ohashi $R$, Sugisaki $Y$, Yamanaka $N$ : Complement-mediated killing of mesangial cells in experimental glomerulonephritis: cell death by a combination of apoptosis and necrosis. Nephron 2000, 86:152-60.

10. Hughes $d$, Nangaku $M$, Alpers CE, Shankland 5 ], Couser WG, Johnson RJ: C5b -9 membrane attack complex mediates endotheliall cell apoptosis in experimental glomerulonephritis. Am JPhysiol 2000, 278:F747-57.

11. Sato T, Van Dixhoorn MG, Priris FA, Mooney $A$, Verhagen $N_{1}$ Muizert $Y$, Savill I Van Es LA, Daha MR: The terminal sequence of complement plays an essential role in antibody-mediated renal cell apoptosis. J Am Soc Nephrol 1999, 10:1242-52.

12. Harris RC. Crowth factors and cytokines in acute renal filure. Adv Ren Replace Ther 1997, $4: 43-53$.

13. Eichholtz T, Jalink K, Fahrenfort $I_{*}$ Moolenaar WH: The bioactive phospholipid lysophosphatidic acid is released from activated platelets. Biochem J 1993, 291(3):677-80.

14. Contos J, \|shii I, Chun J: Lysophosphatidic acid receptors. Mol Pharmacol 2000, 58:11 88-96

15. Contos J], Chun J: The mouse $\mid \mathrm{p}(\mathrm{A} 3) / \mathrm{Edg} 7$ Iysophosphatidic acid receptor gene: genomic structure, chromosomal localization, and expression pattern. Gene 2001, 267:243-53.

16. Levine JS, Koh JS, Triaca V, Lleberthal W: Lysophosphatidic acid: a novel growth and survival factor for renal proximal tubular cells. Am JPhysiol 1997, 273:F575-85.

17. Ashworth SL, Molitoris BA: Pathophysiology and functional significance of apical membrane disruption during ischemia. Curr Opin Nephrol Hypertens 1999, 8:449-58.

18. Ashworth SL, Sandoval RM, Hosford M, Bamburg JR, Molitoris BA: Ischemic injury induces ADF relocalization to the apical domain of rat proximal tubule cells. Am \Physiol 2001, 280:F886-94.

19. Chun J, Goetzl El, Hla $T$, Igarashi $Y$, Lynch KR, Moolenaar W, Pyne S, Tigyi G: International Union of Pharmacology. XXXIV. Lysophospholipid Receptor Nomenclature. Pharmacol Rev $2002,54: 265-9$.

20. Tokumura A, Fukuzawa $\mathbb{K}$, Tsukatani $\mathrm{H}$ : Effects of synthetic and natural lysophosphatidic acids on the arterial blaod pressure of different animal species. Lipids 1978, 13:572-4.

21. Tokumura A, Kume T, Fukuzawa K, Tsukatani H: Cardiovascular effects of lysophosphatidic \#cid and its structural analogs in rats. J Pharmacol Exp Ther 1981, 219:219-24.

22. Hines $O$ J, Ryder $N$, Chu J, McFadden D: Lysophosphatidic acid stimulates intestinal restitution via cytoskeletal activation and remodeling. J Surg Res 2000, 92:23-8.

23. Molitoris BA, Leiser J, Wagner MC: Role of the actin cytoskeleton in ischemia-induced cell injury and repair. Pediatr Nephrol 1997, 11:761-7.

24. Kruidering M, vain de Water B, Zhan $Y$, Baelde J]. Heer E, Mulder Gl, Stevens JL, Nagelkerke JF: Cisplatin effects on F-actin and matrix proteins precede renal tubular cell detachment and apoptosis in vitro. Cell Death Differ 1998, 5:601-14.

25. Van de Water $B$, Kruidering $M$, Nagelkerke JF: F-actin disorganization in apoptotic cell death of cultured rat renal proximal tubular cells. Am I Physiol 1996, 270:F593-603.

26. Kothakota S, Azuma T, Reimhard C, Klippel A, Tang J, Chu K, MCGarry TJ, Kirschner MW, Koths $K$, Kwiatkowski DJ, Williams LT: Caspase-3-generated fragment of gelsolin: effector of morphological change in apoptosis. Sicience 1997, 278:294-8.

27. Goetzl An S: Diversity of cellular receptors and functions for the lysophospholipid growth factors lysophospliatidic acid and sphingosine 1-phosphate. Faseb J 1998, 12:1589-1598

28. Palmetshofer A, Robson SC, Nehls $V$ : Lysophosphatidic acid activates nuclear factor kappa B and induces proinflammatory gene expression in endothelial cells. Thromb Haemosit 1999, $82: 1532-7$. 
29. Rizza $C$, Leitinger $N_{\text {, }}$ Yue J, Fischer $D$, Wang DA, Shin PT, Lee $H$, Thgi $G_{1}$ Berhner JA: Lysophosphatidic acid as a regulator of endothelal/leukocyte interaction. Lab invest 1999, $79: 1227-35$.

30. Chettibi 5, Lawrence A1, Stevenson RD, Young JD. Effect of lysophosphatidic acid on motilty, polarisation and metabolic burst of human neutrophils. FEMS Immunol Med Microblol 1994, 8:271-81.

31. Chandrasekar E, Smith JB, Freeman GL: Ischemia-reperfuston of rat myocardium actwates nuclear factor-Kappas and induces neutrophil infitration va lipopolysaccharide-induced CXC chemokine. Circulation 2001, 103:2296-2302.

32. Donnahoo $K_{K}$ Meldrum DR, Shenkar $R$, Chung CS, Abraham E, Hatken AH: Early renal ischemia, with or without reperfusion, activates NFkappaB and increases TNF-alpha bioactivity in the kidney. J Urol 2000, $163: 1328-32$.

33. Metinko AP, Kunkel St, Standiford TH, Strieter RM: Anoxia-hyperoxia induces monocytederived interleukin-8. J Clin Invest 1992, 90:791-8.

34. Behrensdorf HA, van de Craen M, Knies UE, Vandemabeele P, Clauss $M$ : The endothelial monocyte-activating polypeptide II (EMAP II) is a substrate for caspase-7. FEBS Lett 2000, 466:143-7.

35. Zhou W, Farrar CA, Abe K, Prata JR, Marsh JE, Wang Y, Stah GL, Sacks SH: Predominant role for C5b-9 in renal ischemia/reperfusion injury. J Clin invest 2000, 105:1363-71.

36. Vakeva AP, Agah A, Rollins SA, Matis LA, Li L, Stahl GL: Myocandial infarction and apoptosis after myocardial ischemia and reperfusion: role of the terminal complement components and inhibition by anti-C5 therapy. Circulation 1998, 97:2259-67.

37. Riley RD, Sato H, Zhao ZQ, Thourani VH, Jordan JE, Fernandez $A X_{x}$ Ma XL, Hite DR, Rigel DF, Pellas TC, Peppard ), Bill KA, Lappe RW, Vinten-Johansen I: Recombinant human complement C5a receptor antagonist reduces infarct size after surgical revascularization. I Thorac Cardiovasc Surg 2000, 120:350-8.

38. Amsterdam EA, Stahl GL, Pan HL, Rendig SV, Fletcher MP, Longhurst JC: Limitation of reperfusion injury by a monoclonal antibody to C5a during myocardial infarction in pigs. Am I Physiol 1995, 268:H448-57.

39. Arumugam TV, Shiels IA, Woodruff TM, Reid RC, Fairlie DP, Taylor SM: Protective Effect of a New C5a Receptor Antagonist against Ischemia-Reperfusion injury in the Rat Small intestine. J Surg Res 2002, 103:260-7.

40. Wada $\mathrm{K}$, Montalto $M \mathrm{M}_{\mathrm{x}}$ Stahl GL: Inhibition of complement $\mathrm{C} 5$ reduces local and remote organ injury after intestinal ischemia/reperfusion in the rat. Gastroenterology 2001, 120:126-33.

41. Heller $T$, Hennecke $M$, Baumann $U_{*}$ Gessner JE, zu Vilsendorf AM, Baensch $M$, Boulay $F_{\text {, Kola }}$ $A$, Klos A, Bautsch W, Kohl J: Selection of a C5a receptor antagonist from phage libraries attenuating the inflammatory response in immune complex disease and ischemia/reperfusion injury. J Immunol 1999, 163:985-94.

42. Cragg MS, Howatt WJ, Bloodworth L, Anderson VA, Margan BP, Glennie MI: Camplement mediated cell death is associated with DNA fragmentation. Cell Death Differ 2000, 7:48-58.

43. Nauta AJ, Daha MR, Tijsma O, van De Water B, Tedesco F, Roos A: The membrane attack complex of complement induces caspase activation and apoptosis. Eur J Immunol 2002, 32:783-92.

44. Jordan JE, Montalto MC, Stahl GL: Inhibition of mannose-binding lectin reduces postischemic myocardial reperfusion injury. Circulation 2001, 104:1413-8.

45. Buerke M, Schwertz $H$, Seitz W, Meyer ل, Darius H: Novel small molecule inhibitor of cl s exerts cardioprotective effects in ischemia-reperfusion injury in rabbits. J Immunol 2001, $167: 5375-80$.

46. Mold C, Morris CA: Complement activation by apoptatic endothelial cells following hypoxia/reoxygenation. Immunology 2001, 102:359-64.

47. Leist $M$, Jaattela $M$ : Four deaths and a funeral: from caspases to altermative mechanisms. Nat Rev Moll Cell Biol 2001, 2:589-98.

48. Schwab BL, Guerini D, Didszun C, Bano D, Ferrando-May E, Fava E, Tam J, Xu D, Xanthoudakis 5, Nicholson DW, Carafoli $E_{n}$ Nicotera P: Cleavage of plasma membrane calcium pumps by caspases: a link between apoptosis and necrosis. Cell Death Differ 2002, 9:81 8-31. 
49. Balazs L, Okolicany $J_{i}$ Ferrebee $M_{8}$ Tolley $B_{s}$ Tigyi $G$ : Topical application of the phospholipid growth factor lysophosphatidic acid promotes wound healing in vivo. Am J Physiol 2001" 280:R466-72.

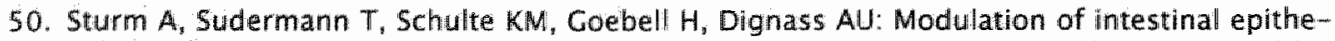
lial wound healing in witro and in vivo by lysophosphatidic acid. Castroenterology 1999, $117: 368-77$.

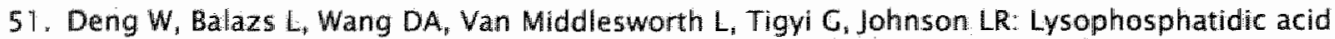
protects and rescues intestinal epithelial cells from radiation- and chemotherapy-induced apoptosis. Gastroenterology 2002, 123:206-16.

52. Tigyi G: Selective ligands for lysophosphatidic acid receptor subtypes: gaining control over the endothelial differentiation gene family. Moll Pharmacol 2001, 60:1161-4. 


\section{CHAPTER}

The mannose binding lectin pathway is involved in complement-activation in the course of renal ischemia-reperfusion injury

Bart de Vries, Sarah J. Walter, Carine J. Peutz-Kootstra, Tim G.A.M. Wolfs, L.W. Ernest van Heurn, and Wim A. Buurman

American Journal of Pathology: 2004; 165(5): 1677-88 
Ischemia-reperfusion (I/R) is an important cause of acute renal failure (ARF). The complement system appears to be essentially involved in $I / R$ injury. However, via which pathway the complement system is activated and in particular whether the mannose binding lectin (MBL)-pathway is activated is unclear. This tempted us to study the activation and regulation of the MBLpathway in the course of experimental renal I/R injury and in clinical posttransplant ARF.

Mice subjected to renal I/R displayed evident renal MBL-depositions, depending on the duration of warm ischemia, in the early reperfusion phase. Renal deposition of $\mathrm{C} 3, \mathrm{C} 6$ and $\mathrm{C} 9$ was observed in the later reperfusion phase. The deposition of MBL-A and $-C$ completely co-localized with the late complement-factor $\mathrm{C} 6$, showing that MBL is involved in complementactivation in the course of renal I/R injury. Moreover, the degree of early MBL-deposition correlated with complement-activation, neutrophil-influx and organ-failure observed in the later reperfusion phase. In serum of mice subjected to renal I/R MBL-A levels increased in contrast to MBL-C levels which dropped evidently. In line, liver mRNA levels for MBL-A increased, whereas MBL-C levels decreased. Renal MBL mRNA levels rapidly dropped in the course of renal I/R.

Finally, in human biopsies MBL-depositions were observed early after transplantation of ischemically injured kidneys. In line with our experimental data, in ischemically injured grafts displaying post-transplant organfailure extensive MBL depositions were observed in peritubular capillaries and tubular epithelial cells.

In conclusion, in experimental renal $/ / R$ injury and clinical post-transplant ARF the MBL-pathway is activated, followed by activation of the complement system. These data indicate that the MBL-pathway is involved in ischemia-induced complement-activation.

\section{INTRODUCTION}

Ischemia-reperfusion (I/R) is an important cause of acute renal failure, associated with a mortality rate of up to $50 \%[1,2]$. Post-transplant renal failure is a common and threatening complication after renal transplantation, in particullar when organs of marginal donors, such as Non Heart Beating (NHB) donors, are used [3]. Effective treatment for $1 / R$ injury is currently not available and hemodialysis is, though symptomatic, the only treatment available. The pathophysiology of renal $I / R$ injury is complicated. Recent studies have shown that the complement system plays a crucial role in pathogenesis of renal injury. Zhou et al. demonstrated that complement 
deficient mice are protected against renal $I / R$ injury [4]. We and others showed that renal I/R injury can be abrogated by treatment with complement inhibitors such as anti-C5 antibodies and C5a receptor antagonists [5-7]. Renal deposition of complement has been well described for the complement-factors $C 3, C 6$ and $C 9[4,7]$. However, via which pathway the complement system is activated in the course of renal I/R is not clear. Park et al. demonstrated that renal $I / R$ does not induce $\lg G$ or $\lg M$ deposition [8]. Moreover, RAG-1 - mice subjected to $1 / \mathrm{R}$ showed renal complement deposition, indicating that renal $I / R$ is not mediated via the classical pathway. Recently, Thurman et al. showed that mice lacking a functional alternative complement pathway (factor $\mathrm{B}^{-1-}$ mice) are partially protected against renal ischemic injury [9]. Whether the alternative pathway is the initiating pathway of ischemia-induced complement-activation or an enhancing pathway for other complement activating pathways remains unclear.

Next to the classical and alternative pathway, the mannose binding lectin (MBL)-pathway forms a third activation route of the complementsystem. Interestingly, whereas in rodents two forms of MBL are present (MBL-A and -C), in humans only one MBL form exists. The MBL-pathway is initiated by binding of MBL to cell surface carbohydrates. Subsequently, two serine proteases, MBL-associated serine protease-1 and -2 (MASP-1 and -2 ), are activated, cleaving $\mathrm{C} 2$ and $\mathrm{C} 4$ to form the classical pathway $\mathrm{C} 3$ convertase [10]. In vitro work shows that complement-activation after endothelial oxidative stress is mediated by the MBL-pathway, by showing that C3-deposition after oxidative stress is attenuated by inhibition of the MBL-pathway [1 1]. Activation of MBL in this in vitro model is reported to be mediated by cytokeratin-1 which is up-regulated and expressed on the cell-surface in hypoxic endothelial cells [12].

In vivo, cardiac $1 / R$ in rats induces MBL-deposition [1 1]. Moreover, inhibition of the MBL-pathway reduces post-ischemic myocardial reperfusion injury in rats. Anti-MBL treatment reduced infarct size and inflammation (neutrophil-infiltration and pro-inflammatory gene-expression) [13]. These data indicate that the MBL-pathway plays an important role in complement-activation in the course of I/R injury. This tempted us to study the activation and regulation of the MBL-pathway in the course of experimental renal I/ $R$ injury and clinical post-transplant $A R F$.

\section{MATERIAL AND METHODS}

Antibodies and reagents

Monoclonal antibodies recognizing mouse $\mathrm{MBL}-\mathrm{A}$ and $-\mathrm{C}$ were kindly provided by Dr. Jensenius (Aarhus University Hospital, Aarhus, Denmark). 
Mouse-anti-human MBL (clone 3E7) was kindly provided by Hbt (Uden, the Netherlands). Rat anti-mouse Clq was a gift from Dr. E. Kremmer (GSFForschungszentrum, München, DE), rabbit anti-mouse $C 6$ was kindly provided by Dr. N.R. Cooper (Scripps Research Institute, La Jolla, CA), rabbit anti-rat $C 9$ by Dr. B.P. Morgan (University of Walles College of Medicine, Cardiff, UK). Goat anti-mouse C3 was purchased from Cappel (ICN Biomedicals, Aurora, $\mathrm{OH}$ ). Secondary antibodies, peroxidase conjugated rabbit anti-goat, goat anti-rabbit and goat anti-rat lgG as well as Texasred-labelled goat anti-rat IgC and FITC-labelled goat anti-rabbit IgG were purchased from Jackson (West Grove, PA). All other reagents were purchased from Sigma (St. Louis, MO).

\section{Experimental renal ischemia-reperfusion model}

Male Swiss mice weighing 20-25 g were obtained from Charles River Breeding Laboratories (Heidelberg, Germany). Animals were housed individually in standard laboratory cages and were allowed free access to food and water throughout the experiments. The studies were carried out under a protocol approved by the Institutional Animal Care Committee of the University of Maastricht. At the start of the experiments, mice were anesthetized with sodium pentobarbital ( $100 \mathrm{mg} / \mathrm{kg}$ i.p.). Body temperature was maintained at $39^{\circ} \mathrm{C}$ by a heating pad until animals recovered from anesthesia. Under aseptic conditions a $1.0 \mathrm{~cm}$ long midline abdominal incision was made and ischemia was induced by applying a non-traumatic vascular clamp to the left renal pedicle for 15,30 , or 45 minutes. Subsequently, the wound was covered with cotton soaked in sterile PBS. After removal of the clamp the left kidney was inspected for restoration of blood flow and the contralateral kidney was removed and stored for analysis. The wound was closed in two layers and $0.25 \%$ bupivacaine was applied topically for postoperative pain management. The animals were sacrificed at indicated timepoints after reperfusion ( $n=6$ per group). At the time of sacrifice, blood was collected and the left kidney and liver were harvested for analysis.

\section{Human renal biopsy material}

As part of our clinical transplantation protocol, pre-transplant needle biopsies are routinely taken from all donor kidneys before start of cold machinepreservation (pre-transplant biopsy). Another biopsy is obtained after approximately $30-60 \mathrm{~min}$ of reperfusion during the transplantation procedure (post-transplant biopsy).

The biopsies evaluated in the present study were chosen based on posttransplant organ function. We studied heart-beating (HB) donor kidneys which are not subjected to evident warm ischemia and functioned immediately after transplantation $(\mathrm{n}=2)$. Also Non-Heart-Beating $(\mathrm{NHB})$ kidneys were used, these organs suffer per definition from evident warm ischemia and often display 
post-transplant organ-failure [14,15]. Pre- and post-transplant biopsies of ischemically injured NHB kidneys displaying a delayed graft function $(n=3)$ or primary non-function $(n=3)$ were analyzed.

For the studied kidneys there were no differences in the duration of cold storage ( $28 \pm 3$ hours) and no acute rejections were observed. All biopsies were immediately embedded in Tissue-Tek (EMS; Washington, PA) and snap-frozen in isopentane at $-80^{\circ} \mathrm{C}$. Biopsies are stored at $-80^{\circ} \mathrm{C}$ until further processing.

\section{Renal Histology}

Cryostat sections $(5 \mu \mathrm{m})$ of frozen murine kidneys were fixed with acetone and stained for complement factors $C 3$ or $C 6$ as reported previously [16], and for $\mathrm{Clq}, \mathrm{MBL}-\mathrm{A}$ and $\mathrm{MBL}-\mathrm{C}$. For $\mathrm{MBL}-\mathrm{A}$ and $-\mathrm{C}$ as well as $\mathrm{Cl} \mathrm{q}$ staining, slides were immersed in Phosphate-buffered saline (PBS) for 5 minutes and subsequently in 5\% normal goat serum in PBS to block aspecific antibody binding. Slides were incubated for 1 hour at room temperature with the anti-MBL-A, $-\mathrm{MBL}-\mathrm{C}$ or $-\mathrm{Clq}$ primary antibody in PBS with $0.1 \%$ bovine serum albumin. After three washes in PBS for 5 minutes each, sllides were incubated for 30 minutes with the peroxidase-labelled secondary antibody diluted in the same buffer. After three washes in PBS staining was visualised by 3-amino-9-ethylcarbazole (AEC) followed by haematoxylin counterstain. Finally, the slides were coverslipped, and viewed with a light microscope. No significant staining was detected in slides incubated with rat IgG instead of the primary antibody indicating the absence of significant background staining.

Murine cryostat sections $(5 \mu \mathrm{m})$ were also double-stained stained for MBL-A or MBL-C and complement factor C6. Briefly, slides were dried, fixed in acetone for 10 minutes and air-dried. Slides were immersed in PBS for 5 minutes and subsequently in 5\% normal goat serum in PBS to block aspecific antibody binding. Slides were incubated for 1 hour at room temperature with anti-MBL-A or $-C$ in combination with anti-C6 primary antibody in PBS with $0.1 \%$ bovine serum albumin. After three washes in PBS for 5 minutes each, slides were incubated for 30 minutes with the appropriate FITC labelled and Texas-red-labelled secondary antibody diluted in the same buffer. After three washes in PBS, the slides were mounted using glycerol-PBS with 1,4diazabicyclo $(2,2,2)$ octane (DABCO) and 4,6-diamidino(2)phenylindole (DAPI), and viewed with an immunofluorescence microscope. No significant staining was detected in slides incubated with control rabbit serum and/or rat $\lg \mathrm{G}$ instead of the primary antibodies indicating the absence of significant background staining or cross-reactivity.

Human cryostat sections $(2 \mu \mathrm{m})$ were stained for MBL and F-actin. Briefly, slides were immersed in PBS for 5 minutes and subsequently in $5 \%$ normal goat serum in PBS to block aspecific antibody binding. Slides were incubated 
with anti-MBL primary antibody in PBS with $0.1 \%$ bovine serum albumin for 2 hours at room temperature. After three washes in PBS for 5 minutes each, slides were incubated for 30 minutes with the appropriate FITC-labelled secondary antibody diluted in the same buffer with the addition of Texas Red-phalloidin that specifically binds to F-actin. After three washes in PBS, the slides were mounted using glycerol-PBS with 1,4-diazabicyclo $(2,2,2) o c t a n e(D A B C O)$ and 4,6 -diamidino(2)phenylindole (DAPI), and viewed with an immunofluorescence microscope.

MBL-A an-C ELISA

To measure serum MBL-A and $-C$ concentrations in mice subjected to renal I/R sandwich ELISA's were used. These ELISA's were kindly provided by Hbt (Uden, the Netherlands).

\section{Measurement of Renal and Hepatic MBL-A and $-C$ mRNA Levels by Reverse Transcriptase-PCR}

For measurement of renal and hepatic MBL-A and $-C$ mRNA levels in the course of experimental renal I/R injury total RNA was extracted from kidneys and livers using the SV Total RNA isolation system (Promega) and treated with RQ1 RNase-Free DNase (Promega). Total RNA was reverse transcribed using oligo (dT) primer and Moloney murine leukemia virus reverse transcriptase. cDNA samples were standardized based on the content of B-actin CDNA as housekeeping gene. $B$-actin cDNA was evaluated by performance of a $B$-actin PCR on multiple dilutions of each cDNA sample. The amount of amplified product was estimated by densitometry of ethidiumbromide stained $1.2 \%$ agarose gels using a CCD camera and Imagemaster VDS software (Pharmacia, Uppsala, Sweden). Primers used for the amplification of murine $B$-actin were: 5"-TAA AAC GCA GCT CAG TAA CAG TCG G-3' (sense primer) and 5'-TCC AAT CCT GTG GCA TCC ATG AAA C-3" (antisense primer). To determine renal and hepatic MBL-A and $-C$ mRNA expression, PCR reactions with specific primers were performed using appropriate dilutions of the CDNA. The sequences of these primers were as follows: MBL-A, $5^{\prime}-C C A$ AAG GGG AGA AGG GAG AAC3' (sense primer) and 5'-GCC TCG TCC GTG ATG CCT AG-3' (antisense primer); MBL-C, 5'-GAC GTG ACG GTG CCA AGG G-3' (sense primer) and 5'CTT TCT GGA TGG CCG AGT TTT C-3' (antisense primer). The following PCR conditions were used: $\mathrm{MBL}-\mathrm{A}$ and $-\mathrm{C}_{1} 95^{\circ} \mathrm{C}$ for $30 \mathrm{~s}, 56^{\circ} \mathrm{C}$ for $45 \mathrm{~s}, 72^{\circ} \mathrm{C}$ for 305; MBL-A, 35 cycles for kidney and 25 cycles for liver samples and MBL-C 40 cycles for kidney and 30 cycles for liver samples.

PCR reactions were performed in a total volume of $25 \mu$ in PCR buffer (Perkin Elmer, Boston MA), in the presence of $0.2 \mathrm{mM}$ dNTP (Pharmacia), 1.0 $\mu \mathrm{M}$ of each primer, $0.3 \mathrm{~m} \mathrm{M} \mathrm{MgCl} 2$ and $0.5 \mathrm{U}$ Taq polymerase (Perkin Elmer). After separation on $1.2 \%$ agarose gel the amplified product was visualized using a CCD camera and Imagemaster VDS software (Pharmacia). 
Renal myeloperoxidase assay

To quantify the extent of renal neutrophil accumulation, renal MPO content was determined [17]. In brief, tissue samples were homogenized in $0.5 \%$ hexadecyltrimethylammonium bromide in $50 \mathrm{mM} \mathrm{PBS}, \mathrm{pH}=6.0,0.17 \mathrm{~g}$ tissue $/ \mathrm{ml}$. After heat incubation $\left(2 \mathrm{~h}, 60^{\circ} \mathrm{C}\right)$ and three freeze-thaw cycles, MPO content was measured in triplicate by incubating supernatants with tetramethylbenzidine (TMB) substrate in a 96-well sample plate (Costar, Cambridge, MA) followed by measurement of optical density (OD) at $450 \mathrm{~nm}$. MPO activity was calculated per $\mathrm{mg}$ renal tissue by comparing $O D$ of samples with a standard titration curve of horseradish peroxidase. Data were standardized with respect to wet/dry ratios of the assayed renal tissue and are presented relative to the amount of MPO present in the contralateral kidney.

\section{Renal function}

Blood urea nitrogen (BUN) was measured in serum obtained 24 hours after reperfusion using a Urea $25 \mathrm{Kit}$ (ABX Diagnostics, Eindhoven, Holland) in a Cobas Fara autoanalyzer (Roche, Basle, Switzerland).

\section{Statistical analysis}

Data are expressed as medians with interquartile ranges or means with SEM and statistical analysis was performed by Mann-Whitney $U$ test. $P<0.05$ was taken to denote statistical significance.

\section{RESULTS}

The MBL-pathway is activated in the course of experimental renal ischemia-reperfusion injury

To investigate activation of the MBL-pathway in the course of renal I/R we first examined renal deposition of MBL-A and $-C$ by immunohistochemistry. In line with a previous report [18], in murine renal control tissue both MBL-A and $-C$ are localized to glomeruli with a mesangial expression pattern, whereas the vasculature and tubular epithelium is negative (Figure $1 \mathrm{~A}$ and $\mathrm{F}$ respectively). Renal warm ischemia of 15,30 , or 45 minutes without reperfusion did not induce any changes in $\mathrm{MBL}-\mathrm{A}$ or - $\mathrm{C}$ expression as compared to healthy controll tissue (data not shown). Warm ischemia of 15 minutes followed by reperfusion did not induce activation of the MBL-pathway (Figure $1 \mathrm{~B}$ and G). Longer renal ischemia of 30 minutes and in particular 45 minutes induced a rapid deposition of MBL-A and $M B L-C$ to tubular and interstitial cells and in peritubular capillaries. These depositions were already detectable after 1 hour of reperfusion for MBL-C (data not shown) and after 2 hours of reperfusion for both MBL-A (Figure $1 C$ and $D$ ) and $M B L-C$ (Figure $1 \mathrm{H}$ and $\mathrm{D}$ ). 
MBL-A and $-C$ depositions were most pronounced after 24 hours of reperfusion when also tubular casts stained positive for MBL (Figure $1 \mathrm{E}$ and J). These data show that warm ischemia followed by reperfusion induces the activation of the MBL-pathway depending on the duration of warm ischemia.

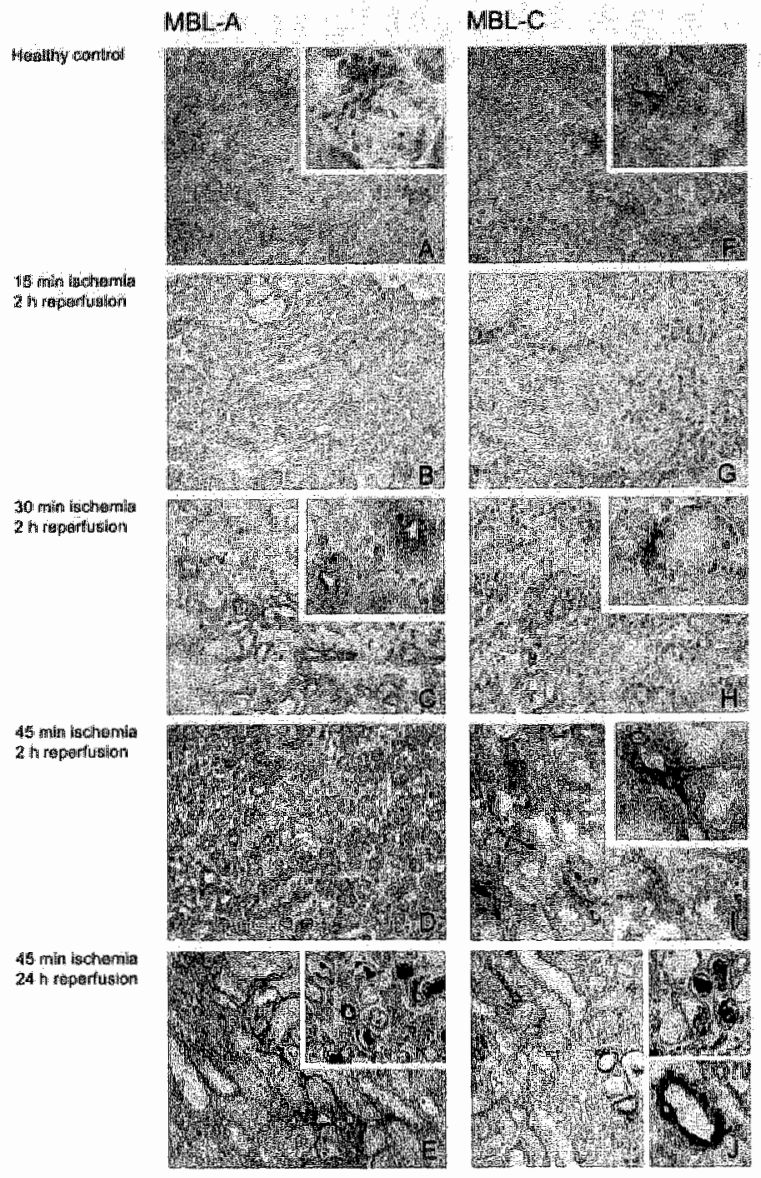

Figure 1. Ischemia followed by reperfusion leads to renall deposition of MBL-A and MBL-C. Positive staining for $M B L-A$ and $-C$ in kidneys from healthy mice is only observed in glomeruli ( $A$ and $\mathbb{F}$ respectively, right upper corner). Renal ischemia for 15 minutes followed by 2 hours of reperfusion did not induce MBL-deposition ( $B$ and $G$ ). After 30-45 minutes of renal ischemia, MBL-A depositions were already evident after 2 hours of reperfusion, mainly localized to tubular epithelium in the medullar region ( $C$ and $D$ respectively). $M B L-C$ depositions were already evident after $1-2$ hours of reperfusion after 30 minutes and most pronounced after 45 minutes af renal ischemia (H and I respectively) and locallized to peritubular capillaries ( $H$ right upper corner) and interstitium (I right upper corner). At the late phase (24 hours of reperfusion) evident depositions of MBL-A were observed in the cortico-medullary region ( $E$ ) and the medulla ( $E$, right upper corner). Most pronounced, depositions of MBL-C were observed in the vasculature $(J$, right lower corner) and on tubular epithelial cells in the cortico-medullary region $(0)$ and the medulla $(J$, right upper corner). Original magnifications $\times 200$ ( $\times 600$ for the inserts in $A, C, F, H, I$ and lower conner $J$ ). 
Next we examined whether, in addition to the MBL-pathway, the classical pathway is also activated in the course of renal $\| / R$ injury. As reported by others we did not observe renal Clq deposition (Table 1). Furthermore, we examined the kinetics of renal deposition of the complement factors $C_{3}$ (common pathway of the complement-cascade), C6 and C9 (both part of the membrane attack complex (MAC)). Ischemia-induced renal deposition of $\mathrm{C}_{3}$ started after 2 hours reperfusion, deposition of $\mathrm{C} 6$ and $\mathrm{C} 9$, was first observed after 12 and 24 hours of reperfusion respectively (Table 1).

Taken together, these data show that the MBL-pathway of complement activation, in contrast to the classical pathway, is activated in the course of renal $/ / R$. Ischemia-induced $M B L$-activation occurs at an early phase, before C3 deposition occurs, indicating that the MBL-pathway is an initiating pathway of complement-activation induced by renal I/R.

Table 1. Immunohistochemical analysis of renall complement-dieposition after ischemia-reperfusion *.

\begin{tabular}{cc|ccc|cc|cc}
\multirow{2}{*}{$\begin{array}{c}\text { Ischemia } \\
\text { (min) }\end{array}$} & $\begin{array}{c}\text { Reperfusion } \\
\text { (hours) }\end{array}$ & \multicolumn{2}{|c|}{\begin{tabular}{c} 
Activation pathway \\
\cline { 3 - 7 }
\end{tabular}} & $\begin{array}{c}\text { Common } \\
\text { pathway }\end{array}$ & \multicolumn{2}{|c}{ MAC } \\
\cline { 3 - 8 } & MBL-A & MBL-C & C1q & C3 & C6 & C9 \\
\hline- & - & - & - & - & - & - & - \\
45 & - & - & - & - & - & - & - \\
45 & 1 & - & + & - & - & - & - \\
45 & 2 & + & ++ & - & ++ & - & - \\
45 & 12 & + & ++ & - & ++ & + & - \\
45 & 24 & ++ & ++ & - & ++ & ++ & ++ \\
- & 24 & - & - & - & - & - & -
\end{tabular}

* Renal deposition of various complement-factors was scored arbitrarily as negative $(-)$, positive $(+)$, intensively positive $(*+)$ after immunohistochemical staining of kîneys from various experimental groups ( $n=4$ per group) subjected to renal ischemia reperfusion.

Ischemia-induced MBL-deposition co-localizes with renal complement-deposition

An important question is whether activation of the MBL-pathway is involved in complement-activation in the course of renal $I / R$. Therefore we determined whether MBL-deposition co-localizes with the deposition of complement factor $C 6$ which is part of the MAC and has been shown to be essentially involved in renal $1 / R$ injury $[4,7]$. For the first time, we demonstrate that MBL-deposition almost completely co-localizes with renal $\mathrm{C} 6$ deposition (Figures 2 and 3 ). 
First, it is shown that in healthy kidneys both $M B L-A$ and $M B L-C$ are present in glomeruli without $\mathrm{C6}$ deposition (Figure 2A and D). Next, in the early reperfusion phase (1 hour reperfusion) after 45 minutes renal ischemia MBL-C, in contrast to MBL-A, is deposited to tubular epithelial cells, whereas no $C 6$ deposition is observed (Figure 2B and E). In the late reperfusion phase (24 hours of reperfusion) both $M B L-A$ and $-C$ are deposited and appear to be located at the same sites as $C 6$ deposition (Figure $2 C$ and $F$ respectively).
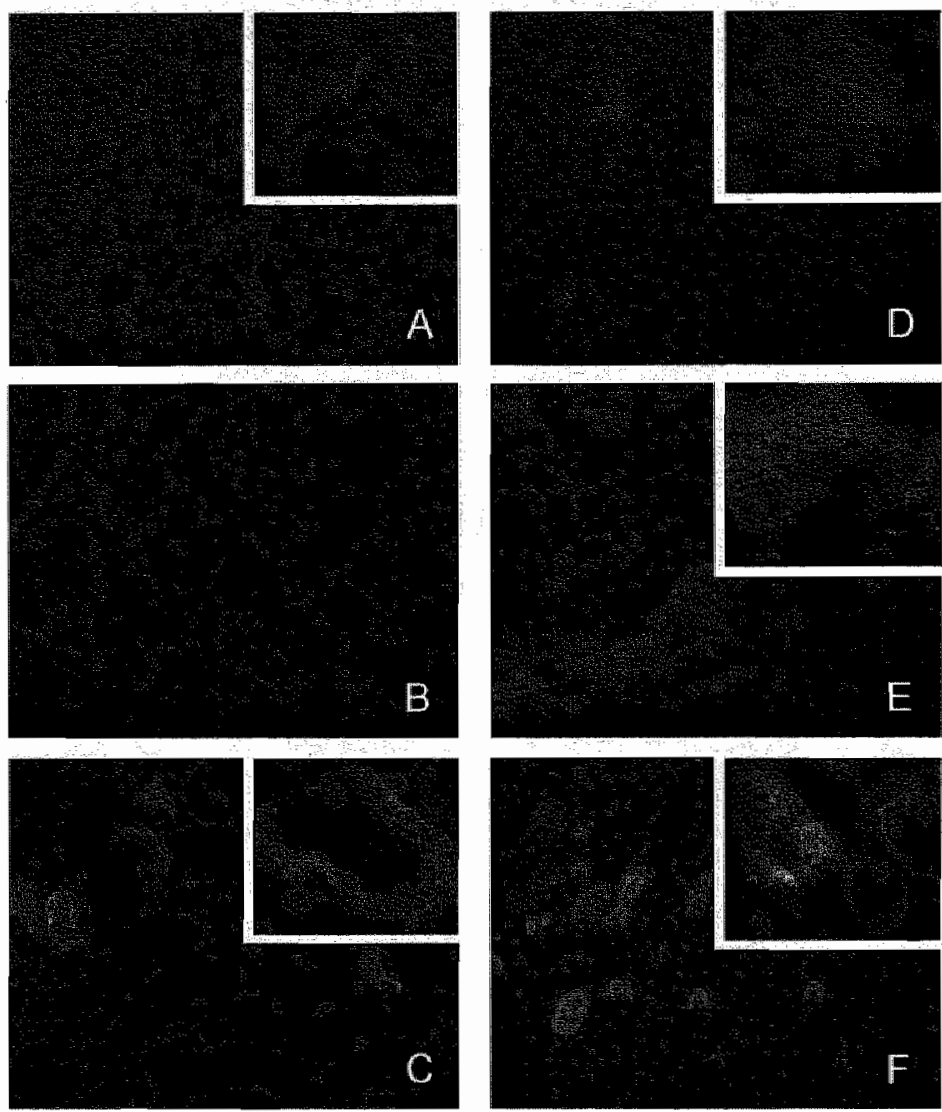

Figure 2. Ischemiaminduced MBL-deposition precedes C6-deposition. Kidneys of healthy animals ( $A$ and $D$ ) showed only glomerular MBL-A and MBL-C staining (in red) and no deposition of C6 (in green). Renal ischemia for 45 minutes followed by 1 hour of reperfusion ( $B$ and $E$ ) induced evident tubular epithelial deposition of MBL-C (E) but no MBL-A deposition (B). However no C6-deposition is observed in the early reperfusion phase ( $B$ and $E$ ). At the late reperfusion phase ( 24 hours of reperfusion) both MBL-A and MBL- $C$ depositions are observed ( $C$ and $F$ respectively). Interestingly, after 24 hours of reperfusion evident $C 6$-staining is present which appears to $C 0$-localize to both MBL-A and $-C$ ( $C$ and $F$ ). Red staining: $M B L-A(A-C)$ and $M B L-C$ (D-F) (Texas-red), green staining: C6 (FITC), blue staining: nuclei (DAPI). (Magnification 200x and 600x for right upper corners). 
In figure 3 the co-localization of both MBL-A and $-C$ with $C 6$ after 24 hours of reperfusion is further examined. MBL-A (left panel) and C6 (middle panel) displayed complete co-localization (right panel). Also MBL-C (left panel) and C6 (middle panel) almost completely co-localized (right panel). However, some tubuli appear to stain positive for $C 6$ without evident $M B L-C$ staining (Figure 3 lower panel).

These data indicate that activation of the MBL-pathway is involved in the initiation of complement-activation and MAC-formation induced by renal ischemia.
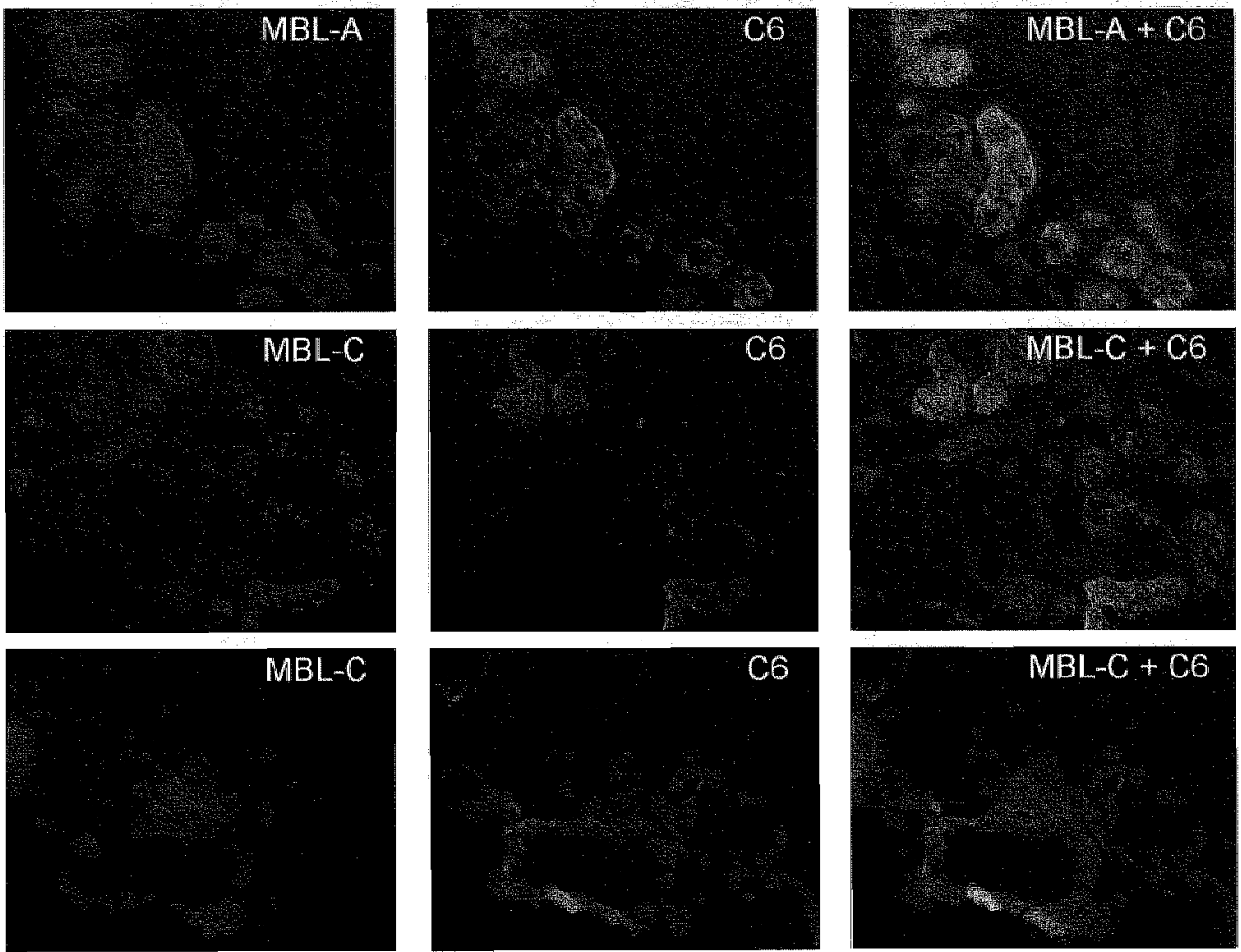

Figure 3. Ischemia-induced MBL-deposition co-localizes with C6-deposition. Kidneys of subjected to 45 minutes ischemia followed by 24 hours reperfusion showed intense MBL-A and MBL-C depositions (left panel). At the same time also evident $C 6$ deposition was observed (middle panel). The overlay pictures show that both MBL-A and MBL-C co-localize with $C 6$ deposition (riglit panel). Interestingly, whereas $C 6$ completely $C D$-localizes with MBL-A, deposition of $C 6$ does also occur without evident MBL $-C$ deposition. Red staining: MBL-A and MBL-C (Texas-red), green staining: C6 (FITC), blue staining: nuclei (DAPI). (Magnification 200x and $600 \times$ for lower panel). 

MBL-levels

Next, serum leveis of MBL-A and $-C$ were measured to investigate the effects of renal $I / R$ on circulating MBL levels. In normal mouse serum (Swiss mice) MBL-A and MBL-C levels were 11.2 and $49.5 \mu \mathrm{g} / \mathrm{ml}$ respectively, which is comparable to reported MBL-levels in other mouse strains [19]. Interestingly, the serum levels of MBL-A increased gradually during reperfusion, leading to a significant twofold increase 24 hours after reperfusion (Figure 4A). This is in line with data from Liu et al. showing that MBL-A is an acute phase protein combined with data from our laboratory that renal I/R induces an acute phase response $[19,20]$. In contrast, serum $M B L-C$ levels decreased after renal I/R leading to a significant halving after 24 hours of reperfusion (Figure 4B). Thus serum levels of $M B L-A$ and $-C$ are differentially regulated in the course of renal $I / R$ injury.
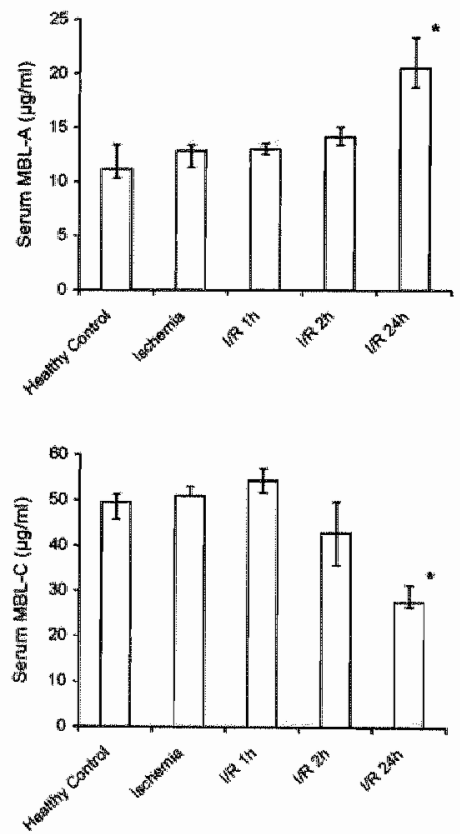

Figure 4. Serum MBL-A and - C levels in the course of renal 1/R. Serum MBL-levels were determined after 45 minutes of ischemia followed by various reperfusion times using a sandwich ELISA. As compared to control mice serum MBL-A levels increased twofold after 24 hours of reperfusion (A). In contrast, serum MBL-C levells dropped gradually during reperfusion resulting in a $50 \%$ reduction after 24 houlrs of reperfusion (B). Statistical significance as compared to control-treated animals was denoted at $p<0.05\left(^{(*)}\right)$. Data are expressed as median serum concentration of MBL $(\mu \mathrm{g} / \mathrm{m} /)$ with interquartile ranges. 
Hepatic and renal MBL-A and $-C$ MRNA levels in the course of renal ischemia-reperfusion

To get more insight in the regulation of $M B L-A$ and $-C$ in the course of renal I/R injury we determined mRNA expression levels of both MBL-forms in kidney and liver tissue after renal $I / R$. First, both $M B L-A$ and $-C$ are expressed in healthy control kidneys as determined by RT-PCR (Figure 5A). Renal I/R induced an evident decrease of both renal MBL-A and $-C$ mRNA levels at 2 hours reperfusion which partially recovered for $M B L-A$ at 24 hours of reperfusion (Figure 5A). Next, in normal liver tissue MBL-A as well as $M B L-C$ areexpressed (Figure 5B). In the early reperfusion phase no changes in expression levels were observed, however at 24 hours reperfusion MBL-A MRNA expression increased, in contrast to MBL-C levels which decreased slightly (Figure 5B). The ischemia-induced changes in liver mRNA levels correlated well with serum MBL levels (Figure 4).

\section{Kidney}

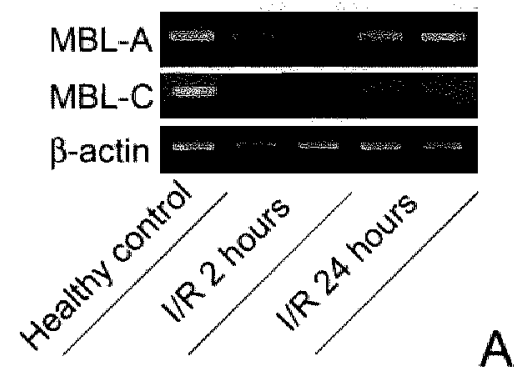

Liver

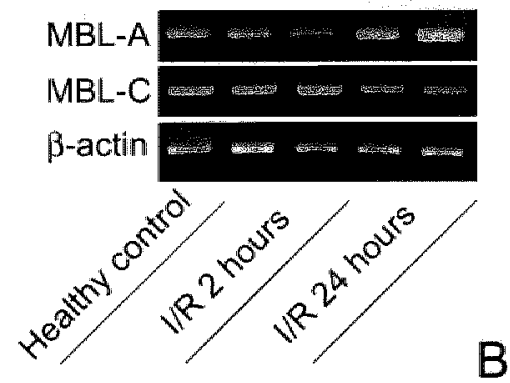

Figure 5. Renal ischemia-reperfusion (I/R) differentially regulates renal and hepatic MBL-A and $-C$ MRNA levels. Renal $1 / R$ induced a rapid down-regulation of renal MBL $-A$ and $-C$ mRNA levels as compared to healthy control tissue (A). Remal ischemia led to an evident up-regulation of hepatic MBL-A mRNA levels at 24 hours of reperfusion in contrast to MBL-C expression levels (B). Shown are representative samples $(n=4$ per group) calibrated against equal amounts of $B$-actin mRNA. 
Activation of the complement-system plays an important role in ischemiainduced inflammation, characterized by the infiltration of neutrophils, and organ failure $[4,6,7]$. We therefore questioned whether the early ischemiainduced deposition of MBL would correlate with inflammation and organ fallure in the course of renal $I / R$ injury. As reported, renall $I / R$ induced no deposition of $\mathrm{MBL}$ after 15 minutes of ischemia, moderate MBL-depositions after 30 minutes of ischemia and evident MBL-depositions after 45 minutes of ischemia followed by $1-2$ hours of reperfusion (Figure 1). Interestingly, the early deposition of MBL correlated with the ischemia-induced influx of neutrophils 24 hours after reperfusion. Whereas 15 minutes of ischemia did not result in the renal infiltration of neutrophils, 30 and 45 minutes of warm ischemia resulted in an increasing amount of infiltrated neutrophils (Figure 6A).
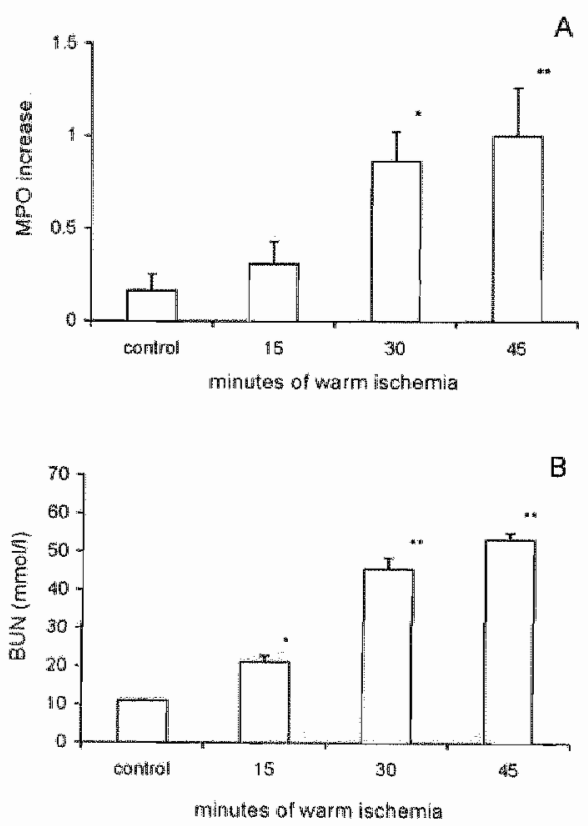

Figure 6. Neutrophil-influx (A) and renal function loss (B) induced by renal warm ischemia. (A) Renal neutrophilminflux was assessed quantitatively by determination of MPO increase in mice subjected to various periods of warm ischemia followed by 24 hours of reperfusion. Values are presented relative to the amount of MPO present in the contralateral kidney harvested immediately after reperfusion and normalized with respect to the MPO increase at $24 \mathrm{~h}$ in mice subjected to $45 \mathrm{~min}$ of ischemia. Statistical significance as compared to controll animals was denoted at $p<0.05\left(^{*}\right)$ and $p<0.011^{* *}$. The presented data are means \pm SEM. (B) Renal function after 15,30 , and 45 min of ischemia and 24 h of reperfusion as reflected by blood urea nitrogen (BUN) content. Statistical significance as compared to control animals was denoted at $p<0.05{ }^{(i n}$ ) and $p<0.01$ ("*). The presented data are means \pm SEM. 
Moreover, the early deposition of MBL correlated with organ failure observed 24 hours after reperfusion. Whereas, 15 minutes of ischemia did only induce a marginal increase in BUN-levels, prolonged ischemia of 30 and 45 minutes resulted in strongly elevated $B U N$-levels reflecting severe organ failure (Figure $6 \mathrm{~B}$ ). Thus the early deposition of MBL correlates with the development of $1 / R$ injury characterized by renal inflammation and organ failure.

These data also suggest that the deposition of MBL, which results in complement-activation, is potentially involved in the development inflammation and organ failure in the course of renal $I / R$ injury.

Post-transplant MBL-deposition in the human kidney

Finally, we determined whether the MBL-pathway is activated in human I/R injury by staining human pre- and post-transplant kidney biopsies for MBL. In normal human kidney no MBL could be detected as described by others [21]. In line with our experimental data all pre-transplant biopsies were negative for MBL (Figure 7AO - FO). Interestingly, post-transplant biopsies of transplanted NHB donor kidneys, which per definition suffer from warm ischemia before organ procurement, stained positive for MBL (Figure $7 \mathrm{~B} 1$ - F1). In particular glomerular staining was observed in such transplanted NHB grafts (Figure 7B1 and $\mathrm{Cl}$ ). In contrast, transplanted $\mathrm{HB}$ kidneys (which do not suffer from evident warm ischemia) were negative for MBL (Figure 7A1). Strikingly, in transplanted NHB kidneys which did not function after transplantation (primary non-function) also interlobular arteries and peritubular capillary walls as well as tubular epithelial cells and casts stained positive (Figure 7D1 - F1), this in contrast to delayed functioning grafts (Figure 7B1 and $\mathrm{Cl}$ ). Double staining of MBL with von Willebrand Factor (staining endothelial cells) shows that MBL is deposited on peritubular capillaries (Figure $7 \mathrm{G}$ ).

Our data show, for the first time, that the MBL-pathway of complement activation is initiated in the early reperfusion phase after renal transplantation of ischemically injured organs. Moreover, in this limited number of studied kidneys the intensity and localization of MBL-deposition appear to correlate with $1 / R$ injury and graft outcome after transplantation of ischemically injured NHB donor organs, which is in line with our experimental data. 

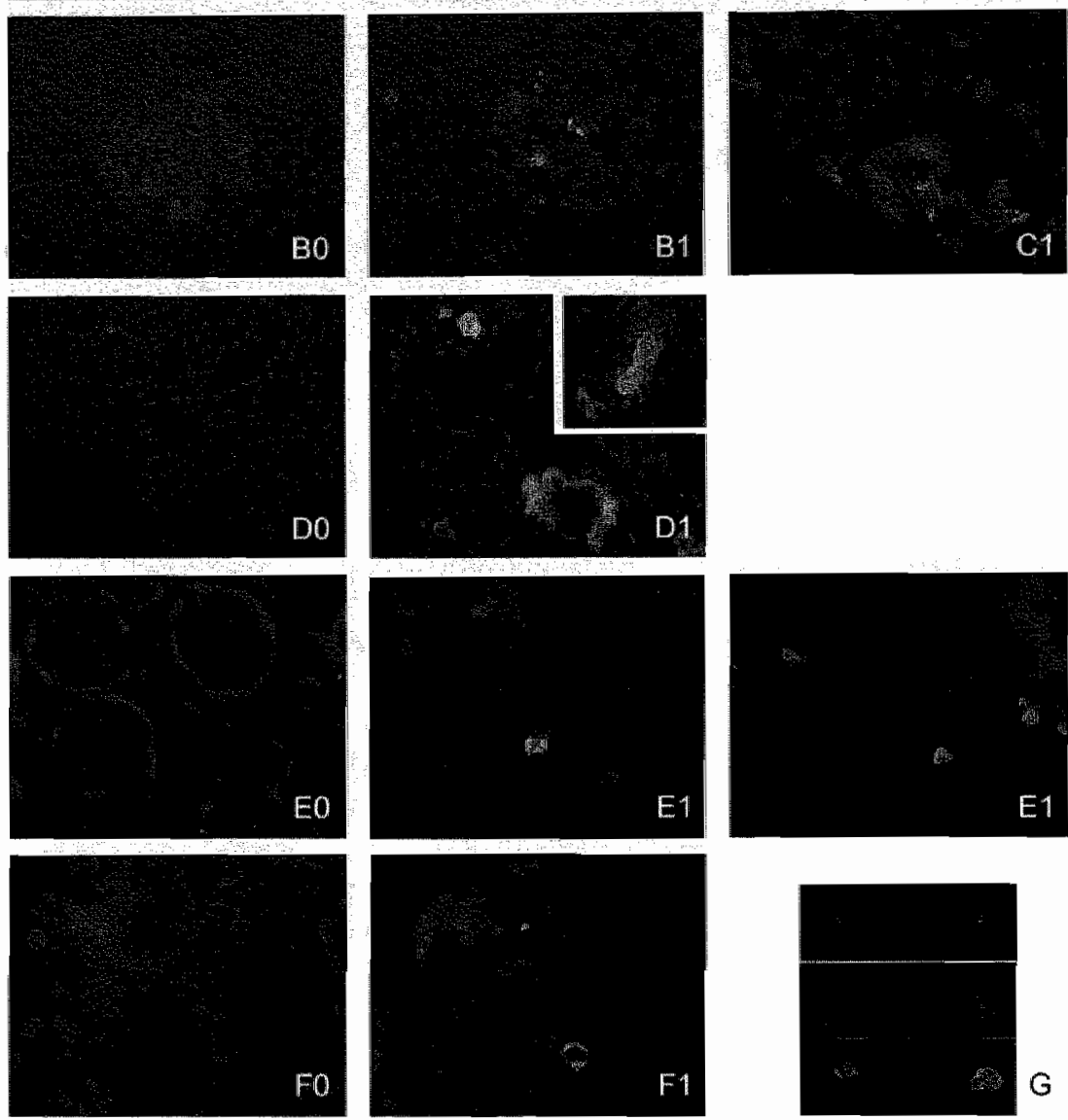

Figure 7. Renal deposition of MBL in early post-transplant biopsies of transplanted human kidneys. In pre-transplant renal biopsies no MBL could be detected (AO-FO). After transplantation of kidneys derived from heart-beating (HB) donors no MBL deposition is present (AI). In contrast, transplantation of ischemically injured Non Heart Beating (NHB) donor kidneys induced rapid glomerular MBL deposition (B1 and C1). Moreover, in NHB grafts which displayed primary nonfunction extensive vascular and tubular MBL-clepositions are observed (DI, interlobular artery

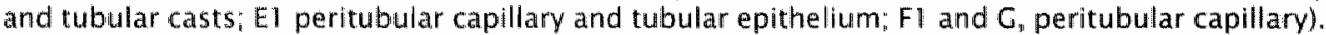
A double-staining for MBL (green) and von Willebrand Factor (red) shows MBL deposition in peritubular capillaries (G). Red staining: filamentous actin (Texas-red), except for $G$ : von Willebrand Factor (Texas-Red); green staining: MBL (FITC), blue staining; nuclei (DAPI). (Magnification 200x for A-D and 600x for E-G). Each letter represents a kidney (pre-transplant biopsy marked with 0 , post-transplant biopsy marked with 1). 
In the present study we show that experimental renal $I / R$ induces significant changes in circulating MBL-levels after reperfusion. Interestingly, whereas levels of MBL-A increased twofold, MBL-C levels showed an almost $50 \%$ reduction. These data are in line with a study by Liu et al. showing that the induction of an acute phase response by casein as well as LPS injection in mice induced a 2 -fold increase of serum MBL-A levels, whereas $M B L-C$ levels were unchanged but tended to decrease after LPS imjection [19]. Interestingly, we previously showed that renal I/R induces an intense acute phase response comparable to the reaction observed after intraperitoneal LPS administration [20]. These data indicate that in the course of renal I/R $M B L-A$ behaves as an acute phase protein. On the other hand serum MBL-C levels decreased significantly during renal //R. MBL-A as an acute phase protein is mainly produced in the liver, although basal renal and pulmonary expression have been described $[18,22,23]$. Basal MBL-C expression is described in the liver, kidney, thymus and small intestine [23]. In line, in the present study we show basal expression of MBL-A and $-C$ in kidney and liver. In the post-ischemic kidney both MBL-A and $-C$ expression rapidly decreased. This in contrast to hepatic expression levels which were regulated differentially. Whereas hepatic MBL-A levels increased after renal ischemia, as has been shown previously for other acute phase proteins [20], MBL-C levels decreased slightly. Hepatic levels MBL-A and $-C$ levels correlated well with serum levels in the early as well as late reperfusion phase, indicating that the liver is the main site of MBL-production in the course of renal $I / R$ injury [24].

In humans MBL deficiency is one of the most common immunodeficiencies, arising primarily from three single point mutations in codons 52,54 and 57 of exon 1 in the MBL gene [25]. These mutations prevent the assembly of fully functional multimeric protein, resulting in low serum levels of MBL. MBL deficiency predisposes to a broad range of serious bacterial, viral and fungal infections as well as auto-immune disease $[25,26]$. On the other hand, a recent report indicates that $\mathrm{MBL}$-deficiency prevents complement-activation and subsequent systemic inflammation in patients undergoing thoracoabdominal aortic aneurysm repair, suggesting that $M B L$ deficiency might be beneficial in conditions of pathophysiologic complement-activation, such as ischemic injury [27].

In renal disease, glomerular MBL-deposition is observed in glomerulonephritis, among others primary and secondary IgA nephropathy, lupus nephropathy, membranous nephropathy, membranoproliferative glomerulonephritis and anti-GBM nephritis $[21,28-30]$. Recent work shows that the MBL-pathway is not activated in renal transplantation, however in that study only living donor recipients suffering acute humoral rejection were studied [31]. 
In acute humoral rejection the classical pathway of complement-activation is regarded to be the main activation route of the complement-system $[31,32]$. In the present study we show for the first time that the MBL-pathway is activated after transplantation of ischemically injured NHB donor kidneys in contrast to $\mathrm{HB}$ donor kidneys. This indicates that activation of the MBL-pathway is initiated on the basis of ischemic injury followed by reperfusion. In particular kidneys which did not function after transplantation (primary non-function) showed widespread MBL-depositions, located to glomeruli, large vessels, peritubular capillaries, tubular epithellial cells and tubular casts, suggesting that the MBL-pathway might be essentially involved in post-transplant $1 / R$ injury. These clinical observations are supported by our experimental data which show that the deposition of MBL is dependent on the duration of warm ischemia and correlates with postischemic inflammation and organ-failure.

Involvement of the complement system in experimental renal $1 / R$ injury was already reported in 1985 by Stein et al. showing complement-deposition in a rat model for renal $1 / R$ injury [33]. Only recentlly, an active role in the pathophysiology of I/R injury was addressed to the complement-system by Zhou and colleagues, showing that complement-deficient mice are protected against I/R injury [4]. The complement system can be activated via three pathways: The classical pathway (activated by antigen-antibody interaction), the MBL-pathway (activated by mannose present on microbial surfaces), and the alternative pathway (activated by microbial products). All three pathways converge at the level of $\mathrm{C} 3$ activation, forming a $\mathrm{C5}$-convertase, which activates $C 5$. Activation of $C 5$ results in the formation of $C 5 a$ and $C 5 b$, the latter one being the first step in the formation of the membrane attack complex (MAC). Both the formation of membrane attack complex (MAC) as well as the generation of the anaphylatoxin $C 5$ a have been shown to mediate renal I/R injury [4-7]. However, via which pathway(s) complement-activation is initiated in the course of renal $I / R$ injury is still unclear. Complement-activation in the kidney has been attributed to the alternative pathway mainly by exclusion of classical complement-activation. Park et al. demonstrated that renal $I / R$ does not induce IgG or IgM deposition [8]. In concordance we did not observe $\mathrm{C} 1 \mathrm{q}$ deposition in our experimental model. RAG-1 ${ }^{-1-}$ mice subjected to $I / R$ still showed renal complement deposition, indicating that renal $I / R$ is not mediated via the classical pathway [8]. Indeed, C4 deficient mice, in contrast to $\mathrm{C} 3$ deficient mice, were not protected against renal $\mathrm{I} / \mathrm{R}$ injury [4]. Moreover, Thurman et al. showed recently that mice lacking a functional alternative complement pathway (factor $B^{-1-}$ mice) are partially protected against renal ischemic injury, showing that the alternative pathway plays an important role in the pathophysiology of renal $I / R$ injury [9]. In an experimental mouse model for renal $1 / R$ injury we show for the first time that renall $I / R$ induces the activation of the MBL-pathway. 
In the healthy mouse kidney only glomerular mesangial cells stained positive as reported by others [18]. After renal I/R both $M B L-A$ and $-C$ deposited to injured tubular epithelial cells. The site of renal MBL-deposition observed in the present study was similar to ischemia-induced $C 3, C 6$ and $C 9$ deposition, as reported previously [7]. Therefore co-localization studies were performed to demonstrate that $\mathrm{MBL}$-deposition precedes and co-localizes with complement-activation. Our data show that MBL-deposition precedes $\mathrm{C} 3$ and $\mathrm{C} 6$ deposition and moreover that $C 6$ deposition completely co-localizes with $\mathrm{MBL}$-deposition. These data are in line with recent in vitro studies showing that endothelial hypoxia followed by reoxygenation induces MBL-deposition which co-localizes with $\mathrm{C} 3$ deposition [11,34]. In vivo, MBL-A deposition has been observed during the early phase of myocardial $I / R$ in a rat model. Moreover, inhibition of MBL-A protected against myocardial I/R injury, attenuating $C 3$ deposition, reducing infarct size and neutrophil infiltration [13]. In combination with our experimental and clinical data showing that the deposition of MBL correlates with post-ischemic organ-failure, these studies indicate that the MBL-pathway of complement-activation plays an active role in $I / R$ injury. However, additional intervention studies are needled to unravel the precise role of this pathway in renal $I / R$ injury.

How the MBL-pathway is activated in the course of $I / R$ injury remains unclear. Recent in vitro work indicates that cytokeratin 1 is involved in activation of the MBL-pathway [12]. The membrane expression of cytokeratin-1 is up-regulated after endothelial hypoxic stress and inhibition of cytokeratin-1 prevented endothelial complement deposition (MBL and C3) [12]. Whether cytokeratin 1 plays a role in complement-activation in renal $1 / R$ injury in vivo remains to be established.

Taken together, in the present study we show for the first time that the $M B L-p a t h w a y$ is activated in the course of experimental as well as clinical renall $1 / R$ injury. Moreover, the $M B L-$ pathway precedes and co-localizes with complement-deposition in the course of $I / R$. These data indicate that the $M B L-$ pathway of complement-activation is essentially involved in renal $I / R$ injury.

\section{REFERENCES}

1. Levy EM, Viscoli CM, Horwitz RI: The effect of acute renal failure on mortality. A cohort analysis. Jama 1996, 275:1489-94.

2. Thadhani R, Pascual $M$, Bonventre JV: Acute renal fallure. N Engl J Med 1996, 334:1448-1460

3. Nicholson ML, Metcalfe MS, White SA, Waller JR, Doughman TM, Horsburgh T, Feehally J, Carr SJ, Veitch PS: A comparison of the results of renal transplantation from non-heart-beating, conventional cadaveric, and living donors. Kidney Int 2000, 58:2585-91.

4. Zlhou W, Farrar CA, Abe K, Pratt JR, Marsh JE, Wang $Y$, Stahl GL, Sacks SH: Predominant role for $C 5 \mathrm{~b}-9$ in renal ischemia/reperfusion injury. J Clin Invest 2000, 105:1363-71. 


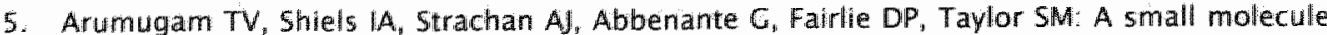
C5a receptor antagonist protects kidneys from ischemia/reperfusion injury in rats. Kidney Int $2003,63: 134-2$

6. De Vries $B$, Kohl $J$, Leclercq $W K$, Wolfs $T C_{\text {, }}$ van Bijnen AA, Heeringa $P$, Butrman WA: Complement factor C5a medlates renal ischemia-reperfusion injury independent from neutrophils. J Immunol 2003, 170:3883-9.

7. De Vries $B$, Matthijsen RA $A_{i}$ Wolfs TC, Van Bijinen AA, Heeringa $P$, Buurman WA: Inhibition of complement factor $C 5$ protects against renal ischemiamreperfusion injury: inhibition of late apoptosis and inflammation. Transplantation 2003, 75:375-82.

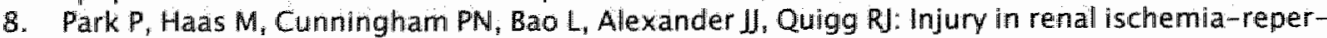
fusion is independent from immunoglobulins and T Iymphocytes. Am J Physiol Renal Physiol $2002,282: F 352-57$

9. Thurman JM, Ljubanovic D, Edelstein CL, Gilkeson GS, Holers VM: Lack of a functional alternative complement pathway ameliorates ischemic acute renal failure in mice. I Immunol $2003,170: 1517-23$.

10. Thiel S, Vorup-Jensen T, Stover CM, Schwaeble $W_{1}$ Laursen $S B$, Poulsen $K$, Willis $A C_{n}$ Eggleton

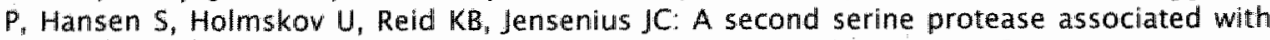
mannan-binding lectin that activates complement. Nature 1997, 386:506-10.

11. Collard CD, Vakeva A, Morrissey MA, Agah A, Rollins SA, Reenstra WR, Buras JA, Meri S, Stahl GL: Complement activation after oxidative stress: role of the lectin complement pathway. Am J Pathol 2000, 156:1549-56.

12. Collard $C D$, Montalto $M C$, Reenstra WR, Buras $\rfloor A$, Stahl GL: Endothelial oxidative stress activates the lectin complement pathway: role of cytokeratin 1. Am J Pathol 2001, 159:1 045-54.

13. Jordan JE, Montalto MC, Stahl GL: Inhibition of Mannose-Binding Lectin Reduces Postischemic Myocardial Reperfusion injury. Circulation 2001, 104:1413-8.

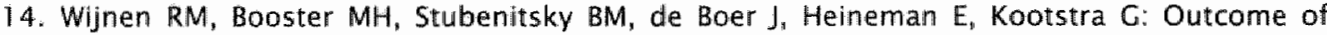
transplantation of non-heart-beating donor kidneys. Lancet 1995, 345:1067-70.

15. Weber $M$, Dindo $D_{*}$ Demartines $N$, Ambuhl PM, Clavien PA: Kidney transplantation from donors without a heartbeat. N Engl J Med 2002, 347:248-55.

16. De Vries $B$, Matthijsen RA, van Bijnen AA, Wolfs TG, Buurman WA: Lysophosphatidic acid prevents renal ischemia-reperfusion injury by inhibition of apoptosis and complement activation. Am J Pathol 2003, 163:47-56.

17. Laight DW, Lad N, Woodward B, Waterfall JF: Assessment of myeloperoxidase activity in renal tissue after ischemia/reperfusion. Eur J Pharmacol 1994, 292:81-8.

18. Wagner S, Lynch NJ. Walter W, Schwaeble WJ, Loos M: Differential expression of the murine mannose-binding lectins $A$ and $C$ in lymphoid and nonlymphoid organs and tissues. J Immumol 2003, 170:1462 -5.

19. Liu H, Jensen L, Hansen S, Petersen SV, Takahashi K, Ezekowitz AB, Hansen FD, Jensenius JC, Thiel S: Characterization and quantification of mouse mannan-binding lectins (MBL $-A$ and MBL-C) and study of acute phase responses. Scand J Immunol 2001.53:489-97.

20. Daemen MA, Heemskerk VH, van't Veer $C$, Denecker $G$, Wolfs $T G$, Vandenabeele $P$, Buurman WA: Functional protection by acute phase proteins alpha(1)-acid glycoprotein and alpha(1)antitrypsin against ischemia/reperfusion injury by preventing apoptosis and inflammation. Circulation 2000, 102:1420-6.

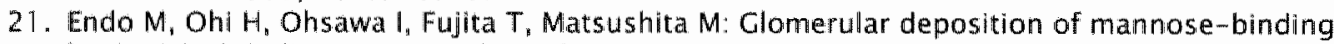
lectin (MBL) indicates a novel mechanism of complement activation in IgA nephropathy. Nephrol Dial Transplant 1998, 13:1984-90.

22. Sastry R, Wang JS, Brown DC, Ezekowitz RA, Tauber Al, Sastry KN: Characterization of murine manmose-binding protein genes $M b 11$ and Mbl2 reveals features common to other collectin genes. Mamm Genome 1995, 6:103-10.

23. Uemura $K$, Saka $M$, Nakagawa $T$, Kawasaki $N$, Thiel $S$, Jensenius JC, Kawasaki $T$ : L-MBP is expressed in epithelial cells of mouse small intestine. J Immunol 2002, 169:6945-50. 
24. Sastry $K$, Zahedi $K$, Lelias JM, Whitehead AS, Ezekowitz RA Nolecular characterization of the mouse mannose-binding proteins. The mannose-binding protein $A$ but not $C$ is an acute phase reactant. J Immunol 1991, 147:692-97.

25. Eisen DP, Minchinton RM: Impact of mannose-binding lectin on susceptibility to infectious diseases. Clin Infect Dis 2003, 37:1496-1505

26. Turner MW: The role of mannose-binding lectin in health and disease. Mol Immunol 2003 , $40: 423-9$.

27. Fiane $A E$, Videm $V$, Lingaas PS, Heggelund $L$, Nielsen EW, Geiran OR, Fung $M_{*}$ Mollnes TE: Mechanism of complement activation and its role in the inflammatory response after thoracoabdominal aortic aneurysm repair. Circulation 2003, 108:849-56.

28. Matsuda M, Shikata K, Wada J, Sugimoto H, Shikata $Y$, Kawasaki T, Makino H: Deposition of mannan binding protein and mannan binding protein mediated complement activation in the glomeruli of patients with IgA nephropathy. Nephron 1998, 80:408-13.

29. Lhotta $K$, Wurzner $R$, Konig $P$ : Glomerular deposition of mannose-binding lectin in human glomerulonephritis. Nephrol Dial Transplant 1999, 14:881-6.

30. Endo $M$, Ohi $H$, Ohsawa I, Fujita $T$, Matsushita $M$ : Complement activation through the lectin pathway in patients with Henoch-Schonlein purpura nephritis. Am J Kidney Dis 2000 , 35:401-7.

31. Sund $S$, Hovig T, Reisaeter AV, Scott H, Bentdal O, Mollnes TE: Complement activation in early protocol kidney graft biopsies after living-donor transplantation. Transplantation 2003 , 75:1204-13.

32. Mauivyedi S, Colvin RB: Humoral rejection in kidney transplantation: new concepts in diagnosis and treatment. Curr Opin Nephrol Hypertens 2002, 11:609-18.

33. Stein JH, Osgood RW, Barnes JL, Reineck HJ, Pinckard RN, McManus LM: The role of complement in the pathogenesis of postischemic acute renall failure. Miner Electrolyte Metab 1985 , $11: 256-61$.

34. Collard CD, Lekowski $R$, Jordan JE, Agah A, Stahl GL: Complement activation following oxidative stress. Mol Immunol 1999, 36:941-8. 


\section{CHAPTER}

\section{Inhibition of complement factor $\mathrm{C} 5$ protects against renal ischemia-reperfusion injury: Inhibition of late apoptosis and inflammation}

Bart de Vries, Robert A. Matthijsen, Tim G. A. M. Wolfs, Annemarie A. J. H. M. van Bijnen, Peter Heeringa, and Wim A. Buurman

Transplantation: $2003 ; 75(3): 375-82$ 


\section{ABSTRACT}

Complement has been implicated in the pathophysiology of renal ischemiareperfusion $(I / R)$ injury. However, the mechanism underlying complementmediated renal $I / R$ injury is thus far unknown. To investigate the involvement of complement in $1 / R$ injury we studied the activation and deposition of complement in a murine model of renal $I / R$ injury. Furthermore, we examined the effect of inhibition of complement-factor $C 5$ on renal $\mathbb{R} / R$ injury.

Mice were subjected to 45 minutes of unilateral ischemia and subsequent contralateral nephrectomy and reperfusion for 2,12 or 24 hours. Mice were control-treated or treated with BB5.1, a monoclonal antibody which prevents cleavage of the complement-factor $C 5$, thereby preventing $C 5$ a generation and formation of the membrane attack complex (MAC).

Renal I/R induced extensive deposition of $C 3$ early after reperfusion, whereas $C 6$ and C9-deposition (MAC-formation) occurred relatively late. I/Rinduced complement deposition mainly localized to tubular epithelium. Treatment with BB5.1 totally prevented MAC-formation but also reduced C3-deposition. Inhibition of C5 strongly inhibited late inflammation, as measured by neutrophil-influx and induction of the murine $\mathrm{CXC}$-chemokines macrophage inflammatory protein-2 (MIP-2), KC and LPS-induced CXC chemokine (LIX). Anti-C5 treatment furthermore abrogated late I/R-induced apoptosis whereas early apoptosis was not affected. Moreover, BB5.1 treatment significantly protected against I/R-induced renal dysfunction.

In conclusion, renal $\mathrm{I} / \mathrm{R}$ is followed by activation of the complement system and intrarenal deposition of $\mathrm{C} 3$ and MAC. Complement-activation plays a crucial role in the regullation of inflammation and late apoptosis. Complement inhibition, by preventing $\mathrm{C} 5$ activation, abrogates late apoptosis and inflammation, being strongly protective against renal function loss.

\section{INTRODUCTION}

Apoptosis plays a crucial role in the pathophysiology of ischemia-reperfusion $(I / R)$ injury [1-5]. Recently, we showed that apoptosis is functionally involved in the induction of inflammation after renal ischemia [1]. This inflammatory response is known to be responsible for tissue damage upon reperfusion $[6,7]$. The $1 / R$-induced inflammatory response is characterized by influx of neutrophils $[6,8]$ a process that is mediated by, among others IL-1, TNF $-\alpha$ and in particular the CXC-chemokines KC, MIP-2 and LIX [7, 911]. Also the complement system is activated in several models of $I / R$ injury $[12-16]$. 
Activation of the complement system results in the release of the anaphylatoxins $\mathrm{C} 3 \mathrm{a}$ and $\mathrm{C} 5 \mathrm{a}$ and the formation of the membrane attack complex (MAC). Both C3a and C5a mediate activation of neutrophils. C5a might be involved in the influx of neutrophils upon $1 / R$, because of its direct chemotactic effect and its property to induce chemokines $[17,18]$. The MAC also mediates neutrophil influx, induces synthesis of pro-inflammatory cytokines and directly causes cell injury, apoptosis and necrosis [19-22]. Complete deficiencies of complement-factor $C 3, C 5$ as well as $C 6$ have been shown to be protective against renal $/ / R$ injury, the latter implying that in particular the MAC is involved [12]. In models of experimental glomerulonephritis the MAC has been implicated in the induction of apoptosis [2325 ]. Since apoptosis is essentially involved in renall/R injury, we investigated the activation of complement and subsequently whether complement activation is involved in the induction of apoptosis and inflammation in a murine model of renal I/R injury. Here, we show that renal I/R induces complement activation and intrarenal deposition of MAC. When $C 5$ activation is prevented subsequent apoptosis as well as inflammation, measured by neutrophil-influx and chemokine-induction, is strongly inhibited, which is accompanied by a significant reduction in function loss.

\section{MATERIALS AND METHODS}

\section{Antibodies and reagents}

For in vivo studies, anti-murine C 5 hybridoma BB5.1 was used (kindly provided by Dr. B. Stockinger, National Institute for Medical Research, London, UK). This is a murine antibody specific for the mouse $C 5$ protein, raised by immunization of C5-deficient mice [26] which has been shown to block C5a and MAC generation in vivo [27]. Murine monoclonal antibody (mAb) ENA-1 (anti-human E-selectin) was used as control antibody. Both murine antibodies have the $\gamma 1$ isotype. Rabbit anti-mouse C6 was kindly provided by Dr. N.R. Cooper (Scripps Research Institute, La Jolla, CA), rabbit anti-rat C9 by Dr. B.P. Morgan (University of Wales College of Medicine, Cardiff, UK) and goat anti-mouse $\mathrm{C} 3$ was purchased from Cappel (ICN Biomedicals, Aurora, $\mathrm{OH}$ ). NIMP-R1 4 (rat anti-mouse neutrophil mAb) was kindly provided by Dr. M. Strath (National Institute for Medical Research, London, UK). Secondary antibodies, peroxidase conjugated donkey anti-goat, goat anti-rabbit and goat anti-rat IgG were purchased from Jackson (West Grove, PA). All other reagents were purchased from Sigma (St. Louis, MO). 
Male Swiss mice weighing 20-25 g were obtained from Charles River Breeding Laboratories (Heidelberg, Germany). Animals were housed individually in standard laboratory cages and were allowed free access to food and water throughout the experiments. The studies were carried out under a protocol approved by the Institutional Animal Care Committee of the University of Maastricht. At the start of the experiments, mice were anesthetized with sodium pentobarbital $(100 \mathrm{mg} / \mathrm{kg}$ i.p.). Body temperature was maintained at $39^{\circ} \mathrm{C}$ by a heating pad until animals recovered from anesthesia. Under aseptic conditions a $1.0 \mathrm{~cm}$ long midline abdominal incision was made and ischemia was induced by applying a non-traumatic vascular clamp to the left renal pedicle for 45 minutes. Subsequently, the wound was covered with cotton soaked in sterile PBS. After removal of the clamp the left kidney was inspected for restoration of blood flow and the contralateral kidney was removed. The wound was closed in two layers and $0.25 \%$ bupivacaine was applied topically for postoperative pain management. The animals were sacrificed at indicated time-points after reperfusion. At the time of sacrifice, blood was collected and the left kidney was harvested for analysis.

Mice were subjected to ischemia and treated with anti-C5 mAb BB5.1, control mAb ENA-1, or PBS. Pharmacological interventions were carried out during ischemia, fifteen minutes prior to removal of the clamps, to be effective immediately upon reperfusion. Mice ( $n=6$ per group) received $1 \mathrm{mg}$ of BB5.1 or ENA-1 dissolved in $1 \mathrm{ml}$ PBS, or $1 \mathrm{ml}$ PBS i.p. The treatment-dose used has been shown to have complement inhibiting capacities in vivo [27]. Mice treated with the isotype-matched control Ab (ENA-1) showed no significant differences when compared to the PBS treated control group regarding renal function, neutrophil-influx, and apoptosis indicating that aspecific murine IgG does not affect evaluated parameters.

\section{$\mathrm{CH} 50$}

CH50 was measured as described previously [28]. In brief, serum samples were titrated in veronal buffered saline containing $\mathrm{MgCl} 2$ and $\mathrm{CaCl} 2$ in $96-$ well plates. Ab-sensitized rabbit erythrocytes were added and plates were incubated for one hour at $30^{\circ} \mathrm{C}$. After centrifugation supernatants were read at $405 \mathrm{~nm}$. CH50 was calculated using water and veronal buffer controls as described [28].

\section{Renal Histology}

Cryostat sections $(5 \mu \mathrm{m})$ of frozen tissue were fixed with acetone and stained for complement factors, C3, C6 and C9, the latter using rabbit anti-rat $\mathrm{C9}$, which cross-reacts with murine $\mathrm{C} 9$, followed by appropriate secondary antibodies. Staining was visualized by 3-amino-9-ethylcarbazole (AEC) followed by hematoxylin counterstain. No significant staining was detected in 
slides incubated with control antibodies (Abs), normal goat serum for $\mathrm{C} 3$ or rabbit serum for $\mathrm{C} 6$ and $C 9$, instead of the specific anti-sera indicating the absence of significant background staining. Staining for neutrophils was performed with mAb NIMP-R 14. Neutrophils were counted by examining 20 fields of vision per kidney section (3-4 sections per kidney) at $\times 200$ magnification in a blinded fashion.

\section{Apoptosis assays}

Presence of internucleosomal DNA cleavage in kidneys was investigated with a commercial ligase mediated (LM)-PCR assay kit (Apoalert, Clontech, Palo Alto, CA) enabling semiquantitative measurement of the extent of apoptosis. In brief, DNA was isolated from tissue samples employing a commercially available DNA purification kit (Promega, Madison, WI). DNA purity and concentration were determined by electrophoresis through a $0.8 \%$ agarose gel containing ethidium bromide followed by visualization under ultraviolet illumination as well as by measuring absorbance at $260 / 280 \mathrm{~nm}$. Dephosphorylated adaptors were ligated to $5^{\prime}$-phosphorylated blunt ends with T4 DNA ligase (during $16 \mathrm{~h}$ at $16^{\circ} \mathrm{C}$ ) and served as primers in a LM-PCR. Amplified DNA was subjected to gel electrophoresis on a $1.2 \%$ agarose gel containing ethidium bromide.

Measurement of Renal TNF- $\alpha$, MIP-2, KC and LIX mRNA Levels by Reverse Transcriptase-PCR

For RT-PCR total RNA was extracted from kidneys using the SV Total RNA isolation system (Promega) and treated with RQ1 RNase-Free DNase (Promega). Total RNA was reverse transcribed using oligo (dT) primer and Moloney murine leukemia virus reverse transcriptase. cDNA samples were standardized based on the content of $B$-actin CDNA as housekeeping gene. B-actin CDNA was evaluated by performance of a B-actin PCR on multiple dilutions of each cDNA sample. The amount of amplified product was estimated by densitometry of ethidiumbromide stained $1.2 \%$ agarose gels using a CCD camera and Imagemaster VDS software (Pharmacia, Uppsala, Sweden). Primers used for the amplification of murine $B$-actin were: $5^{\prime \prime}-$ TAA AAC GCA GCT CAG TAA CAG TCG G-3' (sense primer) and 5'-TGC AAT CCT GTG GCA TCC ATG AAA C-3' (antisense primer). To determine renal TNF- $\alpha$, MIP-2, KC and LIX mRNA expression, PCR reactions with specific primers were performed using appropriate dilutions of the CDNA.

The sequences of these specific primers were as follows : TNF- $\alpha$ : 5'-GCC AGG TCT ACT TTC GAG TCA TTG C-3' (sense) and 5'-ACA TTC GAG GCT CCA GTG AAT TCG G-3' (antisense); MIP-2: $5^{\prime \prime}$ - TGC CGG CTC CTC AGT GCT G $3^{\prime}$ (sense) and 5' - AAA CTT TTT GAC CGC CCT TGA - 3' (antisense); KC : $5^{\prime}$ CGC TCG CTT CTC TGT CCA - 3' (sense) and 5' - ATT TTC TGA ACC AAG GGA GCT - 3' (antisense) ; LIX : 5' - TTC CTC AGT CAT AGC CGC AAC - 3" (sense) 
and $5^{*}-$ TCC GCT TAG CTT TCT TTT TCT C - $3^{\prime}$ (antisense). For each primer couple the following PCR conditions were used: TNF- $\alpha: 95^{\circ} \mathrm{C}$ for $30 \mathrm{sec}, 63^{\circ} \mathrm{C}$ for $30 \mathrm{sec}, 72^{\circ} \mathrm{C}$ for $30 \mathrm{sec}$ during 38 cycles; MIP-2: $95^{\circ} \mathrm{C}$ for $30 \mathrm{sec}, 55^{\circ} \mathrm{C}$ for sec, $72^{\circ} \mathrm{C}$ for sec during 34 cycles; $\mathrm{KC}: 95^{\circ} \mathrm{C}$ for $30 \mathrm{sec}, 55^{\circ} \mathrm{C}$ for $30 \mathrm{sec}, 72^{\circ} \mathrm{C}$ for $30 \mathrm{sec}$ during 35 cycles; LIX: $95^{\circ} \mathrm{C}$ for $30 \mathrm{sec}, 56^{\circ} \mathrm{C}$ for $30 \mathrm{sec}, 72^{\circ} \mathrm{C}$ for 30 sec during 37 cycles.

PCR reactions were performed in a total volume of $25 \mu$ in PCR buffer (Perkin Elmer, Boston MA); in the presence of $0.2 \mathrm{mM}$ dNTP (Pharmacia), 1.0 $\mu \mathrm{M}$ of each primer, $0.3 \mathrm{mM} \mathrm{MgCl} 2$ and $0.5 \mathrm{U}$ Taq polymerase (Perkin Elmer). After separation on $1.2 \%$ agarose gel the amplified product was visualized using a CCD camera and Imagemaster VDS software (Pharmacia).

\section{Renal function}

Blood urea nitrogen (BUN) and serum creatinine were measured in serum obtained at the time of sacrifice using a Urea 25 Kit (ABX Diagnostics, Eindhoven, Holland) and CREA MPR3 Kit (Boehringer Mannheim, Mannheim, Germany) in a Cobas Fara autoanalyzer (Roche, Basle, Switzerland).

Statistical analysis

Data are expressed as medians with interquartile ranges, and statistical analysis was performed by Mann-Whitney $U$ test. $P<0.05$ was taken to denote statistical significance.

\section{RESULTS}

\section{Complement-activation and deposition after renal $\mathrm{V} / \mathrm{R}$}

First, we investigated whether renal $I / R$ leads to consumption of complement by measurement of $\mathrm{CH} 50$. The data (Table 1) show that total complement activity is significantly reduced at 2 hours and 12 hours of reperfusion upon renal ischemia and gradually recovered during the reperfusion period. This led us to investigate whether renal $I / R$ leads to intrarenal deposition of complement factors. Deposition of C3, C6 and C9 was examined at different time-points after renal I/R by immunohistochemistry. Healthy control kidneys showed faint staining for all studied complement-factors along the basement membranes of in particular tubular epithelial cells as well as glomeruli (Figure 1A, 2A and 3A). The same pattern of staining was observed in ischemic kidneys without reperfusion (data not shown). After reperfusion, intense staining for $\mathrm{C} 3$ was observed at 2 hours and remained present during 24 hours of reperfusion (Figure $1 C$ and $1 E$ ). Intense C3-staining localized to cellular debris and injured tubular epithelial cells. 
Intrarenal depositions of C6 were seen at 12 hours after reperfusion and increased in time. The deposition of $C 6$ was primarily localized to tubular casts and injured tubular epithelium (Figure 2C). Deposition of $\mathrm{C9}$, alike $\mathrm{C6}$ indicative for MAC-formation, was first observed after 18 hours of reperfusion and distributed similarly as C6 deposition, although more intense in tubular casts. More clear-cut deposits of $\mathrm{C} 9$ were detected at 24 hours of reperfusion (Figure $3 \mathrm{C}$ ). Control anti-serum staining using kidney sections at 24 hours reperfusion shows that non-specific antibody binding is very low for the anti-sera used in this study (Figure 1B, 2B and 3B respectively).

Table I. Renal ischemia-reperfusion injury induces consumption of complement reflected by loss of $\mathrm{CH} 5 \mathrm{O}^{\prime}$.

\begin{tabular}{ccccc}
\hline & Healthy & U/R 2 hours & I/R 12 hours & I/R 24 hours \\
\hline \multirow{2}{*}{ CH50 (units / ml) } & 209 & $81.5^{2}$ & $136^{2}$ & 151 \\
& $(203.8-210.5)$ & $(77.5-85.5)$ & $(121.8-146.5)$ & $(127.3-270)$ \\
\hline
\end{tabular}

Sera of healthy control mice $(m=6)$ and mice subjected to renal ischemia followed by 2,12 or 24 hours of reperfusion $(n=5-6$ each) were studied. Data shown are median $\mathrm{CH} 50$ with interquartile ranges between brackets

${ }^{2} \mathrm{p}<0.05$ versus healthy controls

Inhibition of C5-activation prevents $\mathrm{I} / \mathrm{R}$ induced complement deposition and MAC-formation

Kidneys from BB5.1 treated animals showed complete abrogation of I/Rinduced $C 6$ and $C 9$ depositions (Figure $2 D$ and $3 D$ respectively). The above reported faint staining seen in healthy kidneys at the tubular and glomerular epithelial was not effected. Inhibition of $\mathrm{C5}$ did not reduce $\mathrm{C} 3$ deposition at two hours reperfusion (Figure 1D). Interestingly, at 12 and 24 hours reperfusion, C3 depositions were substantially reduced in BB5.1-treated animals, when compared to non-treated and control-treated animals (Figure 1F). Taken together inhibition of C5 by BB5.1 did not prevent early C3 deposition, but reduced late $C 3$ deposition and totally prevented the //R-induced deposition of $\mathrm{C} 6$ and $\mathrm{C} 9$ and thus MAC-formation. 

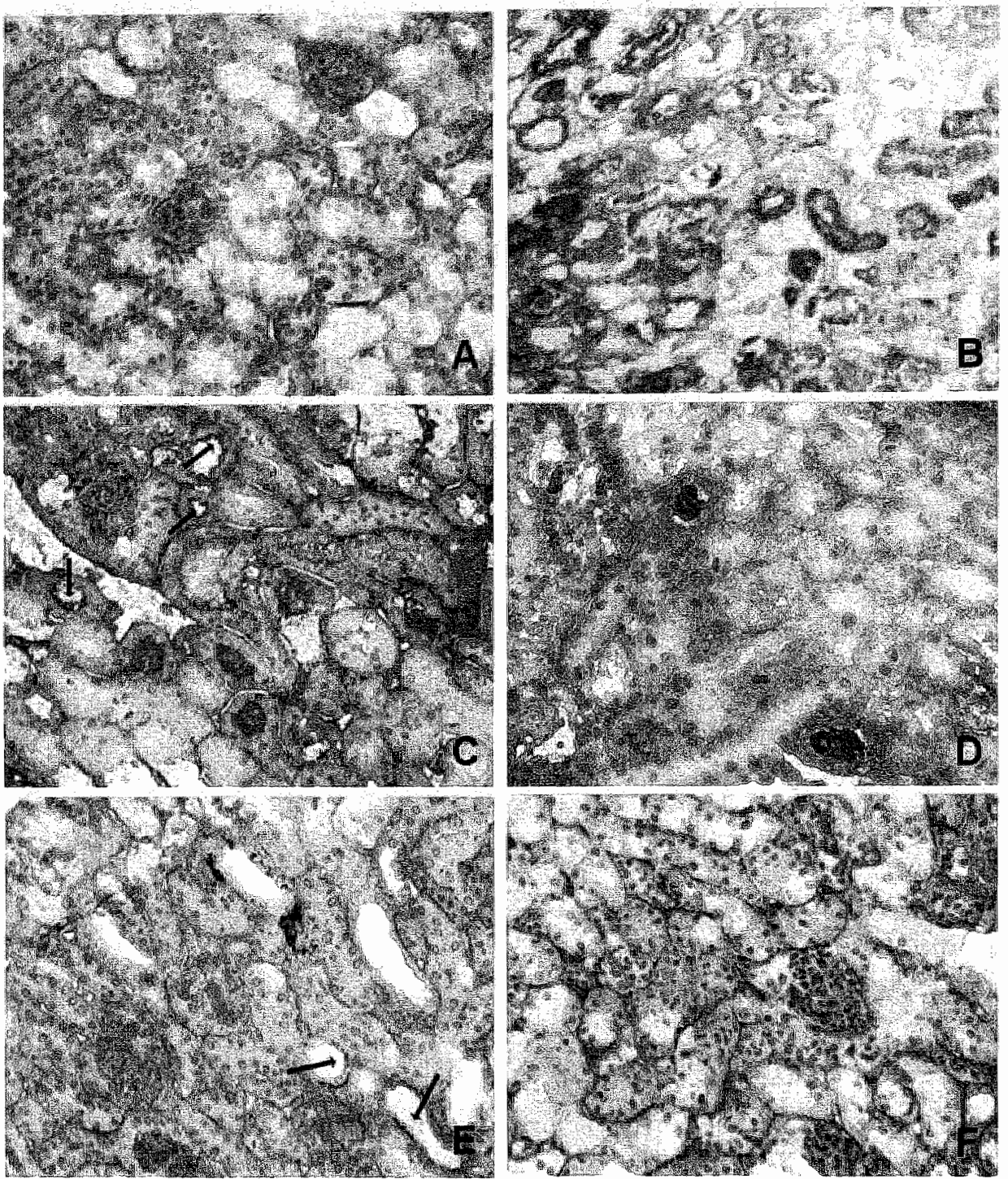

Figure 1. Treatment with BB5. I strangly reciuces $C 3$ deposition induced by renal ischemia reperfuston (I/R). Healthy animals (A) showed linear staining for $\mathrm{C} 3$ at the basement membranes of tubular epithelium. Following $I / R$ an intense staining for $C 3$ localized to injured tubular epithelium (arrows) and tubular debris as shown at 2 and 24 hours reperfusion ( $C$ and $E$ respectively). Anti-C5 treatment did not reduce early $C 3$ deposition at 2 hours reperfusion, whereas the deposition of $C 3$ at 24 hours of reperfusion was substantially reduced (D and F). Non-specific antibody staining was neglectable (B). 

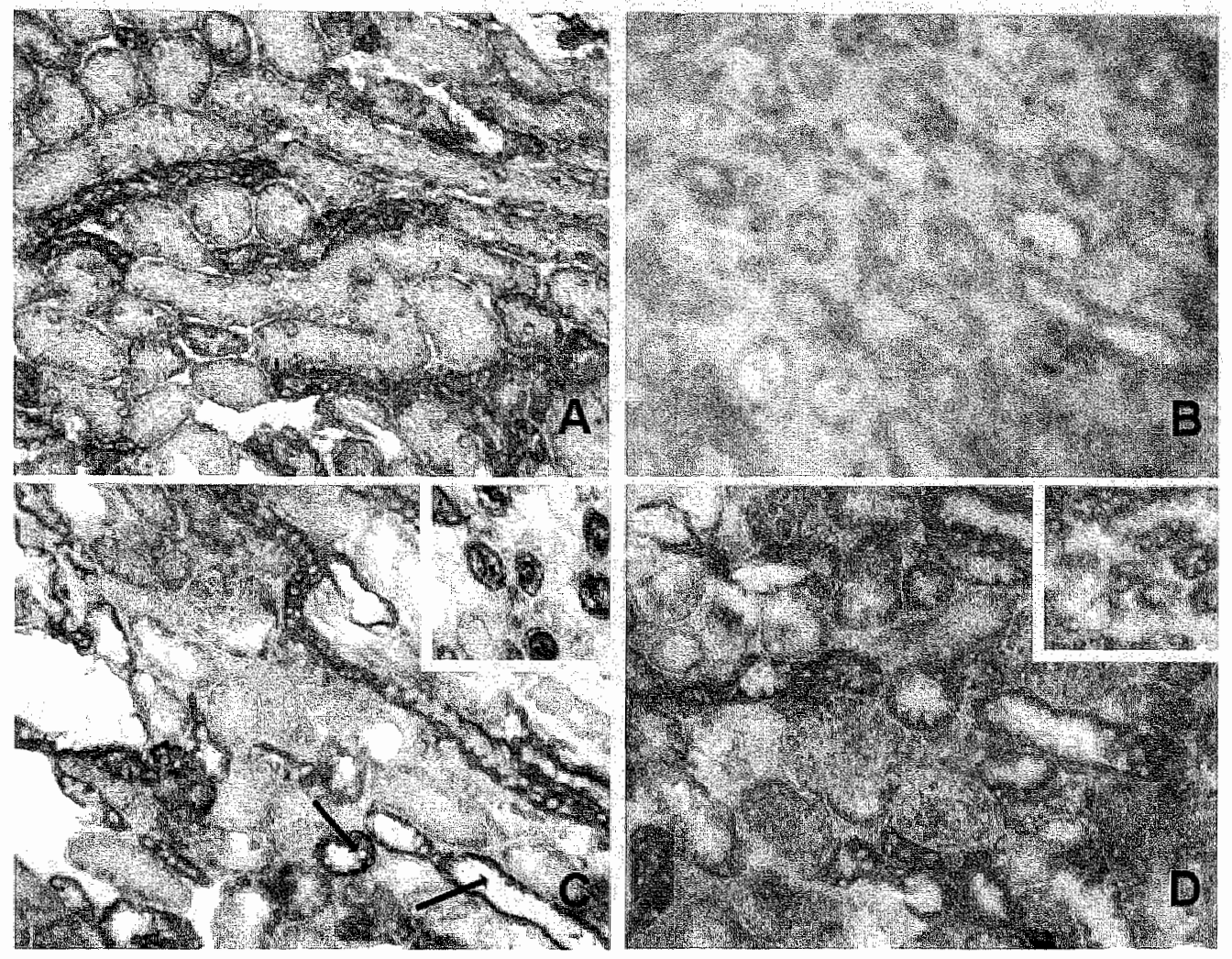

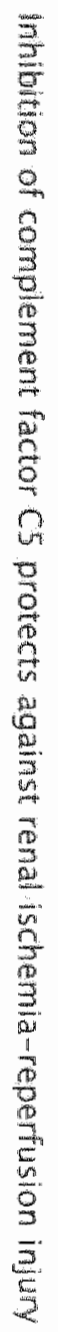

Figure 2. Ischemia followed by reperfusion leads to strong intrarenal deposition of $C 6$, which is totally abrogated by BB5.1 treatment. Healthy (A) and control antibody treated animals (data not shown) showed a linear staining for $C 6$ at the basal aspect of tubular epithelium. $1 / R$ induced intense additional staining of $C 6$ which was localized to damaged tubular epithelium and tubular casts at 24 of reperfusion, shown cortex (C) and medulla (C right upper corner). Anti-C5 treatment totally prevented $I / R$ induced deposition of $C 6$ as shown at 24 hours of reperfusion, shown cortex (D) and medulla (D right upper corner). (B) Control antibody staining. 

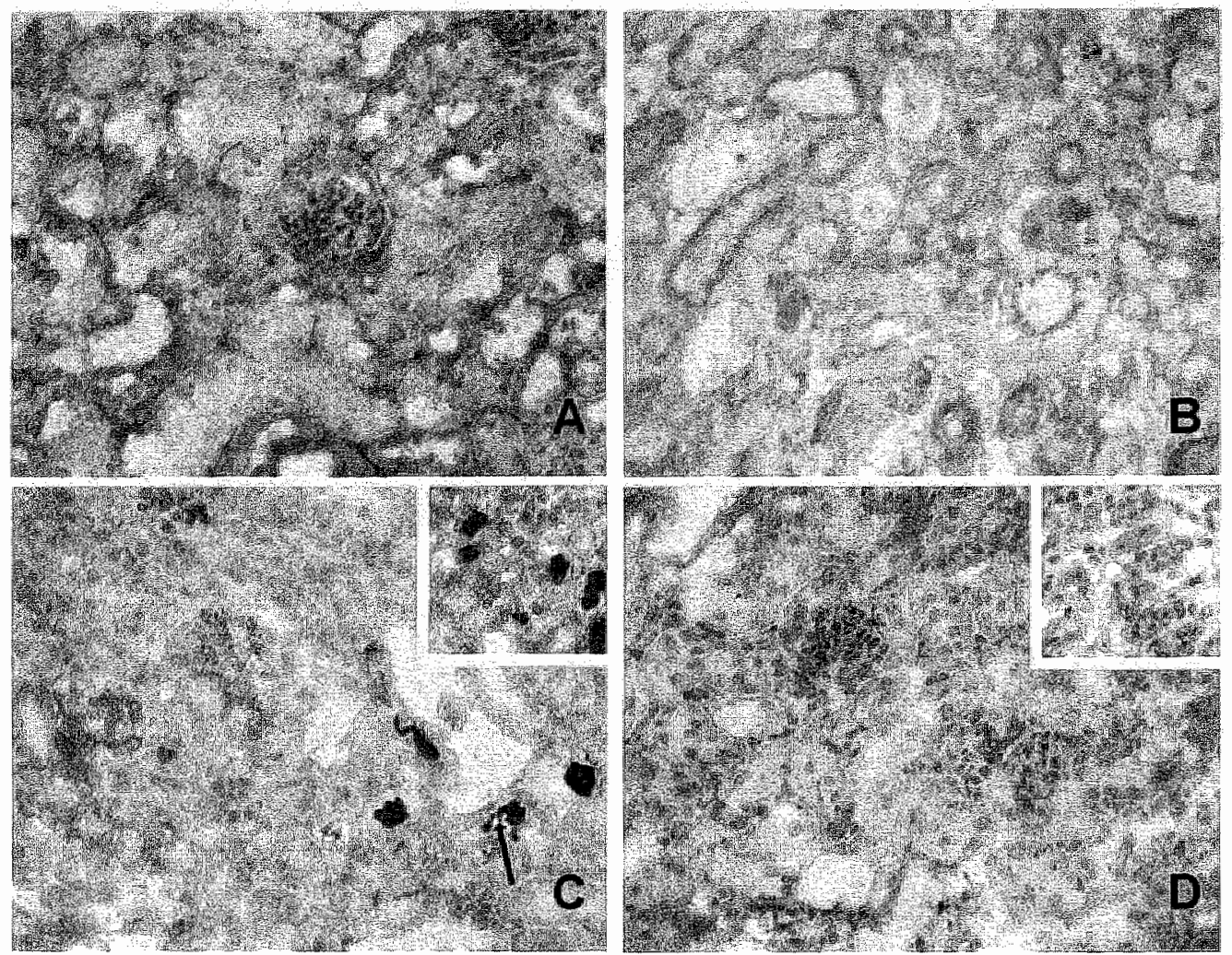

Figure 3. Renal ischemia reperfusion (I/R) induces intense staining for $C 9$, indicating Membrane Attack Complex (MAC) formation, which is totally prevented by BB5.1 treatment. Positive staining for $\mathrm{C} 9$ was observed in healthy animals (A) localized to the basement membranes of the tubular epithelium and glomeruli. After ischemia, strong tubular depositions of C 9 are seen at 24 hours of reperfusion, as shown cortex $(C)$ and medulla ( $C$ right upper corner). Whereas control antibody treatment did not effect $C 3$ deposition (data not shown) BB5. I treatment totally prevented the deposition of $C 9$ induced by $I / R_{\|}$as shown here at 24 hours of reperfusion, as shown cortex (D) and medulla (D right upper comer). Control antibody staining was neglectable (B).

\section{Inhibition of C5 prevents $/ / R$ induced inflammatory response}

The renal influx of neutrophils, an important feature of $I / R$ induced inflammation, was assessed by immunohistochemistry. Renal $1 / R$ induced a strong influx of neutrophils at 24 hours reperfusion (Figure $4 B$ ). Treatment with anti-C5 did clearly reduce the influx of neutrophils at 24 hours (Figure 4C). To quantify the neutrophil infiltration we counted NIMP-R14 positive cells in tissue sections $(n=3-4$ per kidney) of kidneys in control and experimental groups at 12 and 24 hours of reperfusion ( $n=4$ per group). Renal $I / R$ induced a gradual increase in neutrophil-influx that was maximal at 24 hours of 
reperfusion (Figure 4D). Anti-C5 treatment slightly, but significantiy, reducedneutrophil-influx at 12 hours and totally abrogated further neutrophil-influx at 24 hours of reperfusion (Figure 4D). No differences in neutrophil-influx were observed between control antibody and PBS treated animals $(p>0.5)$.

Next, we investigated whether complement activation is responsible for the generation of pro-inflammatory cytokines involved in recruitment of inflammatory cells. We determined renal mRNA levels of TNF- $\alpha$ as well as the mouse CXC-chemokines KC, MIP-2 and LIX. Here, we show that the induction of MIP-2, KC as well as LIX is strongly inhibited after BB5.1 treatment (Figure 5). Typically, the inhibitory effect is most pronounced at 24 hours of reperfusion, which correlates with the inhibitory effect on neutrophil-influx. In contrast, BB5.1 treatment did not effect the $1 / R$-induced renal expression of TNF- $\alpha$ (Figure 5).

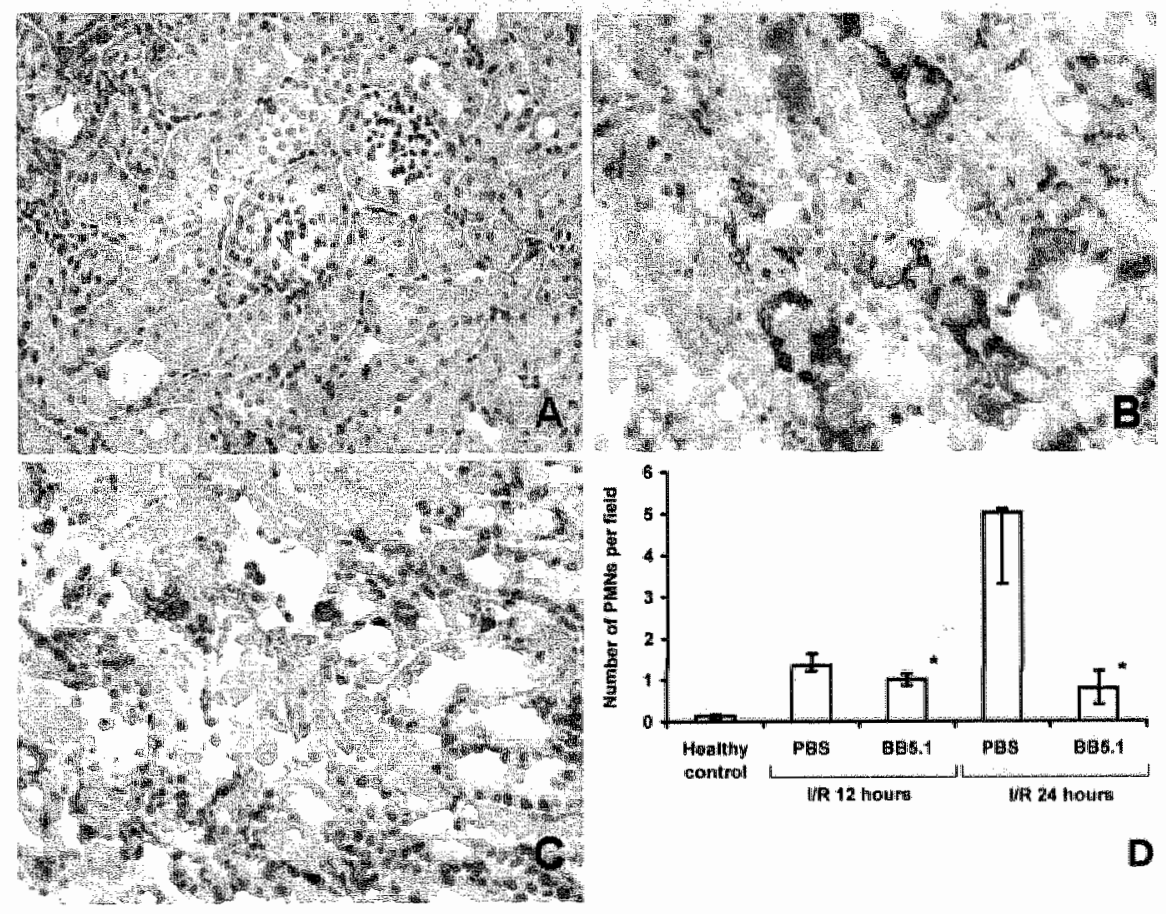

Figure 4. Renal ischemia-reperfusion induces neutrophil influx, which is significantly reduced by inhibition of $C 5$. Neutrophils were scarcely present in kidneys obtained from healthy or sham operated mice (A). Ischemia followed by 24 hours reperfusion led to a strong influx of neutrophils, mainly localized to the corticomedullary region (B). Treatment with BB5.I strongly reduced the influx of neutrophils at 24 hours of reperfusion $(C)$. Neutrophils were counted $(3-4$ sections per kidney, 4 kidneys per group), data are expressed as the median of number of neutrophils per field of vision with interquartile ranges (D). Statistical significance as compared to PBS treated animals at the same time-point was denoted at $p<0.05(\%)$. Control antibody treatment did mat effect neutrophil influx as compared to PBS treated animals $(p>0.5)$. 

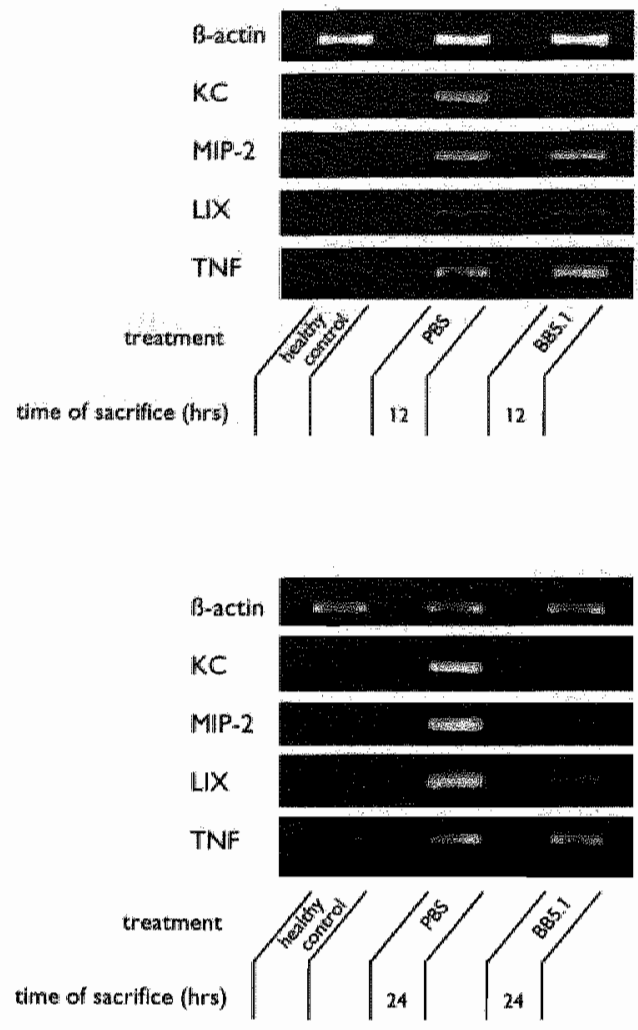

Figure 5. BB5.1 treatment inhibits ischemia-reperfusion (I/R) induced upregulation of KC, MIP-2 and $L I X$ MRNA levels. Renal I/R induces a significant upregulation of $K C, M I P-2, L I X$ and TNF- $\alpha$ at 12 and 24 hours ( $A$ and $B$ respectively). Treatment with $B B 5.1$ stronglly inhibits expression of $K C$ at 72 hours reperfusion, whereas at this time of reperfusion BB5.1 had no effect on MIP- 2 and LIX-levels (A). At 24 hours of reperfusion, BB5.1 significantly reduced the expression of KC, MIP2 and $L I X(B)$. The induction of TNF-a was not effected by BB5.1 treatment. Shown are representative samples ( $n=3$ per group) calibrated against equal amounts of $B$-actin mRNA.

\section{Inhibition of C5 prevents late I/R-induced apoptosis}

Previously, we demonstrated that apoptosis plays a crucial role in renal $I / R$ injury. Since MAC is capable of inducing apoptosis in several models of experimental nephritis, we examined whether inhibition of $C 5$, which abrogated MAC formation, inhibits apoptosis. Typical DNA-cleavage was detected at 2, 12 and 24 hours of reperfusion in ischemic kidneys obtained from controltreated mice. BB5.1 did not affect apoptosis present at 2 and 12 hours of reperfusion. In contrast, apoptosis was strongly inhibited at 24 hours of reperfusion compared to control treated mice (Figure 6). 


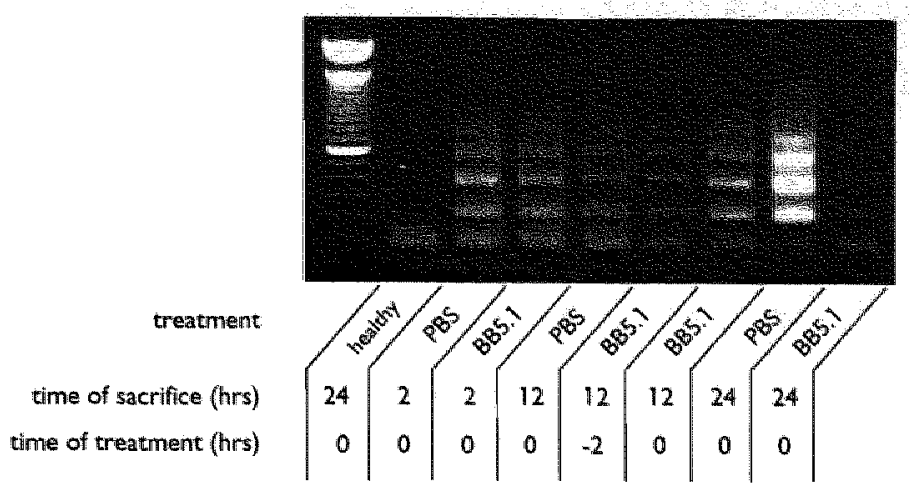

Figure 6. Anti-C5 treatment prevents late ischemia-reperfusion induced apoptosis. The extent of renal apoptosis was reflected by fragmented DNA amplified by LM-PCR and visualized on ethidiumbromide-stained gel. In PBS treated animals internucleosomal DNA cleavage was evident after 2 , 12 and further increased after 24 hours of reperfusion. Treatment with BB5.1 or control antibody did not effect early internucleosomal DNA cleavage, whereas late apoptosis was totally prevented by BB5.1. Data shown are representative for 3 independent ass.ays on different renal samples $(n=3$ per group). $M_{0} 100$ base pairs molecular weight marker.

In order to obtain a better tissue distribution of the anti-C5 antibody at the early phase of reperfusion mice were pretreated with BB5.1, 2 hours prior to ischemia. Also pretreatment did not prevent early apoptosis (Figure 6). Taken together, inhibition of complement factor $\mathrm{C} 5$ did not effect early apoptosis after I/R but rather prevented late apoptosis. The inhibitory effect on late apoptosis correlated with the above reported inhibition of MAC formation.

\section{Inhibition of C5 prevents I/R-induced renal dysfunction}

Next, we investigated whether inhibition of $\mathrm{C} 5$, that prevents MAC-formation as well as C5a generation, and abrogates late apoptosis and inflammation is accompanied by improvement of organ function. Therefore, we determined renal function by measurement of serum creatinine and blood urea nitrogen (BUN) 24 hours upon reperfusion. Compared with PBS or control antibody treated animals, treatment with BB5.1 during ischemia significantly reduced creatinine as well as BUN content. No difference was observed between PBS and control antibody treated animals $(p=0.53$ for serum creatinin and $p=0.41$ for BUN). The control treated group showed a median creatinine of 391.3 $\mu \mathrm{mol} / \mathrm{I}$ and $\mathrm{BUN}$ of $64.5 \mathrm{mmol} / \mathrm{I}$ which was strongly reduced by BB5.1 treatment to $157.5 \mu \mathrm{mol} / /$ respectively $21.9 \mathrm{mmol} / /(\mathrm{p}<0.05)$ (Figure 7 ). 

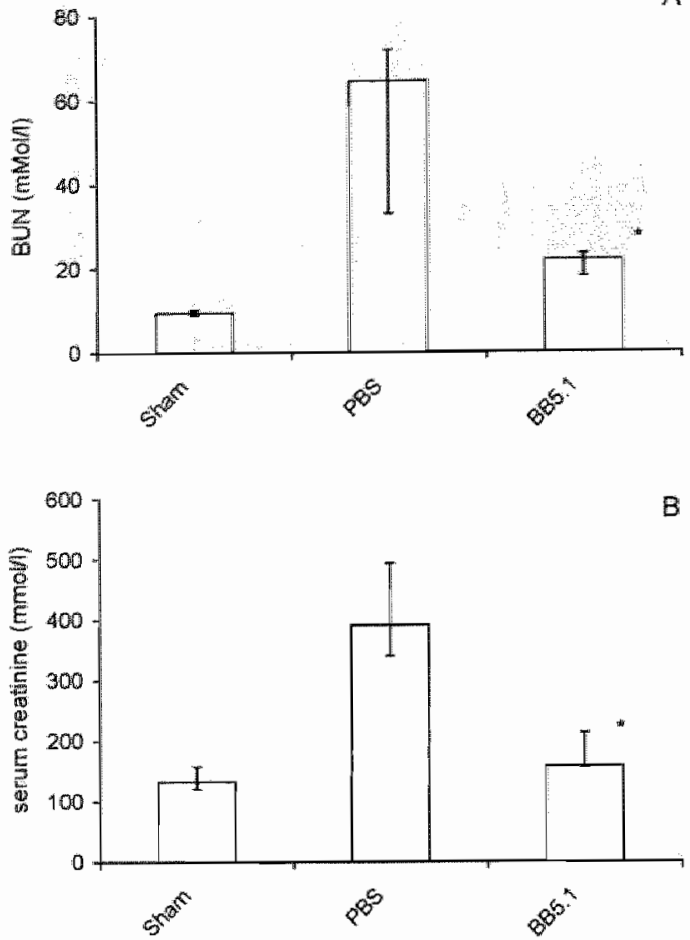

Figure 7. Renal function after 24 hours in the different experimental groups as reflected by blood urea nitrogen (BUN) (A) and serum creatinine (B). Statistical significance as compared to control treated animals was denoted at $\mathrm{p}<0.05$ (\%). Renal function did not differ between contral antibody and PBS treated animals $(p=0.41$ for BUN and $p=0.53$ for serum creatinin). The data shown are medians with interquartile ranges.

\section{DISCUSSION}

In this study, we investigated the involvement of complement-activation in renal $\| / R$. In line with others, the presence of complement factors in healthy kidneys, localized to basement membranes of tubular and glomerular epithelium [29]. In our model, deposition of C3 occurred early after reperfusion, localized to cellular debris and injured tubular epithelial cells. These data are supported by studies showing $C 3$ deposition in rodent kidney after $I / R$ and in infarcted human kidney $[12,15,29]$. For the first time, we showed that renal I/R leads to strong deposition of $C 6$ and $C 9$, representing MAC formation. Interestingly, intrarenal deposition of $\mathrm{C} 6$ and $\mathrm{C} 9$ has previously been reported in old infarcted areas of human post-mortem kidneys [29]. Compared to cardiac and intestinal ischemia complement deposition occurred relatively late in our murine model of renal I/R injury. We observed no MAC formation before 
12 hours of reperfusion. In contrast, in a rat model of myocardial ischemia MAC formation was present as early as at 3 hours after induction of ischemia [14]. Also after intestinal ischemia in a rat model MAC formation was seen early, at 1 hour reperfusion [16]. These differences may be explained by the fact that in renal I/R injury the primary target for complement attack is not the endothelium as reported for intestinal and especially cardiac ischemia, but rather the renal parenchyma. Especially proximal tubular epithelial cells, express relatively low amounts of complement regulatory proteins such as CD46, CD55 and CD59, making these cells potentialy susceptible to complement attack [30]. This fits well with our observations that formation of the MAC is mainly localized to the tubular epithelium.

The MAC has been reported to mediate neutrophil influx and to induce apoptosis and necrosis [19-21]. Experiments with complement-deficient $\left(C 6^{-1}\right)$ animals indicated that the MAC is essentially involved in the development of renal disease such as $I / R$ injury and experimental glomerulonephritis $[12,23-25]$. Our data show that renal MAC formation can be pharmacologically prevented by inhibition of $\mathrm{C} 5$-activation. Administration of the monoclonal anti-murine C5 antibody BB5. 1 totally abrogated I/R-induced renal deposition of $\mathrm{C} 6$ as well as C9. Inhibition of the complement system at the level of complement factor $C 5$ in rat models of myocardial and intestinal $1 / R$ injury indicated that inhibition of $\mathrm{C} 5$ is protective against organ damage upon reperfusion $[13,16]$. Interestingly, inhibition of $C 5$ in our renal model of I/R injury also prevented extensive deposition of $C 3$. As far as we know, no direct feedback-mechanism between $C 5$ and $C 3$ activation has been described. However, inhibition of the formation of $\mathrm{C} 5 \mathrm{a}$ and MAC could well have reduced secondary cellular damage and inflammation. This may subsequently prevent ongoing $C 3$ deposition. The pathways that activate the complement-system in the course of renal I/R injury remain to be elucidated. In myocardial $I / R$ models, recent work indicates that the mannose-binding lectin as well as the classical activation pathways are crucially involved in I/R injury [31,32]. Others showed that C4-deficient mice, in contrast to C3-deficient mice, are not protected against $1 / R$ injury indicating the involvement of the alternative pathway [12].

Influx of neutrophils is an important aspect of renal I/R injury $[6,8,11]$. In this study, administration of the anti-C5 mAb significantly inhibited the influx of neutrophils after $I / R$, starting at 12 hours of reperfusion, totally abrogating the infiltration of neutrophils between 12 and 24 hours of reperfusion. These data indicate that activation of $C 5$ is central to the influx of neutrophils. Activation of $C 5$ results in the formation of $C 5 a$ and $C 5 b$, the latter being the first step in MAC-formation. Both $\mathrm{C} 5 \mathrm{a}$ and MAC have been reported to be involved in the induction of cytokines and chemokines among others TNF $-\alpha, K C$ and MIP-2 which are known to be up-regulated in I/R injury. As a potent chemotactic factor, C5a may also directly mediate neutrophil influx 
upon I/R injury. Recently, KC and MIP-2 have been shown to be functionally involved in $1 / R$-induced neutrophil-influx, whereas Chandrasekar et al. showed that in myocardial $I / R$ the recruitment of neutrophils is largely dependent on LIX rather than KC and MIP-2 $[10,11]$. Here, we show for the first time that the induction of chemokines upon renal $I / R$ is largely dependent on complement-activation, since inhibition of the complement-system using anti-C5 strongly inhibits the induction of the chemokines $L I X, K C$ and MIP-2. Moreover, this paper is the first to describe the induction of LIX after renal $I / R$. The contribution of these different chemokines to neutrophilinflux in the course of renal $/ / R$ remains to be elucidated.

Interestingly, anti-C5 treatment did not effect the $1 / R$-induced up-regulation of TNF- $\alpha$, this in contrast to work of Wada et al. who showed that inhibition of $\mathrm{C} 5$ significantly inhibited local TNF-a expression after intestinal I/R injury [16]. This may be explained by the fact that local TNF- $\alpha$ expression is an early feature of renal $/ / R$ injury, already occurring during ischemia and early reperfusion, probably induced by oxygen free radicals and less dependent on complement activation [9].

We have previously reported that apoptosis in the later phase of reperfusion (18-24 hours) is strongly related with inflammation and loss of renal function [7]. C5a as well as MAC are potentially involved in the induction of apoptosis in the course of renal I/R. C5a is capable to induce apoptosis in thymocytes and neurablastoma cells [33, 34]. Moreover C5a activated neutrophils and their products may cause epithelial apoptosis $[35,36]$. In vitro, the MAC can also directly induce apoptosis [21,22]. Indeed, recent studies in experimental glomerulonephritis have shown that the MAC is essentially involved in apoptosis of mesangial cells and glomerular endothelial cells [2325]. Our data show that inhibition of $C 5$ totally abrogated the occurrence of late apoptosis after renal I/R. Which mechanism underlies complement-mediated apoptosis and which cells die by apoptosis after complement-attack upon renal $I / R$ remains to be resolved.

In contrast to our data, complement inhibition using the rodent $\mathrm{C} 3-\mathrm{conver-}$ tase inhibitor Crry-lg appeared not protective in murine renal $1 / R$, which suggested that the complement system is not essentially involved in renal $1 / R$ injury [37]. The model used in this elegant study is characterized by a very short duration of renal ischemia (20-30 minutes) compared to studies of Zhou et al. and ours that show the involvement of the complement system in renal $I / R$ injury [12]. This could indicate that such a relatively mild ischemic insult does not lead to complement-dependent injury [37]. 
In conclusion, renal $1 / R$ induces complement activation and intra-renal deposition of MAC. Anti-C5 treatment, preventing MAC formation and $\mathrm{C} 5 \mathrm{a}$ generation abrogates late apoptosis and strongly reduces chemokineinduction and neutrophil-influx. These data show that complement-activation is crucially involved in the regulation of both apoptosis and inflammation in the course of renal I/R injury. Moreover, complement-inhibition is strongly protective against the development of renal failure upon $I / R$ injury.

\section{REFERENCES}

1. Daemen: MA, van 't Veer $C$, Denecker $G$, et al. Inhibition of apoptosis induced by ischemlareperfusion prevents inflammation. J Clin Invest 1999; 104 (5): 541 .

2. Yaoita $H$, Ogawa $K$, Maehara $K$, Maruyama $Y$. Attenuation of ischemia/reperfusion injury in rats by a caspase inhibitor. Circulation 1998;97(3):276.

3. Endres $H$, Namura $S$, Skimizu-Sasamata $M$, et al. Attenuation of delayed neuronal death after mild focal ischemia in mice by inhibition of the caspase family. J Cereb Blood Flow Metab 1998; $18(3): 238$.

4. Ikeda $H$, Suzuki $Y$, Suzuki $M$, et al. Apoptosis is a major mode of cell death caused by ischaemia and ischaemia/reperfusion injury to the rat intestinal epithelium. Gut $1998_{i: 42}$ (4): 530 .

5. Cursio $\mathbb{R}$, Gugenheim $\rfloor$, Ricci $\mathbb{E}$, et al. A caspase inhibitor fully protects rats against lethal normothermic liver ischemia by inhibition of liver apoptosis. FASEB \1999;13 (2): 253.

6. Heinzelmainn $M$, Mercer JM, Passmore JC. Neutrophils and renal fallure. Am J Kidney Dis $1999 ; 34(2): 384$.

7. Daemen MA, van de Ven MW, Heineman $\mathbb{E}$, Buturman WA. Involvement of endogenous interleukin-10 and tumor necrosis factor-alpha in renal ischemia-reperfusion injury. Transplantation 1999;67 (6): 792 .

8. De Greef KE, Ysebaert DK, Ghielli $M$, et al. Neutrophils and acute ischemia-reperfusion injury. J Nephrol 1998; 11 (3): 110.

9. Domnahoo KK, Meng X, Ayala A, Cain MP, Harken AH, Meldrum DR. Early kidney TNF-alpha expression mediates neutrophil infiltration and injury after renal ischemia-reperfusion. Am J Physiol 1999; 277: R922.

10. Chandrasekar B, Smith JB, Freeman GL. Ischemia-reperfusion of rat myocardium activates nuclear factor-KappaB and induces neutrophil infiltration via lipopolysaccharide-induced CXC chemokine. Circulation 2001; 103 (18): 2296.

11. Miura $M$, Fu $X$, Zhang $Q W$, Remick DG, Fairchild RL. Neutralization of gro-alpha and macrophage inflammatory protein- 2 attenuates renal ischemia/reperfusion injury. Am $J$ Pathol 2001;159(6): 2137.

12. Zhou $W$, Farrar $C A$, Abe $K$, et al. Predominant role for $C 5 b-9$ in renal ischemia/reperfusion injury. J Clin Invest 2000; 105 (10): 1363.

13. Vakeva AP, Agah A, Rollins SA, Matis LA, Li L, Stahl GL. Myocardial infarction and apoptosis after myocardial ischemia and reperfusion: role of the terminal complement components and inhibition by anti-C5 therapy. Circulation 1998; 97 (22): 2259.

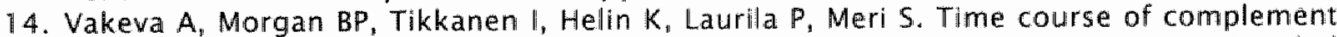
activation and inhibitor expression after ischemic injury of rat myocardium. Am J Pathol 1994: $144(6): 1357$.

15. Stein $J H$, Osgood RW, Barnes $\rfloor \mathbb{L}$, Reineck $H J$, Pinckard RN, MCManus $L M$. The role of com plement in the pathogenesis of postischemic acute renal failure. Miner Electrolyte Metab $1985 ; 11(4): 256$. 
16. Wada $K_{\text {, Montalto }} M C_{\text {i }}$ Stah GL Inhibition of complement $C 5$ reduces local and remote organ injury after intestinal ischemia/reperfusion in the rat. Gastroenterology $2001 ; 120(1): 126$.

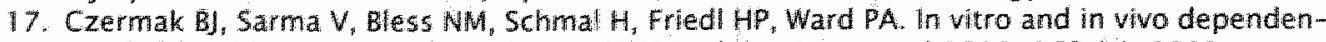
Cy of chemokine generation on C5a and TNF-alpha. Jl Immunol 1999; 162 (4): 2321.

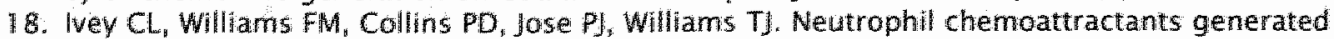
in two phases during reperfusion of ischemic myocardium in the rabbit. Evidence for a role for C5a and interleukin-8. J Clin Invest 1995;95 (6):2720.

19. David $\$$, Biancone L Caserta $C$, Bussolati B, Cambi $V$, Camussi $G$. Altemative pathway complement activation induces proinflammatory activity in human proximal tubular epithelial Cells. Nephrol Dial Transplant 1997; $12(1): 51$.

20. Kilgore $\mathrm{KS}$, Flory CM, Miller BF, Evans VM, Warren $\mathrm{S}$. The membrane attack complex of complement induces interleukin-8 and monocyte chemoattractant protein-1 secretion from human umbilical vein endothellal cells. Am J Pathol 1996; 149 (3): 953.

21. Cragg MS, Howatt WJ, Bloodworth L, Anderson VA, Morgan BP, Glennie MJ. Complement mediated cell death is associated with DNA fragmentation. Cell Death Differ $2000 ; 7$ (1):48.

22. Nauta Al, Daha MR, Tijsma O, wan De Water B, Tedesco F, Roos A. The membrane attack complex of complement induces caspase activation and apoptosis. Eur J Immunol 2002;32 (3): 783 .

23. Hughes J, Nangaku M, Alpers. CE, Shankland 5 J, Couser $W G_{*}$ Johnson RJ. C5b-9 membrane attack complex mediates endothelial cell apoptosis in experimental glomerulonephritis. Am J Physiol 2000; 278 (5): $F 747$.

24. Sato $T$, Van Dixhoom MG, Prins FA, et al. The terminal sequence of complement plays an essential role in antibody-mediated renal cell apoptosis. J Am Soc Nephrol 1999; 10 (6) 242 .

25. Shimizu A, Masuda $Y$, Kitamura $H$, et al. Complement-mediated killing of mesangial cells in experimental glomerulonephritis: cell death by a combination of apoptosis and necrosis. Nephron 2000; 86. (2): 152.

26. Frel $Y$, Lambris JD, Stockinger B. Generation of a monoclonal antibody to mouse C5 application in an ELISA assay for detection of anti-C5 antibodies. Mol Cell Probes 1987; 1 (2): 141.

27. Wang $Y$, Rollins SA, Madri JA, Matis LA. Anti-C5 monoclonal antibody therapy prevents collagen-induced arthritis and amellorates established disease. Proc Natl Acad Sci US A 1995 92 (19): 8955.

28. Klerx JP, Beukelman Cl, Van Dijk H, Willers JM. Microassay for colorimetric estimation of complement activity in guinea pig, human and mouse serum. I lmmunol Methods 1983; 63 (2): 215.

29. Vakeva $A$, Meri $S$, Lehto $T$, Laurila $P$. Activation of the terminal complement cascade in renal infarction. Kidney Int 1995: 47 (3): 918.

30. Ichida S, Yuzawa $Y$, Okada H, Yoshioka K, Matsuo S. Localization of the complement regulatory proteins in the normal human kidney. Kidney Int 1994; 46 (1): 89.

31. Jordan JE, Montalto MC, Stáhl GL, Inhibition of mannose-binding lectin reduces postischemic myocardial reperfusion injury. Circulation 2001; 104 (12): 1413.

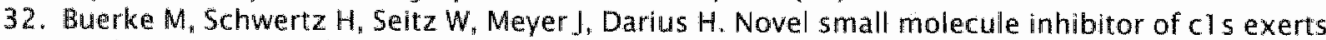
cardiaprotective effects in ischemia-reperfusion injury in rabbits. J Immunol 2001; 167 (9): 5375 .

33. Guo RF, Huber-Lang $M_{n}$ Wang $X_{\text {, }}$ et al. Protective effects of anti-C5a in sepsis-induced thymocrte apoptosis. J Clin Invest 2000; $106(10): 1271$.

34. Farkas I, Baranyi L, Liposits ZS, Yamamoto T, Okada H. Complement CSa anaphylatoxin fragment causes apoptosis in TCW neuroblastoma cells. Neuroscience 1998; 86 (3): 903.

35. Serrao KL, Fortenberry JD, Owens ML, Harris. FL, Brown LA. Neutrophils induce apoptosis of lung epithelial cells via release of soluble Fas ligand. Am J Physiol 2001; 280 (2): L298.

36. Yang J. Preston GA, Pendergraft WF, et al. Internalization of proteinase 3 is concomitant with endothelial cell apoptosis and internalization of myeloperoxidase with generation of intracellular oxidants. Am J Patholl 2001; 158 (2): 581.

37. Park P, Haas $M$, Cunningham $P N$, et all. Inhibiting the complement system does not reduce injury in renal ischemia reperfusion. 1 Am Soc Nephrol 2001: 12 (7): 1383 . 


\section{CHAPTER}

Complement factor C5a mediates renal ischemia-
reperfusion injury independent from neutrophils

Bart de Vries, Jörg Köhl, Wouter K. G. Leclercq, Tim G. A. M. Wolfs, Annemarie A. J. H. M. van Bijnen, Peter Heeringa, and Wim A. Buurman

Journal of Immunology: 2003; 170: 3883-3889 
The complement system has been shown to mediate renal ischemia-reperfusion (I/R) injury. However, the contribution of complement-factor C5a to I/R injury, in particular in the kidney, remains to be established. In this study we investigated the impact of blocking the $C 5$ a receptor pathway on the inflammatory response and on the renal function in a murine model of I/R injury.

First, we analysed C5a receptor expression in kidneys of healthy mice. Intriguingly, we found expression on mesangial as well as on tubular epithelial cells. After I/R injury, C5aR expression was upregulated in tubular epithelial cells. In addition, mRNA levels of $C-X-C$ chemokines and TNF- $\alpha$ increased significantly and kidneys were heavily infiltrated by neutrophils. Blocking the $\mathrm{C} 5$ a receptor pathway by a specific $\mathrm{C5}$ a receptor antagonist (C5aRA) abrogated upregulation of C-X-C chemokines but not of TNF- $\alpha$ and reduced neutrophil infiltration by more than $50 \%$. Moreover, application of the C5aRA significantly reduced loss of renal function. This improvement of function was independent of the presence of neutrophils since neutrophil depletion by mAb NIMP-R14 did not affect the protective effect of C5aRA treatment. Furthermore, blocking of the $\mathrm{C} 5$ a receptor pathway had no influence on renal apoptosis.

These data provide evidence that $\mathrm{C} 5 \mathrm{a}$ is crucially involved in the pathogenesis of renal I/R injury by modulation of PMN dependent as well as PMN independent pathways, which include the regulation of $\mathrm{C}-\mathrm{X}-\mathrm{C}$ chemokines but not TNF- $\alpha$ or apoptotic pathways.

\section{INTRODUCTION}

Organ injury as a consequence of ischemia followed by reperfusion is a major clinical problem. Renal ischemia-reperfusion (I/R) injury is the most common cause of acute renal failure (ARF) as seen after renal transplantation, major abdominal and vascular surgery, coronary bypass surgery, and in trauma and sepsis [1]. I/R injury is characterised by the massive influx of neutrophils, which are believed to play a crucial role in the pathophysiology of postischemic renal failure [2,3]. The infiltration of neutrophils into tissue sites of inflammation is regulated by $\mathrm{CXC}$ chemokines such as $\mathrm{IL}-8$, Gro- $\alpha$, of which cytokine induced neutrophil chemoattractant (KC) is the murine homologue, and macrophage inflammatory protein-2 (MIP-2) [4]. The complement-system has also been shown to be an important mediator of $1 / R$ injury [5-7]. Both the formation of membrane attack complex (MAC) as well as the generation of the anaphylatoxin C5a can potentially mediate I/R injury. The MAC has been reported to mediate neutrophil influx, synthesis of 
pro-inflammatory cytokines and may cause direct cell injury, apoptosis and necrosis $[8-10]$. Responses to $C 5$ a are mediated by the $C 5 a$ receptor (C5aR), a member of the rhodopsin family of seven transmembrane-spanning Gprotein-linked receptors [11]. Activation of C5aR induces recruitment of neutrophils and macrophages, and activates these and other cells to produce cytokines, chemokines and adhesion molecules [12, 13]. Recent work has also attributed a role to $\mathrm{C} 5 \mathrm{a}$ in the regulation of apoptosis $[14,15]$.

Recently, we showed that inhibition of the complement-system by inhibition of $C 5$ activation, preventing $\mathrm{C5}$ a generation as wells as MAC formation, strongly protects against renal I/R injury [16]. Inhibition of $C 5$ abrogated the induction of chemokines and influx of neutrophils and abolished $I / R$ induced late apoptosis. Renal I/R injury has in particular been attributed to the formation of MAC, whereas $C 5$ a has been demonstrated to be involved in $I / R$ injury of the heart and the intestine $[5,17-20]$. No specific data currentlly exist concerning the role of $C 5 a$ in renal $I / R$.

Therefore, we analysed the role of $\mathrm{C} 5 \mathrm{a}$ in $\mathrm{I} / \mathrm{R}$ injury using a specific $\mathrm{C} 5 \mathrm{a}$ receptor antagonist. Our findings give evidence that the $C 5$ a receptor pathway becomes activated in $1 / R$ injury and mediates renal dysfunction as a consequence of a strong $\mathrm{C} 5 \mathrm{a}$ induced inflammatory response and tissue damage, which involves neutrophil dependent as well as neutrophil independent pathways.

\section{MATERIALS AND METHODS}

\section{Antibodies and reagents}

For in vivo studies, a C5a receptor antagonist (C5aRA) was used. This C5aRA has been shown to neutralise C5a function in vitro and in vivo [20]. NIMPR14 (rat anti-mouse neutrophil mAb) was kindly provided by Dr. M. Strath (National Institute for Medical Research, London, UK). This monoclonal antibody has in vivo neutrophil-depleting capacity [21]. Rabbit anti-mouse C5a receptor $\mathrm{pAb}$ (C5aR) was a kind gift from Dr. J. van Beek (College of Medicine, University of Wales, Cardiff, UK).

Secondary peroxidase conjugated goat anti-rabbit and goat anti-rat IgC antibodies were purchased from Jackson (West Grove, PA). FITC-conjugated and Texas-Red-conjugated secondary antibodies were purchased from PickCell Laboratories (Amsterdam, the Netherlands) and Southern Biotechnology Associlates (ITK Diagnostics, Uithoorn, the Netherlands) respectively. All other reagents were purchased from Sigma (St. Louis, MO). 
Male Swiss mice weighing 20-25 g were obtained from Charles River Breeding Laboratories (Heidelberg, Germany). Animals were housed individually in standard laboratory cages and were allowed free access to food and water throughout the experiments. The studies were carried out under a protocol approved by the Institutional Animal Care Committee of the University of Maastricht. At the start of the experiments, mice were anaesthetised with sodium pentobarbital $(100 \mathrm{mg} / \mathrm{kg}$ i.p.). Body temperature was maintained at $39^{\circ} \mathrm{C}$ by a heating pad until animals recovered from anaesthesia. Under aseptic conditions a $1.0 \mathrm{~cm}$ long midline abdominal incision was made and ischemia was induced by applying a non-traumatic vascular clamp to the left renal pedicle for 45 minutes. Subsequently, the wound was covered with cotton soaked in sterile PBS. After removal of the clamp the left kidney was inspected for restoration of blood flow and the contralateral kidney was removed. The wound was closed in two layers and $0.25 \%$ bupivacaine was applied topically for postoperative pain management. The animals were sacrificed at indicated time-points after reperfusion. At the time of sacrifice, blood was collected and the left kidney was harvested for analysis. Renal tissue was divided into representative pieces for the different assays. For immunohistochemistry total cross-sections were embedded in OCT compound and immediately frozen in isopentane / dry ice. For apoptosis and mRNA assays kidney pieces were snap frozen in liquid nitrogen. Tissue samples were divided in four equal parts in a standardized fashion resulting in similar cortex-medulla ratios in each sample.

Mice ( $n=6$ per group) were subjected to ischemia and treated with C5aRA or PBS. Pharmacological interventions were given intraperitoneally, based on pilot experiments, fifteen minutes prior to removal of the clamps, 1 and 2 hours after reperfusion $\left(3 \times 100 \mu 11.8^{*} 10^{-5} \mathrm{M}\right.$ C5aRA dissolved in PBS, or $3 \times$ $100 \mu \mathrm{PBS})$. In separate experiments, neutrophils were depleted using mAb NIMP-R $14(1 \mathrm{ml}$ of $1 \mathrm{mg} / \mathrm{ml}$ in PBS), i.p. 6 hours before induction of ischemia, which has been shown to deplete neutrophils for several days [21].

\section{Renal Histology}

Cryostat sections $(5 \mu \mathrm{m})$ of frozen tissue were fixed with acetone and stained for $C 5 a R$, using a rabbit anti-mouse C5aR pAb, and for neutrophils, using MAb NIMP-R 14.

Staining was either visualized by 3-amino-9-ethylcarbazole (AEC) followed by hematoxylin counterstain or immunofluorescence. No significant staining was detected in slides incubated with control rabbit serum (for C5aR) and rat IgG (for NIMP-RI4) instead of the primary antibody indicating the absence of significant background staining. Neutrophils were quantified in complete cross-sections by examining 20 fields of vision per kidney section (3-4 sections per kidney) at $\times 200$ magnification in a blinded fashion. 
Apoptosis assay

Presence of internucleosomal DNA cleavage in kidneys was investigated with a commercial ligase mediated (LM)-PCR assay kit (Apoalert, Clontech, Palo Alto, CA) enabling semiquantitative measurement of the extent of apoptosis. In brief, DNA was isolated from renal tissue samples employing a commercilally available DNA purification kit (Promega, Madison, WI). DNA purity and concentration were determined by electrophoresis through a $0.8 \%$ agarose gel containing ethidium bromide followed by visualisation under ultraviolet illumination as well as by measuring absorbance at $260 / 280 \mathrm{~nm}$. Dephosphorylated adaptors were ligated to 5 '-phosphorylated blunt ends with T4 DNA ligase (during $16 \mathrm{~h}$ at $16^{\circ} \mathrm{C}$ ) and served as primers in a LM-PCR. Amplified DNA was subjected to gel electrophoresis on a 1.2\% agarose gel containing ethidium bromide.

Measurement of Renal C5aR, MIP-2, KC and TNF-a MRNA Levels by Reverse Transcriptase-PCR

For RT-PCR total RNA was extracted from kidneys using the SV Total RNA isolation system (Promega) and treated with RQ1 RNase-Free DNase (Promega). Total RNA was reverse transcribed using oligo (dT) primer and Moloney murine leukemia virus reverse transcriptase (Life Technologies, Paisley, UK).

For semiquantitative PCR analysis CDNA samples were standardised based on the content of $B$-actin CDNA as housekeeping gene. $B$-actin CDNA was evaluated by performance of a $B$-actin PCR on multiple dilutions of each CDNA sample. The amount of amplified product was estimated by densitometry of ethidiumbromide stained $1.2 \%$ agarose gels using a CCD camera and Imagemaster VDS software (Pharmacia, Uppsala, Sweden). Primers used for the amplification of murine $B$-actin were: $5^{\prime}$-TAA AAC GCA GCT CAG TAA CAG TCG G-3' (sense primer) and 5'-TGC AAT CCT GTG GCA TCC ATG AAA C-3' (antisense primer). To determine renal C5aR, MIP-2 and KC mRNA expression, $P C R$ reactions with specific primers were performed using appropriate dilutions of the cDNA. The sequences of these specific primers were as follows: C5aR: 5'-ATT GCT CCT CAC CAT TCC ATC-3' "sense) and 5"-TGA TAC GGC AGC CAG AAC ATA-3' (antisense); MIP-2: 5'-TGC CGG CTC CTC ACT GCT G3" (sense) and 5'-AAA CTT TTT CAC CGC CCT TGA-3' (antisense); KC: $5^{\circ}-$ CGC TCG CTT CTC TGT GCA-3' (sense) and 5'-ATT TTC TGA ACC AAG GGA GCT3" (antisense); TNF- $\alpha$ : 5'-GGC AGG TCT ACT TTG GAG TCA TTG C-3' (sense)and 5'-ACA TTC GAG GCT CCA GTG AAT TCC G-3' (antisense). For each primer couple the following PCR conditions were used: $C 5 \mathrm{aR}: 95^{\circ} \mathrm{C}$ for $30 \mathrm{sec}, 60^{\circ} \mathrm{C}$ for $30 \mathrm{sec}, 72^{\circ} \mathrm{C}$ for $30 \mathrm{sec}$ during 40 cycles; MIP-2: $95^{\circ} \mathrm{C}$ for $30 \mathrm{sec}, 55^{\circ} \mathrm{C}$ for sec, $72^{\circ} \mathrm{C}$ for sec during 34 cycles; $\mathrm{KC}: 95^{\circ} \mathrm{C}$ for $30 \mathrm{sec}, 55^{\circ} \mathrm{C}$ for $30 \mathrm{sec}, 72^{\circ} \mathrm{C}$ for $30 \mathrm{sec}$ during $35 \mathrm{cycles}$; TNF $-\alpha: 95^{\circ} \mathrm{C}$ for $30 \mathrm{sec}, 63^{\circ} \mathrm{C}$ for $30 \mathrm{sec}, 72^{\circ} \mathrm{C}$ for $30 \mathrm{sec}$ during 38 cycles. PCR reactions were performed 
in a total volume of $25 \mu \mathrm{l}$ in PCR buffer (Perkin Elmer, Boston, MA), in the presence of $0.2 \mathrm{mM}$ dNTP (Pharmacia), $1.0 \mu \mathrm{M}$ of each primer, $0.3 \mathrm{mM}$ $\mathrm{MgCl} 2$ and $0.5 \mathrm{U}$ Taq polymerase (Perkin Elmer). Levels of MIP-2 and KC expression were evaluated by densitometric image analysis, as described above. Relative MIP -2 and $K C$ levels were calculated by comparison of band intensities of the PCR products with standard curves prepared by PCR amplifications on dilution series of a highly concentrated murine renal CDNA.

Real-time quantitative RT-PCR for TNF- $\alpha$ was performed on a Taqman ABI 7700 Sequence Detection System (Applied Biosystems, Foster City, CA). $B$-actin was used as reference gene. The following oligonucleotide primers and probes were used: B-actin: 5'-GAC AGG ATG CAG AAG GAG ATT ACT G$3^{\prime}$ (sense) and 5'-CCA CCG ATC CAC ACA GAC TAC TT-3' (antisense) both at a concentration of $300 \mathrm{nM}$, and internal fluorescence-labeled probe (JOE) 5'-ATC AAG ATC ATT GCT CCT CCT GAG CGC-3' at a concentration of 200 $n$ M. TNF- $\alpha$ : 5'-CAT CTT CTC AAA ATT CGA GTG ACA A-3' (sense) and 5'TGG GAG TAG ACA ACG TAC AAC CC-3" (antisense) both at a concentration of $200 \mathrm{nM}$, and internal fluorescence-labelled probe (FAM) 5'-CAC GTC GTA GCA AAC CAC CAA GTG GA-3' at a concentration of $100 \mathrm{nM}$. All primers and probes were obtained from Applied Biosystems.

\section{Renal function}

Blood urea nitrogen (BUN) and serum creatinine were measured in serum obtained at the time of sacrifice using a Urea 25 Kit (ABX Diagnostics, Eindhoven, Holland) and a CREA MPR3 Kit (Boehringer Mannheim, Mannheim, Germany) respectively in a Cobas Fara autoanalyzer (Roche, Basle, Switzerland).

\section{Statistical analysis}

Data are expressed as medians with interquartile ranges, and statistical analysis was performed by Mann-Whitney $U$ test. $p<0.05$ was taken to denote statistical significance. 
The C5a receptor is widely expressed in the kidney

First, the renal C5aR mRNA expression was examined by RT-PCR. In kidneys of healthy male Swiss mice we found clear expression of C5aR. After renal I/R C5aR MRNA levels increased evidently (figure 1A). Immunohistochemical staining for $\mathrm{C} 5 \mathrm{aR}$ in healthy kidney revealed a faint expression on tubular epithelial cells and more intense staining of mesangial cells (figure 1B). After 24 hours reperfusion the C5aR expression in ischemic kidneys was upregulated on tubular cells. In addition, infiltrating neutrophils stained positive for the C5aR (figure 1C).

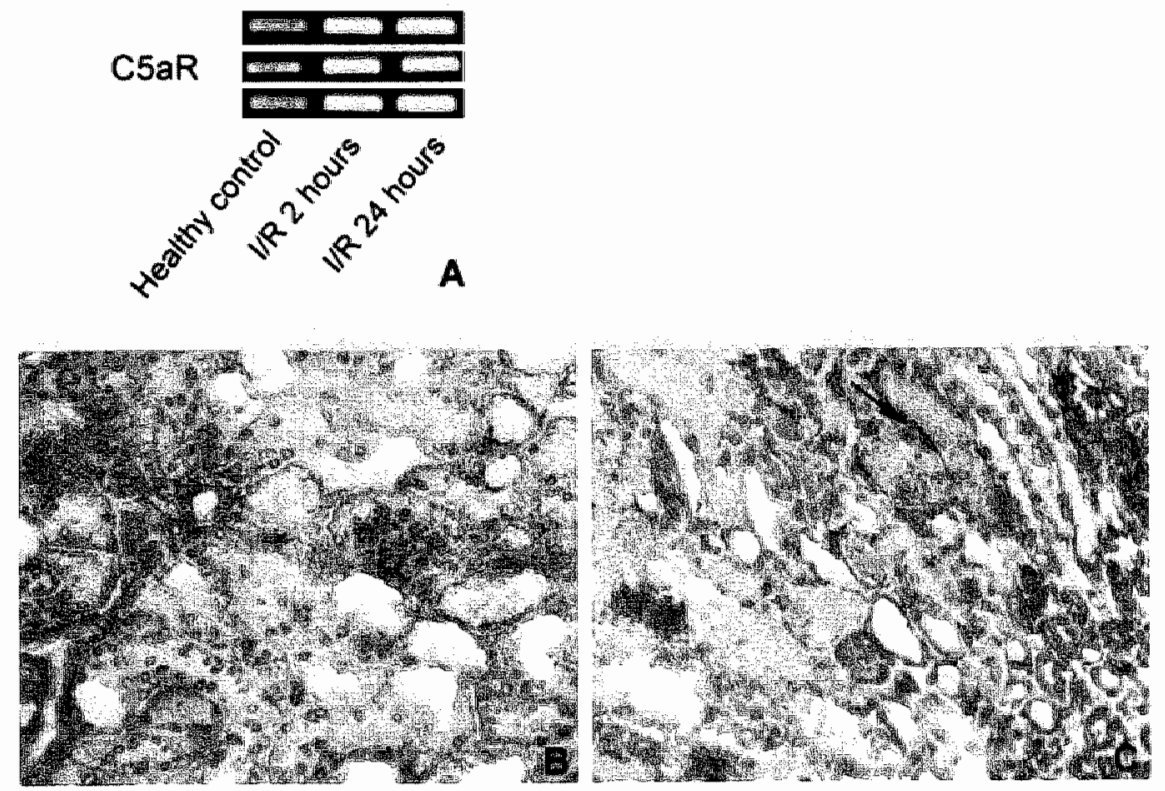

Figure 7 . Expression of $C 5$ a receptor ( $C 5$ aR) in murine kidney tissue. CSaR mRNA is present in healthy kidney tissule and is up-regulated in tissue from mice subjected to renal ischemiareperfusion $\| / R$ (A). Immunohistochemical staining shows the localisation of $C 5$ a receptor in healthy kidney tissue and 24 hours after $\| / R$ (B and $C$ respectively). In healthy kidney, $C 5 a R$ tubular as well as mesangial cells express $C 5 a R$ (B). After renal $I / R, C 5$ aR is upregulated on tubular epithelium, additionally infiltrating meutrophils (arrow) also stain positive for C5aR. Data shown are representative for experiments performed in 4 animals per group. 
To verify the hypothesis that during renal $I / R$ besides infiltrating inflammatory cells also tubular epithelial cells express the C5aR, we performed a doublestaining using immunofluorescence on tissue sections of kidneys subjected to ischemia followed by 24 hours reperfusion. Figure $2 \mathrm{~A}$ shows that renal tissue is infiltrated by neutrophils. The tubular epithelial cells show a strong positive staining for the C5aR (figure 2B). The overlay picture (figure $2 \mathrm{C}$ ) shows that all infiltrating neutrophils express the C5aR but that also tubular epithelial cells express C5aR.
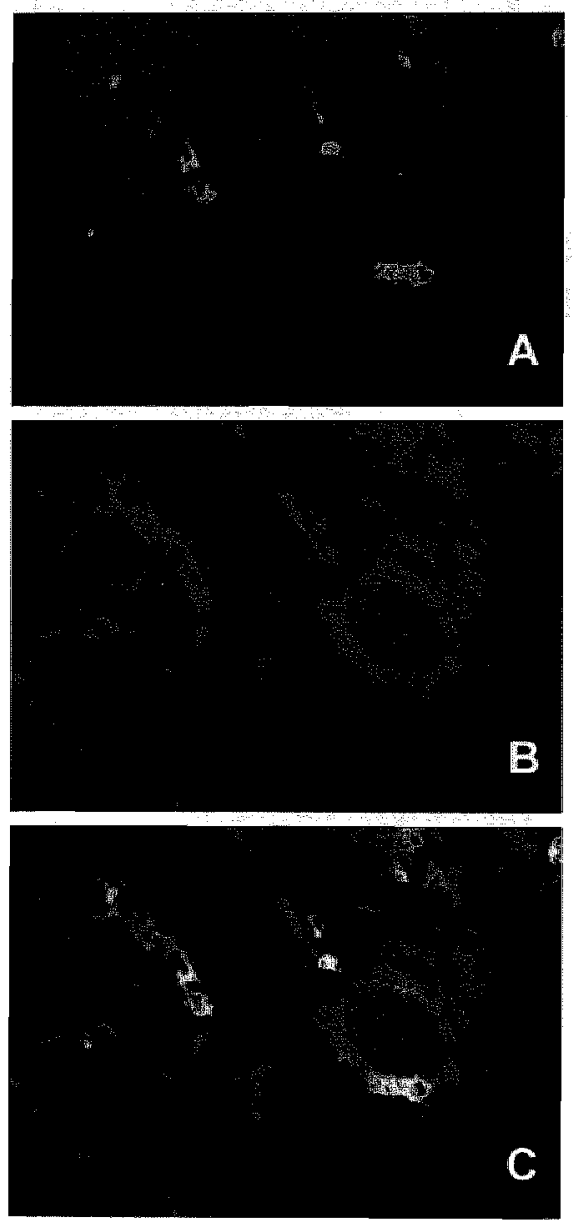

Figure 2. Immunofluorescence double-staining for infiltrating neutrophils and C5a receptor $(C 5 a R)$ on kidney tissue sections after renal ischemia-reperfusion (1/R). Infiltrating neutrophils are present at 24 hours I/R (A), besides C5aR is widely expressed in the same tissue section (B). The overlay plcture (C) shows that infiltrating neutrophils as well as tubular cells widely express $C 5 a R$. Green staining: neutrophils (FITC), red staining: C5aR (Texas-Red). These data are representative for experiments performed in 4 different animals. 
Next, the functional role of $C 5 \mathrm{a}$ in the pathophysiology of renal //R injury was studied. Blood urea nitrogen (BUN) and serum creatinine, as a measure for renal dysfunction, increased significantly from median values of $9.5 \mathrm{mmol} / \mathrm{l}$ (BUN) and $80.4 \mu \mathrm{mol} / 1$ (creatinine) in healthy controls to $58.3 \mathrm{mmol} / \mathrm{l}$ (BUN) and $245.3 \mu \mathrm{mol} / 1$ (creatinine) in animals subjected to renal ischemia followed by 24 hours reperfusion. Treatment with the C5aRA significantly reduced median BUN concentrations from 58.3 to 27.3 mmol/l as well as serum creatinin values from 245.3 to $150.2 \mu \mathrm{mol} / 1(\mathrm{p}<0.05) 24$ hours after $/ / R$ injury (figure $3 \mathrm{~A}$ and $3 \mathrm{~B}$ respectively).

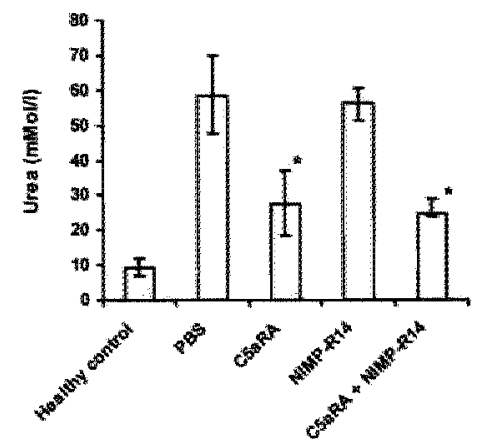

B.

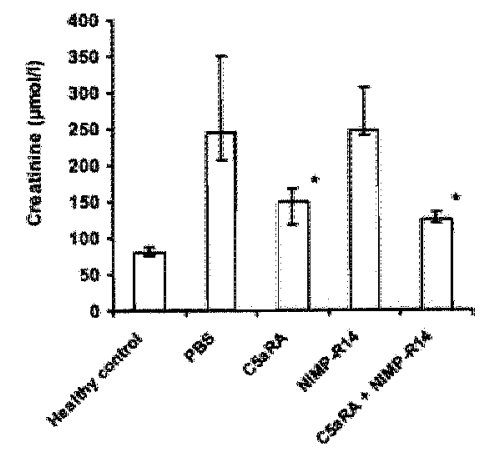

Figure 3. C5a receptor antagonist significantly reduces renal function loss after renal ischemiareperfusion ( $/ R$ ). Renal function was measured by blood urea nitrogen (BUN) (A) and serum creatinine (B) 24 hours after renal $1 / R(n=6$ per group). Renal $/ / R$ induces loss of renal function which is significantly reduced by treatment with $C 5$ a receptor antagonist (C5aRA). Neutrophill-depletion has no effect on loss of renal function, whereas treatment with CSaRA significantly reduces BUN and creatinine values in neutrophil-depleted mice. BUN-and creatinine-values are expressed as medians with interquartile ranges. Statistical significance as compared to control-treated animals was denoted at $\mathrm{p}<0.05 \%$. 

pathway

A key feature of $I / R$ injury is the influx of neutrophils. In fact, renal $/ / R$ induced a significant influx of neutrophils (median of 5.1 PMNs per field of vision) 24 hours after reperfusion. Treatment with the C5aRA significantly reduced the influx of neutrophils, to a median value of 2.3 PMNs per field of vision, compared to control treated animals $(p<0.05$; Figure 4$)$.

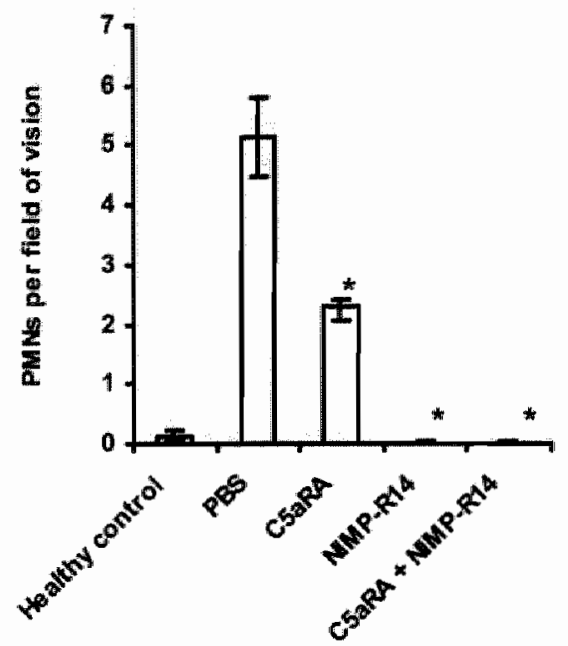

Figure 4. C5a receptor antagonist reduces neutrophil-infiltration after renal //R. Neutrophils were counted in 3-4 sections per kidney, 4 kidneys per group after immunohistochemical staining with mAb NIMP-R 14. Data are expressed as median number of neutrophils per field of vision with interquartile ranges. Statistical significance as compared to PBS treated animals was denoted at $p<0.05(*)$.

Infiltrating neutrophils mainly localized to the corticomedullary region after renal $/ / R$, the inhibitory effect of C5aRA was most pronounced in these regions (data not shown). To further analyse the mechanism of C5a mediated $I / R$ injury the role of neutrophils in the course of renal I/R injury was investigated. For this purpose, neutrophills were depleted before the induction of ischemia by administration of MAb NIMP-R14, 6 hours before renal ischemia. Neutrophil-depleted mice received either the C5aRA or control (PBS) treatment. To our surprise neutrophil-depletion did not protect against I/R induced renal dysfunction (figure 3 ). Renal function did not differ between neutrophil depleted animals and control treated animals (median BUN values of 56.4 vs $58.3 \mathrm{mmol} / \mathrm{l}$ and serum creatinine 245.3 vs $247.5 \mu \mathrm{mol} / \mathrm{l}$; both $\mathrm{p}>0.5$ ). 
These data suggest that neutrophils are not essential for renal dysfunction in the course of renal I/R injury. However, application of the C5aRA significantly protected neutrophil-depleted mice from renal failure. BUN and serum creatinine values decreased significantly from 56.4 (BUN) and 245.3 (serum creatinine) in PMN-depleted mice to $24.7 \mathrm{mmol} / /$ and $125.2 \mu \mathrm{mol} / \mathrm{l}$ in C5aRA treated mice; ( $p<0.05$; figure $3 \mathrm{~A}$ and $\mathrm{B}$ respectively). These data indicate that infiltration of neutrophils alone is not sufficient to mediate renal I/R injury. Moreover our results give evidence that activation of the complement-system and in particular triggering of the C5aR pathway is a crucial mechanism inducing renal dysfunction in $1 / R$ injury.

Induction of the CXC chemokines KC and MIP-2 and TNF- $\alpha$ in the course of renal $I / R$

$\mathrm{C} 5 \mathrm{a}$ is a powerful chemoattractant and can induce neutrophil-influx. C5a is also known to be involved in the induction of chemokine- and cytokine-production. In this context, we investigated the renal expression of the murine chemokines KC and MIP-2 in the absence or the presence of the C5aRA by semi-quantitative PCR techniques. Renal I/R induces a 2- and 5-fold upregulation of renal mRNA levels of the respective murine CXC chemokines KC and MIP-2 at 24 hours reperfusion as compared to healthy controls (figures $5 A$ and $B$ respectively). Treatment with the $C 5$ aRA completely prevented the up-regulation of $K C$ and MIP-2 mRNA (figure $5 A$ and $B$ respectively). These data give evidence that $C 5$ a plays an important role in the regulation of chemokine-induction in the course of renal $\| / R$ injury.

Another important mediator of renal I/R injury is TNF- $\alpha$. TNF- $\alpha$ mediates the induction of chemokines, subsequent neutrophil-influx but is also involved in the induction of apoptosis. Therefore, we assessed the renal expression of TNF- $\alpha$ upon renal I/R by real-time and semi-quantitative PCR. Data did not differ between real-time and semi-quantitative PCR, thus only real-time PCR data are shown. Renal $/ / R$ induced a significant 2.5 fold increase of TNF- $\alpha$ mRNA $(p<0.05)$. Interestingly, treatment with C5aRA did not effect this local up-regulation of TNF- $\alpha$ in the course of renal $I / R$ injury (figure $5 C$ ) suggesting that the $\mathrm{C} 5$ a mediated upregulation of $K C$ and MIP-2 MRNA is independent of TNF- $\alpha$. 
A

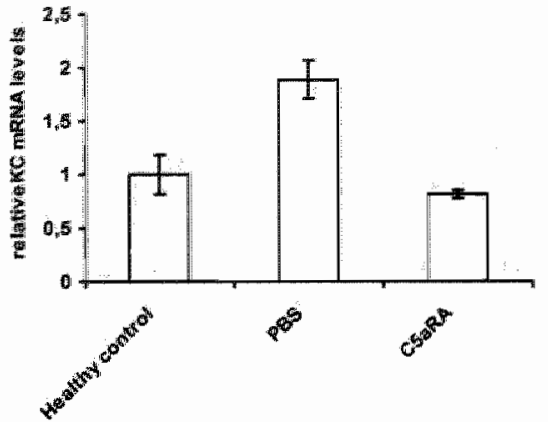

B

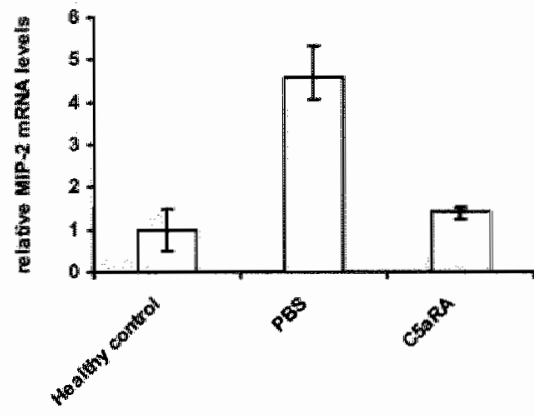

C

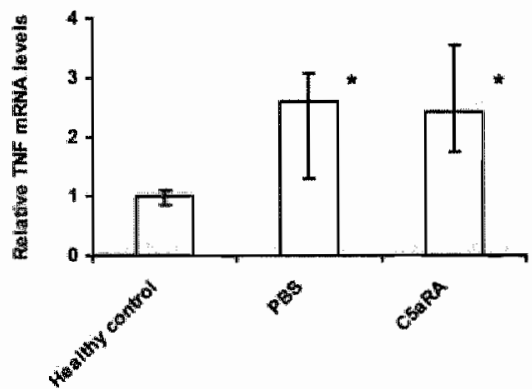

Figure 5. The C5a receptor antagonist (CSaRA) inhibits ischemiawreperfusion (I/R) induced upregulation of $K C$ and MIP- 2 mRNA levels ( $A$ and $B$ respectively) as measured by semi-quantitative PCR. Renal $I / R$ induces an evident upregulation of KC and MIP-2 at 24 hours reperfusion (A and $B$ respectively). Treatment with C5aRA abrogates the upregulation of $K C$ and MIP- 2 MRNA. Data shown are medians with interquartile ranges $(n=4$ per group) calibrated against equal amounts of B-actin mRNA. For TNF- $\alpha$ mRNA levels real-time PCR was used (C). Renal $1 / R$ induces a significant upregulation of TNF- $\alpha$ which is unaffected by C5aRA treatment (C). Data shown are medians with interquartile ranges ( $n=6$ per group) calibrated against $B$-actin mRNA levels. Statistical significance as compared to healthy controls was denoted at $p<0.05(")$. 
Renal apoptosis is an important feature in renal $I / R$ injury. We show here that renal apoptosis occurred as early as 2 hours after reperfusion which was still ongoing at 24 hours (Figure 6). Treatment with the C5aRA has no influence on the induction of renal apoptosis, neither after 2 hours nor after 24 hours of reperfusion. Thus CSa appears to be not involved in renal apoptosis in the course of renal $I / R$ injury.

treatment

time of sacrifice

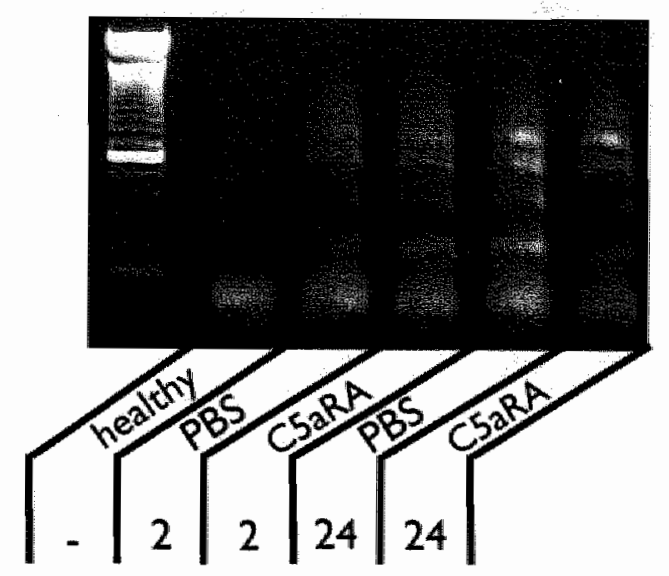

Figure 6. C5a receptor antagonist does not effect ischemia-reperfusion induced apoptosis. The extent of renal apoptosis is reflected by fragmented DNA amplified by LM-PCR and wisualised on ethidium-bromide stained gell. in PBS treated animals internucleosomal DNA cleavage was evident after 2 and 24 hours of reperfusion. Treatment with C5aRA did not effect internucleosomal DNA cleavage. Data shown are representative for 3 independent assays on different renal samples $(n=3$ per group). On the left side a 100 base pairs molecular weight marker is shown.

\section{DISCUSSION}

The complement system has been implicated in several models of $I / R$ injury [5-7]. In myocardial I/R models, recent work indicates that the mannosebinding lectin as well as the classical activation pathway play a role in complement activation and subsequent organ damage [22, 23]. Regarding the precise pathway of complement-activation upon renal $/ / R$ injury much remains to be resolved, however evidence is growing that activation of the complement-system plays a crucial role in the pathogenesis of renal I/R injury [5]. Recently, we showed that inhibition of the activation of complement-factor $\mathrm{C} 5$ is strongly protective against the development of tissue injury upon renal $I / R$, indicating that the complement-system indeed plays a crucial role in the development of renal I/R injury [16]. To further unravel 
the role of the complement system, the involvement of $\mathrm{C5a}$ and its receptor in the pathophysiology of renal $I / R$ injury was investigated. This study shows that C5aRA significantly attenuates renal I/R injury. This appears to be in contrast to studies by Zhou et al. who provided evidence for a crucial involvement of the MAC in renal I/R injury using transgenic mice [5]. They showed that C3, $C 5$ but also $C 6$ deficient mice are protected against tissue damage upon renal I/R. Moreover, inhibition of C5, preventing C5a generation, in C6 deficient mice did not have additional protective effects. On the basis of these data Zhou et al. concluded that renal $I / R$ injury is solely dependent on formation of MAC. However, the lack of additional effects of anti-C5 in these $C 6$ deficient mice could well be explained by co-dominant effects of $C 5 \mathrm{a}$ and MAC as previously reported for $\mathrm{C5a}$ and $\mathrm{IgG} \mathrm{Fc}$ receptors [24]. Furthermore, the model employed by Zhou et al. can not be directly compared to the one used in this study since the experimental setting was different. These authors performed bilateral warm ischemia with a duration of up to one hour, in complement deficient mice with different backgrounds, among others $C 57 \mathrm{BL} / 6$ mice, a mouse strain known to be sensitive for renal $I / R$ injury $[5,25]$. Recently, Park et al. showed that complement inhibition, using the rodent C3-convertase inhibitor Crry-lg, does not protect against renal I/R in the mouse, suggesting that the complement system is not essentially involved in renal $I / R$ injury [26]. The model used in this elegant study is characterized by a very short duration of renal ischemia (20-30 minutes) and heparin pre-treatment. In contrast, studies of Zhou et al. and ours, using longer ischemia times, showed that the complement system is crucially involved in renal $I / R$ injury [5]. Taken together, these studies indicate that the experimental models used, and especially ischemia times, play an important role in the involvement of the complement system and the effect of complement-inhibition on $I / R$ injury. This is in line with recent work of Iwata who showed that duration of ischemia crucially determines the mechanisms involved in I/R injury [27]. Whereas I/R injury due to short ischemic insults is mainly mediated by neutrophils, after longer ischemic insults apoptosis plays a crucial role in the development of I/R injury. Previously, we also showed the important pathogenic role of apoptosis in our 45 minutes renal I/R model [28]. These data suggest that the complement system is most crucially involved in I/R injury due to more severe, clinical relevant, ischemic insults. In this study we indeed show that the application of a specific C5aRA, strongly reduces renal I/R injury implicating an important pathophysiological role of this complement cleavage product.

Our data are in line with findings obtained in intestinal and cardiac I/R models [17-20]. Intravenous as well as oral administration of C5aRA was capable to reduce local and remote tissue injury in intestinal models of $I / R$ injury [19, $20]$. In cardiac $1 / \mathrm{R}$ models inhibition of $\mathrm{C} 5 \mathrm{a}$ has been shown to reduce infarct size and improve cardiac function upon ischemia $[17,29]$. 
C5a functions via the specific $\mathrm{C} 5$ a receptor, a member of the rhodopsin family of seven transmembrane-spanning $G$-protein-linked receptors [11]. The C5aR was originally shown to be present on myeloid cells, among others neutrophils and macrophages [11]. Binding of C5a to the C5aR induces chemoattraction and degranulation of leukocytes. It also functions as an anaphylatoxin, inducing smooth muscle cell contraction, histamine release from mast cells, vasodilatation and increased vascular permeability. More recent work has shown that C5aR is also present on non-myeloid cells, in particular bronchial and alveolar epithelial cells, hepatocytes, endothelial cells, and also in renal tissue on mesangial and (proximal) tubular epithelial cells [30]. In this study, we report the presence of the C5aR on mesangial cells and tubular epithelium of the murine kidney, on mRNA as well as on protein level. Moreover, we show that $\mathrm{C} 5 \mathrm{aR}$ is locally up-regulated in the course of renal I/R injury. These findings are in line with the reported expression of $C 5 \mathrm{aR}$ in human kidney [31, 32].

Administration of C5aRA strongly reduced the influx of neutrophils in the course of renal I/R injury, which is in line with the effects of C5aRA in other inflammatory models in vivo $[17,19,20,33]$. Neutrophils are considered to be crucially involved in the pathophysiology of I/R injury, nevertheless, the role of neutrophils in renal $I / R$ injury remains controversiall $[2,34]$. Amsterdam et al. previously showed that inhibition of $\mathrm{C} 5 \mathrm{a}$, using a monoclonal antibody against $\mathrm{C} 5 \mathrm{a}$, reduced infarct size in the course of cardiac $1 / \mathrm{R}$, without reduction of the influx of neutrophils, indicating that some of the effects of C5a inhibition are independent of infiltrating neutrophils [17, 29]. In our study neutrophil-depletion did not effect the course of renal I/R injury, as previously reported $[35,36]$ but rebutted by others [3]. Interestingly, the protective effects of C5aRA were independent of the influx of neutrophils, as neutrophildepletion in addition to C5aRA did not influence its protective effects. These data suggest that $\mathrm{C} 5 \mathrm{a}$ has other receptor-mediated functions in the course of renal I/R injury, potentially mediated by $C 5 \mathrm{aR}$ expressed on non-myeloid cells such as tubular epithelial cells, leading to renal function loss.

The induction of the chemokines KC and MIP-2 in the course I/R injury has been described previously and is reported to play a crucial role in neutrophilrecruitment and subsequent $I / R$ injury $[3,37,38]$. Here, we show for the first time that $\mathrm{C} 5 \mathrm{a}$ is crucially involved in the regulation of these chemokines in the course of I/R. The importance of C5a in the induction of chemokines has been reported in a rat lung injury model induced by $\mathrm{IgC}$ immune complex deposition, however in this model $\mathrm{C5}$ a mediated chemokine-induction depends on the presence of a costimulus (IgC immune complex) [12,39]. Interestingly, in these studies $C 5$ a did not mediate local TNF- $\alpha$ production [39]. This is in line with our data showing that $\mathrm{C} 5 \mathrm{a}$ is not involved in TNF- $\alpha$ production in the course of renal I/R injury. 
Activation of the complement-system has been implicated in the induction of apoptosis, a process which has been shown to be crucially involved in the pathophysiology of $1 / R$ injury [28]. In particular the MAC is regarded to induce apoptosis in several inflammatory models $[40,41]$. Recently, we showed that inhibition of $\mathrm{C5}$, which prevents both MAC formation and C5a generation, abrogated $I / R$ induced apoptosis [16]. The present study shows that C5a does not play a role in the induction of apoptosis in the course of renal $I / R$, indicating that, with respect to the involvement of the complement-system, the $M A C$ is responsible for $I / R$ induced apoptosis. Furthermore, our data show that loss of renal function is not directly coupled with renal apoptosis. It appears that loss of function is a result of other phenomena, in which C5a plays an important role and which remain to be investigated. Taken together our data suggest that $\mathrm{C5a}-\mathrm{C5}$ aR interaction on tubular epithellial cells induces a local inflammatory response resulting in cellular dysfunction rather than cell-death which plays an important role in the pathophysiology of renal I/R injury.

In conclusion, the data presented here demonstrate a crucial role for $\mathrm{C} 5 \mathrm{a}$ in the pathophysiology of renal I/R injury. C5aRA significantly attenuates I/R-induced renal failure; C5aRA strongly reduces the influx of neutrophils and induction of chemokines. Interestingly, the protective effects of C5aRA are not dependent on the presence of neutrophils but rather on direct abrogation of renal functional loss possibly mediated by direct activation of renal epithelial cells.

\section{REFERENCES}

1. Thadhani, R., M. Pascuall, and J. V. Bonventre. 1996. Acute renal failure. N Engl J Med $334: 1448$.

2. Heinzelmann, M., J. M. Mercer, and J. C. Passmore. 1999. Neutrophils and renal faillure. Am J Kidney Dis 34:384.

3. Miura, M., X. Fu, Q. W. Zhang, D. G. Remick, and R. L. Fairchild. 2001. Neutralization of groalpha and macrophage inflammatory protein-2 attenuates renal ischemia/reperfusion injury. Am J Pathol 159:2137.

4. Lukacs, N. W., C. Hogaboam, E. Campbell, and S. L. Kunkel. 1999. Chemakines: function, regulation and alteration of inflammatory responses. Chem Immunol $72: 102$.

5. Zhou, W., C. A. Farrar, K. Abe, J. R. Pratt, J. E. Marsh, Y. Wang, G. L. Stahl, and S. H. Sacks. 2000. Predominant role for $c 5 b-9$ in renal ischemia/reperfusion injury. J Clin Invest 105:1363.

6. Vakeva, A. P. A. Agah, S. A. Rollins, L. A. Matis, L. Li, and G. L. Stahl. 1998. Myocardial infarction and apoptosis after myocardial ischemia and reperfusion: role of the terminal complement components and inhibition by anti-C5 therapy. Circulation 97:2259.

7. Weisman, H. F., T. Bartow, M. K. Leppo, H. C. Marsh, Jr., G. R. Carson, M. F. Concino, M. P. Boyle, K. H. Roux, M. L. Weisfeldt and D. T. Fearon. 1990. Soluble human complement receptor type 1: in vivo inhibitor of complement suppressing post-ischemic myocardial inflammation and necrosis. Science 249:146. 
8. Killgore, K. S. P. A. Ward, and J. S. Warren. 1998. Neutrophil adhesion to human endothellal cells is induced by the membrane attack complex: the roles of $P$-selectin and platelet activating factor. Inflammation 22:583

9. Killgore, K. S., C. M. Flory, B. F. Miller, V. M. Evans, and J. S. Warren. 1996. The membrane attack complex of complement induces interleukin- 8 and monocyte chemoattractant protein-1 secretion from human umbilical vein endothelial cells. Am J Pathol 149:953.

10. Cragg, M. S. W. J. Howatt, L. Bloodworth, V. A. Anderson, B. P. Morgan, and M. J. Glennie. 2000. Complement mediated cell death is associated with DNA fragmentation. Cell Death Differ $7: 48$.

11. Gerard, C., and N. P. Gerard. 1994. C5A anaphylatoxin and its seven transmembrane-segment receptor. Annu Rev limmunol 12:775.

12. Czermak, B. J., V. Sarma, N. M. Bless, H. Schmal, H. P. Friedl, and P. A. Ward. 1999. In vitro and in vivo dependency of chemokine generation on C5a and TNF- alpha. J Immunol $162: 2321$.

13. Schieferdecker, H. L., G. Schlaf, K. Jungermann, and O. Gotze. 2001. Functions of anaphylatoxin C5a in rat liver: direct and indirect actions on nonparenchymal and parenchymal cells. Int Immunopharmacol 1:469.

14. Guo, R. F., M. Huber-Lang, X. Wang, V. Sarma, V. A. Padgaonkar, R. A. Craig, N. C. Riedemann, S. D. MoClintock . T. Hlaing, M. M. Shi, and P. A. Ward. 2000. Protective effects of anti-C5a in sepsis-induced thymocyte apoptosis. J Clin Invest 106:1271.

15. Mukherjee, P., and G. M. Pasinetti. 2001. Complement anaphylatoxin C5a neuroprotects through mitogen-activated protein kinase-dependent inhibition of caspase 3. J Neurochem 77:43.

16. De Vries, B., R. A. Matthijsen, T. G. Wolfs, A. A. Van Bijnen, P. Heeringa, and W. Buurman. 2003. Inhibition of complement factor $C 5$ protects against renal ischemia-reperfusion injury: inhibition of late apoptosis and inflammation. Transplantation, in press.

17. Riley, R. D., H. Sato, Z. Q. Zhao, V. H. Thourani, J. E. Jordan, A. X. Fernandez, X. L. Ma, D. R. Hite, D. F. Rigel, T. C. Pellas, J. Peppard, K. A. Bill, R. W. Lappe, and J. Vinten-Johainsen. 2000. Recombinant human complement $\mathrm{C} 5$ a receptor antagonist reduces infarct size after surgical revascularization. J Thorac Cardiovasc Surg 1 20:350.

18. Amsterdam, E. A., G. L. Stahl, H. L. Pan, S. V. Rendig, M. P. Fletcher, and J. C. Longhurst. 1995. Limitation of reperfusion injury by a monoclonal antibody to C5a during myocardial infarction in pigs. Am J Physiol 268: 4448.

19. Arumugam, T. V., I. A. Shiels, T. M. Woodruff, R. C. Reid, D. P. Fairlie, and S. M. Taylor, 2002. Protective Effect of a New C5a Receptor Antagonist against Ischemia-Reperfusion Injury in the Rat Small Intestine. J Surg Res 103:260.

20. Heller, T., M. Hennecke, U. Baumann, J. E. Gessmer, A. M. zu Vilsendorf, M. Baensch, F. Boulay, A. Kola, A. Klos, W. Bautsch, and J. Kohl. 1999. Selection of a C5a receptor antagonist from phage libraries attenuating the inflammatory response in immune complex disease and ischemia/reperfusion injury. J Immunol 163:985.

21. Tacchini-Cottier, F., C. Zweifel, Y. Belkaid, C. Mukankundiye, M. Vasel, P. Launois, G. Milon, and J. A. Louis. 2000. An immunomodulatory function for neutrophils during the induction of a $\mathrm{CD} 4+$ Th2 response in BALB/C mice infected with Leishmania major. I Immunol $165: 2628$.

22. Jordan, J. E., M. C. Montalto, and C. L. Stahll. 2001. Inhibition of mannose-binding lectin reduces postischemic myocardial reperfusion injury. Circulation 104:1413.

23. Buerke, M., H. Schwertz, W. Seitz J. Meyer, and H. Darius, 2001. Novel small moleculle inhibitor of cls exerts cardioprotective effects in ischemia-reperfusion injury in rabbits. J Immunol 167:5375.

24. Baumann, U., J. Kohl T. Tschernig, K. Schwerter-Strumpf, J. S. Verbeek, R. E. Schmidt, and J. E. Cessner. 2000. A codominant role of FC gamma RI/III and C5aR in the reverse Arthus reaction. J Immunal 164:1065.

25. Burne, M. J., M. Haq, H. Matsuse, S. Mohapatira, and H. Rabb. 2000. Genetic susceptibility to renal ischemia reperfusion injury revealed in a murine model. Transplantation 69:1023. 
26. Park, P. M. Haas, P. N. Cunningham, J. J. Alexander, L. Bao, J. M. Guthridge, D. M. Kraus, $V$. M. Holers, and R. J. Quigg. 2001. Inhibiting the complement system does not reduce injury in renal ischemia repeirfusion. I Am Soc Nephrol 12:1383.

27. Iwata, A. J. M. Harlan, N. B. Vedder, and R. K. Winn. 2002. The caspase inhibitor Z-VAD is more effective than CD1 8 adhesion blockade in reducing muscle ischemia-reperfusion injury: implication for clinical trials. Blood 100:2077.

28. Daemen; M. A., C. van 't Veer, G. Denecker, V. H. Heemskerk, T. G. Wolfs, M. Clauss, P. Vandenabeele, and W. A. Buturman: 1999. Inhibition of apoptosis induced by ischemia-reperfusion prevents inflanmation. J Clin Invest 104:541.

29. Amsterdam, E. A, S. V. Rendig, and J. C. Longhurst. 1992. Contractile actions of C5a on isolated porcine myocardium. Am J Physiol 263: $\mathrm{H740}$.

30. Zwirner, J. A. Fayyazi, and 0 . Gotze. 1999. Expression of the anaphylatoxin C5a receptor in non-myeloid cells. Mol Immunol 36:877.

31. Zahedi, R, M. Braun, R. A, Wetsel B. H. Ault, A. Khan, T. R. Welch, M. Frenzke, and A. E. Davis. 2000. The C5a receptor is expressed by human renal proximal tubular epithellal cells. Clin Exp Immunal $121: 226$.

32. Abe, K., M. Miyazaki; T. Kojl, A, Furusu, T. Nakamura-Kurashige, T. Nishino, Y. Ozono, T. Harada, H. Sakai, and S. Kohno. 2001. Enhanced expression of complement C5a receptor IMRNA: in human diseased kidney assessed by in situ hybridization. Kidney Int 60:137.

33. Pellas, T, C., W. Boyar, J. van Oostrum, J. Wasvary, L. R. Fryer, G. Pastor, M. Sills, A. Braunwalder, D. R. Yarwood, R. Kiramer, E. Kimble, J. Hadala, W. Haston, R. Moreira-Ludewig, S. Uziel-Fusi, P. Peters, K. Bill, and L. P. Wennogle. 1998. Novel C5a receptor antagonists regulate neutrophil functions in vitro and in vivo. J Immunol 160:5616.

34. Jordan, J. E., Z. Q. Zhao, and J. Vinten-Johansen. 1999. The role of neutrophils in myocardial ischernia-reperfusion injury: Cardiovasc Res 43:860.

35. Paller, M. S. 1989. Effect of neutrophill depletion on ischemic renal injury in the rat. J Lab Clin Med 113:379.

36. Thornton, M. A., R. Winn, C. E. Alpers, and R. A. Zager. 1989. An evaluation of the neutrophil as a mediator of in vivo renal ischemic-reperfusion injury. Am J Pathol 135:509.

37. Daemen "M. A. B. de Vries, C. var't Veer, T. G. Wolfs, and W. A. Buurman. 2001. Apoptosis and chemokine induction after renal ischemia-reperfusion. Transplantation 71:1007.

38. Lentsch, A. B., H. Yoshidome, W. G. Cheadlle, F. N. Miller, and M. J. Edwards. 1998. Chemokine involvement in hepatic ischemia/reperfusion injury in mice: roles for macrophage inflammatory protein-2 and KC. Hepatology 27:1172.

39. Czermak, B. J., A. B. Lentsch, N. M. Bless, H. Schmal, H. P. Friedl, and P. A. Ward. 1999. Synergistic enhancement of chemokine generation and lung injury by C5a or the membrane attack complex of complement. Am J Pathol 154:1513.

40. Sato, T., M. G. Van Dixhoorn, F. A. Prins, A. Moonev, N. Verhagen, Y. Muizert, J. Savill, L. A. Van Es, and M. R. Daha. 1999. The terminal sequence of complement plays an essential role in antibody-mediated renal cell apoptosis. I Am Soc Nephroll 10:1242.

41. Hughes, J., M. Nangaku, C. E. Alpers, S. J. Shankland, W. G. Couser, and R. J. Johnson. 2000. C5b-9 membrane attack complex medlates endothelial cell apoptosis in experimental glomerulonephritis. Am J Physiol 278:F747. 


\section{CHAPTER}

Exogenous alpha-1-acid glycoprotein protects against renal ischemia-reperfusion injury by inhibition of inflammation and apoptosis

Bart de Vries, Sarah J. Walter, Tim G.A.M. Wolfs, Tino Hochepied, Jarkko Räbinä, Peter Heeringa, Jaakko Parkkinen. Claude Libert, Wim A. Buurman

Transplantation: $2004 ; 78(8) ; 1116-24$ 
Although ischemia-reperfusion (I/R) injury represents a major problem in post-transplant organ failure, effective treatment is not availlable. The acute phase protein $\alpha-1$-acid glycoprotein (AGP) has been shown protective against experimental I/R injury. The effects of AGP are thought to be mediated by fucose-groups expressed on the AGP protein inhibiting neutrophilinfiltration. However, the precise mechanism of protection remains to be established. We therefore studied the effects of exogenous human AGP (hAGP) in a mouse model of ischemic acute renal failure.

Mice were subjected to renal I/R and treated with hAGP, fucose-depleted hAGP, or control-treated. Also transgenic mice overexpressing rat-ACP or wild type controls were subjected to renal $I / R$.

Treatment with hAGP as well as fucose-depleted hAGP protected mice against $\mid / R$-induced acute renal failure. Surprisingly, AGP-overexpressing mice were not protected against //R injury. Both natural and fucose-depleted hACP inhibited the activation of the complement-system, as determined by renal C3-deposition, and influx of neutrophils measured by immunohistochemistry and myeloperoxidase-ELISA. Tubular epithelial cell-structure (actin-cytoskeleton) and cell-cell interaction (tight-junction architecture) were completely preserved in AGP-treated mice. Also epithelial caspaseactivation and apoptotic DNA-cleavage were prevented by AGP treatment.

Both natural and fucose-depleted hAGP protect against renal I/R injury by preservation of tubular epithelial structure, inhibition of apoptosis and subsequent inflammation. Therefore hAGP can be regarded as a potential new therapeutic intervention in the treatment of acute renal failure, as seen after transplantation of ischemically injured kidneys.

\section{INTRODUCTION}

Post-ischemic renal failure represents a major problem in clinical medicine, including transplantation, however effective treatment for acute renal failure is currently not available [1]. In a murine model for renal ischemia-reperfusion (I/R) injury we recently showed that administration of the acute phase protein $\alpha-1$-acid glycoprotein (AGP), also called orosomucoid, is protective against I/R induced acute renal failure [2]. In septic as well as hemorrhagic shock and acute liver failure models exogenous ACP provided protection against organ injury and improved animal survival [3-5]. These studies indicate that AGP is potentially a powerful therapeutic agent in a broad range of diseases mediated by ischemic injury. 
AGP appears to have many different functions in vivo and several mechanisms of action have been suggested. In vivo, the effects of AGP are thought to be mediated by fucosylated glycans expressed on the AGP protein $[6,7]$. These glycans inhibit the interaction between neutrophils and endothelium, probably by interfering with selectin dependent cell adherence, thereby preventing neutrophil infiltration $[8,9]$. Indeed Williams et al. showed that fucosylated human AGP protected mice more effectively from intestinal ischemic injury than non-fucosylated AGP [7]. In vitro studies have indicated that AGP inhibits superoxide and hydrogen peroxide generation by stimulated neutrophils suggesting that ACP is also capable to inhibit neutrophil-activation [10].

An interesting observation was done by Libert et al. showing that transgenic mice constitutively overexpressing AGP are not protected against TNF- $\alpha$ /galactosamine-induced acute liver failure, whereas exogenous AGP was shown to be protective in the very same model [1 1]. This finding suggests that only acute administration of ACP, in contrast to endogenously produced AGP, has protective effects.

Thus, although exogenous AGP provides protection in various experimental models, the mechanism of protection remains to be established. The aim of the present study was to characterize the effects of endogenous as well as exogenous AGP in a renal I/R model, with special emphasis on the influence of fucosylation of the AGP protein. To get more insight in the mechanism of protection, we studied the effects of AGP on I/R induced cytoskeletal derangements, apoptotic cell-death and inflammation.

\section{MATERIALS AND METHODS}

\section{Reagents and antibodies}

Rabbit anti-human AGP was purchased from DAKO (St Louis, MO). NIMP-R14 (rat anti-mouse neutrophil mAb) was kindly provided by Dr. M. Strath (National Institute for Medical Research, London, UK). Polyclonal rabbit anti=active caspase- 7 antibody was obtained from Biovision (Mountain View, CA), cross-reacting polyclonal rabbit anti-human ZO-1 antibody from Zymed Laboratories (San Francisco, CA), and Texas-red Phalloidin from Molecular Probes (Eugene, OR). Goat anti-mouse C3 polyclonal antibody was purchased from Cappel (ICN Biomedicals, Aurora, $\mathrm{OH}$ ). Secondary antibodies, peroxidase conjugated goat anti-rat $\mathrm{IgG}$, rabbit anti-goat IgG, as well as FITC-labelled goat anti-rabbit lgG were purchased from Jackson (West Grove, PA). All other reagents were purchased from Sigma (St. Louis, MO). 
Purification of human plasma AGP and fucose-depleted ACP

Human AGP was purified from plasma of healthy blood donors according to the method of Hao and Wickerhauser [12]. Fucose-depleted AGP was prepared by subjecting human plasma AGP to affinity chromatography with agarosebound Aleuria aurantia lectin (Vector Laboratories, Burlingame, CA). About $85 \%$ of plasma AGP was recovered in the non-binding effluent fraction and $15 \%$ was eluted from the lectin column with fucose. Fractions containing nonbinding AGP (designated as fucose-depleted AGP) were pooled, concentrated by ultrafiltration (10 kDa cut-off), and sterile-filtered. Structural analysis of $\mathrm{N}$-glycans in AGP preparations was performed by BioTie Therapies (Helsinki, Finland) by matrix-assisted laser desorption mass spectrometry with time-offlight (MALDI-TOF) detection after enzymatic detaching and purification of glycans. The degree of $\mathrm{N}$-glycan fucosylation in the original plasma AGP and fucose-depleted AGP was $21 \%$ and $12 \%$, respectively. However, AGP molecules having two or more fucosylated glycan chains (proteins with high affinity for selectins) decreased more effective, leading to an $80 \%$ reduction of highly fucosylated AGP, which is capable of interfering with selectin-lectin interactions.

\section{Experimental Protocol}

Male Swiss mice weighing 25-30 g were obtained from Charles River Breeding Laboratories (Heidelberg, Germany). Animals were housed individually in standard laboratory cages and were allowed free access to food and water. The studies were carried out under a protocol approved by the Institutional Animal Care Committee of the University of Maastricht. Mice were subjected to 45 minutes of unilateral ischemia of the left kidney followed by reperfusion and contralateral nephrectomy inducing reversible acute renal failure without mortality as described in detail previously [13]. The animals were sacrificed 24 hours after reperfusion, since at this time-point renal inflammation and organ failure are most pronounced. At the time of sacrifice, blood was collected and the left kidney was harvested for analysis.

During ischemia, just before reperfusion, mice were administered $0.1,0.5$, or $5 \mathrm{mg}$ of hAGP or fucose-depleted hAGP i.p. dissolved in $0.5 \mathrm{ml}$ PBS or 0.5 $\mathrm{ml}$ PBS as control treatment $(n=8$ per group).

In separate experiments, transgenic $\mathrm{C} 57 \mathrm{BL} / 6$ mice overexpressing ratAGP were used [11]. The serum concentration of rat-ACP in transgenic mice is approximately $3.5 \mathrm{mg} / \mathrm{ml}$, which is comparable to serum concentrations obtained after administration of $5 \mathrm{mg}$ exogenous AGP [11]. As described above, rat-ACP overexpressing mice or wild type C57BL6 mice, as a control, were subjected to renal ischemia for 45 minutes followed by 24 hours reperfusion ( $n=6$ per group). 
Human AGP measurement

To measure hAGP concentrations in mice a human AGP sandwich ELISA was used. This ELISA has been developed at our institute as reported previously [14]. The ELISA is specific for hAGP and does not detect mouse ACP.

\section{Renal Histology}

Cryostat sections $(5 \mu \mathrm{m})$ of frozen tissue were cut and stained for active caspase-7, F-actin, and ZO-1 as described in detail previous ly [15]. Briefly, after blocking aspecific antibody binding, slides were incubated for 1 hour at room temperature with the anti-active caspase- 7 or the anti-ZO- 1 primary antibody. After washing in PBS, slides were incubated for 30 minutes with the FITC-labelled secondary antibody with the addition of Texas red-phalloidin which specifically binds to F-actin. After washing, the slides were mounted using glycerol-PBS with DAPI, and viewed with an immunofluorescence microscope. No significant staining was detected in slides incubated with control serum instead of the primary antibody indicating the absence of significant background staining. The number of caspase- 7 positive tubules was quantified by counting 20 fields of vision per kidney section ( 3 sections per kidney, 4 kidneys per group) at $\times 200$ magnification in a blinded fashion.

Cryostat sections were also stained for neutrophils as described previously [13]. Neutrophils were counted by examining 10 fields of vision per kidney section ( $3-4$ sections per kidney, 4 kidneys per group) at $\times 200$ magnification in a blinded fashion.

Staining for complement factor $\mathrm{C} 3$ has been described previously [13]. C3staining was quantified using a computerized morphometry system (Quantimet 570; Leica, Cambridge, UK). To obtain representative data, $4 \mathrm{com}$ plete cross-sections of 4 kidneys per group were included. Per section, 30 fields of vision (10 cortical, 10 corticomedullary, and 10 medullary fields) at $\times 200$ magnification were measured. Data are expressed as percentages of positive stained tissue of the total tissue measured.

\section{MPO-ELISA}

A new ELISA for the measurement of tissue myeloperoxidase (MPO) was used as a quantitative measure for tissue infiltration of neutrophils. Renal tissue was homogenised in a buffer containing $200 \mathrm{mM} \mathrm{NaCl}, 10 \mathrm{mM}$ Tris $\mathrm{HCl}, \mathrm{pH}$ 7.0, $5 \mathrm{mM}$ EDTA, $10 \%$ glycerol, $1 \mathrm{mM}$ PMSF, $0.1 \mu \mathrm{M}$ aprotinin and $1 \mu \mathrm{g} / \mathrm{ml} \mathrm{leu-}$ peptin. After centrifugation at $14,000 \mathrm{~g}$ for 10 minutes supernatants were stored at $-20^{\circ} \mathrm{C}$ until analysis. A monoclonal antibody directed against mouse MPO (8F4) was coated at a concentration of $3 \mu \mathrm{g} / \mathrm{ml}$, in a $0.1 \mathrm{M}$ carbonate buffer ( $\mathrm{pH}$ 9.6), for 1 hour at room temperature onto 96-well plates (ImmunoMaxisorp; Nunc, Roskilde, Denmark). Free binding sites were blocked with $1 \%$ BSA in PBS for 1 hour at room temperature. Wash buffer consisted of $150 \mathrm{mM}$ 
$\mathrm{NaCl}, 10 \mathrm{mM}$ Tris $\mathrm{HCl}, \mathrm{pH} 8.0$, containing $0.05 \%$ Tween-20. Plates were washed 5 times after each incubation step. Samples were diluted in $300 \mathrm{mM}$ $\mathrm{NaCl}, 10 \mathrm{mM}$ Tris $\mathrm{HCl}$, pH 8.0 with $0.25 \%$ Tween-20, 2\% BSA and $1 \%$ normal goat serum. Samples as well as mouse MPO, used as a standard, were incubated for 1 hour at room temperature. Mouse MPO was purified from WEHI-3 cells as described previously [16]. After washing, rabbit anti-human MPO (DAKO, Glostrup, Denmark) was incubated for 1 hour at room temperature. Next, after washing, peroxidase labeled goat anti-rabbit IgG was incubated for 1 hour. After washing color reaction was developed using 3,3',5,5'tetramethylbenzidine (Kirkegaard \& Perry Laboratories, Gaithersburg, MD) and $\mathrm{H}_{2} \mathrm{SO}_{4}$ to stop the reaction. Color intensity was measured by determination of the absorbance at $450 \mathrm{~nm}$ using a micro-ELISA reader.

\section{Apoptosis assay}

Presence of internucleosomal DNA cleavage in kidneys was investigated with a commercial ligase mediated (LM)-PCR assay kit (Apoalert, Clontech, Palo Alto, CA) enabling semiquantitative measurement of the extent of apoptosis. In brief, DNA was isolated from tissue samples employing a commercially available DNA purification kit (Promega, Madison, WI). DNA purity and concentration were determined by electrophoresis through a $0.8 \%$ agarose gel containing ethidium bromide followed by visualisation under ultraviolet illumination as well as by measuring absorbance at 260/280 $\mathrm{nm}$. Dephosphorylated adaptors were ligated to 5'-phosphorylated blunt ends with T4 DNA ligase (during $16 \mathrm{~h}$ at $16 \mathrm{C}$ ) and served as primers in a LM-PCR. Amplified DNA was subjected to gel electrophoresis on a $1.2 \%$ agarose gel containing ethidium bromide.

\section{Renal function}

Blood urea nitrogen (BUN) was measured in serum obtained at the time of sacrifice using a Urea 25 Kit (ABX Diagnostics, Eindhoven, Holland) in a Cobas Fara autoanalyzer (Roche, Basle, Switzerland).

\section{Statistical analysis}

Data are expressed as the mean \pm SEM, except for data obtained from renal histology (C3-deposition and neutrophil-influx) and MPO-ELISA, which are expressed as the median with interquartile ranges. Statistical significance was evaluated by one-way ANOVA with Bonferroni's post-hoc test. $\mathrm{P}<0.05$ was taken to denote statistical significance. 
Treatment with exogenous human ACP protects against renal I/R injury in a dose dependent manner, independently from the degree of fucosylation

First, we determined whether intraperitoneal treatment with AGP results in detectable circulating levels of hACP. Whereas in healthy mice and mice subjected to renal I/R no hAGP could be detected, treatment with hAGP resulted in dose-dependent levels of circulating hAGP as measured 24 hours after renal $\mathrm{I} / \mathrm{R}$ (concentrations of $3.05 \pm 0.37,0.45 \pm 0.05$ and $0.11 \pm 0.03 \mu \mathrm{g} / \mathrm{ml}$ hAGP after 5, 0.5, $0.1 \mathrm{mg}$ hACP treatment respectively).

Next, we examined whether exogenous hAGP provides functional protection against renal $\mathrm{I} / \mathrm{R}$ injury. The data presented here show that hAGP protects against the $1 / R$-induced loss of renal function, as measured by blood urea nitrogen (BUN) levels, in a dose dependent manner (Figure 1). Whereas $0.1 \mathrm{mg}$ hAGP already provided a significant protection as reflected by reduced BUN levels, maximal protection was provided using $5 \mathrm{mg}$ of hAGP.

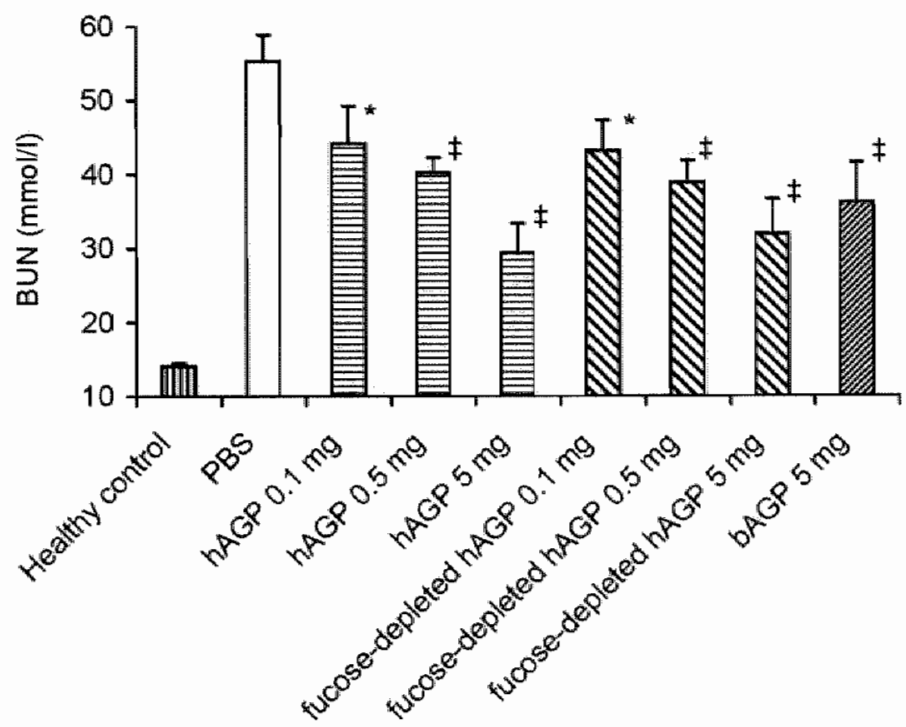

Figure 1. Human ACP (hACP) reduces loss of renal function after ischemia-reperfusion $(I / R)$ inde pendently from the degree of fucosylation. Compared to control-treated animals hAGP dosedependently reduced BUN values as measured 24 hours after renal I/R. Also fucose-depleted hAGP and bovine AGP (BAGP) significantly reduced BUN levels in a dose-dependent manner. There were no significant differences in BUN values of hACP, fucose-depleted hAGP " or bACP treated animals. Statistical significance as compared to control-treated animals was denoted at $p<0.05$ $(*)$ and $p<0.01(\neq)$. The data shown are means \pm SEM. 
To unravel the mechanism of protection by AGP we determined whether the functional protection against renal $I / R$ injury is dependent on the degree of fucosylation of AGP. Hence, mice were treated with hAGP, fucose-depleted hACP or BAGP. The data show that AGP protects against loss of renal function independent from its degree of fucosylation (Figure 1). Equally effective, hACP and fucose-depleted hAGP provided protection against renal function loss as compared to control treated mice in a dose-dependent manner. These data indicate that the protective effects of hACP against renal $1 / R$ injury are not mediated by fucose-groups but rather by other properties.

\section{AGP-overexpressing mice are not protected against renal I/R injury}

Next, we examined whether high levels of endogenous AGP could protect against renal $I / R$ injury. Therefore, transgenic mice over-expressing rat $A G P$ and their wild-type controls, were subjected to renal I/R injury. Libert et al. previously showed that $A G P$-overexpressing mice are not protected against TNF- $\alpha /$ galactosamine-induced hepatitis, in contrast AGP-overexpressing mice showed protection against lethal Gram-negative infection [11, 17]. Here we show that mice with high levels of endogenous AGP, as compared to wildtype mice and control Swiss mice, are not protected against the loss of renal function after renal I/R (Figure 2). There was no significant difference in postischemic BUN-levels between Swiss mice, C57BL/6 wild-type mice and C57BL/6 transgenic (AGP-overexpressing) mice.

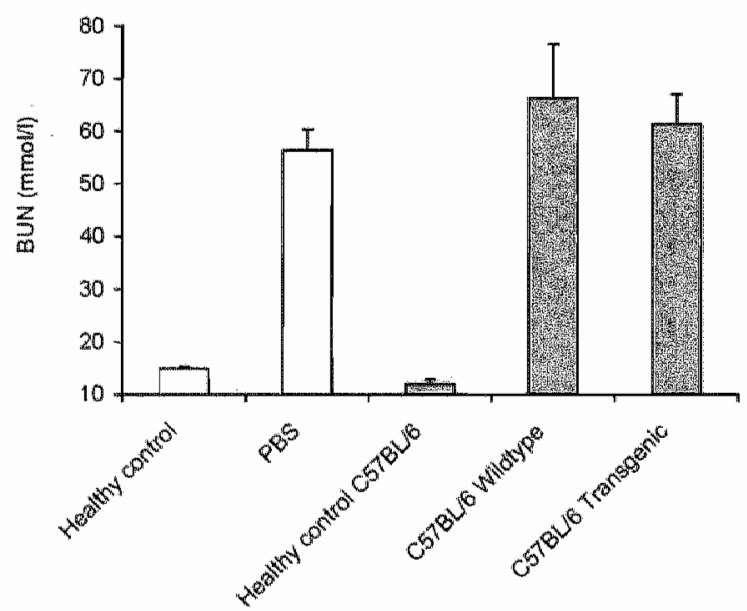

Figure 2. Transgenic mice over-expressing rat AGP are not protected against ischemia-induced loss of renal function. BUN levels 24 hours after renal ischemia-reperfusion of transigenic mice over-expressing rat-ACP were not different from their wild-type controls (C57BL/6) or Swiss mice controls. Statistical significance as compared to control animals (C57BL/6 and Swiss) was denoted at $p<0.05\left(^{(*)}\right)$. The data shown are means \pm SEM. 
Human ACP inhibits $1 / R$ induced inflammation independently from the degree of fucosylation

AGP inhibits the infiltration of neutrophils in post-ischemic tissue [2, 7]. This inhibitory effect has been reported to be dependent on the presence of fucose-groups on the AGP protein in intestinal $1 / R$ injury [7]. Since the influx of neutrophils is a prominent feature of renal $I / R$ injury, we determined whether AGP prevents neutrophil influx after renal $I / \mathbb{R}$ injury, and moreover we examined whether the effects on neutrophil-infiltration are dependent on the degree of fucosylation. Our immunohistochemical data show that AGP dose-dependently reduces the influx of neutrophils induced by renal $/ / R$ injury (Figure 3A). Interestingly, fucose-depleted AGP appeared to have equal inhibitory effects on neutrophil-infiltration as naturally fucosylated ACP (Figure 3A). Moreover, the data show that a high-level of constitutively expressed AGP in ACP-transgenic mice, as compared to wild type mice, does not influence the influx of neutrophils (Figure $3 \mathrm{~A}$ ).

Next to immunohistochemistry, we used a new MPO-ELISA as a quantitative measure of renal neutrophil-influx. The data show that, as compared to renal tissue from healthy control mice, renal $I / R$ induces an evident increase in renal MPO levels (Figure 3B). Treatment with hAGP dose-dependently reduces renal MPO levels as compared to control treated animals. Moreover, fucose-depleted AGP is as effective as naturally fucosylated hAGP in reducing renal MPO-levels. Finally, ACP overexpression in transgenic mice does not reduce renal MPO-levels as compared their wild-type controls (Figure 3B).

Taken together, using semi-quantitative immunohistochemistry as well as a quantitative MPO-ELISA, we show that the influx of neutrophils into postischemic renal tissue is inhibited by exogenous hAGP in a dose-dependent manner independent from the degree of fucosylation. In contrast, endogenous overexpression of AGP does not influence the ischemia-induced influx of neutrophils.

We recently showed that complement-activation, as a part of the inflammatory response, is a crucial event in ischemia-reperfusion injury $[13,18]$. In particular since the complement system plays an important role in post-ischemic neutrophil-infiltration, we determined whether treatment with hAGP could reduce the activation of the complement system. The present data show that hAGP strongly inhibits the ischemia-induced deposition of complement-factor C3 (Figure 4). Whereas renal I/R led to significant renal deposition of C3, treatment with hAGP dose-dependently inhibited C3-deposition (Figure 4).

All together these data indicate that exogenous ACP, in contrast to high levels of endogenous AGP, protects against I/R induced inflammation and renal function loss. Surprisingly, these protective effects of AGP appear to be independent from its fucosylation and are thus mediated by other as yet unknown mechanisms. 

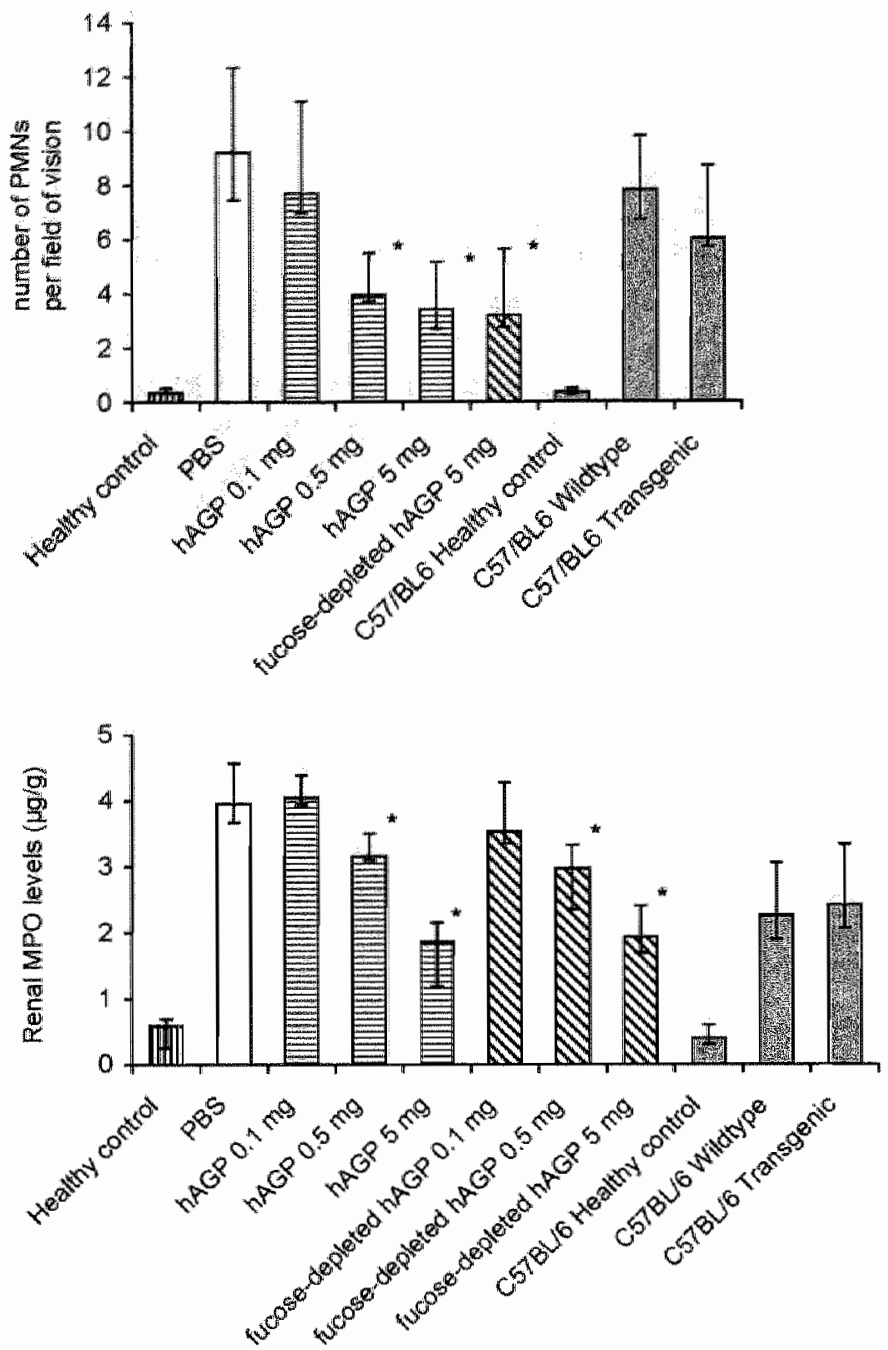

Figure 3. Human AGP (hAGP) inhibits ischemia-induced neutrophill-influx, independently from the degree of fucosylation. Infiltrating neutrophils were counted after immunohistochemical staining (three to four sections per kidney, four kidneys per group) (A). Post-ischemic infiltration of neutrophils was also quantified using a myeloperoxidase (MPO)-ELISA. (B). Neutrophils were scarcely present in kidneys obtained from healthy mice, whereas ischemia followed by reperfusion induced a strong influx of neutrophils. Treatment with hACP dose-dependently reduced the influx of neutrophils at 24 hour's reperfusion. Fucose-depleted hAGP was as effective as natural hAGP. Transgenic mice over-expressing rat AGP were not protected against ischemia induced influx of neutrophils as compared to their wild type littermates. Statistical significance as compared to control-treated animals was denoted at $p<0.05$ ( $\left.{ }^{*}\right)$. Data are expressed as median number of neutrophils per field of vision with interquartile ranges (A) or median concentration of MPO ( $\mu \mathrm{g} /$ g) with interquartille ranges (B). 

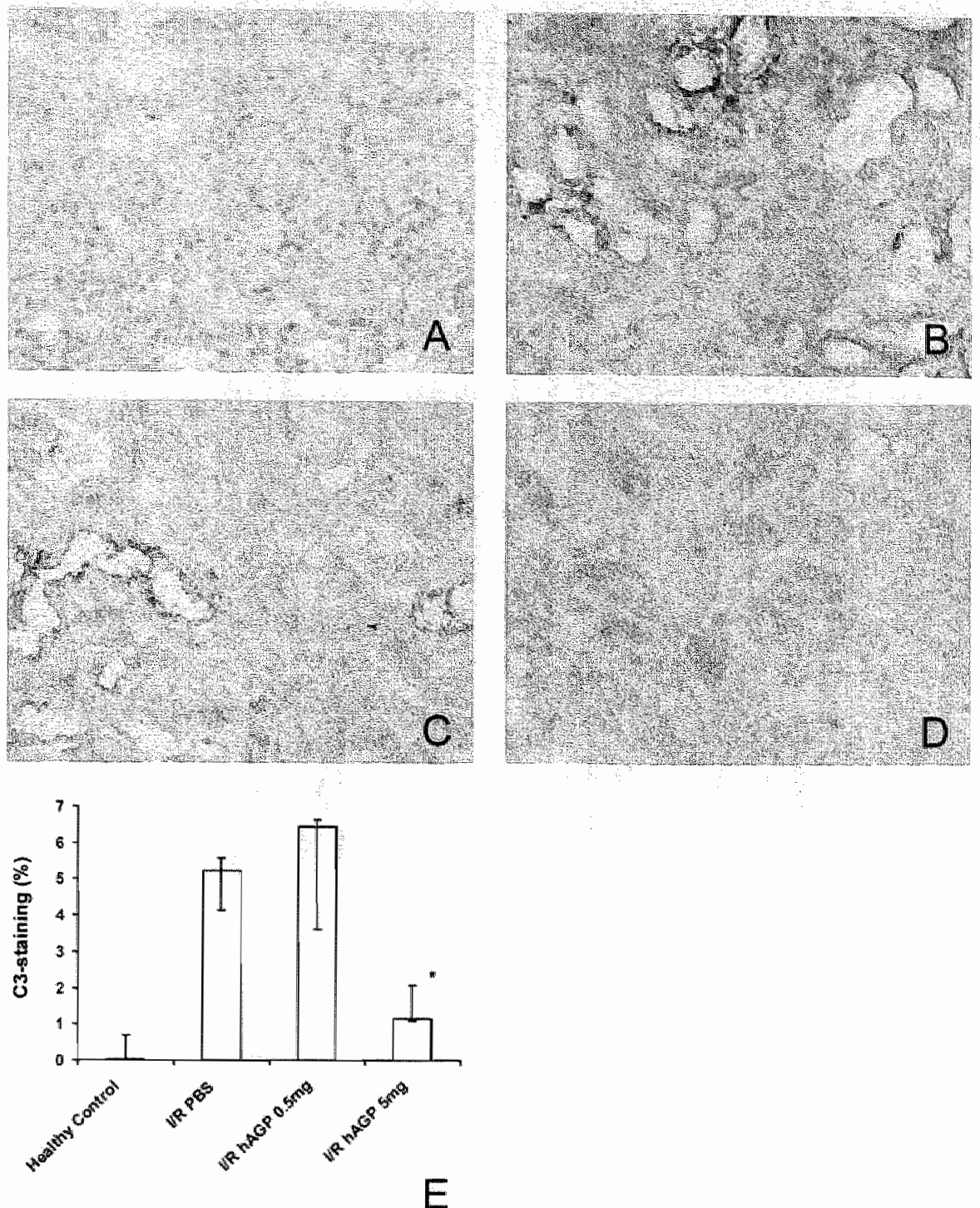

Figure 4. Human ACP (hACP) significantly reduces complement-activation after renal ischemiareperfusion. Renal C3-deposition was assessed by immunohistochemistry and quantified using the Leica Quantimet 570 system (3-4 kidneys per group, 30 fields of vision per kidney). As compared to healthy control mice $(A)$, renal ischemia foliowed by 24 hours of reperfusion induced $C 3-$ deposition which was most prominent in the corticomedullary region (B). Treatment with hAGP dosedependently reduced renal complement-deposition ( $C, 0.5 \mathrm{mg}$ hAGP and $D, 5 \mathrm{mg}$ hAGP), Quantification of C3-staining showed that indeed hAGP significantly inhibited renal complementdeposition (E). Data are expressed as median percentages of positive stained tissue with interquartile ranges. Statistical significance as compared to control treated mice was denoted at $P<0.05 \%$. 
Human AGP inhibits $1 / R$ induced apoptosis independently from the degree of fucosylation

Apoptosis plays a crucial role in the initiation of renal $1 / R$ injury [19]. Therefore, we questioned whether hAGP would inhibit renal apoptosis. Here we show that kidneys of animals treated with hAGP, showed a reduction in internucleosomal DNA cleavage, a specific hallmark of apoptosis, as compared to control treatment (Figure 5). Fucose-depleted hAGP inhibited renal apoptosis as effective as natural $h A G P$ and $B A G P$, indicating that the inhibitory effects of the ACP protein on apoptotic cell-death are independent from its fucosylation (Figure 5).
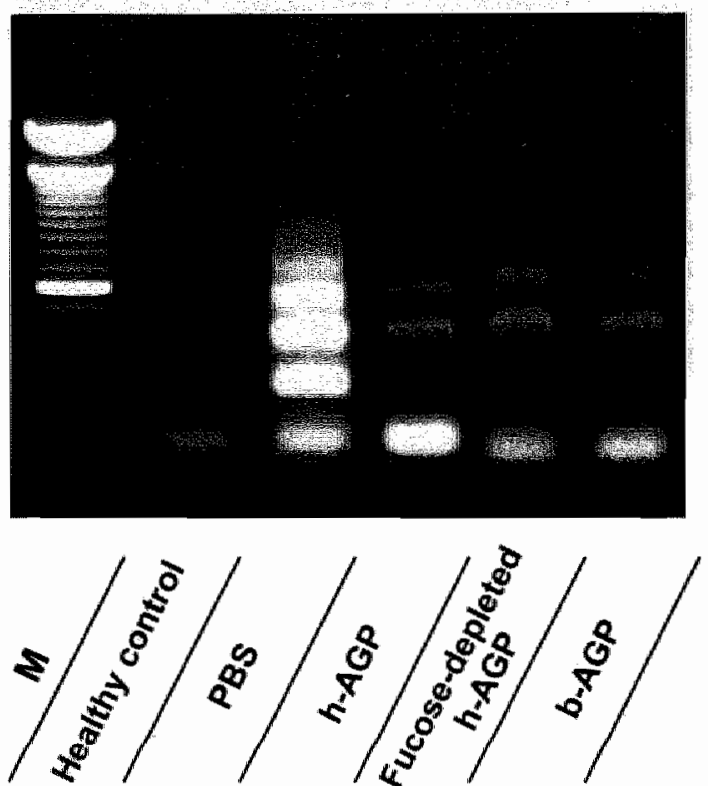

Figure 5. Treatment with human AGP (hACP) abrogates ischemia-reperfusion (1/R) induced apoptosis. The extent of renal apoptosis was reflected by fragmentated DNA amplified by ligase-mediated PCR and visualized on ethidium-bromide - stained gel. In control-treated animals I/R induced evident internucleosomal DNA cleavage. Natural hAGP, fucose-depleted hAGP as well as bovine AGP reduced renal apoptosis. Data shown are representative for three independent assays on different renal samples (three per group). $M_{*} 100$-bp molecular weight marker. 

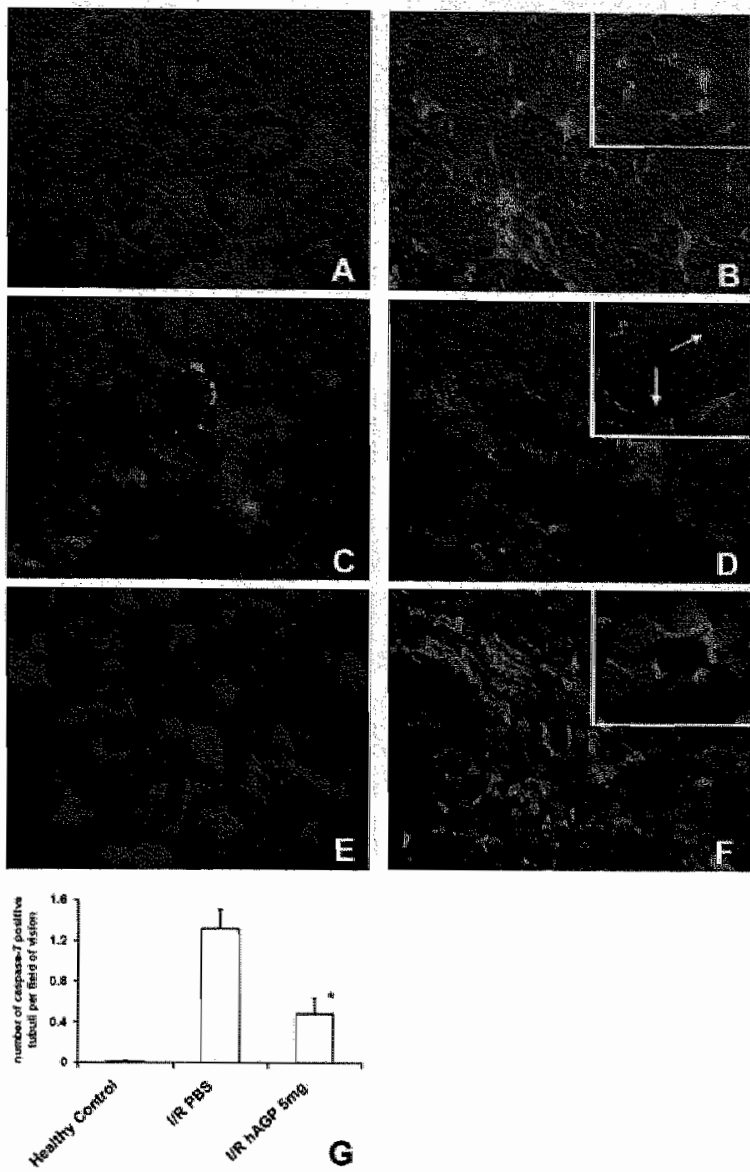

Figure 6. Human AGP abrogates ischemia-reperfusion (I/R)-induced apoptosis and disruption of epithellal integrity. In figure A, C and E filamentous actin (F-actin) was stained red (Texas-Red) and active caspase-7 was stained green (fluorescein isothiocyanate). Nuclei were stalned blue $(4,6$-diamidino(2)phenylindole) in all sections. Reral $I / R$ induced activation of caspase- 7 in tubular epithelial cells, (C, in green) as compared to the normal kidney where active caspase- 7 is not present (A). ACP treatment prevented caspase-7 activation (E). Quantification of the number of caspase-7 positive tubuli shows that ACP significantly inhibited apoptotic cell-cleath induced by renal $I / R(C)$. In healthy animals tubular epithelial brush-borders are intact as determined by filamentous actin ( $F$-actin) staining $\left(A_{*}\right.$ in red). After $/ / R$ tubular epithelial cells lost brush-border integrity and caspase-7 activation is mainly present in tubular epithelial cells with complete disrupted brush-border (C). Treatment with ACP evidently preserved tubular epithelial brush-border integrity (E).

In figure $B, D$ an $F$ the tight-junction protein $Z O-1$ is stained in green (fluorescelin isothiocyanate). In the normal kidney $Z O-1$ is mainly located at the apical side of tubular epithelial cells ( $B$, in green). Renal $/ / R$ induced a severe disintegration of epithelial tight -junctions (D); tubular cells with complete disruption of $\mathrm{ZO}-1$ showed nuclear condensation and fragmentation, two hallmarks of apoptotic cell-death (D, white arrows). ACP treatment completely prevented tight-junction disintegration (F). Original magnification: $\times 600$. 
Actin cytoskeletal changes are reported to precede the induction of apoptosis in (renal) epithelial cells [20-22]. Indeed, we recently showed that apoptotic cell-death in the course of renall I/R injury is localized to tubular cells which show severe actin cytoskeletal derangements [15]. Thus we questioned whether the protective, among others anti-apoptotic, effects of hAGP could be mediated by cytoskeletal protection. Hence, we stained renal tissue for active caspase -7 , as a marker of apoptosis, and filamentous actin (F-actin), the main component of the cytoskeleton, mainly present in the brush-border of tubular epithelial cells. The data show that, whereas in control kidneys no apoptotic cell-death could be detected, after renal I/R a significant number of injured tubuli stained positive for active caspase-7 (Figure $6 \mathrm{~A}$ and $\mathrm{C}$ ). Apoptosis mainly localised to tubular epithelial cells with severe cytoskeletal derangements (Figure $6 \mathrm{~A}$ and C). Treatment with hAGP significantly reduced the number of caspase- 7 positive tubuli (Figure $6 \mathrm{E}$ and $\mathrm{G}$ ). Most striking was the protective effect of hAGP on tubular cytoskeletal structure; in contrast to control treated mice, hAGP treated animals showed minimal injury to the tubular brush-border and a well-preserved tubular structure (Figure $6 \mathrm{E}$ ).

An important determinant of cell survival, next to maintenance of cellstructure, is the maintenance of cell-matrix and cell-cell interactions such as tight-junctions [23]. Therefore we stained tissue sections for ZO-1, an intracellular protein which takes part in the tight-junction. The present data show that in the normal kidney the $Z O-1$ protein localizes to the apical side of the tubular epithelial cells (Figure 6 B). Renal ischemia induced a severe disruption of tight junctions, as demonstrated by the disappearance of the normal ZO-1 organisation (Figure 6 D). Besides, ZO-1 is found in the tubular lumen, probably in tubular cellular debris (Figure $6 \mathrm{D}$ ). Interestingly, in particular tubular cells with complete disruption of their tight-junctional complex showed nuclear condensation and fragmentation, two hallmarks of apoptotic cell-death (Figure $6 \mathrm{D}$, white arrows). Treatment with hAGP prevented this $1 / R$-induced destruction of tight-junctions; the $Z O-1$ protein remained well organised in kidneys from AGP treated mice, comparable to control kidneys (Figure $6 \mathrm{~F}$ ). These data show that AGP treatment preserves cellular structure and cell-cell interactions after renal I/R.

\section{DISCUSSION}

ACP is an acute phase protein, and as for more acute phase proteins, the function of AGP is not known. In general AGP is considered to be an important drug-binding protein, binding a wide variety of drugs as well as endogenous substances [24]. Moreover AGP has been implicated to have various immuno- 
modulating effects, such as inhibition of lymphocyte proliferation, inhibition of platelet aggregation, activation of mononuclear cells and inhibition of neutrophil-activation [8].

Exogenous AGP has been shown protective against lethal inflammatory hepatitis induced by galactosamine in combination with either TNF- $\alpha$ or LPS $[5,25]$. This in contrast to LPS-induced systemic shock in absence of livertoxicity, in which AGP treatment was not protective $[4,5]$. In the same study AGP provided protection against septic peritonitis and hypovolemic shock [4]. It was suggested that the protective effects of AGP were mediated by preservation of capillary barrier function [4]. In line, Johnsson and Haraldsson showed that AGP is essential for the maintenance of glomerular capillary permselectivity $[26,27]$.

Highly fucosylated AGP has been shown protective against ischemic injury in a rat intestinal $\| / R$ model [7]. Local as well as remote (liver and lung) injury were inhibited by recombinant hAGP obtained by cotransfection of CHO cells with a human fucosyltransferase more efficiently than by non-fucosylated recombinant hAGP [7]. Fucose-groups present on neutrophils form an essential part of the ligand for endothelial selectin molecules promoting neutrophil adhesion and migration. It is therefore suggested that AGP protects against $I / R$ injury via fucose-mediated interference of neutrophil-endothelium interaction [7, 9]. In contrast, in the present study we show that the protective effects of AGP against renal $I / R$ injury are independent from the degree of fucosylation, indicating that the effects of AGP are not mediated by direct interference with neutrophil-selectin interactions. Natural fucosylated and fucose-depleted AGP equally reduced the post-ischemic influx of neutrophils. For quantification of neutrophil-influx we used a newly developed MPO-ELISA. Our semiquantitative immunohistological data correlated well with the renal MPO levels as measured with this ELISA. The classical enzymatic MPO-assays, which are often used to quantify neutrophil-influx, are hard to interpret and in particular in renal tissue have high background values and are difficult to reproduce, probably due to high endogenous peroxidase levels $[28,29]$. These difficulties are circumvented applying an EL_ISA using antibodies specifically recognising murine MPO.

AGP has been shown to inhibit apoptotic cell-death in vivo $[2,3,30]$. In TNF- $\alpha /$ galactosamine and TNF- $\alpha /$ actinomycin D induced hepatitis as well as renal I/R injury AGP prevented apoptotic DNA-cleavage [2,3]. We previously showed that the inhibition of apoptosis, by a broad-spectrum caspaseinhibitor (Z-VAD-fmk), is protective against I/R injury, among others by inhibition of neutrophil-influx [19]. These data would suggest that the effects of AGP on renal function and inflammation are primarily mediated by the inhibition of apoptotic cell-death. Indeed the present study shows that ACP reduces tubular epithelial apoptosis, an effect independent from the presence of fucose-groups. However, a direct inhibition of caspase-activation is 
not the case (Libert, unpublished results), suggesting that the effects of AGP on apoptosis are most likely indirect [30].

Cytoskeletal derangements have been reported to initiate apoptosis in epithelial cells in vitro [20]. Also disruption of cell-cell interaction has been implicated in the induction of apoptosis in vitro [23]. Recently, we showed in vivo that apoptotic cell-death co-localizes with cytoskeletal derangements, e.g. F-actin breakdown, after renal I/R [15]. The present study shows for the first time that AGP prevents this ischemia-induced breakdown of the actin cytoskeleton. ACP also prevents the disruption of tight-junctions. We therefore hypothesize that the protective effects of AGP observed in the present study are mediated by the preservation of cellular structure and cell-cell interaction of renal epithelial cells. The mechanism by which AGP protects against ischemia-induced loss of cellular structure, cell-cell interaction, apoptotic celldeath and subsequent inflammation still remains to be established.

In vitro studies by Sörensson et al. demonstrated that AGP increases the intracellular CAMP concentration in endothelial cells [31]. Interestingly, enhancement of cellular CAMP levels has been reported to increase number of tight-junctions and decrease epithelial and endothelial permeability in vitro $[32,33]$. In addition, CAMP enhancement inhibits apoptosis in stimulated epithelial cells [34]. Therefore, an intriguing hypothesis would be that the protective effects of AGP observed in the present study are mediated by upregulation of CAMP. This in particular tempting since enhancement of CAMP levels has already been shown to protect against renal I/R injury [35]. Of course additional studies are required to establish the potential role of CAMP in AGP mediated effects in vivo.

An interesting new finding in the present study is the observation that transgenic mice constitutively overexpressing rat-AGP, in contrast to mice treated with exogenous AGP, are not protected against renal I/R injury. This is in line with studies by Libert et al. showing that transgenic mice overexpressing AGP are not protected against TNF- $\alpha$ / galactosamine-induced acute liver failure, whereas exogenous AGP was shown to be protective in the very same model [11]. Apparently, endogenous circulating AGP is essentially different from acute administered AGP. As hypothesized by Libert et al. an important difference between endogenous and exogenous AGP might be related to the binding properties of the AGP protein; endogenous circulating ACP might be bound to a binding factor making it inactive, whereas exogenous, unbound, ACP is protective as described in several in vivo models [11].

The present study describes the protective effects of hAGP against renal I/R injury. Treatment with hAGP has been shown to be without adverse effects even in high doses in rats [36]. Clinical treatment with hAGP, which is an endogenous protein, would have several interesting applications. Based on the present study, hAGP could be used preventive if acute renal failure is to be expected, for instance after cardiovascular surgery or transplantation of mar- 
ginal kidneys. In the setting of organ-transplantation one could also consider donor-treatment and even the addition of AGP to cold preservation-solution in particular when using marginal donors.

In summary, the present study shows that hAGP protects against renal $\mathbb{R} R$ injury by preservation of epithelial integrity, the inhibition of apoptosis and reduction of inflammation. Moreover, the protective effects were shown to be independent from the degree of fucosylation of the AGP protein. We conclude that hAGP, which has been shown to be non-toxic and safe, might be a potential therapeutic agent in the treatment of clinical acute renal failure as seen after renal transplantation.

\section{REFERENCES}

1. Thadhani R, Pascual M, Bonventre JV. Acute renal failure. N Engl J Med 1996; $334(22): 1448$.

2. Daemen MA, Heemskerk VH, van't Veer $C$, et al. Functional protection by acute phase proteins alpha(1)-acid glycoprotein and alpha(1)-antitrypsin against ischemia/reperfusion injury by preventing apoptosis and inflammation. Circulation 2000; 102 (12): 1420.

3. Van Molle W, Denecker $C$, Rodriguez I, Brouckaert $P$, Vandenabeele $P$, Libert $C$. Activation of caspases in lethal experimental hepatitis and prevention by acute phase proteins. I Immunol $1999 ; 163(10): 5235$.

4. Muchitsch EM, Auer W, Pichler L. Effects of alpha 1-acid glycoprotein in different rodent models of shock. Fundam Clin Pharmacol 1998; 12 (2): 173.

5. Libert C, Brouckaert P, Fiers W. Protection by alpha 1-acid glycoprotein against tumor necrosis factor-induced lethality. J Exp Med 1994; 180 (4): 1571.

6. De Graaf TW, Van der Stelt $M E_{\text {, }}$ Anbergen $M G_{\text {, van }}$ Dijk W. Inflammation-induced expression of sialyl Lewis $X$-containing glycan structures on alpha 1 -acid glycoprotein (orosomucolid) in human sera. J Exp Med 1993; 177 (3): 657.

7. Williams JP, Weiser MR, Pechet TT, Kobzik L, Moore FD, Jr., Hechtman HB. alpha 1-Acid glycoprotein reduces locall and remote injuries after intestinal ischemia in the rat. Am J Physilol 1997; 273: G103».

8. Hochepied $T$, Berger FG, Baumann $H$, Libert $C$. alpha(1)-Acid glycoprotein: an acute phase protein with inflammatory and immunomodulating properties. Cytokine Growth Factor Rev $2003 ; 14(1): 25$.

9. Fournier T, Medjoubi NN, Porquet D. Alpha-1 1-acid glycoprotein. Biochim Biophys Acta 2000; 1482:157.

10. Vasson MP, Roch-Arveiller M, Couderc R, Baguet JC, Raichvarg D. Effects of alpha-1 acid glycoprotein on human polymorphonuclear neutrophils: influence of glycan microheterogeneity. Clin Chim Acta 1994; 224 (1): 65.

11. Libert C, Hochepied T, Berger FG, Baumann H, Fiers W, Brouckaert P. High-level constitutive expression of alpha 1 -acid g/ycoprotein and lack of protection against tumor necrosis factor-induced lethal shock in transgenic mice. Transgenic Res 1998; 7 (6): 429.

12. Hao $Y L$, Wickerhauser M. Development of large-scale fractionation methods. IV. A simple method for the large-scale preparation of alphal wacid glycoprotein. Biochim Biophys Acta $1973 ; 322(1): 99$.

13. De Vries $B$, Matthijsen RA, Wolfs TG, Van Bijnen AA, Heeringa $P$, Buurman WA. Inhibition of complement factor $C 5$ protects against renal ischemia-reperfusion injury: inhibition of late apoptosis and inflammation. Transplantation 2003; 75 (3): 375.

14. Van Dielen FM, van't Veer $C$, Schols $A M$, Soeters PB, Buurman WA, Greve JW. Increased leptin concentrations correlate with increased concentrations of inflamimatory markers in morbidly obese individuals. Int J Obes Relat Metab Disord 2001:25 (112): 1759 . 
15. De Wries B, Matthijsen RA, Van Bijnen $\mathrm{AA}_{4}$, Wolfs TG, Buurman WA. Lysophosphatidic Acid prevents renal ischemia-reperfusion injury by inhibition of apoptosis and complement activation. Am I Pathol $2003 ; 163(1): 47$.

16. Xiao $H$, Heeringa $P, H u P$, et al. Antineutrophil cytoplasmic autoantibodies specific for myeloperoxidase cause glomerulonephritis and vasculitis in mice. 1 Clin Invest $2002 ; 110$ (7): 955.

17. Hochepled T, Van Molle W, Berger FG, Baumann H, Libert C. Involvement of the acute phase protein alpha 1 -acid glycoprotein in nonspecific resistance to a lethal gram-negative infection. J Biol Chem 2000;275 (20): 14903.

18. De Vries B, Kohl J, Leclercq WK, et all. Complement factor C5a mediates renal ischemiareperfusion injury independent from neutrophils: I Immunol 2003; $170(7): 3883$.

19. Daemen MA, van 't Veer $C$, Denecker $G$, et al. Inhibition of apoptosis induced by ischemiareperfusion prevents inflammation. J Clin Invest 1999; 1104 (5): 541.

20. White SR, Williams $\mathrm{P}$, Wojcik $\mathrm{KR}$, et al Initiation of apoptosis by actin cytoskeletal derangement in human airway epithelial cells. Am J Respir Cell Moll Biol 2001; 24 (3): 282.

21. Van de Water B, Kruidering M. Nagelkerke JF. F-actin disorganization in apoptotic cell death of cultured rat renal proximal tubular cells. Am J Physiol 1996; 270 : F593.

22. van de Water B, Nagelkerke JF, Stevens JL. Dephosphorylation of focal adhesion kinase (FAK) and loss of focal contacts precede caspase-mediated cleavage of FAK during apoptosis in renal epithelial cells. J Bloll Chem 1999; 274 (19): 13328.

23. Bergin E, Levine JS, Koln JS, Lieberthal W. Mouse proximal tubular cell-cell adhesion inhibits apoptosis by a cadherin-dependent mechanism. Am J Physiol 2000; 278 (5): F758.

24. Isralli $Z$ H, Dayton PG. Human alpha-1-glycoprotein and its interactions with drugs. Drug Metab Rev 2001; $33(2): 161$.

25. Moore DF, Rosenfell MR, Gribbon PM, Winlove CP, Tsai CM. Alpha-1-acid (AAG, orosomucoid) glycoprotein: interaction with bacterial lipopolysaccharide and protection from sepsis. Inflammation 1997; 21 (1): 69.

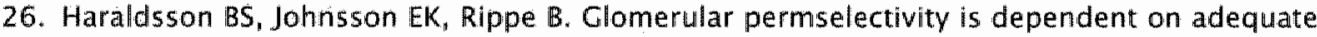
serum concentrations of orosomucoid. Kidney Int 1992; 41 (2): 310.

27. Johnsson $\mathbf{E}$, Haraldsson B. Addition of purified orosomucoid preserves the glomerular permeability for albumin in isolated perfused rat kidneys. Acta Physiol Scand 1993; 147 (1): 1.

28. Hillegass LM, Griswold DE, Brickson B, Albrightson-Winslow C. Assessment of myeloperoxi-

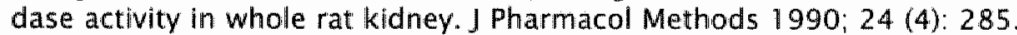

29. Laight DW, Lad N, Woodward B, Waterfall JF. Assessment of myeloperoxidlase activity in renal tissue after ischemia/reperfusion. Eur J Pharmacol 1994; 292 (1):81.

30. Van Molle W, Libert C. Fiers W, Brouckaert P. Alpha 1-acld glycoprotein and alpha $\mathbb{1}$-antitrypsin inhibit TNF-induced but not anti-Fas-induced apoptosis of hepatocytes in mice. $J$ Immunol 1997; $159(7): 3555$.

31. Sorensson J, Ohlson $M_{n}$ Bjornson A, Haraldsson B. Orosomucoid has a CAMP-dependent effect on human endothelial cells and inhibits the action of histamine. Am J Physiol 2000; $278(5): H 1725$

32. Adarmson RH, Liu $B_{*}$ Fry GN, Rubin LL, Curry FE. Microvascular permeability and number of tight junctions are modulated by CAMP. Am J Phys lol 1998; 274: H1885.

33. Friedman CB, Taylor CT, Parkos CA, Colgan SP. Epithelial permeability induced by neutrophil transmigration is potentiated by hypoxia: role of intracellular CAMP. I Cell Physiol $1998 ; 176(1): 76$.

34. Nakamura $A_{1}$ llmaizumi A, Yanagawa $Y$, Niimi R, Kohsaka T, Johns. El. Beta2-adrenoceptor activation inhibits Shiga toxin 2 -induced apoptosis of renal tubular epithellal cells. Biochem Pharmacol 2003; $66(2): 343$.

35. Riera $M_{n}$ Torras $J$, Cruzado $\mathbb{I} M$, et al. The enhancement of endogenous CAMP with pituitary adenylate cyclase-activating polypeptide protects rat kidney against ischemia through the modulation of inflammatory response. Transplantation $2001 ; 72(7): 1217$.

36. Keyler DE, Pentel PR, Haughey DB. Pharmacokinetics and toxicity of high-dose human alpha 1 -acid glycoprotein infusion in the rat. J Pharm Scil 1987; 76 (2): 101. 


\section{CHAPTER

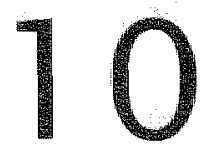

General discussion

Renal ischemia-reperfusion injury: Basic science and clinical applications 
Organ injury as a consequence of ischemia represents a major problem in clinical medicine. Diseases mediated by ischemic injury, in particullar myocardial infarction and cerebrovascular accidents, but also sepsis and shock impose an enormous burden on health-care being the major cause of morbidity and mortality in the Western world [1].

Acute renal failure (ARF) is a common clinical event affecting $2-5 \%$ of all hospitalised patients, and up to 10-30\% of those in intensive care units [2]. Renal ischemia is one of the most important antecedent factors in ARF, causative in $50 \%$ of cases [2]. ARF due to ischemia-reperfusion (I/R) injury is seen after renal transplantation, major abdominal and vascular surgery, coronary bypass surgery, and in trauma and sepsis. ARF is associated with a mortality of approximately $50 \%$, rising as high as $80 \%$ in patients with postoperative ARF, a figure which has not changed in the past decades [2]. In the Western world, clinical ARF is an increasing problem in healthcare. In particular since age is a risk factor for ARF, its incidence is likely to increase in future years. In the field of renal transplantation the same problem rises: the increasing shortage of donor organs, leads to general acceptance of older donors and the increased use of ischemically damaged organs. This results in a more frequent occurrence of post-transplant ARF.

To improve patient care, studies giving insight in the molecular and cellular processes leading to development of clinical ARF are of crucial importance. Despite all the advances in the understanding of experimental ARF, no effective therapy has yet emerged in clinical ARF. In fact, the only available therapy for clinical ARF is renal replacement therapy. A major discrepancy between experimental and clinical studies lies in the fact that most experimental studies are based on single insults such as ischemia-reperfusion, drugs or toxins, radiocontrast agents and rhabdomyolysis. In contrast, human ARF is often multifactorial. Moreover, whereas the onset and duration of ischemia in experimental models is well-defined, in clinical ischemic ARF the onset, duration and degree of ischemia/hypoxia are variable and often hard to determine. Recent focus on experimental models based on multiple insults appear to resemble the complex nature of clinical ARF in a better way [3, 4]. In contrast, post transplant ARF in the clinical situation, especially after NHB organ transplantation, is mainly due to isolated warm ischemia. Using recent experimental insights, new potent tools to improve patient care, in particular in clinical transplantation are emerging, as is discussed below.

\section{Ischemia-induced apoptosis}

In both human and mouse models for renal warm ischemia we have demonstrated the initiation of the apoptotic cascade during warm ischemia (Chapter 2). The degree of apoptosis initiated during warm ischemia correlates well with the duration of ischemia and subsequent organ injury. In clinical trans- 
plantation, apoptotic cell-death has been demonstrated in post-transplant biopsies [5]. The induction of pro-apoptotic proteins in pre-transplant biopsies has also been correlated with duration of cold-ischemia in clinical transplantation [6]. This suggests that proteins involved in the apoptotic process determined in pre-transplant kidney biopsies could estimate ischemic damage, either warm or cold, and thereby predict concomitant graft function. Indeed apoptotic cell-death detected in pre-transplant biopsies of heart-beating donors has been shown to have predictive value on early renal allograft function [7]. These data also implicate that apoptosis initiated during warm ischemia plays an important role in the pathophysiology of $I / R$ injury.

Experimental work from our group has demonstrated the crucial role of apoptotic cell-death in $1 / R$ injury [8-10]. Interventions using anti-apoptotic agents, such as the specific caspase-inhibitor ZVAD-fmk, are new potent therapeutic strategies in reducing renal I/R injury [8]. Also anti-apoptotic survival factors, such as LPA, ICF-1 and HGF have been successfully used in experimental models [8-11]. Human studies have to confirm the great potential of the inhibition of apoptosis as a therapeutic strategy in the treatment of clinical ARF. The administration of anti-apoptotic agents in acute disorders such as post-transplant ARF would be short-termed, thereby diminishing the potential carcinogenic effect of these agents, which is generally feared when inhibiting cell death in human disease. Also anti-apoptotic treatment during cold storage would be a feasible option to circumvent systemic effects of apoptosis inhibition in clinical transplantation [12]. Currently, a double-blind, placebo-controlled phase II trial is initiated to evaluate the effects of a caspase-inhibitor given to patients undergoing liver transplantation. In this trial the caspase-inhibitor is administered to the donor organ (in the preservation fluid) as well as intravenously to the transplant recipient on the first day after surgery.

\section{I/R injury and the complement-system}

Renal apoptosis has been shown to be functionally involved in the induction of inflammation after renal ischemia $[8,9]$. This inflammatory response is believed to play a central role in the pathophysiology of renal $1 / \mathbb{R}$ injury [9]. Our recent work indicates that the complement system is activated in experimental renal I/R injury $[13,14]$. However, via which pathway(s) the complement system is activated in the course of renal I/R remains unclear. Park et all. demonstrated that renal $I / R$ does not induce $\lg G$ or $\lg M$ deposition [15]. Moreover, RAG-1 $\%$ mice subjected to I/R showed renal complement deposition, indicating that renal $I / R$ is not mediated via the classical pathway [15].

Recently, Thurman et al. showed that the alternative complement pathway is involved in experimental I/R injury [16]. Our work indicates that also the MBLpathway is activated in experimental but also clinical I/R injury (Chapter 6) [17]. 
Based on these results one could hypothesize that the alternative pathway is not the initiating pathway of ischemia-induced complement-activation but rather functions as an enhancing pathway.

In experimental models, deficiencies of complement-factors have been shown to be protective against renal $1 / R$ injury whereas the lack of endogenous complement-regulators aggravated renal injury [1 6, 1 8,1 9]. Also various therapeutic interventions inhibiting complement-activation have provided evidence that the complement system plays an important pathophysiological role in experimental $1 / R$ injury $[13,14,20,21]$. In experimental transplantation models complement-inhibition has been shown to reduce ischemia-reperfusion injury as well as allograft rejection and improve short and long term graft outcome [22]. Also in clinical transplantation we observe activation of the complement-system shortly after transplantation of ischemically injured kidneys (Chapter 6). This implies that in clinical transplantation complement-inhibition could have beneficial effects in particular in the context of NHB kidney transplantation. Recent clinical trials using a recombinant, single chain, anti-C5 monoclonal antibody (which prevents activation of $\mathrm{C} 5$ into $\mathrm{C} 5 \mathrm{a}$ and $\mathrm{C5b}$ ) in acute myocardial infarction and cardiopulmonary bypass surgery are promising [23-27]. Clinical trials applying complement-inhibition in renal transplant recipients and potentially patients suffering ARF are awaited for. Recently a randomized, double blind, placebo-controlled phase II trial has started to evaluate the effects a novel membrane-targeted complement regulator in patients receiving a renal transplant. Also isolated organ treatment prior to transplantation would be an opportunity, as has been shown in experimental kidney transplantation [22].

\section{The role of redox-active iron in I/R injury}

Although the molecular mechanisms underlying renal $\| / R$ injury are only partially understood, oxidative stress and the formation of oxygen free radicals are considered to be essentially involved in the pathophysiology of $I / R$ injury [28]. Oxygen free radicals have been reported to crucially mediate the induction of apoptotic as well as necrotic cell-death and subsequent inflammatory responses in the course of $I / R$ injury [28, 29]. Redox-active iron catalyses the formation of tissue damaging oxygen free radicals [30]. Moreover redox-active iron is capable of activating the complement-system, which is crucially involved in renal //R injury, via direct (cleavage of C5) as well as indirect mechanisms (oxygen free radicals) [31-33]. These data suggest that redox-active iron, in particular in the extracellular environment, could be involved in ischemia-induced complement-activation and subsequent organ failure. Indeed, redox-active iron is released during I/R injury in several organ systems $[34,35]$. Applying a rat model for warm renal I/R injury, Baliga et al. showed that levels of redox-active iron in renall tissue are increased during reperfusion [34]. 
Also cold ischemia thas been indicated to induce tissue accumulation of redox-active iron, which is considered a critical step in cold-storage induced injury $[36,37]$. It is hypothesized that ischemia, either warm or cold, induces the release of iron from its normal intracellular storage sites. Recent work provides evidence that besides intracellular, also extracellular iron might play an important role in the pathophysiology of $1 / R$ injury [38]. Indeed, systemic hypoxia has been shown to increase the amount of free iron in the circulation [39]. In a mouse model for renal I/R injury we have shown for the first time that a local ischemic insult gives rise to the release of redox-active iron into the circulation during reperfusion. Treatment with apotransferrin, an endogenous circulating iron-binding protein, reduced the amount of circulating redox-active iron and abrogated renal superoxide formation. Apotransferrin, dose-dependently inhibited post-ischemic inflammation and organ failure. Also iron-scavenging with deferoxamine is protective against $I / R$ mediated organ failure in experimental models $[34,35,40]$. Thus, redox-active iron appears to be crucially involved in experimental $I / R$ injury.

In clinical I/R injury the role of redox-active iron is largely unresolved. We therefore have investigated the release of redox-active iron during machinepreservation of ischemically injured Non-Heart Beating (NHB) donor kidneys. During machine preservation redox-active iron was released into the preservation fluid in substantial amounts depending on the type of donor. Whereas the amount of redox-active iron released from heart-beating (HB) donor kidneys was limited, redox-active iron levels increased evidently in ischemically injured NHB donor kidneys. Redox-active iron levels correlated well with donor characteristics, such as warm ischemic injury. Moreover, redox-active iron levels during machine preservation adequately predicted post-transplant organ failure of ischemically injured kidneys. Therefore pre-transplant assessment of redox-active iron levels could potentially be used for viabilitytesting of ischemically injured organs. Next to diagnostic importance in the assessment of graft-viability the presence of redox-active iron in perfusion fluid during machine preservation is likely to have pathophysiological relevance. Recently, the formation of oxygen free radicals during machine preservation has been reported prognostic for delayed graft function in clinical transplantation [41]. In concordance with our data this would implicate that the release of redox-active iron and subsequent oxygen free radical formation during warm and/or cold ischemic injury are essentially involved in post-transplant organ failure. Preliminary data from our laboratory indicate that the addition of apotransferrin to UW preservation fluid, in vitro as well as during clinical machine preservation, is highly effective in scavenging redox-active iron.

Thus apotransferrin added to UW during machine preservation could potentially ameliorate ischemic injury and thereby improve functional outcome in the setting of clinical NHB kidney transplantation. In line, a recent clinical randomised trial demonstrates that the addition of among others anti- 
oxidants to UW during machine preservation of $H B$ donor kidneys improves early graft function after transplantation [42]. These clinical studies, in combination with data obtained from experimental studies, suggest that the addition of iron-scavengers during machine preservation, and possibly recipient treatment after transplantation, could improve functional outcome of transplanted ischemically injured organs $[42,43]$. A major advantage regarding the use of apotransferrin as a clinical treatment of acute renal failure is that apotransferrin has already been used safely in clinical studies without drug-related adverse effects [44, 46-49]. Apotransferrin treatment binds circulating redoxactive iron very efficiently after myeloablation in haematological stem cell transplant patients [44]. Thus, apotransferrin may be a potential safe ironscavenger in the treatment of disease states mediated by $I / R$ injury.

\section{Treatment strategies in clinical $/ / R$ injury}

Apoptosis, necrosis or non-lethal cell injury [50], ATP or GTP [51], oxidative or nitrosative stress [52], innate or adaptive immunity [21,53,54], complement, chemokines or cytokines $[21,55,56]$, neutrophils, macrophages, $T$ - or $\mathrm{B}$-cells $[54,57,58]$, all have been implicated to be play a crucial role in renal I/R injury; indicating that renal I/R injury is complex, involving multiple interacting pathways [59]. This also stresses the need for interventions interfering with multiple pathways in the treatment of renal I/R injury. In particular since, interventions acting on individual pathways, though effective in experimental models, have been deemed ineffective in the treatment of clinical ARF [60-64].

The acute phase protein ACP has been shown, in a wide variety of in vitro and in vivo models, to interfere with various processes which are involved in I/R injury. Among others, AGP inhibits apoptotic cell-death, reduces influx of neutrophils, reduces activation of neutrophils, inhibits platelet aggregation, inhibits complement-activation and preserves endothelial barrier function [65]. In our experimental model AGP has been shown protective against renal I/R injury by inhibition of apoptotic cell-death, preservation of epithelial cellstructure and cell-cell interaction, inhibition of complement-activation and reduction of neutrophil-infiltration. Therefore we suggest that AGP treatment, interfering with multiple pathways, could potentially provide efficient protection against clinical ARF such as observed after NHB renal transplantation. Especially since AGP is an endogenous protein clinical trials appear tempting.

Combination therapy is another promising way of interfering with the multiple pathways involved in experimental and in particular in clinical I/R injury [66]. A recent randomized clinical trial using a combined intervention, interfering with oxidative stress, vasoconstriction, platelet aggregation and inflammation, during machine preservation showed an impressive effect on posttransplant acute renal failure, indicating that combination therapy is a promising strategy to treat clinical $I / R$ injury [67]. 
Taken together, although ARF is a common clinical event and results in an unacceptably high morbidity and mortality, currently no effective treatment is available. However, recent experimental work applying new experimental models and evaluating new therapeutic strategies has provided potent tools to ultimately overcome clinical ARF. Current clinical studies are promising and will hopefully lead to adequate medical care for the patient suffering ARF.

\section{REFERENCES}

1. World Health Organization. The World Health Report 2002. Available at: http://www.who.int/whr/previous/en/. Accessibility verified Juny 16, 2004.

2. Thadhani R, Pascual M, Bonventre JV. Acute renal failure. N Engl J Med 1996;334(22):1448-60.

3. Burne-Taney $M$ J, Kofler J, Yokota $N$, Weisfeldt $M_{3}$, Traystman R, Rabb $H$. Acute renal failure after whole body ischemia is characterized by inflammation and $T$ cell-mediated injury. Am J Physiol Renal Physiol 2003;285(1):F87-94.

4. Miyaji T, Hu X, Yuen PS, Muramatsu Y, Iyer S, Hewitt SM, et al. Ethyl pyruvate decreases sepsis-induced acute renal failure and multiple organ damage in aged mice. Kidney int 2003;64(5):1620-31.

5. Burns AT, Davies DR, Mclaren AJ, Cerundolo L, Morris PJ, Fuggle 5V. Apoptosis in ischemia/reperfusion injury of human remall allografts. Transplantation 1998;66(7):872-6.

6. Castaneda MP, Swiatecka-Urban A, Mitsnefes MM, Feuerstein $D$, Kaskel FJ, Tellis $V_{n}$ et all. Activation of mitochondrial apoptotic pathways in human renal allografts after ischemiareperfusion injury. Tramsplantation 2003:76(1):50-4.

7. Oberbauer R, Rohrmoser M, Regele H, Muhlbacher F, Mayer G. Apoptosis of tubular epithelial cells in donor kidney biopsies predicts early renal allograft function. I Am Soc Nephrol $1999 ; 10(9): 2006-113$.

8. Daemen $M A_{n}$ van "t Veer $C$, Denecker $G$, Heemskerk VH, Wolfs TG, Clauss $M$, et al. Inhibition of apoptosis induced by ischemlia-reperfusion prevents inflammation. J Clin Invest 1999;104(5):541-9.

9. Daemen $M A$, de Vries $B$, Buurman WA. Apoptosis and inflammation in remal reperfusion injury. Transplantation 2002;73(11); 693-700.

10. De Vries B, Matthijsen RA, van Bijnen AA, Wolfs TG, Buurman WA. Lysophosphatidic acid prevents renal ischemia-reperfusion injury by inhibition of apoptosis and complement activation. Am J Pathol 2003;163(1):47-56.

11. Okusa MD, Ye H, Huang L, Sigismund L, Macdonald T, Lynch KR. Selective blockade of \|ysophosphatidic acid $L P A 3$ receptors reduces murine renal ischemia-reperfusion injury. Am J Physiol Renal Physiol 2003:285(3):F565-74.

12. Natori $S$, Higuchi $H$, Contreras $P$, Gores $G$. The caspase inhibitor IDN-6.556 prevents caspase activation and apoptosis in sinusoidal endothelial cells during liver preservation injury. Liver Transpl 2003:9(3):278-84.

13. De Vries $B$, Kohl J, Leclercq WK, Wolfs TG, van Bijnen AA, Heeringa $P$, et al. Complement factor $\mathrm{C} 5$ a mediates renall ischemia-reperfusion injury independent from neutrophils. J Immunol $2003 ; 170(7): 3883-9$.

14. De Vries B, Matthijsen RA, Wolfs TG, Van Bijnen AA, Heeringa P, Buurman WA, Inhibition of complement factor $C 5$ protects against remal ischemia-reperfusion injury: inhibition of late apoptosis and inflammation. Transplantation 2003;75(3):375-82.

15. Park $P$, Haas $M$, Cunningham $P N$, Bao $L$, Alexander $ل$, Quigg $R J$. Injury in renal ischemia-reperfusion is independent from immunoglobulins and T lymphocytes. Am I Physiol Renal Physiol $2002 ; 282(2): F 352-7$. 


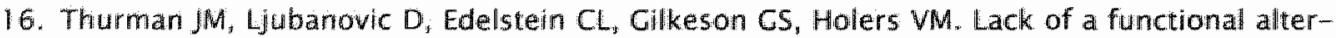
native complement pathway ameliorates ischemic acute renal failure in mice. I Immunol $2003 ; 170(3): 1517-23$.

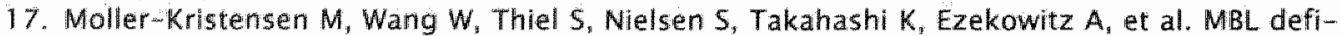
clency protects from renal ischema reperfusion injury. Abstract from the $X \times x$ th International Complement Workshop. Molecular Immunology 2004:41:280-1.

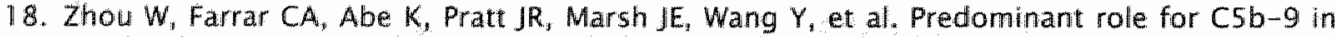
renal ischemia/reperfusion injury. J Clin inwest 2000; $705(10): 1363-71$.

19. Yamada K, Miwa $T$, Liu J, Nangaku M, Song WC. Critical protection from renal ischemia reperfusion injury by CD55 and CD59. J Immunol 2004;172(6):3869-75.

20. Arumugam TV, Shiels IA, Strachan AV, Abbenante $G$, Fairlie DP, Taylor SM. A small molecule C5a receptor antagonist protects kidneys from ischemia/reperfusion injury in rats. Kidney int $2003 ; 63(1): 1344-42$.

21. Arumugam TV, shiels IA, Woodruff TM, Granger DN, Taylor SM. The role of the complement system in ischemia -reperfusion injury. Shock 2004:21(5):401-9.

22. Pratt JR, Jones ME, Dong J, Zhou W, Chowdhury P. Smith RA, et al. Nontransgenic hyperexpression of a complement regullator in donor kidney modulates transplant ischemia/reperfusion damage, acute rejection, and chronic nephropathy. Am \Pathol 2003;163(4):1457-65.

23. Fitch JC, Rollins S, Matis L. Alford B, Aranki S, Collard CD, et al. Pharmacology and biological efficacy of a recombinant, humanized, single-chain antibody $C 5$ complement inhibitor in patients undergoing coronary artery bypass graft surgery with cardiopulmonary bypass. Circulation 1999, 100(25):2499-506.

24. Granger CB, Mahaffey KW, Weaver WD, Theroux $P$, Hochman JS, Filloon TG, et al. Pexelizumab. an anti-C5 complement antibody, as adjunctive therapy to primary percutaneous coronary intervention in acute myocardial infarction: the COMplement inhibition in Myocardial infarction treated with Angioplasty (COMMA) trial. Circulation 2003;108(10):11 84-90.

25. Mahaffey KW, Granger CB, Nicolau JC, Ruzyllo W, Weaver WD, Theroux $P$, et al. Effect of pexelizumab, an anti-C5 complement antibody, as adjunctive therapy to fibrinolysis in acute myocardial infarction: the COMPlement inhibition in myocardial infarction treated with thrombolYtics (COMPLY) trial. Circulation 2003;108(10):1176-83.

26. Shernan SK, Fitch JC, Nussmeier NA, Chen JC, Rollins SA, Mojcik CF, et al. Impact of pexelizumab, an anti-C5 complement antibody, on total mortality and adverse cardiovascular outcomes in cardiac surgical patients undergoing cardiopulmonary bypass. Ann Thorac 5 urg 2004;77(3):942-9; discussion 949-50.

27. Verrier ED, Shernan SK, Taylor KM, Van de Werf F, Newman MF, Chen JC, ett al. Terminall complement blockade with pexelizumab during coronary artery bypass graft surgery requiring Cardiopulmonary bypass: a randomized trial. Jama 2004;291(19):2319-27.

28. Lloberas $N$. Torras J, Herrero-Fresneda I, Cruzado JM, Riera M, Hurtado I, et al. Postischemic renal oxidative stress induces inflammatory response through PAF and oxidized phospholipids. Prevention by antioxidant treatment. Faseb J 2002;16(8):908-10.

29. Chien CT, Lee PH, Chen CF, Ma MC, Lai MK, Hsu SM. De novo demonstiation and co localization of free-radical production and apoptosis formation in rat kidney subjected to ischemia/reperfusion. J Am Soc Nephrol 2001;12(5):973-82.

30. Pietrangelo A. Physiology of iron transport and the hemochromatosis gene. Am 』Physiol Gastrointest Liver Physiol 2002;282(3):G403-14.

31. Governa $M$, Fenoglio I. Amati M, Valentino $M$, Bolognini $L$, Coloccini $S$, et al. Cleavage of the fifth component of human complement and release of a split product with C5a-like activity by crystalline slica through free radical generation and kallikrein activation. Toxicol App Pharmacol 2002; 179(3): : 29-36.

32. Vogi $W$. Nolte $R$, Brunahl $D$. Binding of iron to the 5 th component of human complement directs oxygen radical-mediated conversion to specific sites and causes nonenzymic activation. Complement Inflamm 1991;8(5-6):313-9. 
33. Vogt $W$, Damerau $B$, von Zabern $\|$ Nolte R, Brunahl D. Non-enzymic activation of the fifth component of human complement, by oxygen radicals: Some properties of the activation product, C5b-like C5. Mol Immunol 1989;26(12): I1 133-42.

34. Baliga R, Ueda $N$, Shah SV. Increase in bleomycin-metectable iron in ischaemia/reperfusion injury to rat kidneys. Biochem J 1993;291 (Pt 3):901-5.

35. Kirschner RE, Fantini CA. Role of iron and oxygen-derived free radicals in ischemia-reperfusion injury. J Am Coll Surg 1994:179(1):103-17.

36. Healing G, Gower J, Fuller B, Green C. Intracellular iron redistribution. An important determinant of reperfusion damage to rabbit kidneys. Biochem Pharmacol 1990;39(7):1239-45.

37. Huang $H$, Salahudeen $A K$. Cold induces catalytic iron release of cytochrome $P-450$ origin: a critical step in cold storage-induced renal injury. Am J Transplant 2002;2(7);631-9.

38. Tacchini L, Fusar Poll D, Bernelli-Zazzera A, Cairo G. Transferrin receptor gene expression and transferrin-bound iron uptake are increased during postischemic rat liver reperfusion. Hepatology" $2002 ; 36(1): 103-11$.

39. Dorrepaal $C A_{*}$ Berger $H M$, Benders $M J$, van Zoeren-Grobben $D$, Van de Bor $M$, Van Bel $F$. Nonprotein-bound iron in postasphyxial reperfusion injury of the newborm. Pediatrics 1996;98(5):883-9.

40. Green CJ, Gower JD, Healing G, Cotterill LA, Fuller BJ, Simpkin S. The importance of iron, calcium and free radicals in reperfusion injury: an overview of studies in ischaemic rabbit kidneys. Free Radic Res Commun 1989;7(3-6):255-64.

41. Kosieradzki M, Kuczynska J. Piwowarska J, Wegrowicz-Rebandel I, Kwiatkowski $A_{1}$ Lisik W, et al. Prognostic significance of free radicals: mediated injury occurring in the kidney donor. Transplantation 2003;75(8):1221-7.

42. Guarrera JV, Polyak M, Arrington BO, Kapur S, Stubenbord WT, Kinkhabwala M. Pulsatile Machine Perfusion with Vasosol Solution Improves Early Graft Function after Cadaveric Renal Transplantation. Transplantation 2004;77(8):1264-1268.

43. Baron $P$, Comez-Marin $O$, Casas $C$, Heil $J$, Will $N$, Condie $R$, et al. Renal preservation after warm ischemia using oxygen free radical scavengers to prevent reperfusion injury. J Surg Res $1991 ; 51(1): 60-5$.

44. Sahlstedt $L$, von Bonsdorff $L$, Ebeling $F$, Ruutu $T$, Parkkinen J. Effective binding of free iron by a single intravenous dose of human apotransferrin in haematological stem cell transplant patients. Br J Haematol 2002;1 19(2):547-53.

45. Dragsten PR, Hallaway PE, Hanson GJ, Berger AE, Bernard B, Hedlund BE. First human studies with a high-molecular-weight iron chelator. J Lab Clin Med 2000;135(1):57 65.

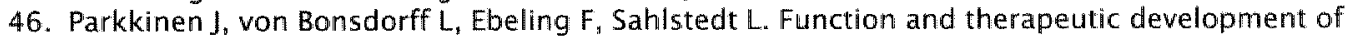
apotransferrin. Vox Sang 2002;83 Suppl 1:321-6.

47. Von Bonsdorff L, Tolo $H_{*}$ Lindeberg E, Nyman T, Harju A, Parkkinen J. Development of a pharmaceutical apotransferrin product for iron binding therapy. Biologicals $2001 ; 29(1) ; 27-37$.

48. Von Bonsdorff $L$, Sahlstedt L., Ebeling $F$, Ruutu T, Parkkinen J. Apotransferrin administration prevents growth of Staphylococcus epidermidis in serum of stem cell transplant patients by binding of free iron. FEMS Immunal Med Microbiol 2003:37(11):45-51.

49. Fellman $V$, von Bonsdorff $L$, Parkkinen $\rfloor$. Exogenous apotransferrin and exchange transfusions in hereditary iron overload disease. Pediatrics 2000; 105(2):398-401.

50. Padanilam BJ. Cell death induced by acute renal injury: a perspective on the contributions of apoptosis and necrosis. Am J Physiol Renal Physiol 2003;284(4):F608-27.

51. Kelly $\mathrm{KJ}$, Plotkin $Z_{n}$ Dagher $P C$. Guanosine supplementation reduces apoptosis and protects renal function in the setting of ischemic injury. J Clin Invest 2001;108(9):1291-8.

52. Noiri $E$, Nakao $A$, Uchida $K$, Tsukahara $H$, Ohno $M$, Fujita $T$, et al. Oxidative and nitrosative stress in acute renal ischemia. Am J Physiol Renal Physiol 2001;281(5):F948-57.

53. Rabb $H$. The $T$ cell as a bridge between innate and adaptive immune systems: implications for the kidney. Kidney Int 2002;61 (6):1935-46.

54. Burne-Taney MJ, Ascon DB, Daniels F, Racusen L, Baldwin W, Rabb H. B cell deficiency confers protection from renal ischemia reperfusion injury. J llmmunol 2003;171(6):3210-5. 
55. Miura $M$, Fu $X$, Zhang $O W$, Remick $D G$, Fairchild $R L$. Neutralization of Gro alpha and macrophage inflammatory protein-2 attenuates renal ischemia/reperfusion injury. Am I Pathol 2001:159(6):2137-45.

56. Donnahoo $\mathrm{KK}_{s}$ Shames $\mathrm{BD}_{\mathrm{s}}$ Harken $\mathrm{AH}$, Meldrum DR. Review article: the role of tumor necrosis factor in renal ischemia-reperfusion injury. J Urol 1999;162(1):196-203.

57. Rabb H, Daniels F, O'Donnell M, Haq M, Saba SR, Keane W, et al. Pathophysiological role of T Iymphocytes in renal ischemia-reperfusion injury in mice. Am J Physiol Renal Physiol $2000: 279(3): 5525-31$.

58. Heinzelmann $M_{1}$ Mercer-Jones MA, Passmore JC. Neutrophils and renal failure. Am J Kidney Dis 1999:34(2):384-99.

59. Farrar CA, Wang $Y$, Sacks SH, Zhou W. Independent pathways of P-selectin and complementmediated renal ischemia/reperfusion injury. Am J Pathol 2004;164(1):133-41.

60. Hirschberg $R$, Kopple $J_{11}$ Lipsett $P$, Benjamin $E$, Minei $J_{\text {" Albertson }} T$, et al. Multicenter clinical trial of recombinant human insulin-like growth factor $I$ in patients with acute renal failure. Kidney Int 1999;55(6):2423-32.

61. Solomon R, Werner C, Mann D, D'Elia J, Silva P. Effects of saline, mannitol, and furosemide to prevent acute decreases in renal function induced by radiocontrast agents. $N$ Engl J Med $1994: 331(21): 1416-20$.

62. Denton MD, Chertow GM, Brady HR. "Renal-dose" dopamine for the treatment of acute renal failure: scientific rationale, experimental studies and clinical trials. Kidney $\|$ nt 1996;50(1):4-14.

63. Lewis J, Salem MM, Chertow GM, Weisberg LS, MCGrew F. Marbury TC, et al. Atrial natriuretic factor in oliguric acute renal failure. Anaritide Acute Renal Fallure Study Group. Am J Kidney Dis 2000;36(4):767-74.

64. Allgren RL, Marbury TC, Rahman SN, Weisberg LS, Fenves AZ, Lafayette RA, et all. Anaritide in acute tubular necrosis. Auriculin Anaritide Acute Renal Failure Study Group. N Engl J Med $11997 ; 336(12): 828-34$.

65. Hochepled $T$, Berger $F_{\text {, }}$ Baumann $H$, Libert $C$. Alpha(1)-acid glycoprotein: an acute phase protein with inflammatory and immunomodulating properties. Cytokine Growth Factor Rev $2003 ; 14(1): 25-34$.

66. Kelly KJ, Molitoris BA. Acute renal fallure in the new millennium: time to consider combination therapy. Semin Nephroll 2000;20(1):4-19.

67. Guarrera JV, Polyak M, O'Mar Arrington B, Kapur S, Stubenbordl WT, Kinkhabwala M. Pulsatile machine perfusion with wasosol solution improves early graft function after cadaveric renal transplantation. Transplantation 2004;77(8):1264-8. 


\section{CHAPTER ]}

Summary / Samenvatting 
In Chapter $I$ the relevance of ischemia-reperfusion (I/R) injury in renal transplantation is discussed. In particular in the setting of Non-Heart-Beating (NHB) organ donation // $R$ injury is a major concern since it may result in posttransplant organ failure. Therefore $I / R$ injury limits the general acceptance and broad implementation of NHB organs as a source of organs for transplantation. It is of crucial importance to gain insight into the early events which ultimately result in $I / R$ injury and post-transplant organ failure. Therefore the main goals of this thesis were:

* The development of diagnostic methods which can estimate ischemic injury prior to transplantation and thereby predict post-transplant organ function

* The development of effective therapeutic strategies to treat or prevent $l / R$ injury thereby improving post-transplant organ function

In the second section the general pathophysiological principles of $1 / R$ injury are shortly addressed. Initial cellular injury induced by ischemia results in celldeath which can be necrotic or apoptotic. Cell-death subsequently induces an inflammatory response which is regarded to be crucially involved in the development of $I / R$ injury and organ failure.

In the third section of the introduction the basic aspects of apoptotic celldeath in relation to I/R injury are discussed. Next, the role of inflammation, in particular the role of the complement-system in $I / R$ injury is outlined. Renal $I / R$ induces activation of the immune system which is, among others, characterized by complement-activation. The complement-system can be activated via three pathways: the classical pathway (activated by antigen-antibody interaction), the lectin pathway (activated by mannose recognized by mannose binding lectin (MBL)) and the alternative pathway (activated by microbial products). All three pathways ultimately activate complement factor $\mathrm{C5}$ which results in the formation of $\mathrm{C5a}$ and $\mathrm{C5b}$, the latter one being the first step in the formation of the membrane attack complex (MAC). Both the formation of the MAC and the generation of CSa are believed to be important in the pathophysiology of I/R injury.

In Chapter 2 the initiation of apoptotic cell-death during warm ischemia was studied. A human model for warm ischemia was used applying kidneys nephrectomized because of small renal cell carcinoma. Ex vivo, kidneys were stored at $37^{\circ} \mathrm{C}$ and consecutive bilopsies were taken to investigate apoptotic processes. During warm ischemia the renal levels of the pro-apoptotic protein Bax increased. In contrast the anti-apoptotic proteins $\mathrm{BCl}-2$ and cFLIP were depleted in a time-dependent manner. Warm ischemia resulted in the activation of caspase-9, whereas caspase-8 and caspase- 3 were not activated. 
Thus, warm ischemia in the human kidney initiates the apoptotic cascade. Moreover, the duration of ischemia correlates with the degree of activation of the apoptic cascade. Therefore, we hypothesize that the determination of early apoptotic changes allows estimation of ischemic injury prior to transplantation, thereby predicting post-transplant function. Furthermore, this study provides opportunities to delineate targets in apoptotic pathways for pharmacological interventions to reduce clinical manifestations of reperfusion injury.

Since redox-active iron has been implicated in the induction of apoptotic cell-death and inflammation, in Chapter 3 the role of circulating redox-active iron in the development of experimental renal $1 / R$ injury was investigated. Mice were subjected to unilateral renal ischemia for 45 minutes, followed by contralateral nephrectomy and reperfusion. To investigate the role of circulating iron, mice were treated with apotransferrin, an endogenous iron-binding protein, or iron-saturated transferrin (holotransferrin) as control treatment. Renal ischemia induced a significant increase in circulating redox-active iron levels during reperfusion, indicating that during experimental $I / R$ the endogenous iron-binding capacity is overwhelmed. Exogenous apotransferrin, in contrast to holotransferrin, reduced the amount of circulating redox-active iron and abrogated renal oxidative stress as determined by superoxide generation. Apotransferrin treatment did not affect $1 / R$-induced apoptotic cell-death, however holotransferrin aggravated renal apoptosis. Apotransferrin inhibited inflammation, characterized by the influx of neutrophils and activation of the complement-system. Most importantly, apotransferrin, by inhibition of oxidative stress and inflammation, inhibited post-ischemic organ failure. Therefore apotransferrin could potentially be used in the treatment of acute renal failure, as seen after transplantation of ischemically damaged organs.

Based on the experimental data described in Chapter 3, we investigated the involvement of redox-active iron in clinical transplantation in Chapter 4 . We therefore measured redox-active iron levels in preservation fluid during machine-preservation of $218 \mathrm{NHB}$ kidneys which were machine preserved at the University Hospital Maastricht between July 1998 and January 2003 and transplanted within the Eurotransplant region. During machine preservation of NHB donor kidneys, in contrast to heart-beating donor kidneys, redox-active iron was rapidly released into the preservation fluid in substantial amounts. The levels of redox-active iron in the preservation fluid correlated well with donor characteristics, such as warm ischemic injury. Moreover, redox-active iron levels during machine preservation adequately predicted post-transplant organ failure of NHB category 2 donor kidneys, kidneys which most evidently suffer from warm ischemia. These data suggest that redox-active iron is involved in clinical transplantation of ischemically injured organs. Since redox-active iron levels correlate well with post-transplant organ function, pre-transplant assessment of redox-active iron could potentially be used for 
viability-testing of ischemically injured organs. The addition of iron-scavengers to preservation fluid could possibly improve functional outcome of machinepreserved ischemically injured grafts.

In Chapter 5 we investigated the role of the endogenous survival factor lysophosphatidic acid (LPA) in the protection against experimental renal I/R injury. LPA is an endogenous phospholipid growth factor with anti-apoptotic properties. Since the inhibition of apoptosis is protective against $I / R$ injury, we studied the effects of exogenous LPA in a murine model of renal $/ / R$ injury. LPA administered at time of reperfusion dose-dependently inhibited renal apoptosis. $/ / R$-induced renal apoptosis was present in tubular epithelial cells with evident disruption of the brush-border. LPA treatment prevented tubular epithelial cell apoptosis and also reduced the I/R-induced loss of brush-border integrity. Besides, LPA showed strong anti-inflammatory effects, inhibiting the renal expression of TNF- $\alpha$ and abrogating the influx of neutrophils. Next, LPA dose-dependently inhibited activation of the complement-system which is induced by renal I/R. Finally, treatment with LPA almost completely abrogated the loss of renal function in the course of renal $I / R$. This study illustrates that ischemia-induced apoptosis, inflammation, and organ failure can be abrogated by application of endogenous anti-apoptotic compounds and thereby provides new means to treat clinical conditions associated with I/R injury, in the kidney and potentially also in other organs.

Based on the observation in Chapter 5 that experimental renal I/R induces activation of the complement-system in Chapter 6, 7, and 8 we more extensively studied the role of the complement-system in experimental as well as clinical acute renal failure.

First, in Chapter 6 , we demonstrated that the mannose-binding lectin $(\mathrm{MBL})$ pathway is involved in complement-activation in the course of renal $I / R$ injury. In experimental renal $\mathrm{I} / \mathrm{R}$ injury and in clinical post-transplant organ failure we assessed the activation and regulation of the MBL-pathway. Mice subjected to renal $/ / R$ displayed evident renal $M B L$-depositions in the early reperfusion phase indicating activation of the $\mathrm{MBL}$-pathway. In the later reperfusion phase also renal deposition of $C 3, C 6$, and $C 9$ was observed. Deposition of MBL-A and $-C$ completely co-localized with the late complement-factor $C 6$, showing that $M B L$ is involved in complement-activation in the course of renal $I / R$ injury. In serum of mice subjected to renal $I / R, M B L-A$ levels increased in contrast to $M B L-C$ levels which dropped evidently. Finally, in human post-transplant biopsies MBL was deposited early after reperfusion, in contrast to pre-transplant biopsies in which no MBL depositions could be detected. In particular in NHB-grafts displaying post-transplant organ failure extensive MBL depositions were observed in peritubular capillaries and tubular epithelial cells. Taken together, in experimental renal I/R injury and clini- 
cal post-transplant ARF the MBL-pathway is activated, followed by activation of the complement system. These data indicate that the MBL-pathway is involved in ischemia-induced complement-activation.

Next, in Chapter 7, the pathophysiological role of complement-activation in renal $/ / R$ injury was addressed. To investigate the involvement of complement in $I / R$ injury we examined the effect of complement-inhibition on post-ischemic organ failure. Therefore mice were subjected to 45 minutes of unilateral ischemia and subsequent contralateral nephrectomy and reperfusion for 2, 12 or 24 hours. Mice were control-treated or treated with BB5.1, a monoclonal antibody which prevents cleavage of the complementfactor $\mathrm{C} 5$, thereby preventing $\mathrm{C} 5$ a generation and formation of the membrane attack complex (MAC). Renal $I / R$ induced extensive deposition of $C 3$ early after reperfusion, whereas $\mathrm{C} 6$ and $\mathrm{C} 9$-deposition (MAC-formation) occurred relatively late. $\mid / R$-induced complement deposition mainly localized to tubular epithelial cells. Treatment with BB5.1 totally prevented MAC-formation. Inhibition of $C 5$ strongly inhibited late inflammation, as measured by neutrophil-influx and induction of the murine $\mathrm{C}-\mathrm{X}-\mathrm{C}$ chemokines macrophage inflammatory protein-2 (MIP-2), KC and LPS-induced $C-X-C$ chemokine (LIX). Anti-C5 treatment furthermore abrogated late I/R-induced apoptosis whereas early apoptosis was not affected. Finally, BB5.1 treatment significantly protected against I/R-induced organ failure. These data show that complement-activation is crucially involved in the regulation of both apoptosis and inflammation in the course of renal $I / R$ injury. Moreover, complement-inhibition is strongly protective against the development of post-ischemic acute renal failure.

In Chapter 8 the specific role of complement-factor $\mathrm{C} 5 \mathrm{a}$ and its interaction with the $\mathrm{C} 5 \mathrm{a}$-receptor ( $\mathrm{C} 5 \mathrm{aR}$ ) in the development of postischemic acute renal failure was examined. We analysed the expression of the C5aR in kidneys of healthy mice. The C 5 aR was expressed on mesangial as well as tubular epithelial cells. After $1 / R$ injury, C5aR expression was upregulated in tubular epithelial cells. In addition, after renal I/R mRNA levels of $\mathrm{C}-\mathrm{X}-\mathrm{C}$ chemokines and TNF- $\alpha$ increased significantly and kidneys were heavily infiltrated by neutrophils. Blocking the C5aR pathway applying a specific $C 5$ a receptor antagonist (C5aRA) abrogated upregulation of $C-X-C$ chemokines but not of TNF- $\alpha$ and significantly reduced neutrophil infiltration. Application of the C5aRA abrogated post-ischemic organ failure. The improvement of renal function was independent of the presence of neutrophils since neutrophil depletion (with the monoclonal antibody NIMP-R 14) did not affect the protective effect of C5aRA treatment. Furthermore, blocking of the $C 5$ a receptor pathway had no influence on renal apoptosis. These data provide evidence that $\mathrm{C} 5 \mathrm{a}$ is crucially involved in the pathogenesis of renal I/R injury by modulation of PMN dependent as well as PMN independent pathways, which include the regulation of $\mathrm{C}-\mathrm{X}-\mathrm{C}$ chemokines but not TNF- $\alpha$ or apoptotic pathways. 
Thus, the complement-system is activated in the course of renal $/ / R$ injury. Post-ischemic activation of the complement-system is, at least partially, mediated by the MBL-pathway. The complement-system is crucially involved in ischemia-induced cell-death, inflammation and organ failure, in which MAC and C5a play different but significant roles.

In Chapter 9 the protective effects of the acute phase protein $\alpha-1$-acid glycoprotein (AGP) against experimental $/ / R$ injury were studied. AGP has been described to regulate apoptosis, complement-activation, neutrophil-influx and neutrophil-activation, all processes crucially involved in renal $1 / \mathbb{R}$ injury. Therefore the effects of exogenous as well as endogenous AGP were studied in our mouse model for renal I/R injury. Mice were subjected to renal $I / R$ and treated with human AGP, fucose-depleted human AGP (since fucose-groups expressed on the AGP protein potentially mediate the effects of AGP), or control-treated. Also transgenic mice overexpressing rat-AGP or wild type controls were subjected to renal I/R. Treatment with AGP as well as fucosedepleted AGP protected mice against I/R-induced acute renal failure. Surprisingly, AGP-overexpressing mice were not protected against $1 / R$ injury. Both natural and fucose-depleted AGP inhibited activation of the complementsystem and influx of neutrophils. Tubular epithelial cell-structure (actin-cytoskeleton) and cell-cell interaction (tight-junction architecture) were completely preserved in AGP-treated mice. Epithelial caspase-activation and apoptotic DNA-cleavage were prevented by AGP treatment. Thus, both natural and fucose-depleted AGP protect against renal I/R injury by preservation of tubular epithelial structure, inhibition of apoptosis and subsequent inflammation. Therefore AGP can be regarded as a potential new therapeutic intervention in the treatment of acute renal failure, as seen after transplantation of ischemically injured kidneys.

Finally, in Chapter 10, the possible clinical application of the experimental studies described in the present thesis was discussed. These and other experimental studies will hopefully result in new therapeutic interventions in the treatment of patients suffering acute renal failure. 
In Hoofdstuk 1 werd de relevantie van ischemie-reperfusie (1/R) schade met betrekking tot niertransplantaties besproken. Met name in het kader van NonHeart-Beating (NHB) orgaandonatie speelt I/R schade een belangrijke rol omdat I/ $R$ vaak resulteert in orgaanfalen na transplantatie. I/ $R$ schade limiteert op deze manier de algemene acceptatie en brede implementatie van NHB orgaandonoren als een bron van organen voor transplantatie.

Het is van groot belang inzicht te verkrijgen in de vroege processen die leiden tot het ontstaan van $I / R$ schade en orgaanfalen na transplantatie. Daarom waren de twee belangrijkste onderzoeksdoelen voor het voorliggende proefschrift :

* De ontwikkeling van diagnostische middelen die de mate van ischemische schade voor transplantatie kunnen vaststellen en op die manier het orgaan-functioneren na transplantatie kunnen voorspellen

* De ontwikkeling van effectieve therapeutische middelen om I/R schade te voorkomen of te reduceren om daarmee het functioneren van een getransplanteerd orgaan te verbeteren

In het tweede deel van Hoofdstuk 7 werden de algemene pathofysiologische principes van $1 / R$ schade kort toegelicht. Initiële ischemie-geïnduceerde celschade resulteert in celdood, necrotisch danwel apoptotisch. Celdood leidt vervolgens tot een ontstekingsreactie die als essentieel beschouwd wordt in het ontstaan van $1 / R$ schade en orgaanfalen.

In het derde deel van de introductie werden de basale aspecten van apoptotische celdood in relatie met $I / R$ schade besproken. Vervolgens werd de rol van ontsteking in thet ontstaan van I/R schade verder toegelicht. Met name de rol van het complement-systeem, als onderdeel van de ontstekingsreactie, werd besproken. Het complement-systeem kan worden geactiveerd via één van de volgende drie routes: de klassieke route (geactiveerd door antigeenantilichaam interactie), de lectin route (geactiveerd door mannose dat herkend wordt door 'mannose binding lectin' (MBL)) en de alternatieve route (geactiveerd door microbiële producten). Alle drie de routes leiden tot activatie van complement factor $\mathrm{C} 5$, resulterend in de vorming van $\mathrm{C} 5 \mathrm{a}$ en $\mathrm{C} 5 \mathrm{~b}$, waarbij $\mathrm{C} 5 \mathrm{~b}$ de eerste stap vormt in de vorming van het 'membrane attack complex" (MAC). Het MAC alsook C5a spelen mogelijk een belangrijke rol in de pathophysiologie van I/R schade.

In Hoofdstuk 2 werd de inductie van apoptotische celdood ten gevolge van warme ischemie bestudeerd. Humane nieren, verwijderd vanwege een niercelcarcinoom, werden ex vivo bij $37^{\circ} \mathrm{C}$ bewaard en in de tijd werden biopten genomen om apoptotische processen te analyseren. Gedurende warme ischemie nam de hoeveelheid van het pro-apoptotische eiwit Bax in de nier sterk toe. Daarentegen nam de hoeveelheid van de anti-apoptotische eiwitten 
BCl-2 en CFLIP af gedurende ischemie. Warme ischemie leidde tot de activatie van caspase- 9 , terwijl caspase- 8 en caspase -3 niet werden geactiveerd. Deze data laten zien dat warme ischemie in de humane nier leidt tot de activatie van apoptotische processen. Bovendien correleert de duur van de ischemie met de mate van activatie van deze apoptotische processen. Het bepalen van vroege apoptotische veranderingen kan potentieel gebruikt worden om vóór transplantatie ischemische schade vast te stellen en op die manier orgaan-functioneren na transplantatie te voorspellen. Bovendien, bieden de verworven inzichten de mogelijkheid om middels farmacologische interventies in te grijpen in deze apoptotische processen om daarmee het optreden van I/R schade te verminderen.

Aangezien redox-actief ijzer een rol speelt bij de inductie van apoptose en ontsteking werd in Hoofdstuk 3 de rol van circulerend redox-actief ijzer bij het ontstaan van renale $1 / R$ schade onderzocht. Muizen werden blootgesteld aan 45 minuten ischemie van de linker nier, gevolgd door het verwijderen van de rechter nier en reperfusie. De rol van redox-actief ijzer werd onderzocht door muizen te behandelen met apotransferrine, een endogeen ijzer-bindend eiwit, of met ijzer verzadigd transferrine (holotransferrine) als controlebehandeling. Renale ischemie leidde ten tijde van reperfusie tot het vrijkomen van grote hoeveelheden redox-actief ijzer in de bloedsomloop. Dit wijst erop dat de endogene capaciteit om ijzer te binden ten tijde van renale I/R tekort schiet. Exogeen apotransferrine, in tegenstelling tot holotransferrine, bleek in staat de hoeveelheid vrij circulerend redox-actief ijzer na $/ / R$ sterk te verminderen. Behandeling met apotransferrine verminderde het optreden van oxidatieve schade, maar had geen effect op het optreden van apoptotische celdood. Apotransferrine reduceerde de infiltratie van neutrofiele ontstekingscellen en het optreden van complement-deposities in de post-ischemische nier. Bovenal beschermde apotransferrine, door het remmen oxidatieve schade en inflammatoire processen, tegen het optreden van post-ischemisch orgaanfalen. Apotransferrine biedt daarom nieuwe mogelijkheden om acuut renaal falen na transplantatie van ischemisch beschadigde organen te behandelen.

Naar aanleiding van de experimentele data beschreven in Hoofdstuk 3 , hebben we in Hoofdstuk 4 de betrokkenheid van redox-actief ijzer bij klinische transplantaties bestudeerd. Daartoe werd redox-actief ijzer gemeten in preservatie-vloeistof afgenomen gedurende machine-preservatie van 218 NHB nieren die in het Academisch Ziekenhuis Maastricht tussen juli 1998 en januari 2003 op de machine gepreserveerd werden en getransplanteerd werden binnen de Eurotransplant regio. Gedurende machine-preservatie van NHB donornieren werden, in vergelijking met heart-beating donornieren, hoge concentraties redox-actief ijzer in de preservatie-vloeistof gemeten. De concentraties redox-actief ijzer in de preservatie-vloeistof correleerden 
uitstekend met donor karakteristieken, waaronder warme ischemie. Bovenal had de concentratie redox-actief ijzer gedurende machine-preservatie een goede voorspellende waarde voor het optreden van orgaanfalen na transplantatie van NHB categorie 2 donornieren; nieren die het meest uitgesproken worden blootgesteld aan warme ischemie. Deze gegevens, in combinatie met de gegevens in Hoofdstuk 3, suggereren dat redox-actief ijzer een rol speelt bij het optreden van orgaanschade na transplantatie van ischemisch beschadigde organen. Aangezien redox-actief ijzer concentraties goed correleren met orgaan-functie na transplantatie, kan het vór transplantatie bepalen van redox-actief ijzer potentieel worden gebruikt als viability-test voor ischemisch beschadigde organen. Bovendien kan het toevoegen van ijzer-bindende stoffen aan preservatie-vloeistof mogelijk het orgaan-functioneren van machine-gepreserveerde, ischemisch beschadigde nieren na transplantatie verbeteren.

In Hoofdstuk 5 werd het beschermende effect van de endogene groel-factor lysophosphatidic acid (LPA) tegen het optreden van experimentele renale I/R schade onderzocht. LPA is een endogene fosfolipide groei-factor met antiapoptotische eigenschappen. Omdat inhibitie van apoptotische celdood beschermt tegen renale I/R schade, bestudeerden we de effecten van exogeen LPA in een muizen-model voor renale I/R schade. LPA, toegediend ten tijde van reperfusie voorkwam dosis-afhankelijk renale apoptose. I/R-geïnduceerde renale apoptose was aanwezig in tubulaire epitheelcellen met evidente beschadiging van de brush-border. Behandeling met LPA inhibeerde apoptose van tubulaire epitheelcellen en het I/R-geïnduceerde verlies van brush-border integriteit. Naast anti-apoptotische werking bleek LPA sterke anti-inflammatoire effecten te hebben; het inhibeerde de renale expressie van TNF- $\alpha$ en de infiltratie van neutrophiele ontstekingscellen. Bovendien remde LPA dosisafhankelijk ischemie-geinduceerde activatie van het complement-systeem. Tot slot voorkwam behandeling met LPA bijna volledig het optreden van nierfunctie-verlies ten gevolge van I/R. Dit illustreert dat met behulp van endogene anti-apoptotische middelen het optreden van ischemie-geïnduceerde apoptose, inflammatie en orgaanfalen kan worden voorkomen en voorziet daarmee in nieuwe middelen om klinische ischemie-gemedieerde aandoeningen in de nier, maar mogelijk ook in andere organen, te behandelen.

Naar aanleiding van de bevinding in Hoofdstuk 5 dat experimentele renale I/R leidt tot activatie van het complement-systeem, werd in Hoofdstuk 6, 7 en 8 de rol van het complement-systeem bij het ontstaan van experimenteel alsook van klinisch acuut nierfalen bestudeerd.

Allereerst toonden we in Hoofdstuk 6 aan dat de 'mannose-binding lectin' (MBL) route betrokken is bij complement activatie ten gevolge van renale $I / R$ schade. Gedurende experimentele renale I/R en klinisch orgaanfalen na trans- 
plantatie werd de activatie en regulatie van de MBL-route van het complement-systeem bestudeerd. Muizen die blootgesteld werden aan $I / R$ van de nier lieten kort na reperfusie uitgebreide renale MBL-deposities zien. In de latere reperfuslefase werd ook renale depositie van de complement-factoren C3, C6 en C9 waargenomen. De lokalisatie van MBL-A en -C bleek volledig overeen te komen met de plaats waar depositie van complement-factor $\mathrm{C}_{6}$ werd waargenomen. Dit impliceert dat MBL betrokken is bij complement-activatie na renale $1 / R$. De MBL-A concentraties in het serum van aan I/R blootgestelde muizen stegen sterk in tegenstelling tot de MBL-C concentraties die sterk daalden. In humane nierbiopten, genomen na transplantatie, werden al vroeg MBL deposities gedetecteerd, terwijl in biopten genomen vóór transplantatie geen MBL deposities werden waargenomen. Met name in biopten van NHB nieren met orgaanfalen na transplantatie werden uitgebreide MBL deposities waargenomen in peritubulaire capillairen en tubulaire epitheelcellen. Deze studie toont aan dat gedurende experimentele renale $/ / R$ alsook klinisch nierfalen na transplantatie de MBL-route wordt geactiveerd, gevolgd door activatie van het complement systeem. Deze gegevens laten zien dat de MBL-route betrokken is bij //R-geinduceerde complement-activatie.

Vervolgens werd in Hoofstuk 7 de pathofysiologische rol van complementactivatie bij het ontstaan van renale $I / R$ schade geanalyseerd. Om de oorzakelijke rol van het complement-systeem te bestuderen werd het effect van complement-inhibitie op post-ischemisch orgaanfalen onderzocht. Daartoe werden muizen blootgesteld aan 45 minuten unilaterale nierischemie gevolgd door contralaterale nefrectomie en reperfusie gedurende 2, 12 danwel 24 uur. De muizen werden controle-behandeld of behandeld met BB5.1, een monoclonaal antilichaam dat de activatie van complement-factor $\mathrm{C} 5$ inhibeert, en daarmee de vorming van $\mathrm{C} 5 \mathrm{a}$ en het membrane attack complex (MAC) voorkomt. Renale I/ $R$ leidde snel na reperfusie tot uitgebreide renale depositie van complement factor $\mathrm{C} 3$, terwijl $\mathrm{C} 6$ en $\mathrm{C} 9$-deposities (MAC-vorming) relatief laat optraden. I/R-geinduceerde complement-deposities werden met name waargenomen op tubulaire epitheel-cellen. Behandeling met BB5.1 voorkwam MAC-vorming volledig. Inhibitie van C5 inhibeerde het optreden van een ontstekingsreactie, gemeten middels neutrofiel-influx en inductie van CXC-chemokines (MIP-2, KC en LIX). Daarnaast voorkwam behandeling met BB5.1 late I/R-geïnduceerde apoptose, dit in tegenstelling tot vroege apoptose die niet werd beïnvloed. Tot slot beschermde behandeling met BB5.1 tegen het optreden van ischemie geïnduceerd orgaanfalen. Deze studie toont aan dat complement-activatie in belangrijke mate betrokken is bij het optreden van apoptose en inflammatie ten gevolge van renale $I / R$. Bovendien werkt inhibitie van het complement systeem beschermend tegen het optreden van post-ischemisch nierfalen. 
In Hoofdstuk 8 werd de rol van complement-factor CSa en zijn interactie met de $C 5 a$-receptor (C5aR) bij het ontstaan van renale $1 / R$ schade onderzocht. De C5aR kwam in nieren van gezonde muizen tot expressie op mesangiale cellen en op tubulaire epitheelcellen. Renale $U / R$ verhoogde de $C 5 a R$ expressie in tubulaire epitheelcellen sterk. Daarnaast leidde I/R tot een sterke toename van renale mRNA levels voor $\mathrm{C}-\mathrm{X}-\mathrm{C}$ chemokines en TNF- $\alpha$ alsook een massale infiltratie van neutrofiele ontstekingscellen. Het blokkeren van C5a-C5aR interactie met behulp van een specifieke C5a receptor antagonist (C5aRA) voorkwam de verhoogde expressie van $C-X-C$ chemokines, maar niet van TNF- $\alpha$. C5a-C5aR blokkade leidde tot een significante daling van het aantal geïnfiltreerde neutrofielen. Bovenal beschermde de behandeling met C5aRA tegen het optreden van ischemie-geïnduceerd nierfunctie-verlies. De verbetering van nierfunctie bleek onafhankelijk te zijn van de influx van neutrofielen aangezien neutrofiel-depletie (middels het monoclonale antilichaam NIMP-R14) geen effect had op het beschermende effect van C5aRA behandeling. Tot slot bleek het blokkeren van de C5aR geen invloed te hebben op het optreden van apoptotische celdood. Deze studie toont aan dat $\mathrm{C} 5 \mathrm{a}$ in belangrijke mate betrokken is bij het ontstaan van renale $/ / R$ schade. Hierbij spelen zowel neutrofiel-afhankelijke alsook neutrofiel-onafhankelijke mechanismen een rol waaronder de regulatie van $\mathrm{C}-\mathrm{X}-\mathrm{C}$ chemokines.

Het complement-systeem wordt geactiveerd ten gevolge van renale $1 / R$. Deze ischemie-geinduceerde activatie van het complement-systeem wordt ondermeer gemedieerd door de MBL-route. Complement-activatie is essentieel betrokken bij het ontstaan van ischemie-geïnduceerde celdood, ontsteking en orgaanfalen, waarbij zowel MAC als C5a een belangrijke rol spelen.

In Hoofdstuk 9 werden de beschermende effecten van het acute fase eiwit $\alpha-1-$ acid glycoprotein (AGP) tegen het optreden van experimentele renale $I / R$ schade bestudeerd. AGP wordt beschreven als remmer van apoptotische celdood, complement-activatie, meutrofiel-influx en neutrofiel-activatie; processen die betrokken zijn bij het ontstaan van renale $1 / R$ schade. Daarom hebben we in een muizenmodel voor renale $I / R$ schade de effecten van exogeen alsook endogeen AGP bestudeerd. Muizen werden blootgesteld aan renale $/ / R$ en behandeld met humaan $A G P$, fucose-gedepleteerd humaan $A G P$ (aangezien fucose-groepen op het ACP eiwit mogelijk een rol spelen bij de werking van $A G P$ ), ofwel controle-behandeld. Ook transgene muizen die in verhoogde mate rat-AGP produceren en wild type controles werden blootgesteld aan renale I/R. Behandeling met AGP alsook fucose-gedepleteerd AGP bood bescherming tegen $1 / R$-geinduceerd nierfalen. Transgene muizen met een verhoogde rat-AGP productie waren niet beschermd tegen $I / R$ schade. Zowel natuurlijk als fucose-gedepleteerd AGP inhibeerden de activatie van het complement-systeem en de influx van neutrofiele ontstekingscellen. In tegenstelling tot muizen in de controlle-groep waren er nauwelijks ischemische ver- 
anderingen van de tubulaire epitheliale cel-structuur (actine-cytoskelet) en de cel-cel interactie (tight-junctions) in ACP-behandelde muizen. Epitheliale caspase-activatie en apoptotische DNA-laddering werden eveneens geremd door AGP behandeling.

Zowel natuurlijk als fucose-gedepleteerd AGP beschermen tegen renale $I / R$ schade middels behoud van tubulaire epitheliale structuur, inhibitie van apoptotische celdood en de daarop volgende onstekingsreactie. AGP kan worden beschouwd als een nieuwe therapeutische interventie bij de behandeling van nierfalen na transplantatie van ischemisch beschadigde nieren.

Tot slot werden in Hoofdstuk 10 de mogelijkheden voor klinische toepassing van de in dit proefschrift beschreven experimentele studies bediscussieerd. Deze en andere experimentele studies zullen hopelijk op korte termijn leiden tot nieuwe therapeutische interventies in de behandeling van patiënten met acuut nierfalen. 
DANKWOORD 


\section{DANKWOORD}

Beginnend aan het dankwoord, de afsluiting van dit proefschrift, passeren de afgelopen jaren nog eens rustig de revue. Ongelofelijk hoeveel mensen, variërend van heel dichtbij tot op een veilige afstand, betrokken zijn geweest bij het tot stand komen van dit proefschrift. Voor allen, ook voor degenen die ik ongetwijfeld vergeet te noemen, mijn dank.

In het tweede jaar van mijn studie geneeskunde werd voor het eerst de interesse voor de chirurgie gewekt. Mijn vroegere overbuurjongen, Jan-Willem Daemen, die vila ons beider ouders had gehoord dat ik geneeskunde studeerde, vroeg me of ik interesse had om als "kidney-racer" te komen werken op het preservatie-lab waar hij als transplantatiecoördinator werkte. Uiteraard leek me dit wel wat en behalve een eerste kennismaking met de transplantatie-chirurgie werd die jaren tevens de interesse gewekt in de wetenschap. Jan-Willem, Gauke, Ralph, Arno, Jur, Otto, Leon, Eric, Willem, Ming, Bobby, Mieke en alle anderen bedankt. Het was een fantastische tijd in een omgeving vol met enthousiasmerende mensen. Het kan geen toeval zijn dat drie van de vier toenmalige kidney-racers inmiddels in opleiding zijn tot chirurg. Gauke, ik vind het een bijzondere eer dat je in mijn beoordelingscommissie hebt willen plaatsnemen.

Toen mijn studie op z'n eind liep en ik op mijn co-schappen terugkeek, zag ik bevestigd wat ik eigenlijk al wist, namelijk dat ik chirurg wilde worden en me het liefst met transplantatie-chirurgie zou bezighouden. Met deze boodschap bezocht ik Prof. Gauke Kootstra, toentertijd hoofd van het preservatielab en bovenal van de vakgroep chirurgie. Op zijn advies maakte ik een afspraak bij Dr. Wim Buurman, hoofd van het experimentele chirurgische lab. Er zou daar een AlO-plek vrijkomen, basaal wetenschappelijk onderzoek gericht op Non-Heart-Beating orgaandonatie en -transplantatie. Op mijn lijf geschreven, dacht ik zo. Wim, ik vraag me nog vaker af wat jij gedacht hebt die eerste gesprekken. Met mijn interesse zal het wel goed gezeten hebben, maar volledig overdonderd door termen als "apoptotische celdood", "neutrofiel-influx", "chemokine-inductie" vroeg ik me af wat dit alles in hemelsnaam met niertransplantaties te maken zou kunnen hebben? Blij dat ik het uit kon spreken, er al eens van gehoord had, maar om in mechanismen te denken, verbanden te leggen, laat staan er een zinnige discussie over te voeren, zover was ik toen in ieder geval nog lang niet. Wim, mijn promotor, ik wil je bedanken dat je me de kans hebt gegeven en geduld met me hebt gehad, uiteraard was dit proefschrift er zonder jou nooit gekomen. Je bent voor mij bijzonder inspirerend geweest, op wetenschappelijk maar zeker ook op persoonlijk vlak, en ik hoop in de nabije toekomst nog vaker met je te kunnen samenwerken. 
Ernst, co-promotor, eigenlijk jammer dat je pas in een later stadium betrokken bent geraakt bij het proefschrift. Om vanuit de basale wetenschap de stap naar directe klinische toepassingen te nemen is vaak lastig, maar ik denk dat we daar mede dankzij jou toch behoorlijk in geslaagd zijn, of in ieder geval nu goed op weg zijn. Ik hoop dan ook dat we in de nabije toekomst de klinische toepassingsmogelijkheden verder kunnen uitbreiden.

Dear Jaakko, I would like to thank you for your enthousiasm, our extensive and interesting discussions in Maastricht, most of the time about plasma proteins but also about Finland, the Netherlands and everything in between.

Collegae van het eerste uur:

Marc, mijn voorganger, cum laude gepromoveerd, het was dus niet gemakkelijk om jou waardig op te volgen, maar het was prettig goed ingewerkt te worden en terug te kunnen vallen op een schat aan relevante kennis.

Tim, allereerst kamergenoot, maar al snel een vriend, talloze, eindeloze PCRsessies maar ook vele uren praten over werk, collegae, relaties en toekomst. Dat laatste zullen we ook in de toekomst blijven doen.

Francois, kamergenoot, lotgenoot (graag promoveren maar eigenlijk vooral dokter willen zijn) dus al snel een vriend, gesprekken over eigenlijk alles, computers, opleiding, wijnen, surfen, skaten en tegenwoordig zelfs kinderen, wie had dat ooit gedacht.

Sarah, "rinsy", it was great to work with you. All the best for you and Alex, we will keep in touch.

Kees, ik heb veel van je geleerd, ontzettend met je gelachen. Jammer dat je uit Maastricht bent vertokken.

Robert, ook met jou heb ik met veel plezier samengewerkt, eerst als studentassistent en nu als AlO aan jou de taak vervolg te geven aan het ischemiereperfusie werk. Mijn vertouwen heb je.

Alle anderen van het lab: Trudi, Annemarie, Juanita, Mieke, Anita, Patricia, Marloes, Mo. Misha, Kyoko, Miriam, Sjoerd, Jeroen, Martien, Joep, Sylvia, Marcel, Yvonne, Mick, Hans en natuurlijk Mickey en Kim mijn dank voor jullie bijdrage.

Mijn dank gaat verder uit naar de beoordelingscommissie: Prof. Hugo Ten Cate, Prof. Mat Daemen, Prof. Gauke Kootstra, Dr. Maarten Christiaans en Prof. Jaques Pirenne. 
Graag zou ik ook nog willen bedanken:

* Peter Heeringa en Dennis Huugen van de vakgroep Immunologie

Carine Peutz-Kootstra en Adriaan DeBruïne van de vakgroep Pathologie Gosse Oosterhof van de vakgroep Urologie Jorg Kohl (the C5aR story)

Bruce Molitoris

Peter Vandenabeele, Mickey Kalai, Nicky Vercammen, Bart Depuydt Tino Hochepied, Claude Libert Het preservatie-lab: John, Margriet, Wim, Irene, Sandra, en alle anderen De mensen van de Centrale Proefdieren Voorziening, met name Peter, Richard, Paulien en Harrie

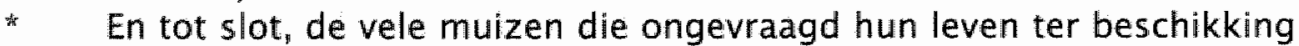
hebben gesteld om uiteindelijk hier zwart-op-wit als proefschrift voort te leven

Misschien wel de meeste dank ben ik verschuldigd aan de mensen die de vaak zo ondergewaardeerde randvoorwaarden schiepen om tot een afgerond proefschrift te komen. Mijn ouders, Beppie en Wiebe, schoonouders, Riny en Guus, broer en (schoon)-zussen; Robbert, Annemiek, Ingeborg en Hester. Alleen al te weten dat ik ten alle tijde kon terug vallen op jullie heeft het tot stand komen van dit alles zoveel makkelijker gemaakt. Met name jullie onvoorwaardelijke aanwezigheid en steun de afgelopen maanden heeft mij en ook Daphne ontzettend geholpen.

Daphne, je hebt me gestimuleerd hieraan te beginnen, je bent me blijven stimuleren, ook op de momenten dat ik er zelf iets minder in geloofde, tot het afronden van het proefschrift aan toe. Met name de afgelopen maanden zijn niet gemakkelijk geweest, maar vooral dankzij jou werden ook de allerlaatste zinnen op papier gezet, daar waar mijn hoofd niet naar schrijven stond. Ik hoop dat ik nog heel lang gelukkig met je mag zijn, met Arne en alles wat nog komen gaat. 


\section{CURRICULUM VITAE}

Bart de Vries was born on september 27 th, 1975 in Geleen, the Netherlands. He attended St. Michiel high school in Geleen (Gymnasium) from 1987 to 1993. From 1993 until 1999 he attended Medical School at the University of Maastricht. As a medical student he started working for the Non-HeartBeating Donor program at the Department of General Surgery (Prof. Dr. G. Kootstra). The work presented in this thesis was accomplished between 1999 and 2004 when he was a PhD-student at the Laboratory of Experimental Surgery of the University of Maastricht (Prof. Dr. W.A. Buurman). In July 2004 he started as a surgical resident at the Department of General surgery, University Hospital Maastricht (Prof. Dr. M.J.H.M. Jacobs and Prof. Dr. J.W.M. Greve). 
De Vries B, Walter SJ, Peutz-kootstra CJ, Wolfs TA, van Heurn LW, Buurman WA. The mannose binding lectin pathway is involved in complement-activation in the course of renall ischemia-reperfusion injury. Am J Pathol 2004 Nov; 165(5):1677-88.

Wolfs TA, de Vries B, Walter SJ, Peutz-Kootstra CJ, van Heurn LW, Oosterhof GO, Buurman WA. Apoptotic cell-death is initiated during normothermic ischemia in human kidneys. Am J Transplantation in press.

De Vries B, Walter SJ, Wolfs TG, Hochepied T, Räbinä J, Heeringa P, Parkkinen J, Libert C. Buurman WA. Exogenous alpha-1-acid glycoprotein protects against renal ischemia-reperfusion injury by inhibition of inflammation and apoptosis. Transplantation 2004 OCt 27;78(8):1116-24.

De Vries $B$, Walter $S$ J, von Bonsdorff $L$, Wolfs TG, van Heurn LW, Parkikinen J, Buurman WA. Reduction of circulating redox-active iron by apotransferrin protects against renal ischemia-reperfusion injury. Transplantation. 2004 Mar 15;77(5):669-75.

Everts $M_{1}$ Asgeirsdottir SA, Kok RJ, Twisk J, de Vries B, Lubberts $E$, Bos EJ, Werner $N$, Mejer DK, Molema C. Comparison of E-5electin expression at $m$ RNA and protein levels in murine models of inflammation. Inflamm Res. 2003 Dec;52(12):512-8.

De Vries B, Matthijsen RA, van Bijnen AA, Wolfs TC, Butrman WA. Lysophosphatidic acid prevents renal ischemia-reperfusion injury by inhibition of apoptosis and complement activation. Am J Pathol. 2003 Jul; $163(1): 47-56$.

De Vries $B$, Kohl J, Leclercq WK, Wolfs TG, van Bijnen AA, Heeringa $P$, Buurman WA. Complement factor $C 5$ a mediates renal ischemia-reperfusion injury independent from neutrophils. J Immunol. 2003 Apr 1;170(7):3883-9.

De Vries B, Matthijsen RA, Wolfs TG, Van Bijnen AA, Heeringa P, Buurman WA. Inhibition of complement factor $C 5$ protects against renal ischemia-reperfusion injury: inhibition of late apoptosis and inflammation. Transplantation. 2003 Feb $15 ; 75(3): 375-82$.

Daemen $M A_{\text {, }}$ de Vries $B$, Buurman WA. Apoptosis and inflammation in renal reperfusion injury. Transplantation. 2002 \un 15;73(11) 1):1693-700.

Van Heurn LW, Cheng $W$, de Vries B, Saing $H$, Jansen NJ, Kootstra $G$, Tam PK. Anomallies associated with oesophageal atresia in Asians and Europeans. Pediatr Surg Int. $2002 \mathrm{May}^{\prime} 18(4): 241-3$.

Wolfs TG, Buurman WA, van Schadewijk A, de Vries B, Daemen MA, Hiemstra PS, van 't Veer $C$. In vivo expression of Toll-like receptor 2 and 4 by renal epithelial cells: IFN-gamma and TNF-alpha mediated up-regulation during inflammation. J Immunol. 2002 Feb 1;168(3):1286-93.

Daemen MA, de Vries $B$, van 't Veer $C$, Wolfs TG, Butrman WA. Apoptosis and chemokine induction after renal ischemia-reperfusion. Tramsplantation. 2001 Apr 15:71:7):1007-11.

Daemen $\downarrow H_{*}$ de Vries $B$, Kootstra $G$. The effect of machine perfusion preservation on early function of non-heart-beating donor kidneys. Transplant Proc. 1997 Dec:29(8):3489.

Kievit JK, Oomen AP, de Vries B, Heineman E, Kootstra G. Update on the results of nonheart-beating donor kidney transplants. Transplant Proc. 1997 Nov;29(7):2989-91.

Daemen $\mathrm{JH}$, de Vries B, Oomen AP, DeMeester J, Kootstra G. Effect of machine perfusion preservation on delayed graft function in non-heart-beating donor kidneysearly results. Transpl Int. 1997;10(4):317-22. 